\title{
Carers' experiences of seeking help for relatives with first-episode psychosis: a systematic review of qualitative evidence
}

Suzanne Dawson BAppSc in Occ Therapy, GradDip in CBT

Master of Clinical Science (Evidence Based Healthcare)

The School of Translational Health Science

Faculty of Health Sciences

The University of Adelaide

Australia

$17^{\text {th }}$ September 2013 


\section{Table of contents}

LIST OF FIGURES

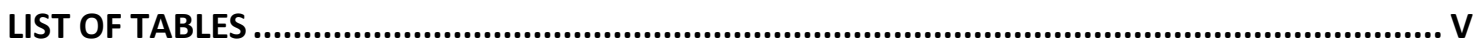

ABSTRACT

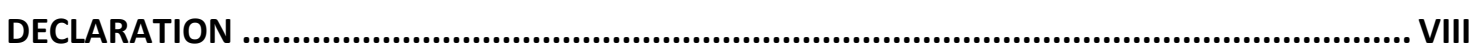

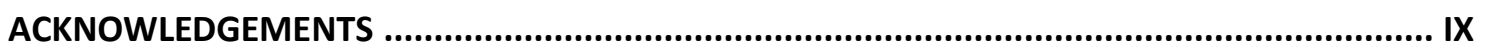

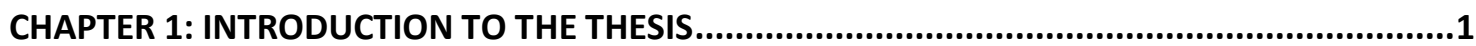

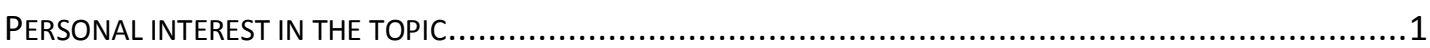

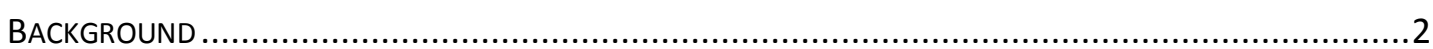

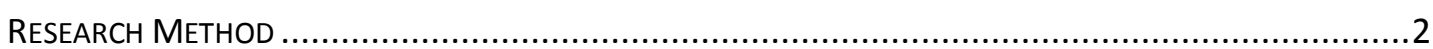

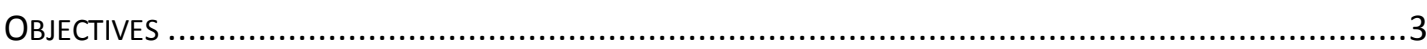

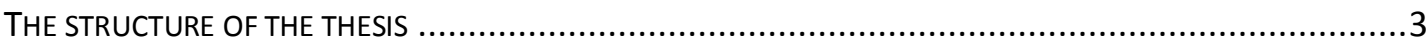

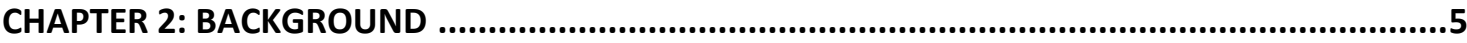

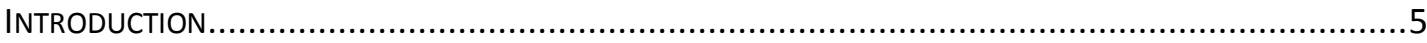

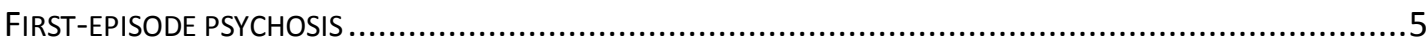

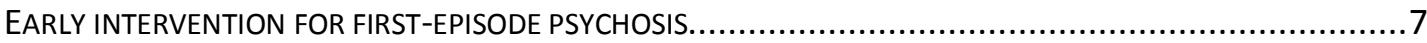

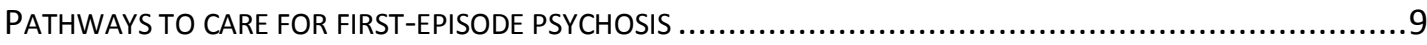

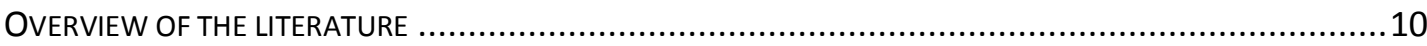

RESEARCH METHOD

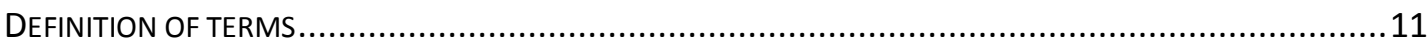

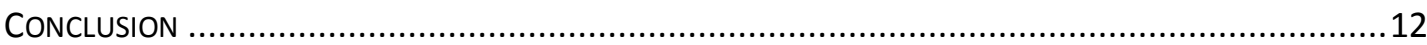

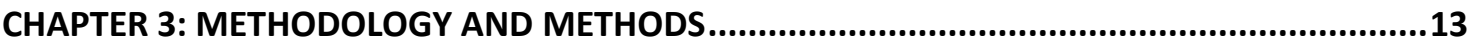

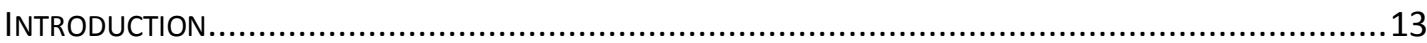

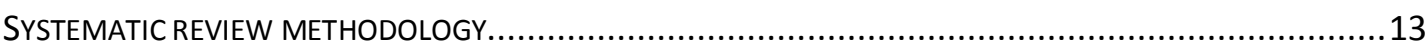

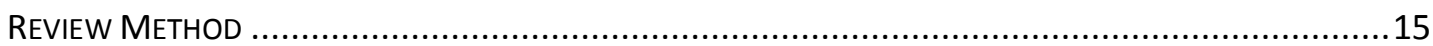

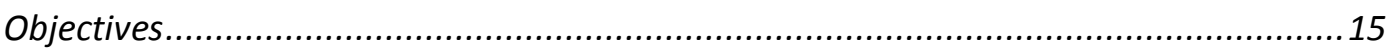

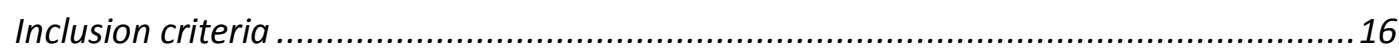

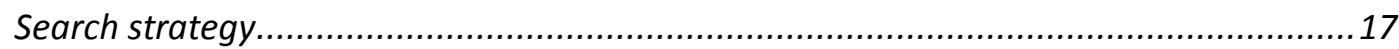

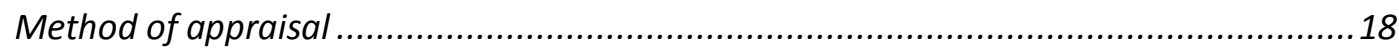

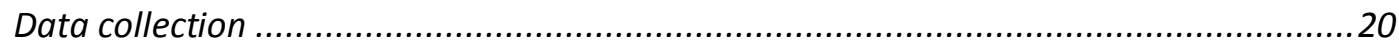

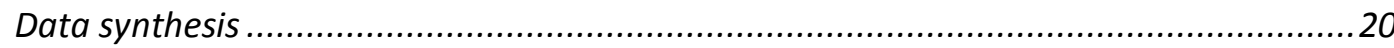

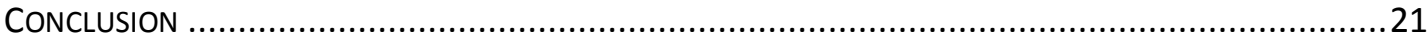


CHAPTER 4: RESULTS

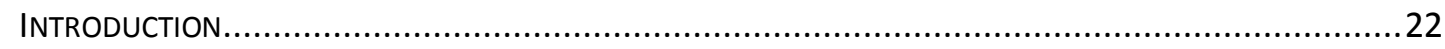

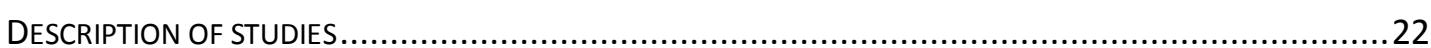

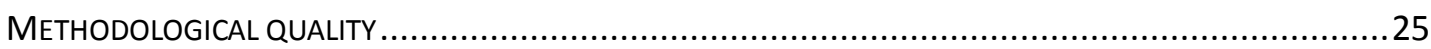

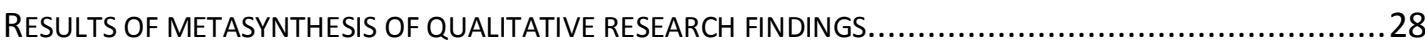

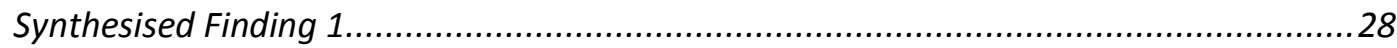

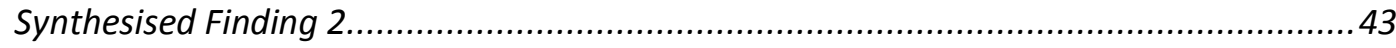

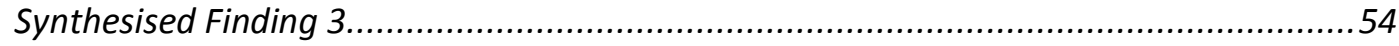

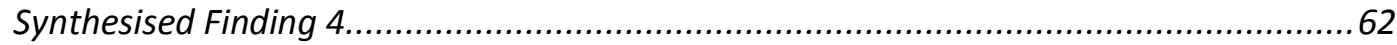

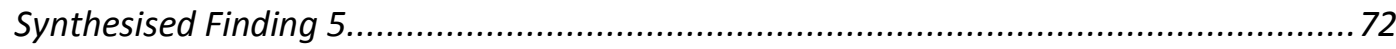

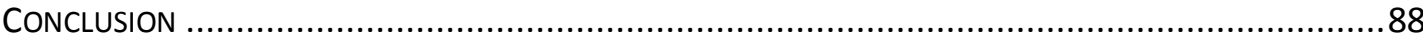

CHAPTER 5: DISCUSSION

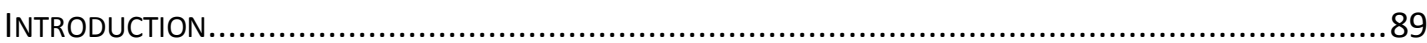

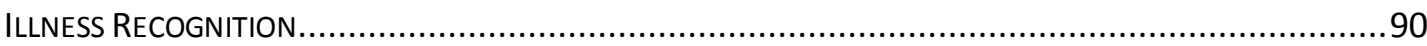

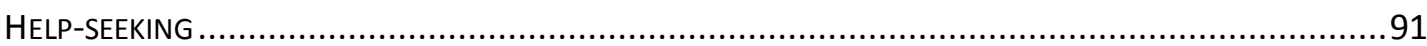

SERVICE RESPONSE

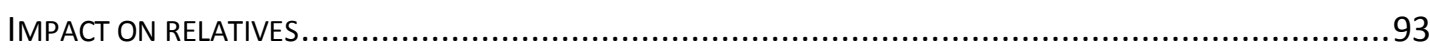

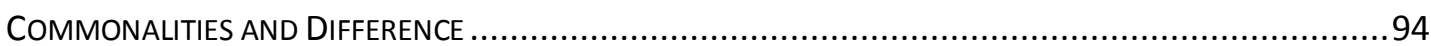

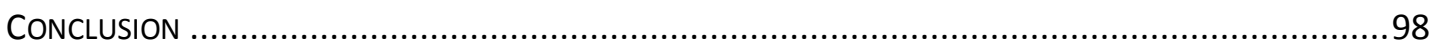

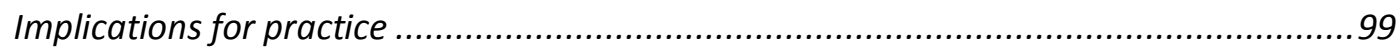

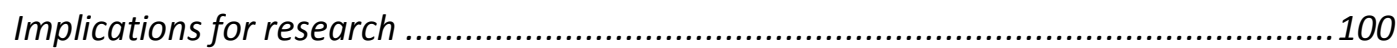

Implications for education .................................................................................. 100

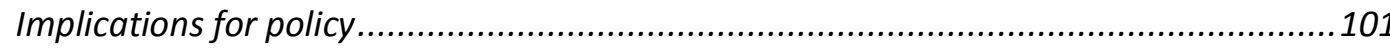

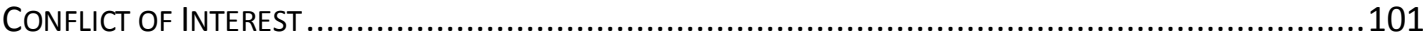

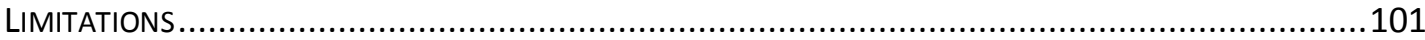

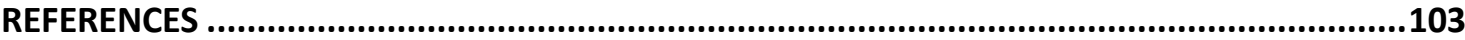

APPENDICES

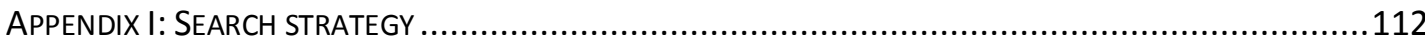

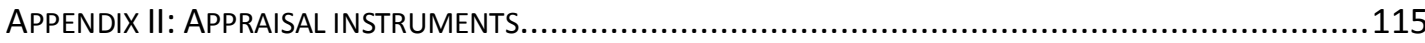

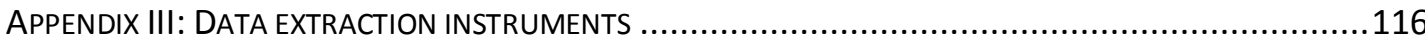

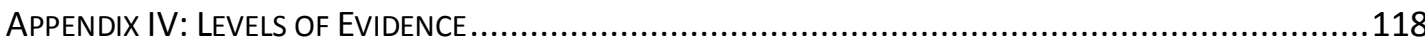

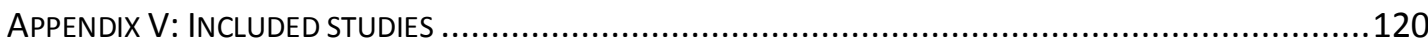

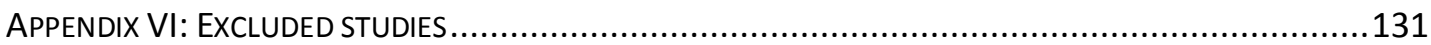


APPENDIX VII: LIST OF STUDY FINDINGS

131

Page | iv 


\section{List of figures}

FIGURE 1: FLOW DIAGRAM FOR RETREIVAL AND SELECTION OF STUDIES.

\section{List of tables}

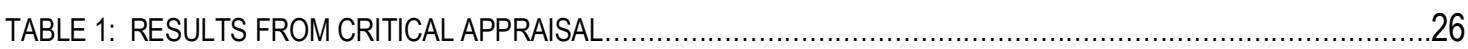

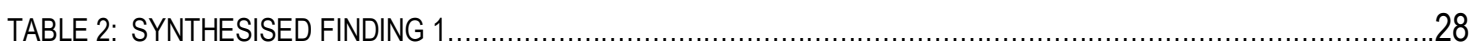

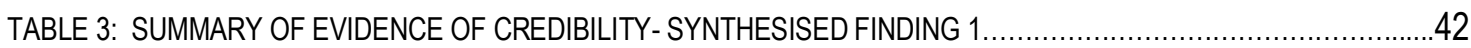

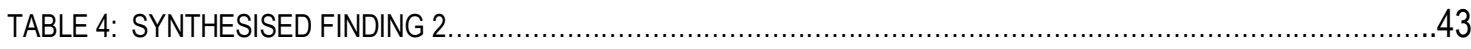

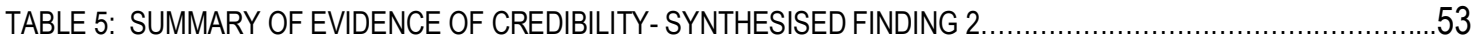

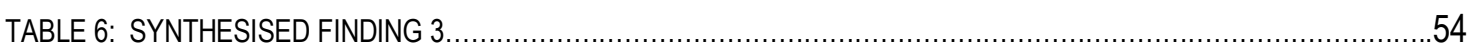

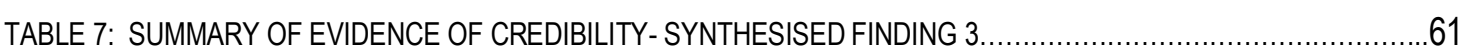

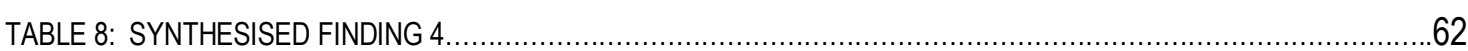

TABLE 9: SUMMARY OF EVIDENCE OF CREDIBILITY- SYNTHESISED FINDING 4

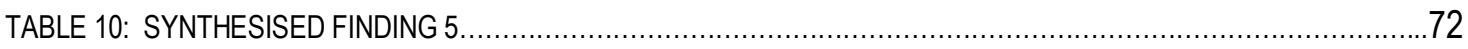

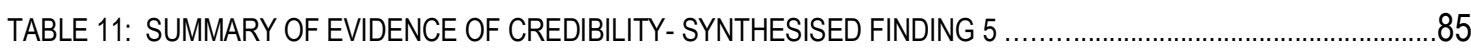




\section{Abstract}

\section{Background}

Individuals with a first-episode psychosis often have a prolonged and complicated path to accessing appropriate treatment. Research shows carers frequently initiate treatment though often delays remain even after problems have been detected. Qualitative studies have been conducted with the view to explore carers' experiences and inform the exploration of factors contributing to a long duration of untreated psychotic illness. Minimising the impact of psychosis for individuals and improving outcomes remain a priority in Clinical Practice Guidelines in many countries. Understanding and improving pathways to care is crucial to this goal.

\section{Objectives}

To synthesise the best available evidence on the lived experience of carers of a relative with a first-episode psychosis and in particular their experience preceding and of seeking help.

\section{Inclusion criteria}

\section{Types of participants}

Carers of a relative presenting with a first-episode psychosis. Carers could be a parent, sibling, spouse or other relative of any age.

\section{Phenomena of interest}

Carers' experience of a relative with a first-episode psychosis, and in particular their experience preceding and of seeking help from both informal (family and friends) and formal (services) sources.

\section{Context}

Research conducted in any mental health care setting in any country.

\section{Types of studies}

This review considered a wide range of qualitative studies including but not limited to designs such as phenomenology, grounded theory, ethnography and action research.

\section{Search strategy}

Published and unpublished studies in English from January 1990 to August 2012 were identified by searching various electronic databases. 


\section{Methodological quality}

Papers selected for retrieval were assessed by two independent reviewers for methodological validity prior to inclusion in the review using standardised critical appraisal instruments from the Joanna Briggs Institute Qualitative Assessment and Review Instrument (JBI-QARI).

\section{Data collection}

Data was extracted from identified papers using the standardised data extraction tool from JBI-QARI. This included specific details about the phenomena of interest, populations, study methods and outcomes of significance to the review objectives.

\section{Data synthesis}

Research findings were pooled using JBI-QARI. Study findings were rated according to their quality, and categorised on the basis of similarity in meaning. These categories were then subjected to a meta-synthesis to produce a set of synthesised findings.

\section{Results}

Twenty-two studies were identified following appraisal that considered carers' experiences of help-seeking for a relative with a first-episode psychosis. Five synthesised findings were derived from 16 categories and 213 findings.

Delays often began at the stage of illness recognition. The main barriers to seeking help were fear of stigma and reluctance of the ill relative to participate in the process. A crisis and overt psychotic symptoms were the main promoters of active help-seeking and facilitators to accessing services. Service response was often viewed as a barrier to service access. A significant negative impact on carers of individuals with a psychotic illness was reported during the early stages of illness development, recognition, management and help-seeking, though the impact for each family member may differ.

\section{Conclusions}

Delays in accessing appropriate treatment arise at the illness recognition, help-seeking and service response stages. These areas were found to be interrelated. There was significant impact on carers throughout each of these stages.

\section{Keywords}

Help-seeking; Carers; First-episode psychosis; Qualitative, Systematic Review 


\section{Declaration}

I, Suzanne Dawson, certify that this work contains no material that has been accepted for the award of any other degree or diploma in any University of any other tertiary institution, and, to the best of my knowledge and belief, contains no material previously published or written by any other person, except where due reference has been made in the text. In addition, I certify that no part of this work will, in the future, be used in a submission for any other degree or diploma in any university or other tertiary institution without the prior approval of the University of Adelaide and where applicable, any partner institution responsible for the joint award of this degree.

I give consent to this copy of my thesis, when deposited in the University Library, being made available for loan and photocopying, subject to the provisions of the Copyright Act 1968.

I also give permission for the digital version of my thesis to be made available on the web, via the University's digital research repository, the Library Catalogue, and also through web search engines, unless permission has been granted by the University to restrict access for a period of time.

Suzanne Dawson

$17^{\text {th }}$ September 2013 


\section{Acknowledgements}

I would like to thank my supervisors, Associate Professor Zoe Jordan, my primary supervisor, for her guidance, encouragement and ability to quickly clarify any issues I encountered along the path and Dr Melanie Attard, my co-supervisor and second reviewer, for her interest shown in my chosen topic and in-depth knowledge around the qualitative research paradigm.

My thanks and appreciation also extends to Maureen Bell, Research Librarian at the University of Adelaide, for her invaluable advice around the development and refinement of my search strategy.

Thank you to the Joanna Briggs Institute staff for all the support over the past 18 months, and to the other Masters and PhD students, for their ongoing encouragement and good humour throughout the programme.

Finally, I would like to express thanks and appreciation to my husband and two children, whom have helped me to create a small corner in the house from which I have managed to complete this body of work. 


\section{Chapter 1: Introduction to the thesis}

\section{Personal interest in the topic}

As an Occupational Therapist, I have more than 20 years' experience working within community based mental health care settings. During this time I have worked with many individuals with psychotic illnesses at varying stages of presentation, ranging from those presenting with a firstepisode psychosis (FEP) to those experiencing a more chronic course of illness. Throughout my years as a clinician I have worked closely with families and witnessed the enormous amount of support they often provide throughout the course of their family member's illness and subsequent involvement with mental health services. I have seen people present to services in a timely and straightforward manner, but also those whom eventually present to mental health services after a very prolonged period of time in the community with untreated illness. Families often describe very complicated pathways to mental health services, even those who appear to have had a quick and timely entry to services.

During the past 20 years there has been significant research, development and funding of early intervention services specifically for young people experiencing FEP. The locations that I have worked in during this period have either not had funding for specialist services or clients have not met the strict criteria for accessing such services due to age limitations or restrictions around length of time on psychotropic medication (typically 6 months or less). Consequently, adult mental health services in many locations continue to see many individuals presenting for the first time with a psychotic illness, and as there is no age limit to accessing generalist adult services, at times individuals are seen who have had a very protracted period of untreated illness. My interest in this topic derives directly from experience in clinical practice of complicated pathways to care for this client group, as well as exposure to research conducted around the topic. As it is often the family that bring their relative to treatment, I was interested in exploring the families' experience as well as identify factors that help or hinder help-seeking efforts and service access. 


\section{Background}

Onset of first-episode psychosis (FEP) is most common during late adolescent and early adult years. ${ }^{1,2}$ Some individuals recover fully after one episode; however psychosis is associated with substantial and persistent disability for a significant number. ${ }^{2}$ People suffering a psychotic illness commonly have complicated pathways to care and take, on average, two years to access appropriate treatment. ${ }^{3}$ The family are typically the initiators of the help-seeking process. ${ }^{4}$ Impacts of a prolonged duration of untreated psychosis can be significant and may include: disruption to a person's general independence, social and vocational development; individuals and families being required to cope with distressing symptoms for extended periods and poorer recovery in the early stages of illness. ${ }^{5}$ There is also significant cost at a societal level subsequent to earnings forgone and the high costs of care provision. ${ }^{6}$

Minimising the impact of psychosis has been prominent in clinical guidelines in many countries for the past few decades and significant funding has been directed towards research and development of service provision for individuals in the early stages of psychosis. ${ }^{7-10}$ Aims of early intervention services for individuals with a FEP include: shortening the course of the initial psychotic episode; reducing the severity of the illness and minimising disruption to a person's life. ${ }^{5}$ Given the frequent delay for many individuals with a FEP to receive appropriate treatment, this research aims to explore the carers' experience in the stages preceding and during helpseeking in order to provide information regarding illness recognition and pathways to care for those experiencing a FEP.

\section{Research Method}

The systematic review (SR) was the chosen methodology for this research. More specifically the review presented in this thesis followed the Joanna Briggs Institute (JBI) method for conducting qualitative systematic reviews. ${ }^{11}$ The SR, or evidence synthesis, is defined as "the evaluation or analysis of research evidence and opinion on a specific topic to aid in decision-making in healthcare". 12p.212 Evidence-based healthcare, which has grown in recognition over the past few decades, involves identifying the best evidence to answer specific clinical questions. ${ }^{13}$ Evidence synthesis of quantitative data is referred to as the gold standard approach for evaluating the effectiveness of health interventions, however 'best evidence' is not restricted to randomised control trials and meta-analyses. ${ }^{13,} 14$ This research was interested in carers' lived experience 
preceding and during help-seeking for a relative with a FEP, and thus 'best evidence' for this topic involved the search, appraisal and synthesis of qualitative research. The Joanna Briggs Institute, acknowledging the value of qualitative evidence, has developed a method of appraisal and synthesis that mirrors the meta-analysis of quantitative data, whilst maintaining the integrity of qualitative methods. ${ }^{15}$ Furthermore, as evidence-based health care is about the translation of 'best evidence' into clinical practice and policy, this thesis aims to develop recommendations as such based on the results of the systematic review.

\section{Objectives}

The objective of this review was to synthesise the best available evidence on the lived experience of carers of a relative with a first-episode psychosis (FEP) and in particular their experience preceding and of seeking help.

More specifically, the objectives were to explore:

Perceived promoters and inhibitors to help-seeking during a FEP;

Perceived barriers and facilitators to accessing services during a FEP.

\section{The structure of the thesis}

This thesis will be presented in five chapters. Following is a brief overview of the objectives of the various chapters.

Chapter 1 provides an introduction to the thesis topic and an understanding of the author's interest in the topic. It presents the review objectives and provides an overview of the following chapters.

Chapter 2, Background, is concerned with setting the scene for the thesis and provides the reader with the context from which the review objectives arose. First-episode psychosis (FEP) is defined and its impact on the individual, family and society explored. Early intervention services for FEP are discussed, including an exploration of the contentious issues surrounding delivery of these services. Pathways to care and factors that impact upon this are considered and an 
explanation of why this research has focussed on carers' experience of the help-seeking process.

Chapter 3, Methodology and Methods, describes the methodology used for the systematic review presented within this thesis. The Joanna Briggs Institute (JBI) method for undertaking systematic reviews was followed and the process is explained in detail as it relates to this review.

Chapter 4, Results, details the results from the systematic review which are presented by synthesised finding. This includes tabular presentation of level 1 findings, categories and synthesised findings as formulated by JBI-QARI, a software programme developed to assist in the above process. Additionally, summaries of each synthesised finding are presented with associated categories and selected level 1 findings and illustrations to detail how each synthesised finding was reached.

Chapter 5, Discussion, places the synthesised results into a framework from which the findings are discussed. Similarities and differences between the findings are also detailed. Overall many similarities were found. The main differences were related to differing beliefs that were culturallybased. Recommendations for clinical practice, education, policy and research are presented which are based upon the synthesised findings from this review. 


\section{Chapter 2: Background}

\section{Introduction}

First-episode psychosis (FEP) is associated with significant impact and cost to the individual, family and society. Early intervention services for individuals with FEP aim to minimise the above costs, though recent reviews suggest the evidence of benefits to be inconclusive. Regardless, it is acknowledged that many individuals presenting with a FEP have long and complicated pathways to care causing significant disruption and distress to both them and their families. Research has focussed on various determinants of pathways to care that may impact upon the help-seeking process as well as the lived experience of individuals presenting with a FEP and their family. This thesis is concerned with carers' experience of help-seeking as they are often the initiators of the help-seeking process. A systematic review of the qualitative evidence on this topic was the selected method to explore the lived experience of carers of a relative with a first-episode psychosis, and in particular their experience preceding and of seeking help.

\section{First-episode psychosis}

Psychotic disorders are low prevalence disorders, affecting between 1-2\% of the adult population. ${ }^{1}$ Onset of first-episode psychosis (FEP), the first presentation of psychotic symptoms, is typically during late adolescent and early adult years. ${ }^{1,2}$ Positive psychotic symptoms may include hallucinations, delusions, disorganised speech and behaviour. 8, 16 Onset may be sudden or insidious, though most individuals experience a prodromal phase manifested by the gradual development of a variety of signs and symptoms that are commonly vague and non-specific, such as functional and social decline, sleep disturbance and mood symptoms. ${ }^{16-18}$ Individuals detected in this phase are considered to be 'ultra high risk' clinically, though development of psychosis is not inevitable. ${ }^{19}$

Though low in prevalence, psychotic disorders account for a high proportion of resources allocated to mental health services and are associated with significant challenges for those with the illness as well as their families.1, 2 During late adolescent and early adult years a young person is developing in many areas including formation of friendships, vocational goals, and general independence. ${ }^{2}$ The experience of mental illness during these formative years can divert 
a person from the trajectory of normal life development and significantly disrupt the person's life goals. 5,20 For those presenting at a later stage in life, other developmental issues will be of importance such as partners and children. ${ }^{21}$ The World Health Organisation reported schizophrenia and bipolar disorder were amongst the six leading causes of disease burden for those between the ages of 15-44 years and acknowledged the significant impact of mental illness on families citing emotional and economic consequences and impacts. ${ }^{22}$

In addition to the above costs experienced by individuals with a psychotic illness and their families there is also significant societal impact. ${ }^{6,}{ }^{22}$ Carr et al ${ }^{6}$ reported on the estimated cost of psychosis to government and society. The report was based on the data from the Low Prevalence Disorders Study conducted in Australia between 1996-1997 which was a censusbased survey of people with psychotic disorders in contact with mental health services across four metropolitan regions of Australia. Carr et $a^{6}$ estimated the cost of psychosis to the Australian Government to be $\$ 1.45$ billion per annum and to Australian Society, $\$ 2.25$ billion per annum. They also stated they believed their evaluations to be conservative. More specifically, the researchers found that costs related to mental health care were the greatest contributor to total costs for the government, and lost earnings the greatest contributor to total costs for society. ${ }^{6}$ Potential earnings forgone and subsequent impacts can be experienced throughout the life stages. In the earlier years a person's chosen vocational pursuit may be disrupted and in later years the disruption may coincide with the period when a person is typically most financially productive. It is considered that earnings forgone by individuals are due to a combination of effects of the illness, discrimination and stigma.6, 22

A second national Australian survey of people living with a psychotic illness, conducted in 2010, was designed to capture the impact of psychosis and concluded that "psychosis is associated with substantial and persistent disability". ${ }^{2}$ More specifically, participants who were surveyed named the following as the most important challenges facing them over the next year: financial difficulties (42.7\%), loneliness (37.2\%), unemployment (35.1\%), poor physical health $(27.4 \%)$, uncontrolled symptoms of mental illness (25.7\%), lack of stable/suitable housing (18.1\%) and stigma $(11.6 \%){ }^{2}$ Whilst some people will experience one psychotic episode and obtain full recovery, a significant number $(61.5 \%)$ reported recurrent episodes with good or partial recovery between episodes and $30.5 \%$ experienced a continuous chronic illness. ${ }^{2}$ 


\section{Early intervention for first-episode psychosis}

Early intervention for FEP has been a focus of care for several decades. It arose from the premise that the early years of illness are a 'critical period' for intervention, when there can be significant decline but also most scope for influencing longer term prognosis. 5, 21, 23 The main aims of such services are to shorten the course of the initial psychotic episode, reduce the severity of the illness, and subsequently minimise disruption to the person's life. ${ }^{5,23}$ Key components of early intervention include medication to reduce symptoms and psychosocial interventions aimed at supporting the individual's recovery. ${ }^{24}$ Even after onset of psychosis there is typically a delay in accessing appropriate treatment. ${ }^{25}$ The period of time between onset of first psychotic symptom and first treatment, referred to as the duration of untreated psychosis (DUP) has been a major focus of research and intervention. This is because DUP is considered to be an important and malleable prognostic factor. A systematic review to establish whether DUP is associated with prognosis included a meta-analysis of 26 studies including 4490 participants from diverse cultural backgrounds. ${ }^{3}$ The results showed there is evidence of a moderate association between DUP and symptomatic and functional outcomes in the short term (6-12 month follow up), though it remains inconclusive as to whether reducing a person's DUP improves overall prognosis. Mean DUP was found to be two years. ${ }^{3}$ The Treatment and Intervention in Psychosis (TIPS) early detection and intervention programme in Norway successfully reduced median DUP from 16 to 5 weeks. ${ }^{26}$ At 10 -year follow up, though reported symptoms were comparable across the early detection group and usual detection group, there were significant gains in recovery for the early detection group due to increased employment. ${ }^{27}$ Reducing DUP remains a common service goal. ${ }^{24}$

DUP is typically long, meaning individuals ${ }^{28}$ and their families ${ }^{29-31}$ are often required to cope with distressing symptoms for many months or longer. Many individuals and families report high levels of distress during the stage of untreated psychosis. First-episode psychosis is a high risk period for suicidality ${ }^{32}$ which is important as previous suicide attempts are predictors of later attempts and completed suicide. ${ }^{33}$ Gersen et al ${ }^{34}$ found that families of relatives with a FEP predominantly use adaptive coping strategies. In contrast, families of individuals with a more chronic illness reportedly use increased maladaptive strategies, suggesting the impact of burden and stress of care over time on coping. ${ }^{34,35}$ 
Early intervention services have received significant funding and resource allocation in recent years which has led to an ongoing debate regarding the superiority and value of such services over treatment as usual. ${ }^{20}$ Supporters of early intervention services often cite cost effectiveness and treatment effect as prominent reasons to fund and continue to develop specialist services. ${ }^{36}$ Two recent systematic reviews have been conducted evaluating the clinical and cost effectiveness of early intervention. ${ }^{36,37}$ Both were found to be inconclusive. Marshall and Rathbone $(2011)^{37}$ conducted a systematic review measuring the effectiveness of early intervention on clinical outcomes. They stated the effect was inconclusive, with the exception of some positive impact in the areas of employment and family therapy. ${ }^{37}$ Based on these findings the authors stated there was "some support for phase specific treatment focussed on employment and family therapy".37p.2 Vocational training was found to lead to increased employment during a six month period and family therapy in addition to standard care was found to reduce readmission. ${ }^{37}$ Amos $(2012)^{36}$ critically evaluated the literature reporting economic evaluations of early intervention programmes and found there was no evidence to support the claim "that early intervention for psychosis reduces costs or achieves cost-effectiveness". It is clear however, that the findings relating to increased employment and reduced readmission due to family involvement are important outcomes. Specifically, positive gains in employment could positively impact on an individual's financial difficulties and social isolation. These issues were rated the top three challenges by people living with a psychotic illness in the recent survey conducted in Australia. ${ }^{2}$ Support with employment should not however be restricted to early intervention services. In addition to the above results, there are also claims of inequity in service provision for those whom do not meet the 'youth focus' of most early intervention services. ${ }^{20}$ This is of relevance as one third of individuals will experience onset of psychosis after the age of 25 years, and therefore fall outside the age limit to be able to access many of the specialist services.

Whilst the above findings relating to the clinical and cost effectiveness of early intervention may have implications for future funding directives, it does not reduce the need for individuals with a FEP to receive early and appropriate intervention. Minimising the impact of psychosis for individuals and improving outcomes remains a priority in Clinical Practice Guidelines in many countries. $^{7-9}$ Quick and timely access to services can positively impact on the distress experienced by both the ill person and their families. Reaching those individuals experiencing a 
FEP during the early stages of illness requires "early detection of psychosis in the community and understanding factors associated with and contributing to delay in help-seeking". ${ }^{25 p .76}$

\section{Pathways to care for first-episode psychosis}

The literature related to pathways to care explores barriers and facilitators to accessing services. This encompasses help-seeking behaviour, accessibility of services and service response. $5,38,39$ 'Help-seeking can be defined as "the behaviour of actively seeking help from other people" and can be directed towards formal sources, such as mental health professionals, or informal sources, such as family and friends'. (Dr Coralie Wilson, personal communication, 2012 Mar 27) For young people informal sources are the preferred source of help. ${ }^{40,41}$ In FEP it is frequently the family that initiate successful contacts for their relatives, ${ }^{30,4}$ and often without the affected individual participating in the contact. 42

Before help-seeking can occur there needs to be a recognition that the person is in need of help. ${ }^{41}$ Recognition that a disorder is developing, knowledge of treatment options and knowledge of effective help-seeking strategies are all components of 'mental health literacy'. ${ }^{41}$ Community surveys of mental health literacy show that many people are unable to recognise mental illness, though there is evidence that improvements can be made by education strategies at a community level.27, 41 This knowledge is now impacting upon policy development, with programmes designed to develop people's mental health literacy and help-seeking skills. ${ }^{9}, 27,41,43$

In a systematic review aiming to understand and measure pathways to care in FEP, Singh $(2006)^{25}$ notes that there remains a delay for relatives to seek help even when a problem has become evident. A foundation paper published in 1986 highlighted the difficulties individuals with a 'first-episode of schizophrenia' had in accessing appropriate treatment. 44 This paper reported on the findings from the Northwick Park Study of First Episodes of Schizophrenia, conducted in the UK, whereby data was collected from 253 participants and their families pertaining to the presentation of the illness and problems relating to admission. Families reported being required to manage very difficult behaviours and make multiple contacts with services before accessing appropriate help. Delays in accessing services were often more than one year. Several decades forward, pathways to care for individuals with a FEP remain complicated with individuals presenting to services after an average of 2 years of untreated illness. ${ }^{3}$ 


\section{Overview of the literature}

Both quantitative $4,44,45$ and qualitative ${ }^{31,46,47}$ studies have been conducted to add to the understanding of pathways to care for individuals experiencing a FEP. Quantitative studies typically provide information regarding promoters to seeking help, number of attempts made to access appropriate treatment and sources of help contacted. ${ }^{4}$ Qualitative studies provide the detail of individuals' experiences of the above processes. Understanding individuals' personal narratives and journeys is one method of enhancing understanding of the processes that affect help-seeking. ${ }^{25}$ This thesis was concerned with engaging in an in-depth understanding of carers' experiences during this period and hence restricted its focus to qualitative research studies.

An initial search of the literature identified various qualitative studies exploring pathways to care during a FEP. In summary, delays in accessing appropriate treatment arise at all levels including illness recognition, help-seeking and service response. Help-seeking is just one factor that can impact on delay to treatment. ${ }^{48}$ Delays at service level can also be significant and occur for varied reasons, e.g. lack of affordable services, inflexibility of appointments ${ }^{49}$ and delayed diagnosis within mental health services. ${ }^{50}$ Common themes relating to delayed help-seeking include: stigma, misattribution of symptoms (e.g. drugs, stress or typical changes of adolescence), not knowing where to go, hope that the symptoms will go away without intervention, and a high threshold for seeking help.46, 47, 51 Factors associated with successful help-seeking include: frank psychotic symptoms; depression and suicidal thinking, and reaching a crisis. ${ }^{28,} 30,46$ When studies include both individuals with FEP and their family members, considerable congruence between the themes relating to their experiences of help-seeking is reported. 28,31

\section{Research Method}

Given there were a number of primary studies found on the topic of interest the systematic review (SR) was the chosen methodology to answer the study objectives. The SR method would facilitate the synthesis of the best available evidence on the lived experience of carers seeking help for a relative with FEP. The SR goes beyond the traditional literature review as the process is both more rigorous and transparent. This is achieved through the adherence to strict methods 
outlined within a protocol prior to the commencement of the research. The SR is embedded in the evidence-based health care movement and facilitates the development of recommendations for clinical practice, research and policy based on evidence from primary studies that have been systematically identified, appraised and synthesised. ${ }^{52}$ It was considered that a synthesis of the relevant studies of carers' experiences would add to the understanding of illness recognition, help-seeking strategies utilised and service response, and provide important information to improve pathways to care for those experiencing a FEP. A search of the Cochrane Library, Joanna Briggs Institute Library of Systematic Reviews, PubMed, CINAHL and PROSPERO databases did not reveal any previous or planned systematic reviews of qualitative evidence on this topic.

\section{Definition of terms}

First-episode psychosis (FEP)

For the purpose of defining the eligibility criteria for studies to be included in this review all operational definitions of FEP were considered. This means 'first-episode' may be defined as first treatment contact; duration of antipsychotic medication use or duration of psychosis. ${ }^{53}$

Carer

A carer can include anybody who looks after a family member, partner or friend who needs help because of illness, frailty or disability. All care provided is unpaid. 54 'Caring may include help and support in any of the daily activities of the person being cared for.'55 This could include physical, emotional, social or financial support as well as prompting to attend appointments and dealing with emergencies. ${ }^{55}$

Interestingly many carers do not consider themselves to be carers, and it is reported that it takes an average of two years to acknowledge the role of carer. A carer is not defined by their relationship to the ill individual and may include parent, sibling, child and spouse, amongst other relations. ${ }^{54}$

This thesis refers to 'carer', 'relative' and 'family member' interchangeably though the author has attempted to remain true to how each included paper described their participants. 


\section{Conclusion}

Research to date provides information regarding potential barriers and facilitators to help-seeking in a FEP. Increased awareness of the impact of prolonged DUP and benefits of early intervention has driven the need to further explore and understand the pathways to care for people experiencing a FEP. A preliminary search of the literature revealed qualitative studies exploring individuals' and their carers' experiences of help-seeking during a FEP. As carers play a crucial role in accessing help for relatives, and are often the primary and sole help-seeker, the systematic review presented within this thesis focussed on carers' experiences of help-seeking. 


\section{Chapter 3: Methodology and Methods}

\section{Introduction}

The review presented in this thesis is a systematic review (SR) of primary qualitative research studies. There is a long history of methodological development in relation to the conduct of systematic reviews of evidence and the review of qualitative research continues to be debated and further developed. This review followed the Joanna Briggs Institute (JBI) method for the conduct of qualitative systematic reviews which takes an aggregative approach to the synthesis of evidence. The methodology follows the processes of search, appraisal and synthesis initially designed for quantitative studies, though keeps to the traditions of qualitative research methodology. Further, the SR provides a platform for the development of recommendations for clinical decision making based on a synthesis of the best available evidence on a chosen topic. Thus the systematic review is located within the broader context of evidence-based practice and healthcare.

\section{Systematic review methodology}

The purpose of the systematic review is to collate, appraise and synthesise the best available evidence on the specific topic, and thereby inform decision making regarding clinical practice, education, policy and further research. The Cochrane Collaboration is recognised as an early leader in evidence synthesis of quantitative data and developed what is referred to as a gold standard approach for evaluating the effectiveness of health interventions. ${ }^{14}$ Systematic reviews of rigorous studies are said to "provide the best evidence on the effectiveness of different strategies to promote the implementation of research findings'. ${ }^{6}$ p.1 It was recognised however that a broader conceptualisation of what constitutes 'best evidence' was needed in order to answer complex questions related to health care provision. ${ }^{14,52}$ This realisation has led to the inclusion of qualitative research in systematic reviews and the subsequent development of a variety of models for synthesising findings based on qualitative data. ${ }^{14,}$, 2,57

The systematic review presented in this thesis is based upon the methodology of synthesis of qualitative data developed by the Joanna Briggs Institute (JBI). The Joanna Briggs Institute Reviewer's Manual: 2011 Edition provides detailed information on conducting a qualitative systematic review. ${ }^{11}$ One of the advantages of the systematic review is that it is required to be 
transparent throughout the process. Sufficient information regarding the review process should be provided to allow for the study to be replicated by others, as well as allow the reader to understand how conclusions were reached. To facilitate this transparency a protocol for the study is developed prior to the researcher embarking on the review process. The protocol includes development of a specific question(s) or objective(s); clarification of inclusion and exclusion criteria; and details of review methods including search strategy, appraisal, data extraction and synthesis. ${ }^{11}$ At the time of conducting this systematic review, protocols for JBI systematic reviews were peer-reviewed by the Science Synthesis Unit and then published. As this systematic review was undertaken towards a Masters in Clinical Science degree the protocol was also presented to an academic panel which included two academics with expertise in the topic area of this review. If any deviation is made to the published protocol it must be clearly justified and the original protocol included in the appendices. There were no changes made to the protocol for this review once it had been finalised and published.

This thesis was interested in exploring carers' personal narratives and journeys in order to enhance the understanding of the processes that affect help-seeking for relatives with a FEP. It was therefore deemed appropriate to restrict the focus to qualitative research studies. Qualitative research is based within the interpretative paradigm and includes various methodologies including phenomenology, grounded theory, ethnography, action research and feminist research. Inherent in each of these methodologies is the aim to develop a greater understanding of the chosen phenomena of interest, which in this instance was: Carers' experience of seeking help for relatives with a FEP. Given the various methodologies, debates have arisen regarding methods for the appraisal, synthesis and application of qualitative evidence and it continues to be a developing area of research. ${ }^{14}, 15$ The systematic review is a research method that is designed to synthesise the best available evidence on a specific topic. Meta-aggregation is "a method of systematic review that mirrors the processes of the quantitative review whilst holding to the traditions and requirements of qualitative research". $15 p .1$ It is this interpretation that the Joanna Briggs Institute have followed in the development of their model of qualitative synthesis.

The JBI method of synthesis needs to be viewed within the larger context of evidence basedpractice and the JBI-conceptualised model of evidence-based healthcare. ${ }^{12}$ This model defines evidence-based practice as "clinical decision-making that considers the best available evidence, 
the context in which the care is delivered, client preference and the professional judgement of the health professional". 12 p.209 The model identifies the four major components of the evidencebased healthcare process as being: evidence generation; evidence synthesis; evidence transfer and evidence utilisation. The systematic review is inherent to all these processes. Furthermore, $\mathrm{JBI}$ emphasise the importance of the concepts of feasibility, appropriateness, meaningfulness and effectiveness for evidence generation. ${ }^{12}$ These concepts are inherent in the development of the recommendations for clinical practice, research and policy and are based on the results of the systematic review.

Software programmes to assist with the management and documentation of the information, results and findings of a systematic review have been developed. The specific analytic tool utilised in this review is known as the JBI Qualitative Assessment and Review Instrument (JBIQARI). This programme was utilised to enter the information collected during data extraction, as well as findings, supporting illustrations and subsequent development of categories and synthesised findings. JBI-QARI sorts the above data into a meta-synthesis table that allows the reader to view the individual findings and categorisations for each synthesised finding. The tables presented in the Results chapter of this thesis are formulated by JBI-QARI to present each of the synthesised findings. Illustrations for each level 1 finding are listed in Appendix VII. These are presented by study.

\section{Review Method}

\section{Objectives}

The objective of this review was to synthesise the best available evidence on the lived experience of carers of a relative with a first-episode psychosis (FEP) and in particular their experience preceding and of seeking help.

More specifically, the objectives were to explore:

Perceived promoters and inhibitors to help-seeking during a FEP.

Perceived barriers and facilitators to accessing services during a FEP. 


\section{Inclusion criteria}

\section{Types of participants}

This review considered studies that included carers of a relative with a FEP. This means first presentation of psychotic symptoms with no limit to duration of untreated psychosis. Method of diagnosis was according to any of the editions of the Diagnostic and Statistical Manual of Mental Disorders (DSM), International Statistical Classification of Diseases (ICD), research diagnostic criteria relevant to the country of study or confirmed by a Psychiatrist or other health care professional.

Psychotic symptoms may include hallucinations and delusions.

Psychotic disorders may include:

Schizophrenia

Schizoaffective disorders

Mania with psychotic symptoms

Depression with psychotic symptoms

Delusional disorders

Acute and transient psychotic disorders

Other and unspecified non-organic psychotic disorder

There will be no age restriction for the person experiencing the psychosis.

Carers could be a parent, sibling, spouse or other relative of any age.

Studies that predominantly included individuals in the prepsychotic or ultra-high risk stage of illness were excluded due to the 'low' conversion rate to psychosis.

\section{Phenomena of interest}

This review considered studies that investigated the experience of carers of a relative with a firstepisode psychosis, and in particular their experience preceding and of seeking help from both informal (family and friends) and formal (services) sources. 


\section{Types of studies}

This review considered studies that focussed on qualitative data including, but not limited to, designs such as phenomenology, grounded theory, ethnography, action research and feminist research.

Other papers and reports using qualitative data were also considered.

\section{Context}

The review considered research conducted in any mental health care setting including inpatient, outpatient and community. All country and cultural contexts were considered.

\section{Search strategy}

The search strategy aimed to find both published and unpublished studies. A three-step search strategy was utilised in this review. An initial limited search of MEDLINE and CINAHL was undertaken followed by analysis of the text words contained in the title and abstract, and of the index terms used to describe articles. A second search using all identified keywords and index terms was then undertaken across all included databases. Thirdly, the reference lists of all identified reports and articles were searched for additional studies. Only studies published in English were considered for inclusion in this review as no translation resources were available. Studies published between January 1990 and August 2012 were considered for inclusion in this review due to focus of care on first-episode psychosis and pathways to care developing in the early 1990's.

The databases searched included:

CINAHL, PubMed, Scopus, PsycINFO and Embase.

The search for unpublished studies included:

Mednar, ProQuest Dissertations and Theses, Trove, relevant professional bodies in the field of Early Intervention in Psychosis and carers in mental health.

A detailed account of the search strategy utilised for each search engine can be found in Appendix I. 


\section{Method of appraisal}

Papers selected for retrieval were assessed by two independent reviewers for methodological validity prior to inclusion in the review using standardised critical appraisal instruments from the Joanna Briggs Institute Qualitative Assessment and Review Instrument (JBI-QARI) (Appendix II). Following appraisal of a selected few studies, the reviewers met to clarify interpretation of the appraisal tool and to discuss any discrepancies in scoring. This included clarifying standards for inclusion or exclusion for the review. No disagreements arose between the reviewers.

The JBI-QARI appraisal instrument consists of a ten-point checklist designed to assess the methodological quality of qualitative research papers. A detailed summary of each criterion is provided in the user manual for JBI-QARI. ${ }^{58}$ Following below are the ten statements listed on the JBI-QARI Critical Appraisal Checklist and the reasoning behind the way each criterion was interpreted for the purposes of this review:

Criterion 1: There is congruity between the stated philosophical perspective and the research methodology.

If there was no explicit statement of the philosophical perspective it was decided to mark as unclear. This was due to the distinction of philosophical perspective rarely being reported in journal articles.

Criterion 2: There is congruity between the research methodology and the research question or objectives.

If no methodology was stated, it was interpreted as being congruent if there was congruency between method and research question or objectives.

Criterion 3: There is congruity between the research methodology and the methods used to collect data.

No further clarification was necessary.

Criterion 4: There is congruity between the research methodology and the representation and analysis of data.

No further clarification was necessary. 
Criterion 5: There is congruity between the research methodology and the interpretation of results.

No further clarification was necessary.

Criterion 6: There is a statement locating the researcher culturally or theoretically.

No further clarification was necessary.

Criterion 7: The influence of the researcher on the research, and vice-versa, is addressed.

It was considered this was addressed if the researcher considered this at the point of data analysis or review of data, in addition to the conditions outlined in the JBI Reviewer's Manual (2011).

Criterion 8: Participants, and their voices, are adequately represented.

It was decided to broaden the definition and consider papers the researcher had allowed for the 'voice' to show through rather than only consider if the individual participant quotes were clear. The 'voice' of the participants was considered adequately represented when their accounts and perspectives came through clearly in the results section.

Criterion 9: The research is ethical according to current criteria or, for recent studies, there is evidence of ethical approval by an appropriate body.

No further clarification was necessary.

Criterion 10: Conclusions drawn in the research report do appear to flow from the analysis, or interpretation, of the data.

No further clarification was necessary.

For this systematic review the inclusion/exclusion of papers were based on the following:

Criteria 2, 3, 4, 5 and 8: These criteria were considered critical to the assessment of the quality of the paper. Any paper where any one of these criteria was not met was excluded and any paper where two or more of these criteria were rated as unclear was excluded.

Criteria 6, 7, 9 and 10: These criteria, though considered important in the assessment of quality 
of the paper, were individually considered to be less significant. Any paper where three of these criteria were not met was excluded.

Criterion 1: This criterion was not considered when making the decision to include or exclude the papers as very few authors referred explicitly to a philosophical perspective.

\section{Data collection}

Data was extracted from qualitative research papers included in the review using the standardised data extraction tool from JBI-QARI (Appendix III). The data extracted includes specific details about the phenomena of interest, populations, study methods and outcomes of significance to the review question and specific objectives.

\section{Data synthesis}

Qualitative research findings were pooled using JBI-QARI. This involved the aggregation or synthesis of findings to generate a set of statements that represent that aggregation. The first stage was extracting level 1 findings with supporting illustrations from each paper that related specifically to the phenomena of interest to this systematic review. These findings were then rated according to their quality, and categorised on the basis of similarity in meaning. The categories were then subjected to a meta-synthesis in order to produce a single comprehensive set of synthesised findings that can be used as a basis for evidence-based practice.

Each level 1 finding was assigned a level of credibility, based on the congruency of the finding with the supporting illustration from the study that the finding was extracted. The findings were rated against three levels of credibility: ${ }^{11}$

Unequivocal- relates to evidence beyond reasonable doubt which may include findings that are matter of fact, directly reported/observed and not open to challenge.

Credible- relates to those findings that are, albeit interpretations, plausible in light of the data and theoretical framework. They can be logically inferred from the data. Because the findings are interpretative they can be challenged.

Unsupported- is when findings are not supported by the data. 
Only findings rated as Unequivocal and Credible were utilised in the synthesis. In addition level 1 findings were allocated to more than one category when appropriate.

As this systematic review was undertaken towards a Masters in Clinical Science degree, the stages of data extraction and synthesis were performed independently by the primary reviewer, author of this thesis.

\section{Conclusion}

The SR is a method of research that facilitates the rigorous and thorough examination of the available evidence to ensure the development of recommendations for clinical practice, education, research and policy are based on the best available evidence. The JBI method of SR of qualitative evidence achieves this through a clear methodology that includes the search, appraisal and synthesis of primary research related to the topic of interest. Recommendations based on the synthesised findings can be considered alongside the concepts of feasibility, appropriateness, meaningfulness and effectiveness for evidence generation. 


\section{Chapter 4: Results}

\section{Introduction}

Five synthesised findings were derived from 16 categories and 213 level 1 findings. Each of the five synthesised findings are presented in table format with associated categories and level 1 findings. The tables were produced by the JBI-QARI software programme. Following each table presentation there is a detailed summary of each synthesised finding to inform the reader how each meta-synthesis was reached. A few key findings with their supporting illustrations are presented within a summary of each category.

\section{Description of studies}

As shown in Figure 1, 6975 papers were identified from a detailed search across selected databases. After removing duplicates, 5797 were examined against the inclusion criteria by reading title and abstracts. Fifty-one papers were retrieved for full examination and a further four papers were identified from reference lists of these papers. Twenty-six studies met criteria for critical appraisal. Following critical appraisal, a further four papers were excluded. A total of 22 papers were included in this review. Three of the papers included were unpublished theses. 
Figure 1: Flow diagram for retrieval and selection of studies.

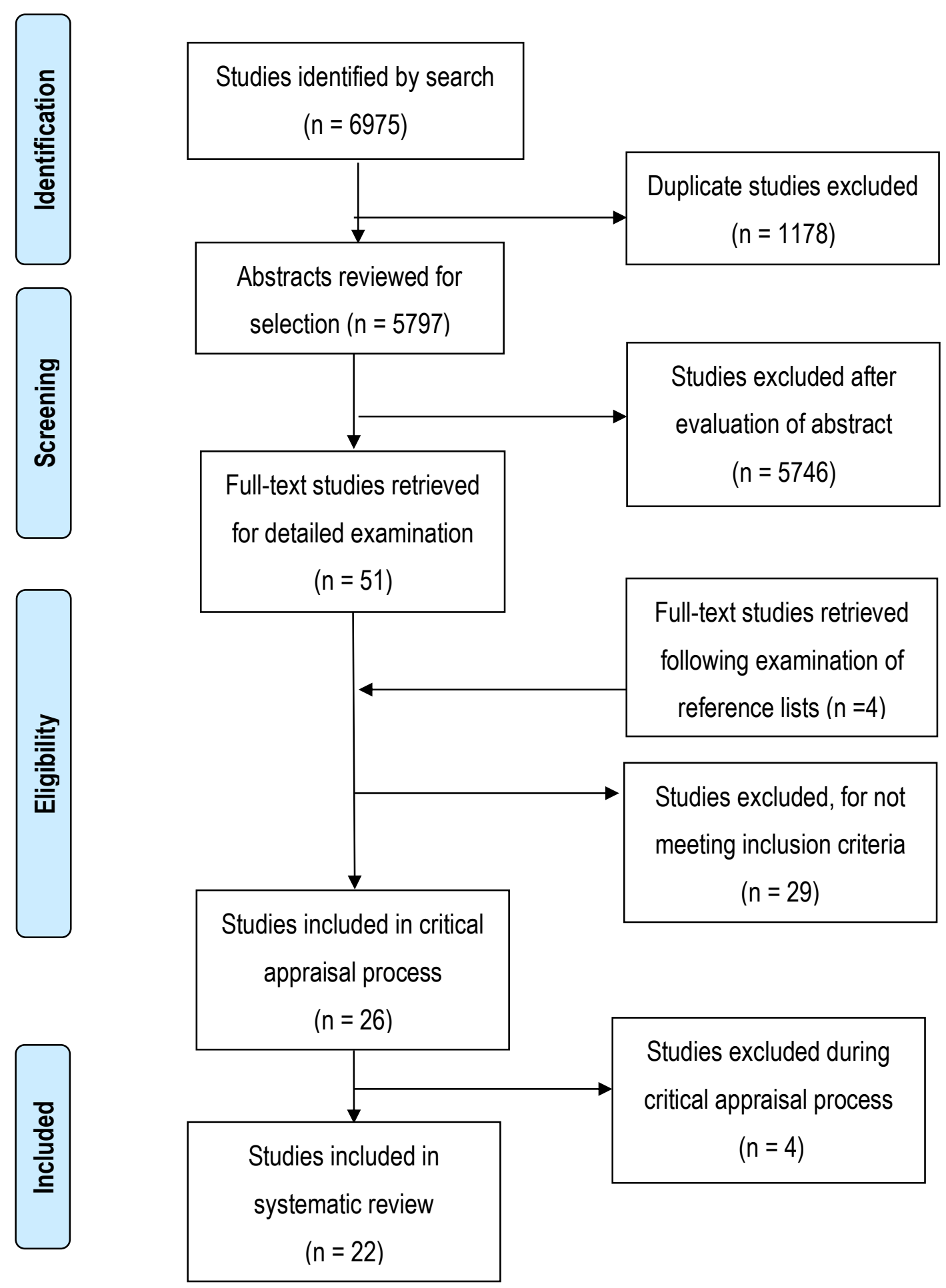


The included studies were conducted over a 14 year period (1998-2012), with the majority occurring (no=14) since 2006.

Ten different countries were represented in the review:

- USA $46,49,59-62$

- UK 28,63-66

- Canada $30,67,68$

- Brazil 69,70

- Australia 47

- Korea ${ }^{71}$

- Germany ${ }^{72}$

- Hong Kong 73

- Japan ${ }^{74}$

- New Zealand 31

In addition to the variation in the countries where the studies were located, various studies took further steps to explore the experience of relatives from specific cultural groups. Bergner et al, ${ }^{49}$ Franz et al ${ }^{62}$ and Compton et al ${ }^{19}$ engaged participants of African American ethnicity and Donnelly ${ }^{60}$ participants of Korean American ethnicity. Other authors reported cultural diversity of participants due to the location of the study. ${ }^{28,46,61}$ Bergner et al ${ }^{49}$ and Franz et al62 reported from the same data collection as did Gerson et al61 and Corcoran et al. ${ }^{46}$ As each of these studies had a different phenomenon of interest, variation in findings was presented within the papers. Czuchta and McCay ${ }^{30}$ reported a summary of their qualitative findings and referred to plans for an additional article to be published to further describe the qualitative findings. No further article was found during the search process. The researcher emailed the second author seeking further information but received no response.

The stated phenomenon of interest for the studies was significantly varied. Some studies were concerned with exploring the carers' experiences preceding and during help-seeking, ${ }^{30,31,46,49}$ others explored carers' experiences over a longer timeframe67, 68, 74 and additional studies focussed specifically on service access. ${ }^{47,} 61$ Other specific foci included exploring cultural interpretations of illness ${ }^{60}$ and carers' experience of service contact after treatment initiation. ${ }^{65}$ Reasons for delays in help-seeking were another focus including exploration of specific determinants such as the impact of stigma ${ }^{62}$ and ethnicity. ${ }^{59}$ Several studies considered both the carers' as well as the ill relatives' experience. ${ }^{31,61,63}$ Findings were extracted from the various included studies relevant to the phenomena of interest of this review. 
Whilst it could be inferred that the majority of studies were conducted within the interpretative paradigm, only eight studies clearly stated the methodology utilised. These were: Phenomenology (4); Grounded Theory (3) and Ethnography (1).

A broad range of participants met the criteria for carers of a relative with FEP. These included: mothers; fathers; siblings; aunts; uncles; cousins; grandmother; girlfriends; boyfriends and stepparents. Whilst the majority of participants were parents, and more specifically mothers, some studies focussed on a specific relation to the ill individual including sibling, 67,68 husband ${ }^{74}$ and spouse. ${ }^{72}$ Sample sizes varied with 11 studies having between two and ten participants, seven studies between 11 and 20 participants, one study with 58 participants, one with 103 participants and two where the number was unclear.

\section{Methodological quality}

All papers included were considered to be of good methodological quality. Of the five prioritised criteria all 22 papers demonstrated congruency of: methodology and objectives (criterion 2); methodology and methods (criterion 3); methodology and reporting of results (criterion 5) and provided a good representation of participants and their voices (criterion 8). Compton ${ }^{59}$ was the only study not to meet criterion 4 relating to congruity between methodology and data analysis. The authors did not report the process they undertook to analyse the data but it was presumed that it was akin to a thematic analysis based on the presentation of results.

Thirteen papers explicitly reported seeking ethics approval (criterion 9); though some additional studies outlined steps they had undertaken to address ethical issues. Fourteen studies reported on the influence of the researcher on the research (criterion 7). Many of the papers acknowledged this influence during the stage of interpretation of the data. This was done in a variety of ways including reporting that authors were required to reach a consensus of themes ${ }^{46}$ or that authors conducted independent reviews of the data. ${ }^{47}$ Some authors sought participant confirmation of the accuracy of interpretation 63,67 and, in addition, one paper discussed the impact the first author's clinical training may have had in influencing interpretation of the data. ${ }^{63}$ Fourteen authors made a statement locating the researcher culturally or theoretically (criterion 6). It was clear that some of the lower scoring was due to reporting methods in the paper rather than quality of research as demonstrated by an instance where two papers based on the same 
data 49,62 scored differently on criteria 6 and 7 .

The poorest reporting across all papers was regarding criterion 1 which was concerned with congruency between the philosophical perspective and research methodology. Only eight papers clearly stated the philosophical perspective. It was however possible to infer that most studies came from the interpretative philosophical perspective, based on methodology, methods used and data analysis. The three papers for which it was difficult to ascertain the philosophical perspective were: Czuchta and McCay; 30 Compton et al59 and McKenzie. 65

Table 1: Results from Critical Appraisal

Number of studies included and excluded

\begin{tabular}{|c|c|}
\hline Number of studies included & Number of studies excluded \\
\hline 22 & 4 \\
\hline
\end{tabular}

\begin{tabular}{|c|c|c|c|c|c|c|c|c|c|c|}
\hline \multicolumn{11}{|l|}{ Final Assessment Table } \\
\hline Citation & Q1 & Q2 & Q3 & Q4 & Q5 & Q6 & Q7 & Q8 & Q9 & Q10 \\
\hline $\begin{array}{l}\text { Mizuno, E., Misuzu, I., \& } \\
\text { Sakai, I., } 2011\end{array}$ & $U$ & Y & Y & $\mathrm{Y}$ & Y & $\mathrm{N}$ & $\mathrm{Y}$ & Y & Y & $\mathrm{Y}$ \\
\hline $\begin{array}{l}\text { Bergner, E., Leiner, A. S., } \\
\text { Carter, T., Franz, L., } \\
\text { Thompson, N. J., Compton, } \\
\text { M. T., } 2008\end{array}$ & $U$ & Y & Y & Y & Y & $\mathrm{N}$ & $\mathrm{N}$ & Y & $U$ & Y \\
\hline $\begin{array}{l}\text { Gerson, R., Davidson, L., } \\
\text { Booty, A., Wong, C., } \\
\text { McGlashan, T., Malespina, } \\
\text { D., Pincus, H. A., Corcoran, } \\
\text { C., } 2009\end{array}$ & $U$ & Y & Y & Y & Y & $\mathrm{N}$ & Y & Y & Y & $\mathrm{Y}$ \\
\hline $\begin{array}{l}\text { Tanskanen, S., Morant, N., } \\
\text { Hinton, M., Lloyd-Evans, B., } \\
\text { Crosby, M., Killaspy, H., } \\
\text { Raine, R., Pilling, S., } \\
\text { Johnson, S., } 2011\end{array}$ & $U$ & Y & Y & Y & Y & $\mathrm{N}$ & $\mathrm{N}$ & Y & $U$ & Y \\
\hline $\begin{array}{l}\text { Barnable, A., Gaudine, A., } \\
\text { Bennett, L., Meadus, R., } \\
2006\end{array}$ & $U$ & Y & Y & Y & Y & $\mathrm{Y}$ & Y & Y & Y & $Y$ \\
\hline Jung, M., 2000 & Y & $Y$ & Y & $Y$ & Y & $Y$ & Y & Y & $\mathrm{N}$ & $Y$ \\
\hline $\begin{array}{l}\text { McCann, T. V., Lubman, D. I., } \\
\text { Clark, E., } 2011\end{array}$ & Y & Y & Y & Y & Y & Y & Y & Y & Y & Y \\
\hline Redko, C, 2003 & Y & Y & Y & Y & Y & Y & $\mathrm{N}$ & Y & $\mathrm{N}$ & Y \\
\hline McKenzie, L. H., 2006 & $U$ & $\mathrm{Y}$ & $Y$ & $Y$ & $Y$ & $\mathrm{~N}$ & $\mathrm{~N}$ & Y & Y & $Y$ \\
\hline
\end{tabular}




\begin{tabular}{|c|c|c|c|c|c|c|c|c|c|c|}
\hline Wong, D. F. K., 2007 & $U$ & Y & Y & Y & Y & $\mathrm{Y}$ & $\mathrm{Y}$ & Y & $\mathrm{N}$ & Y \\
\hline $\begin{array}{l}\text { Cadario, E., Stanton, J., } \\
\text { Nicholls, P., Crengle, S., } \\
\text { Wouldes, T., Gillard, M., } \\
\text { Merry, S. N., } 2012\end{array}$ & U & Y & $\mathrm{Y}$ & $\mathrm{Y}$ & $\mathrm{Y}$ & $\mathrm{Y}$ & $\mathrm{Y}$ & $\mathrm{Y}$ & $\mathrm{Y}$ & $\mathrm{Y}$ \\
\hline Jungbauer, J, 2002 & $U$ & Y & Y & $\mathrm{Y}$ & $\mathrm{Y}$ & Y & Y & Y & $\mathrm{N}$ & $\mathrm{Y}$ \\
\hline $\begin{array}{l}\text { Compton, M. T., Kaslow, N. } \\
\text { J., Walker, E. F., } 2004\end{array}$ & U & Y & $\mathrm{Y}$ & U & $\mathrm{Y}$ & $\mathrm{N}$ & $\mathrm{N}$ & $\mathrm{Y}$ & Y & $\mathrm{Y}$ \\
\hline $\begin{array}{l}\text { Franz, L., Carter, T., Leiner, } \\
\text { A. S., Bergner, E., } \\
\text { Thompson, N. J., Compton, } \\
\text { M. T., } 2010\end{array}$ & U & Y & $\mathrm{Y}$ & $\mathrm{Y}$ & Y & $\mathrm{Y}$ & $\mathrm{Y}$ & Y & U & $\mathrm{Y}$ \\
\hline $\begin{array}{l}\text { Corcoran, C., Gerson, R., } \\
\text { Sills-Shahar, R., Nickou, C., } \\
\text { McGlashan, T., Malaspina, } \\
\text { D., Davidson, L., } 2007\end{array}$ & U & Y & $\mathrm{Y}$ & $\mathrm{Y}$ & $\mathrm{Y}$ & $\mathrm{N}$ & $\mathrm{Y}$ & $\mathrm{Y}$ & $\mathrm{Y}$ & $\mathrm{Y}$ \\
\hline $\begin{array}{l}\text { Czuchta, D. M. \& McCay, E., } \\
2001\end{array}$ & U & Y & $\mathrm{Y}$ & $\mathrm{Y}$ & $\mathrm{Y}$ & $\mathrm{Y}$ & $\mathrm{N}$ & $\mathrm{Y}$ & $\mathrm{Y}$ & $\mathrm{Y}$ \\
\hline Donnelly, P. L., 2005 & Y & Y & Y & $\mathrm{Y}$ & $\mathrm{Y}$ & $\mathrm{Y}$ & $\mathrm{Y}$ & $\mathrm{Y}$ & $U$ & $\mathrm{Y}$ \\
\hline $\begin{array}{l}\text { Monteiro, V. B. M., Dos } \\
\text { Santos, J. Q., Martin, D., } \\
2006\end{array}$ & U & Y & $\mathrm{Y}$ & $\mathrm{Y}$ & Y & $\mathrm{Y}$ & $\mathrm{N}$ & Y & $Y$ & $\mathrm{Y}$ \\
\hline Champion, S., 2007 & Y & Y & Y & Y & $\mathrm{Y}$ & Y & Y & Y & Y & $\mathrm{Y}$ \\
\hline Dodge, C. E, 2011 & Y & Y & Y & $\mathrm{Y}$ & Y & Y & $\mathrm{N}$ & $\mathrm{Y}$ & Y & Y \\
\hline Pearse, W. A., 1998 & Y & Y & Y & $\mathrm{Y}$ & $\mathrm{Y}$ & $\mathrm{N}$ & $\mathrm{Y}$ & $\mathrm{Y}$ & $\mathrm{Y}$ & Y \\
\hline $\begin{array}{l}\text { Barker, S., T. Lavender, T. , } \\
\text { Morant, N., } 2001\end{array}$ & $\mathrm{Y}$ & Y & $\mathrm{Y}$ & $\mathrm{Y}$ & $\mathrm{Y}$ & $\mathrm{Y}$ & $\mathrm{Y}$ & $\mathrm{Y}$ & $U$ & Y \\
\hline \% 'yes' responses & 36 & 100 & 100 & 95 & 100 & 64 & 64 & 100 & 59 & 100 \\
\hline
\end{tabular}

$Y=$ yes; $N=$ no; $U=$ unclear 


\section{Results of metasynthesis of qualitative research findings}

Meta-synthesis of studies included in the review generated five Synthesised Findings. These Synthesised Findings were derived from 213 Study Findings that were subsequently aggregated into 16 Categories. The Study Findings are listed in Appendix VII.

\section{Synthesised Finding 1}

Recognising an illness is developing and that the person is in need of help is often delayed. Beliefs about mental illness further impact upon the timing as well as type of help sought.

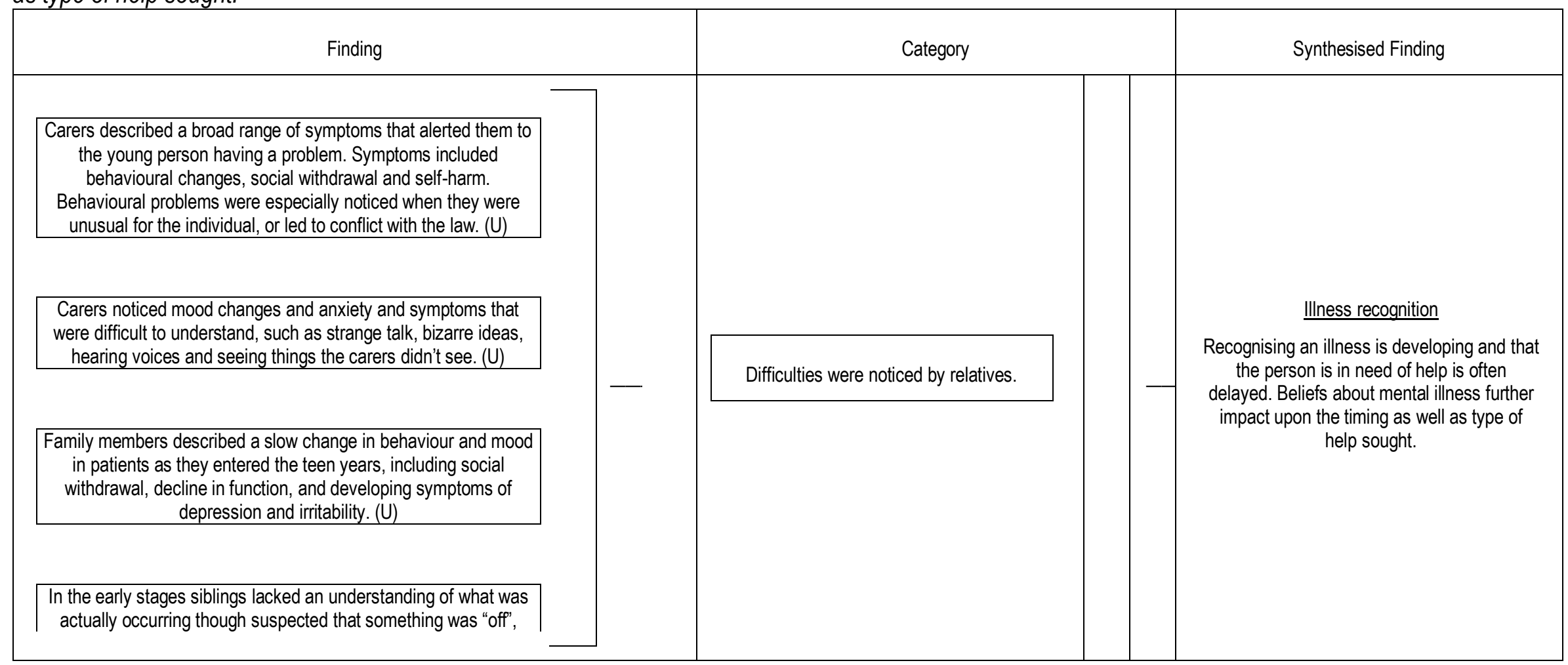




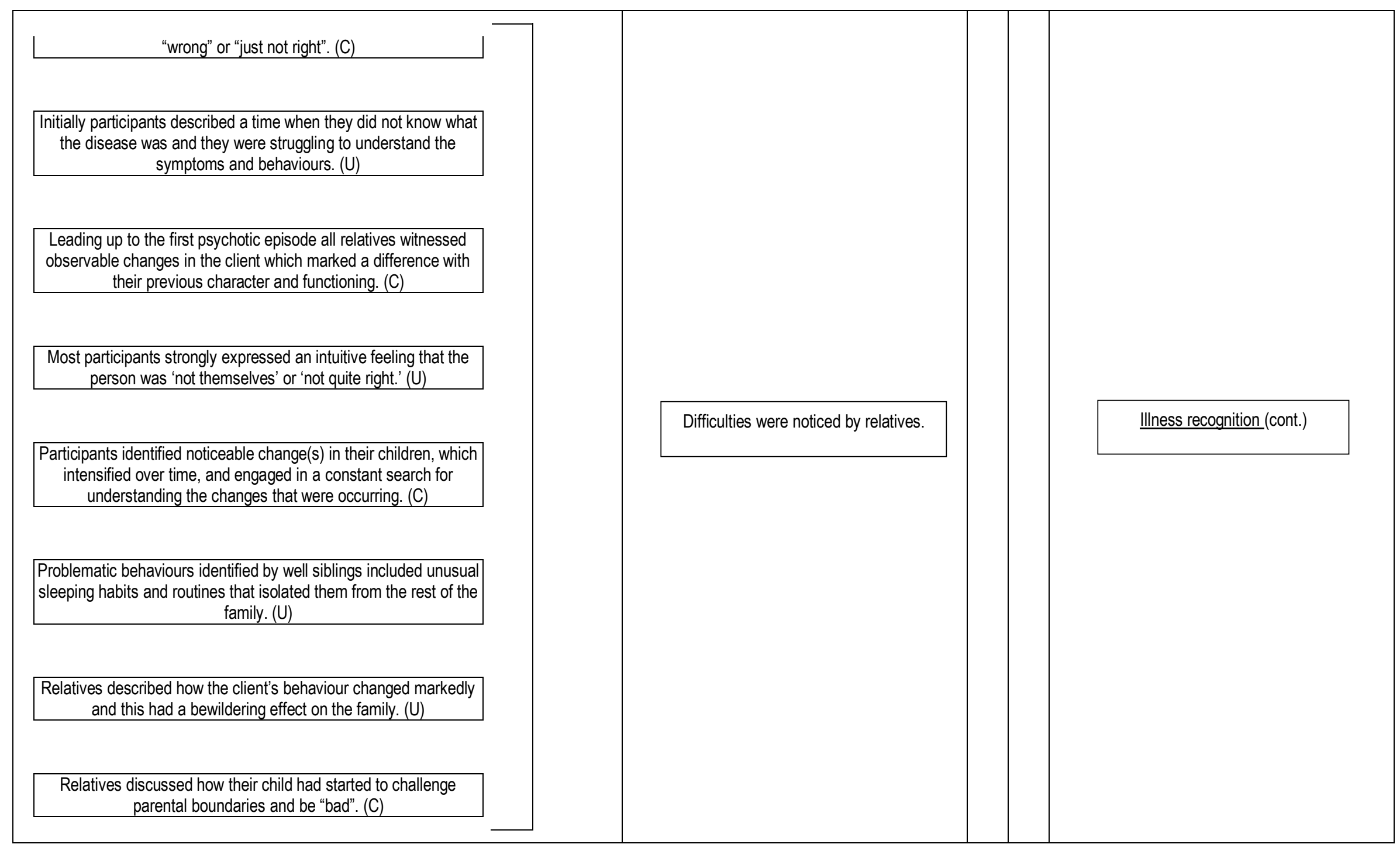




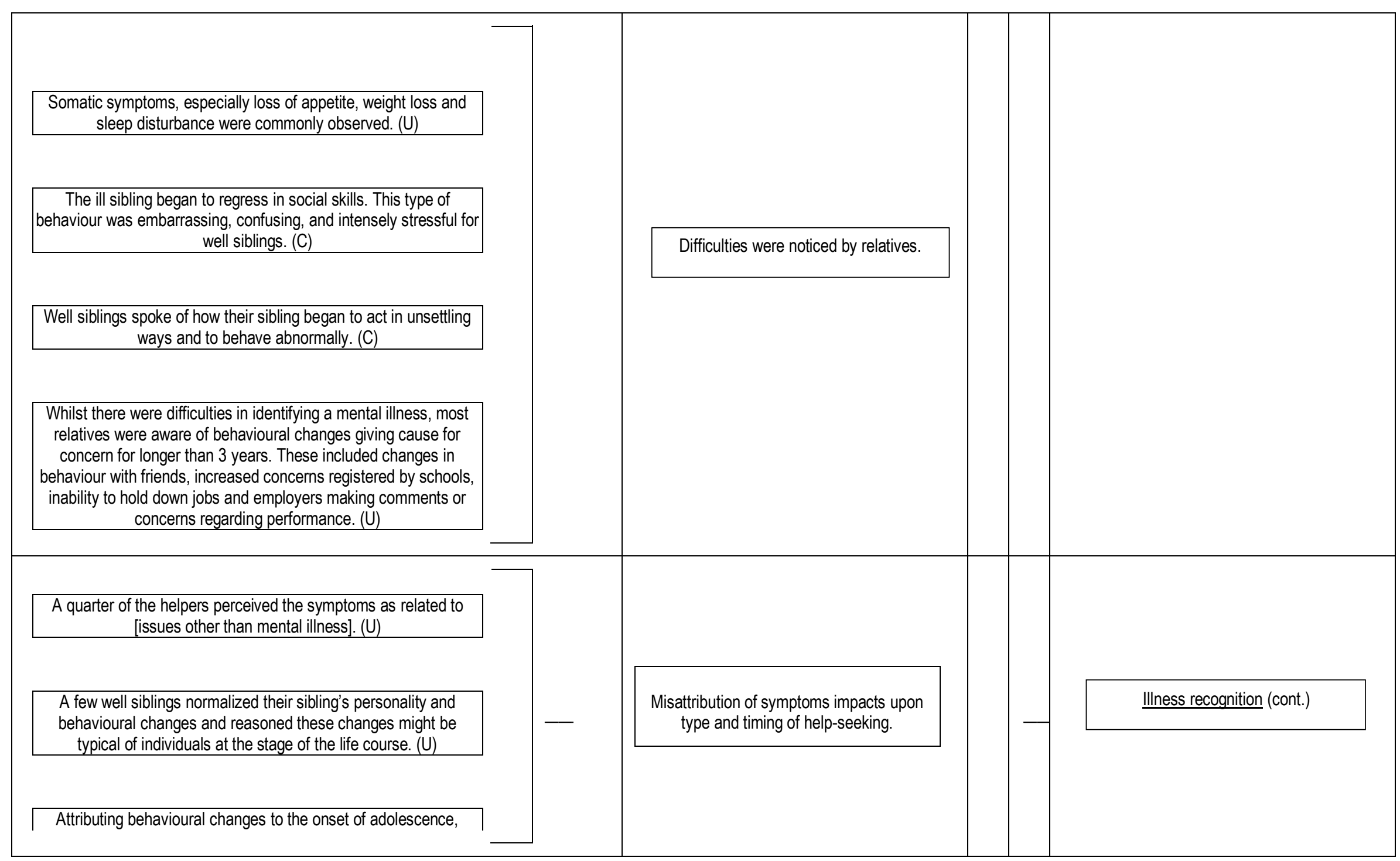




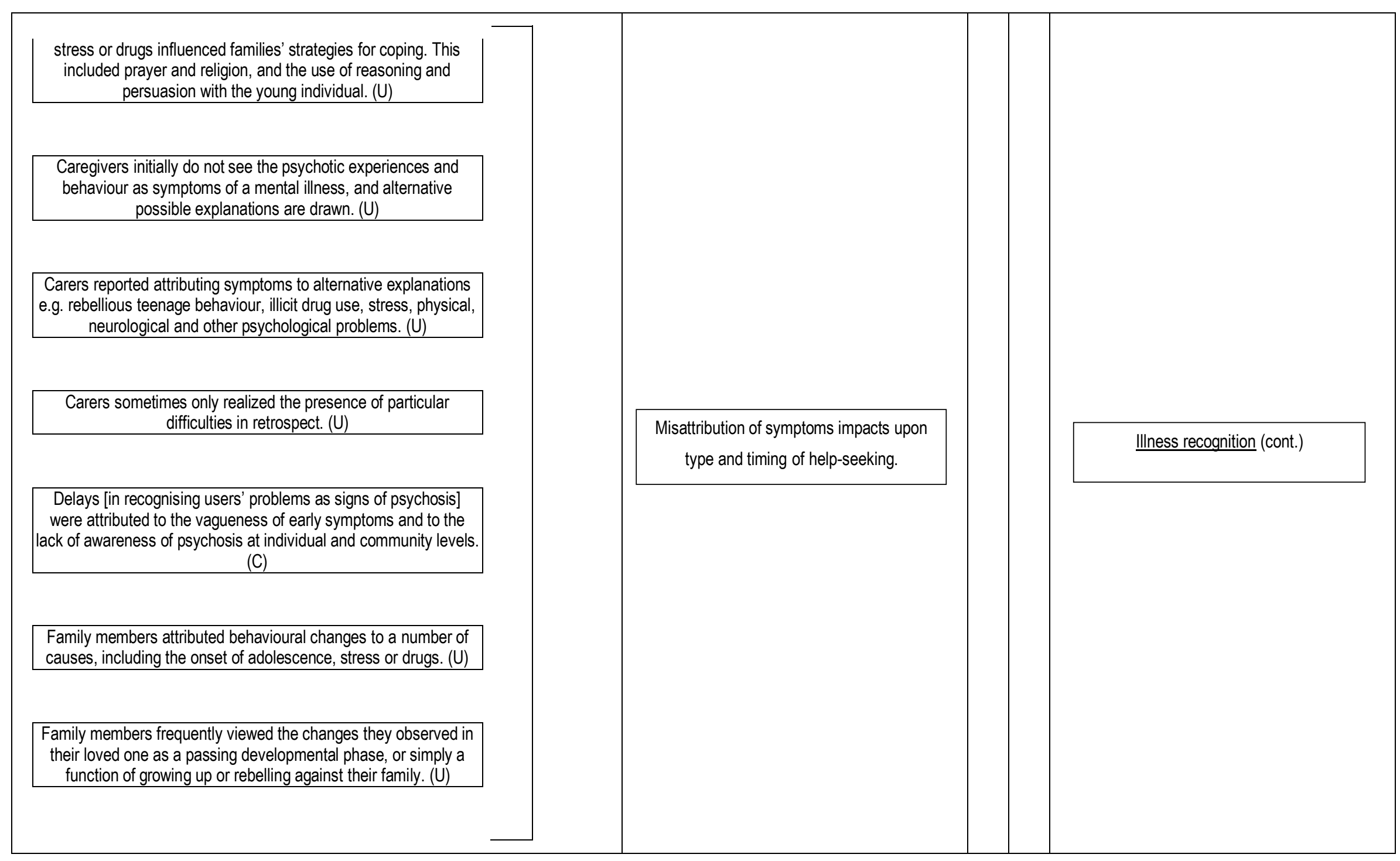




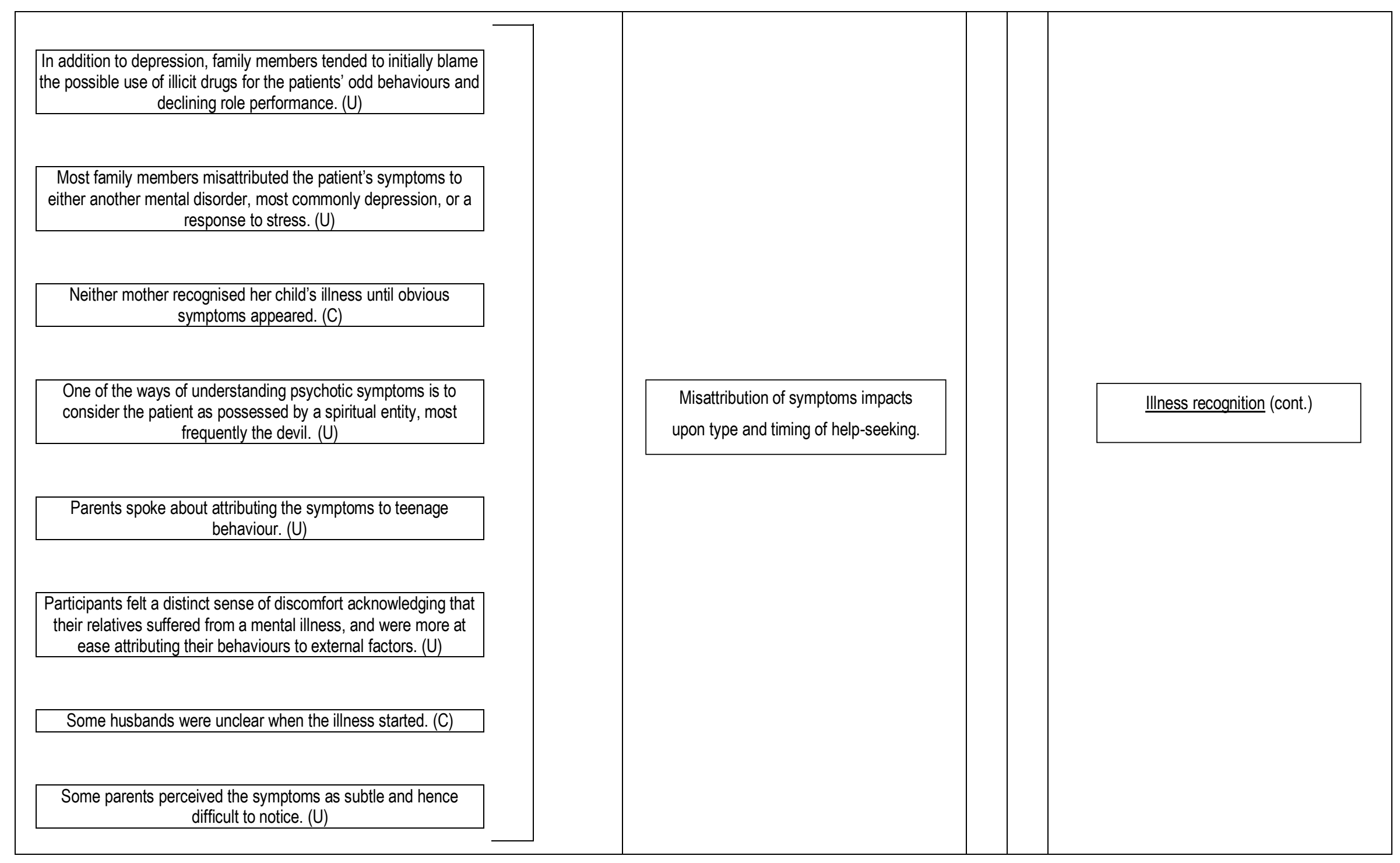




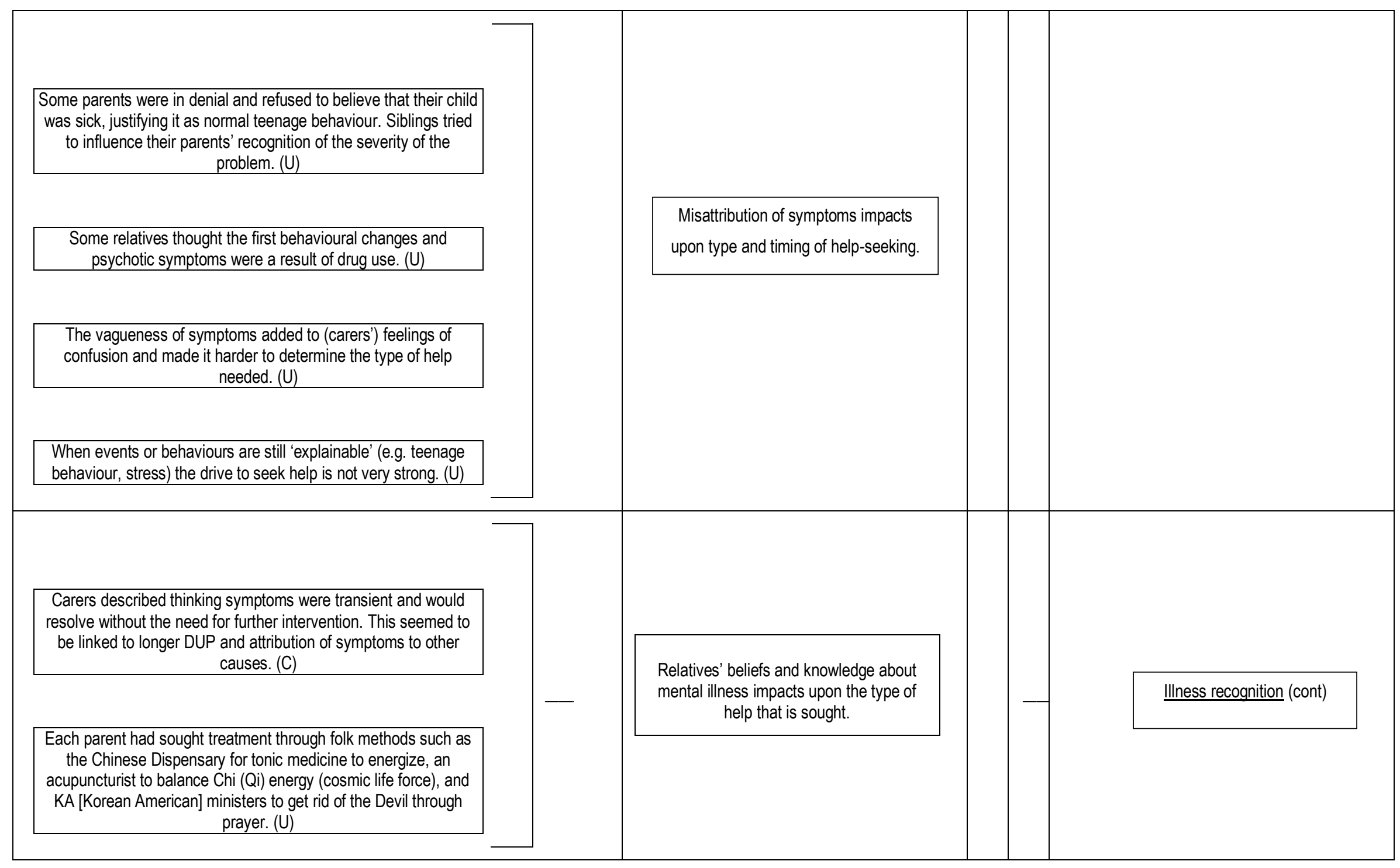




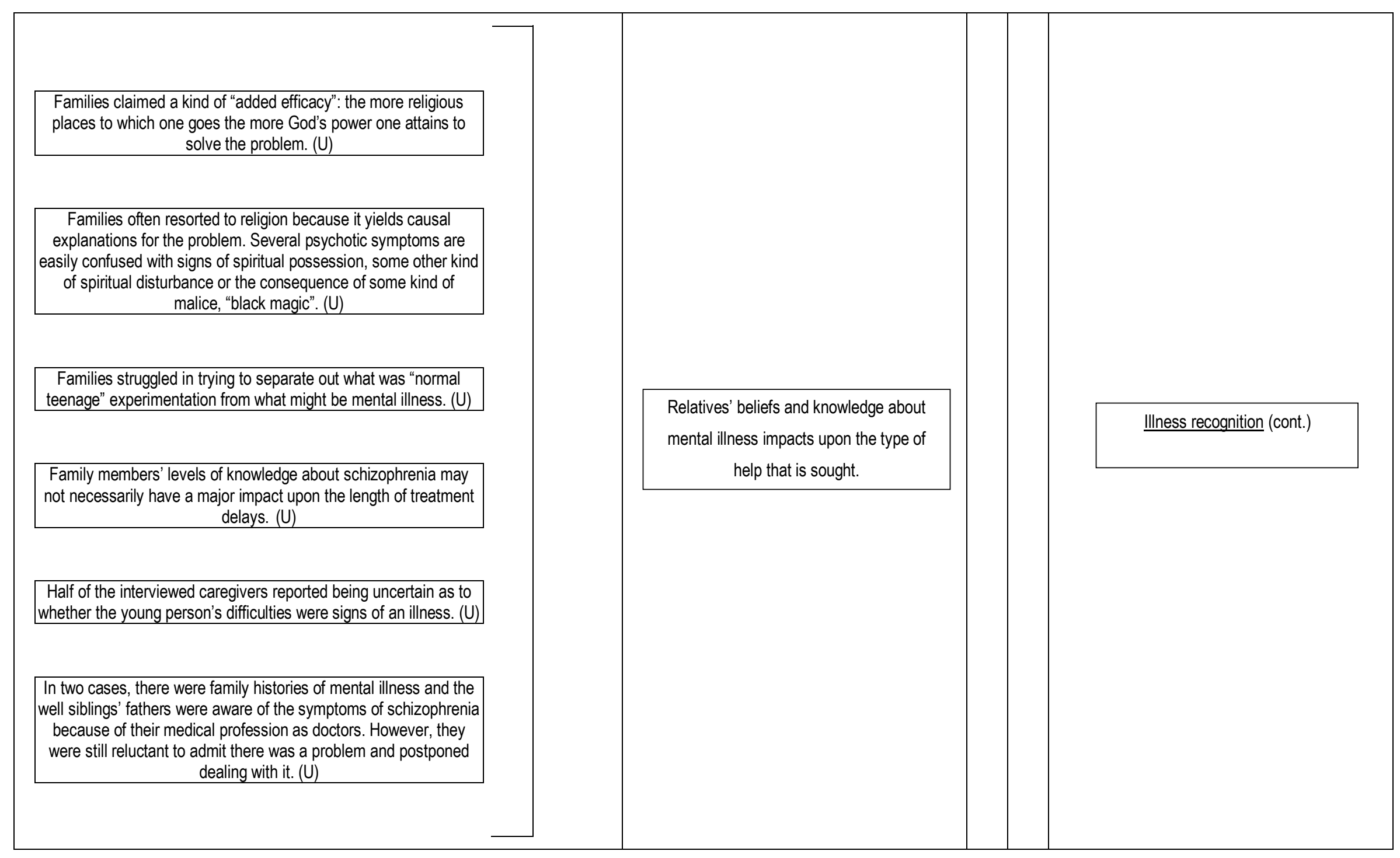




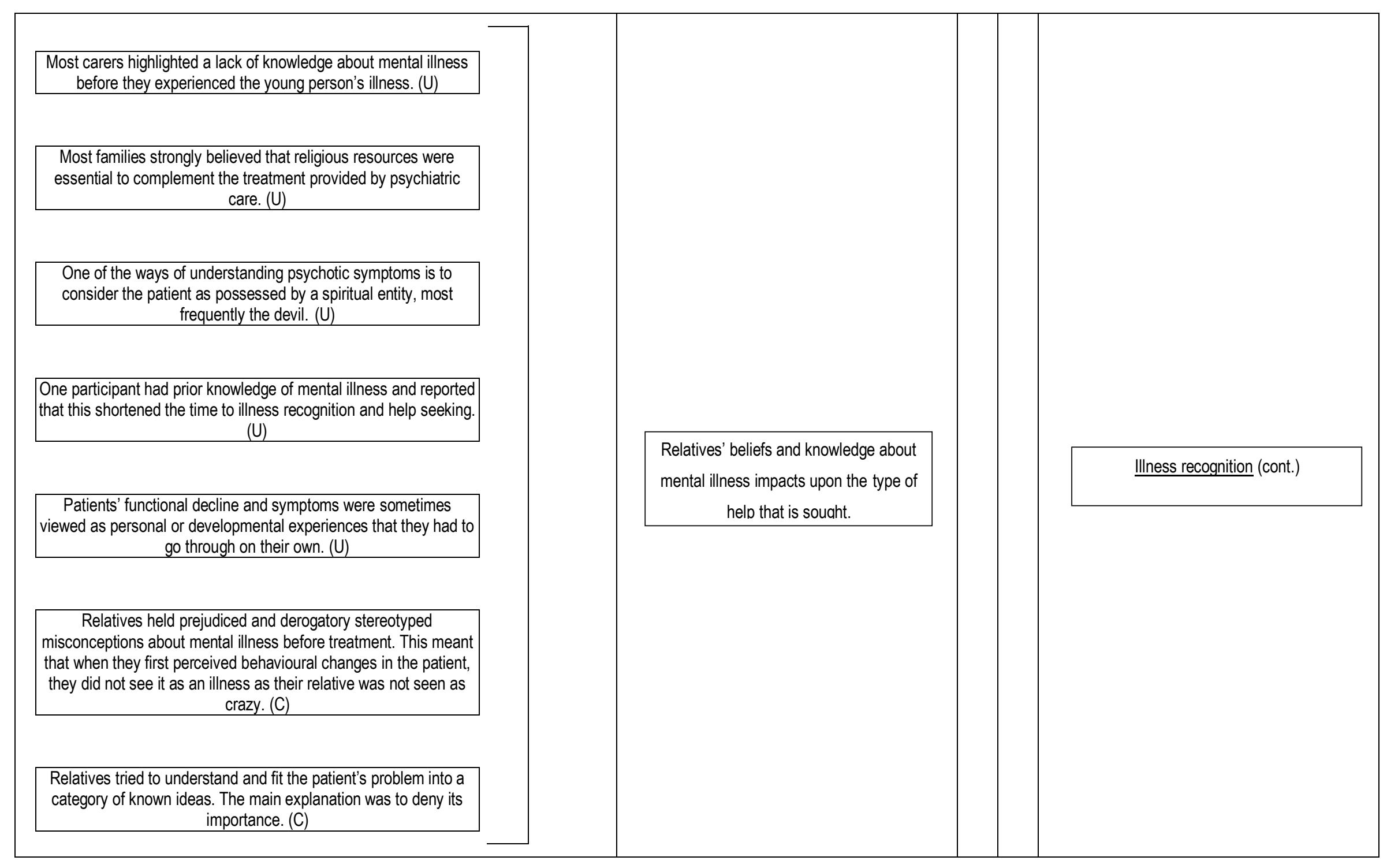




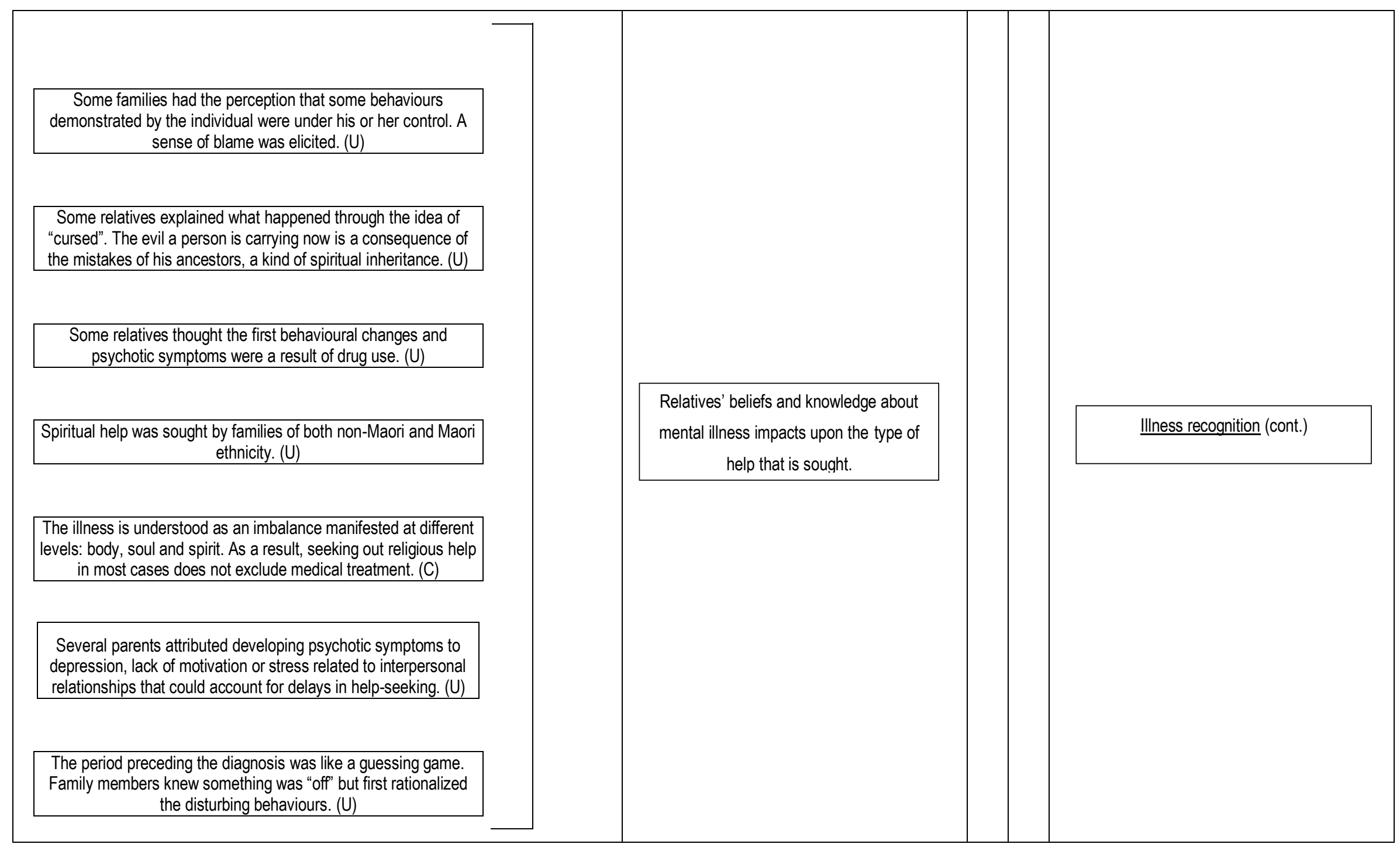




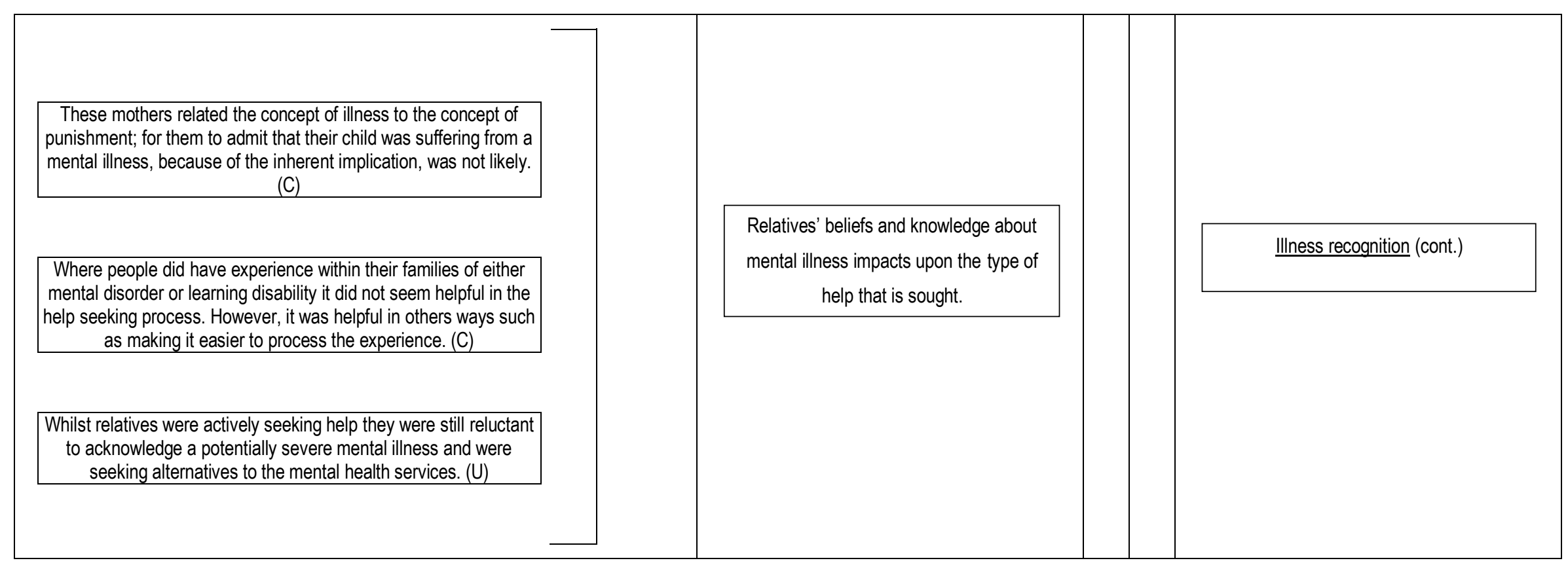




\section{Synthesised finding 1:}

Recognising an illness is developing and that the person is in need of help is often delayed.

Beliefs about mental illness further impact upon the timing as well as type of help sought.

The first synthesised finding was derived from three categories with a total of 61 findings. A few key findings with their supporting illustrations will be presented within a summary of each category.

Category: Difficulties were noticed by relatives.

Various mood and behavioural changes, as well as general functional decline, alerted relatives to there being something 'wrong' with the individual developing a psychotic illness. The following illustration summarises this category well:

Whilst there were difficulties in identifying a mental illness, most relatives were aware of behavioural changes giving cause for concern for longer than three years. These included changes in behaviour with friends, increased concerns registered by schools, inability to hold down jobs and employers making comments or concerns regarding performance: 66

"He was 15 or 16 when we started to get calls from college that he was having panic attacks. At sixth form he couldn't sit in a class room but they didn't help him. He's tried to go into employment but things keep going wrong and he loses the job". (Maxine) (p.71)

Mood and behavioural changes were noticed by carers ${ }^{31}, 46,63,66$ alerting them to there being something "not quite right" 64 or "wrong"68 with the individual developing a psychotic illness. As in the example above, ${ }^{66}$ sometimes these changes were noted over a prolonged period of time. General functional decline was also noted during this stage.46, 63, 66, 68 Some carers reported beginning the search to understand what was occurring with their relative ${ }^{30}$ though generally the presence of an illness was not yet being considered. ${ }^{67}$ Even in these early stages the beginning signs of a developing illness impacted upon other family members. ${ }^{63,} 68$ Family members described the noted changes as bewildering, ${ }^{63}$ embarrassing and confusing. ${ }^{68}$ 
Category: Misattribution of symptoms impacts upon type and timing of help-seeking.

The early phase and symptoms of psychotic illnesses are commonly attributed to factors other than mental illnesses including changes due to the onset of adolescence, ${ }^{31,46,68}$ stress or drugs. ${ }^{28,46,70}$ Many findings referred to these common misattributions.

Carers reported attributing symptoms to alternative explanations e.g. rebellious teenage behaviour, illicit drug use, stress, physical, neurological and other psychological problems: ${ }^{28}$

"If I talked to people they would say 'he sounds like a normal teenager to me'. You do sort of wonder, because the other two had not been like this at all, you wonder whether if this is what they mean by 'stroppy obnoxious teenagers' and so you put it down to that". (Carer; mother, 49, White British)(p.4)

Family members attributed behavioural changes to a number of causes, including the onset of adolescence, stress or drugs: 46

"A 16-year-old who is grumpy and doesn't want to talk to his mother" seemed to one mother like typical teen behaviour. Another parent suspected it was "probably a change of age, from a little boy to a teenager". Another relative recalled, "I didn't know whether it was her age. I mean, she was rebellious and she didn't like school as much". (p.312)

Many relatives cited the stress of school and its many transitions. A few parents suspected drugs or alcohol: "In the club maybe, maybe she drink something", "[He] got involved with different people . . not healthy people . . late parties, they talk a lot of funny things, some into drugs", "I thought he was on drugs". (p.312)

Early symptoms were often vague 28,31 and some family members reported realising the presence of symptoms only in retrospect 31,74 or at the point that symptoms became more obvious. ${ }^{71}$ The misattribution of symptoms impacts upon the type and timing of help-seeking, as illustrated by the following two findings.

Attributing behavioural changes to the onset of adolescence, stress or drugs influenced families' 
strategies for coping. This included prayer and religion, and the use of reasoning and persuasion with the young individual:46

One woman prayed to understand why her son had become like a stranger, and to gain understanding as to how she could help him. Another mother sent her daughter to a church retreat, and tried to push her to find a job. The elder brother of one patient remembers, "I told him to go get a job and don't sleep too much ... He was just taking his sweet time finding a job and I remember screaming at him sometimes". (p.312)

When events or behaviours are still 'explainable' (e.g. teenage behaviour, stress) the drive to seek help is not very strong: 64

"And he'd say things as if he was talking to himself. I just thought he was talking to himself. I mean, I go round the house talking to myself."(p.36)

In instances when mental illness was being considered at this early stage, carers reported feeling uncomfortable with acknowledging the presence of an illness, and more at ease attributing changes to other factors as described above. ${ }^{62}$

Category: Relatives' beliefs and knowledge about mental illness impacts upon the type of help that is sought.

After a problem has been acknowledged, carers attempt to understand the problems within their own belief system. Many were unable to make sense of the presenting difficulties and were unsure of how to respond. ${ }^{31,68}$ Carers reported thinking the symptoms were transient and would resolve without intervention. $28,46,49$

Relatives tried to understand and fit the patient's problem into a category of known ideas. The main explanation was to deny its importance: 70

"It's nothing." (p.107)

Some families had the perception that some behaviours demonstrated by the individual were 
under his or her control. A sense of blame was elicited: 62

"I was seeing it as being lazy. I would say, 'You don't want to do anything. You started school and then you stopped going, and you had a job.' And I was thinking it was just him being lazy and not wanting to do anything". (p.5)

Carers' understanding, including causal attributions and interpretation of their relatives' difficulties, further impacts upon the type of help sought. Many of the studies referred to an interpretation of symptoms based on religious and cultural beliefs held by the participants. $60,69-71$

Families often resorted to religion because it yields causal explanations for the problem. Several psychotic symptoms are easily confused with signs of spiritual possession, some other kind of spiritual disturbance or the consequence of some kind of malice, 'black magic':69

This can be exemplified by the case of a youth that will be called José. His mother was convinced that José's problem had a supernatural causation: some 'evil spirit' was disturbing her son, or that he was the prey of some black magic perpetrated by her exlover. This belief motivated José's mother to force her son to be exorcised in a Pentecostal church. (p.515)

If the concept of having an illness was viewed as negative then it could lead to a further delay in acknowledging an illness was present. ${ }^{70,71}$

Relatives held prejudiced and derogatory stereotyped misconceptions about mental illness before treatment. This meant that when they first perceived behavioural changes in the patient, they did not see it as an illness as their relative was not seen as crazy:70

Some relatives used the terms "loucos" (crazy) and "malucos" (lunatics) to refer to individuals with mental disorders... "For me, lunatics tear up money, throw rocks at people [...] Curse at people, you know, for me that was crazy. You know, I didn't have this business of a head problem, you know, get upset by something, say things that don't... I had no idea what that was". (p.107) 
In the instances where religious help was sought this was often in conjunction with medical help.69, 70 Interestingly prior knowledge of mental illness, from either a family history or professional knowledge from work, did not necessarily lead to earlier help-seeking. 59,68

\begin{tabular}{|c|c|c|c|}
\hline Category & Unequivocal & Credible & Total \\
\hline Difficulties noticed & 9 & 6 & 15 \\
\hline Misattributions & 18 & 3 & 21 \\
\hline Beliefs/knowledge & 19 & 6 & 25 \\
\hline Total & 46 & 15 & 61 \\
\hline
\end{tabular}

TABLE 3: Summary of evidence of credibility; Synthesised finding 1. 


\section{Synthesised Finding 2}

The predominant barriers to seeking help were the perceived stigma of having a mental illness and reluctance of the ill relative to participate in the help-seeking process. Lack of knowledge of treatment options, and the ill individuals' wider social context and informal networks may also inhibit help-seeking.

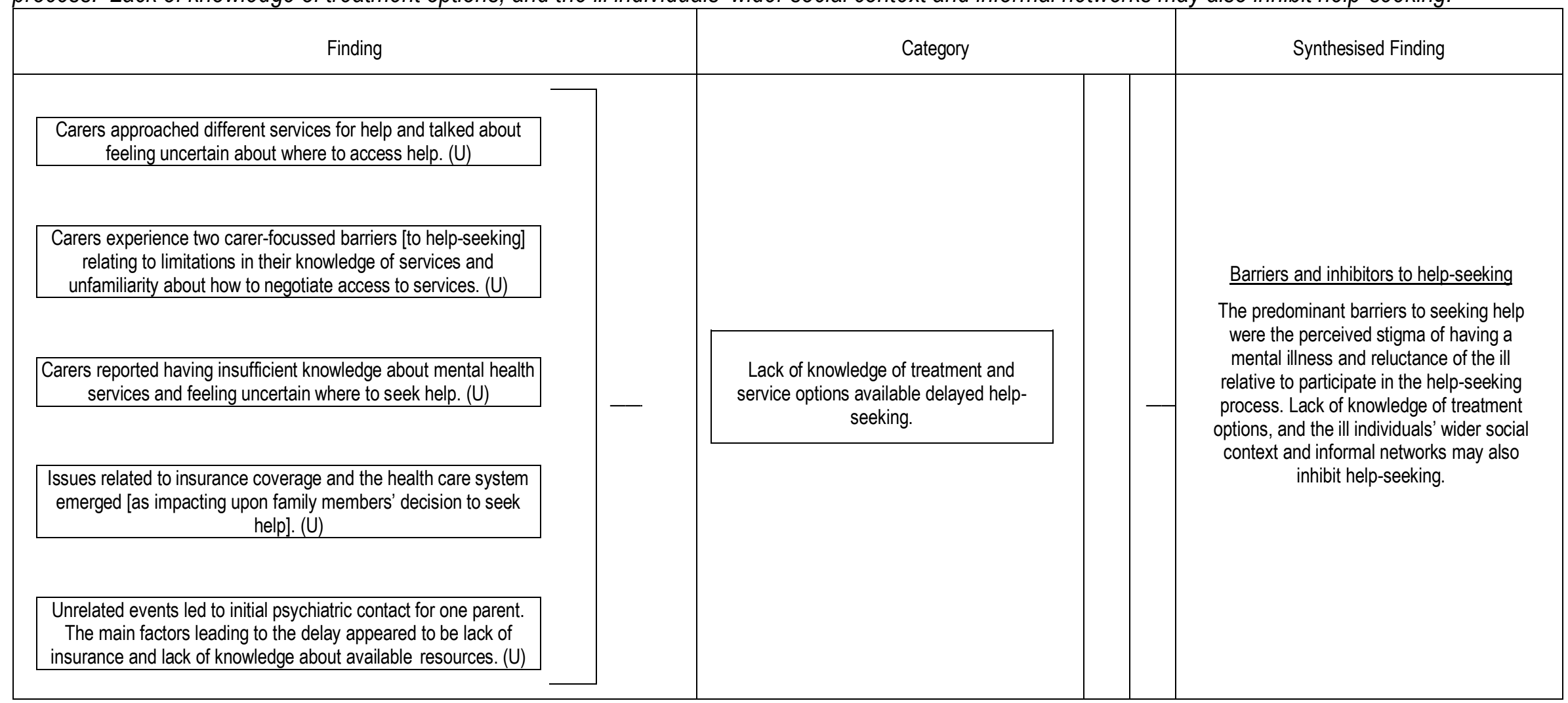




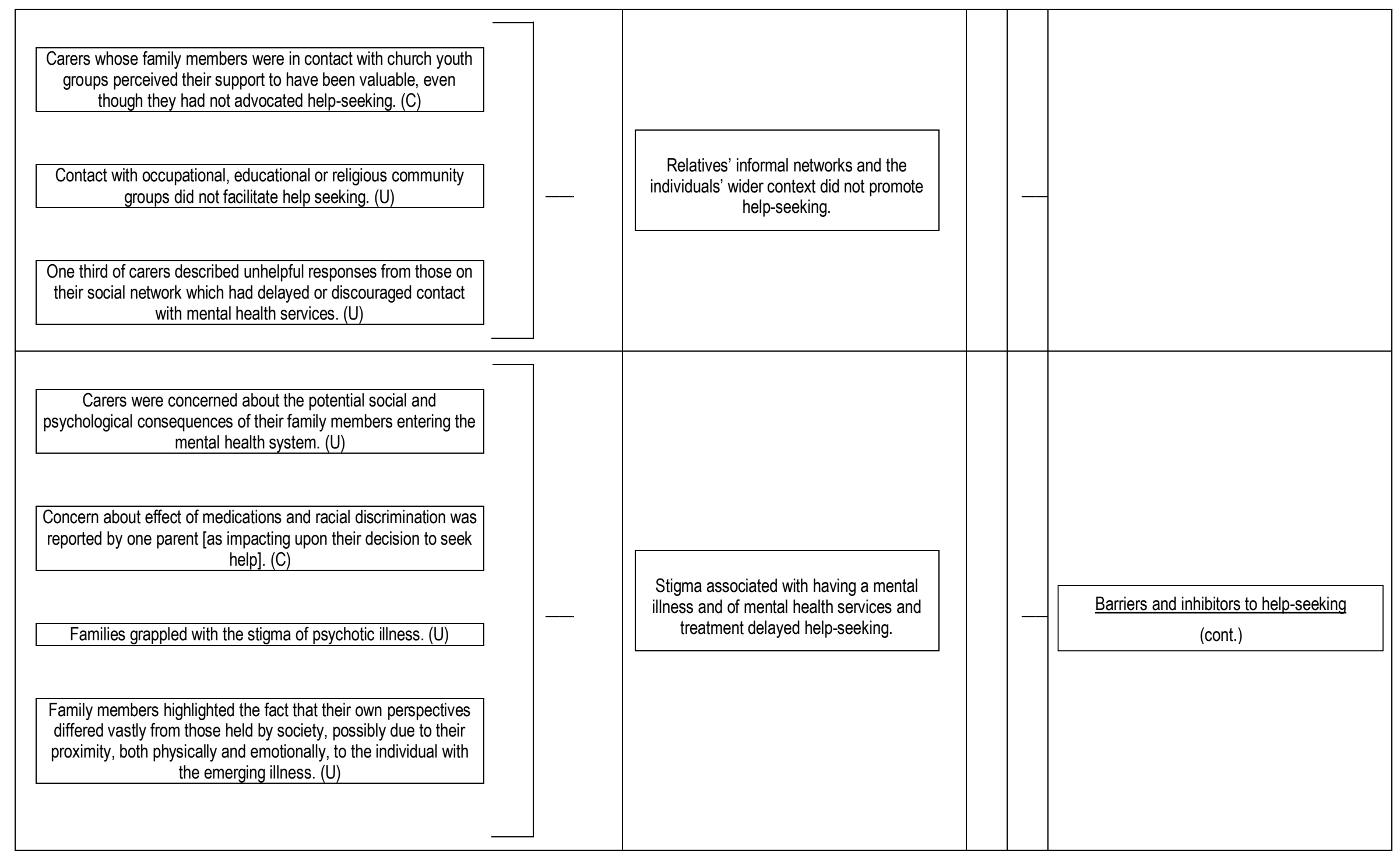




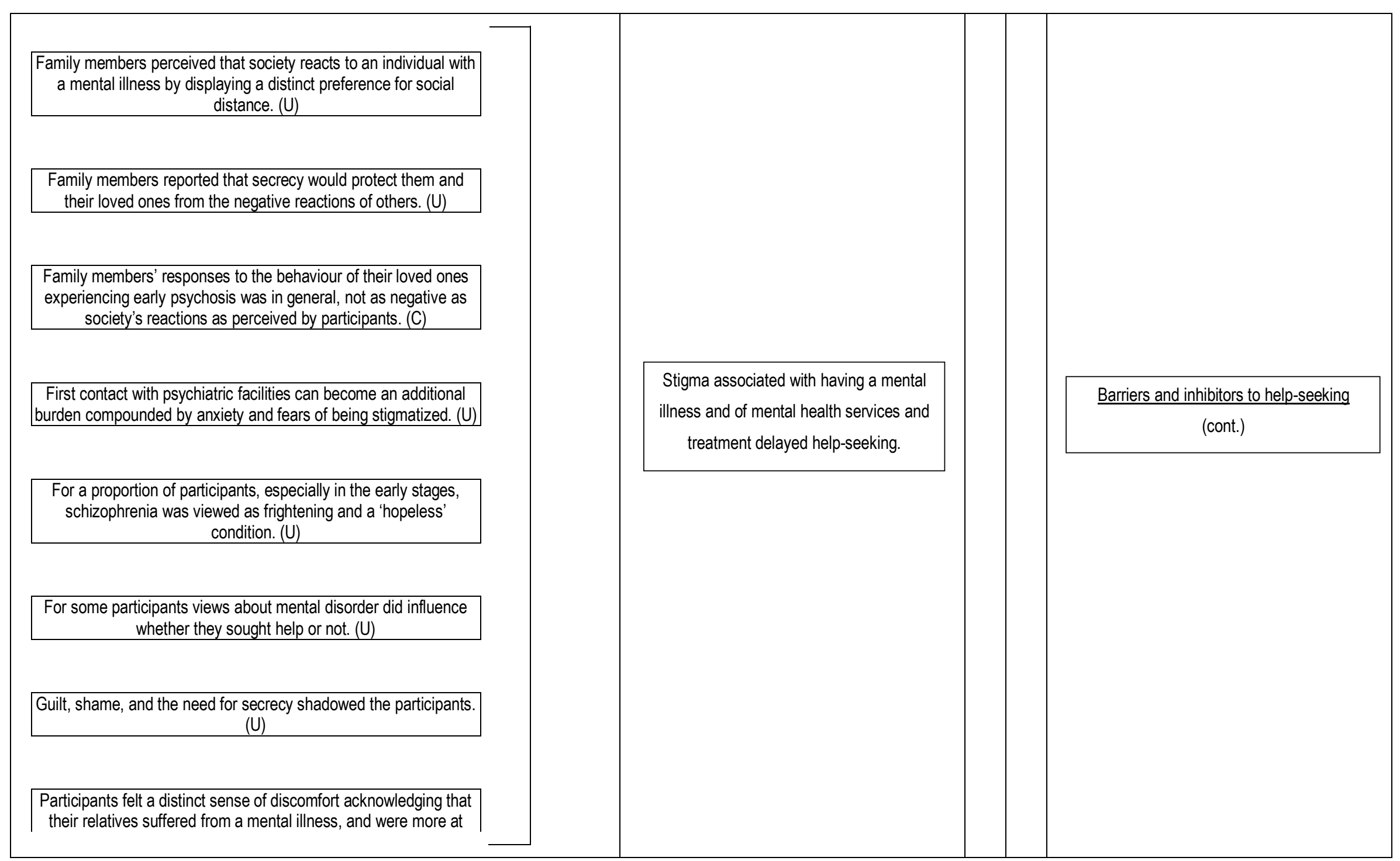




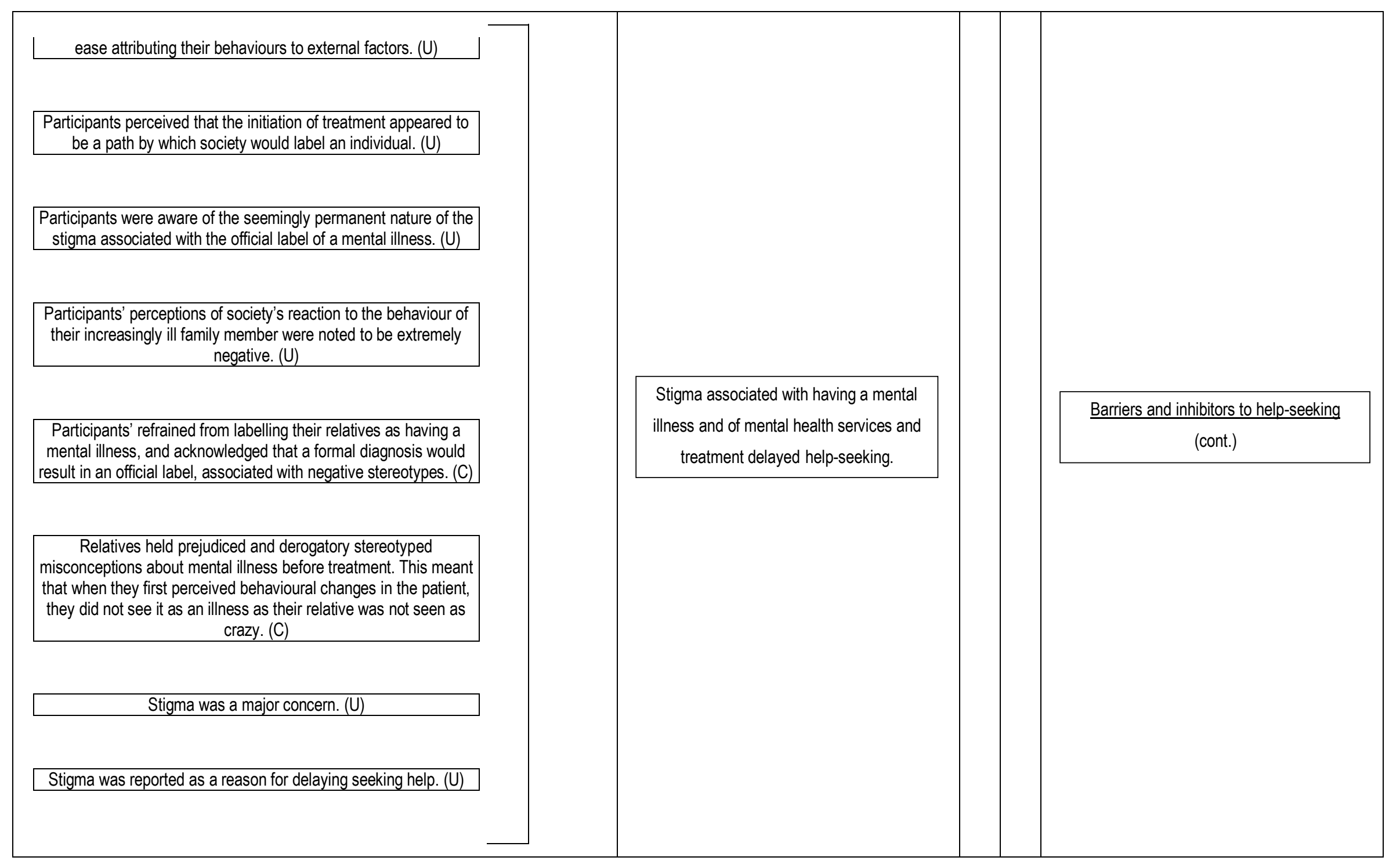




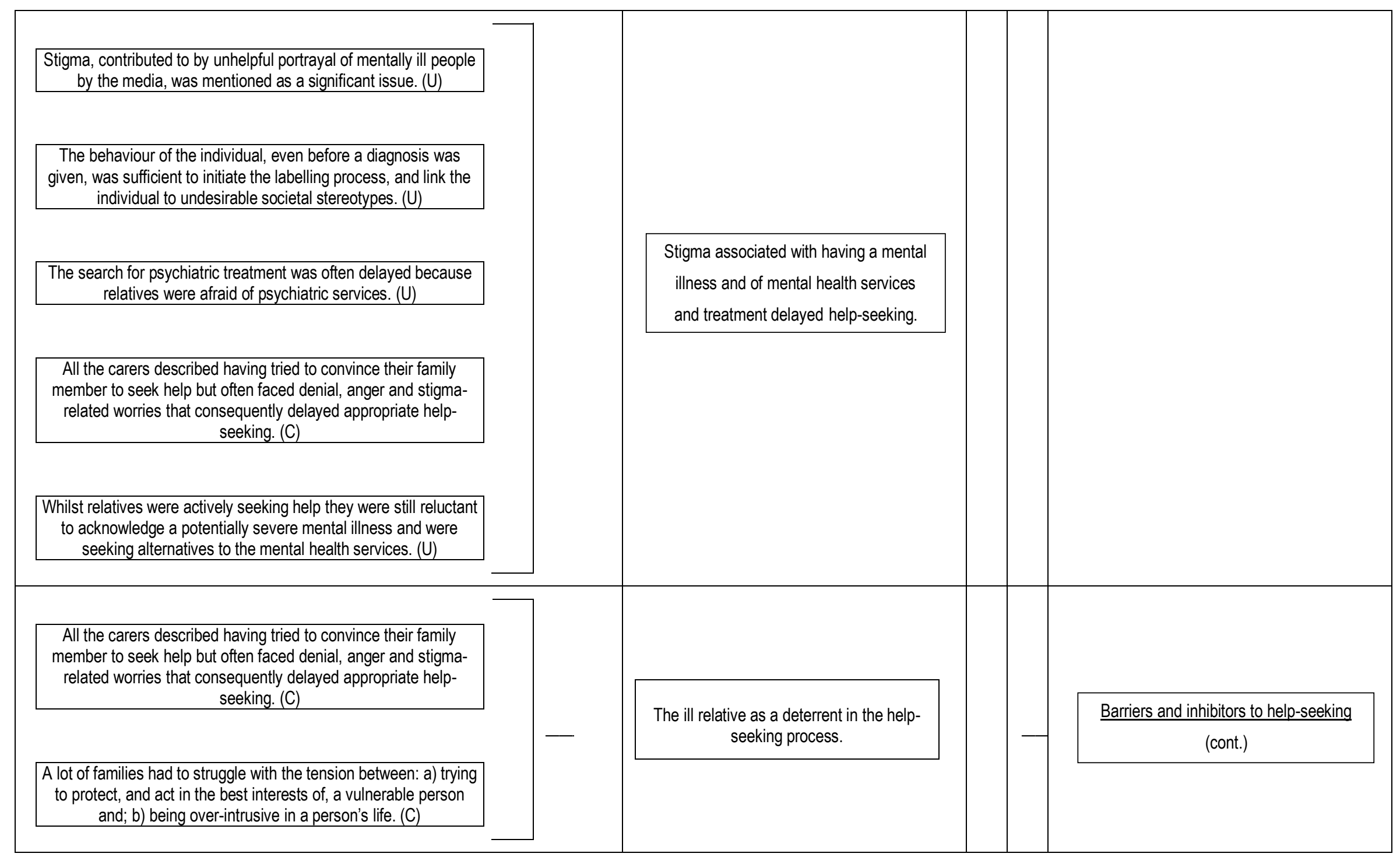

Page | 47 


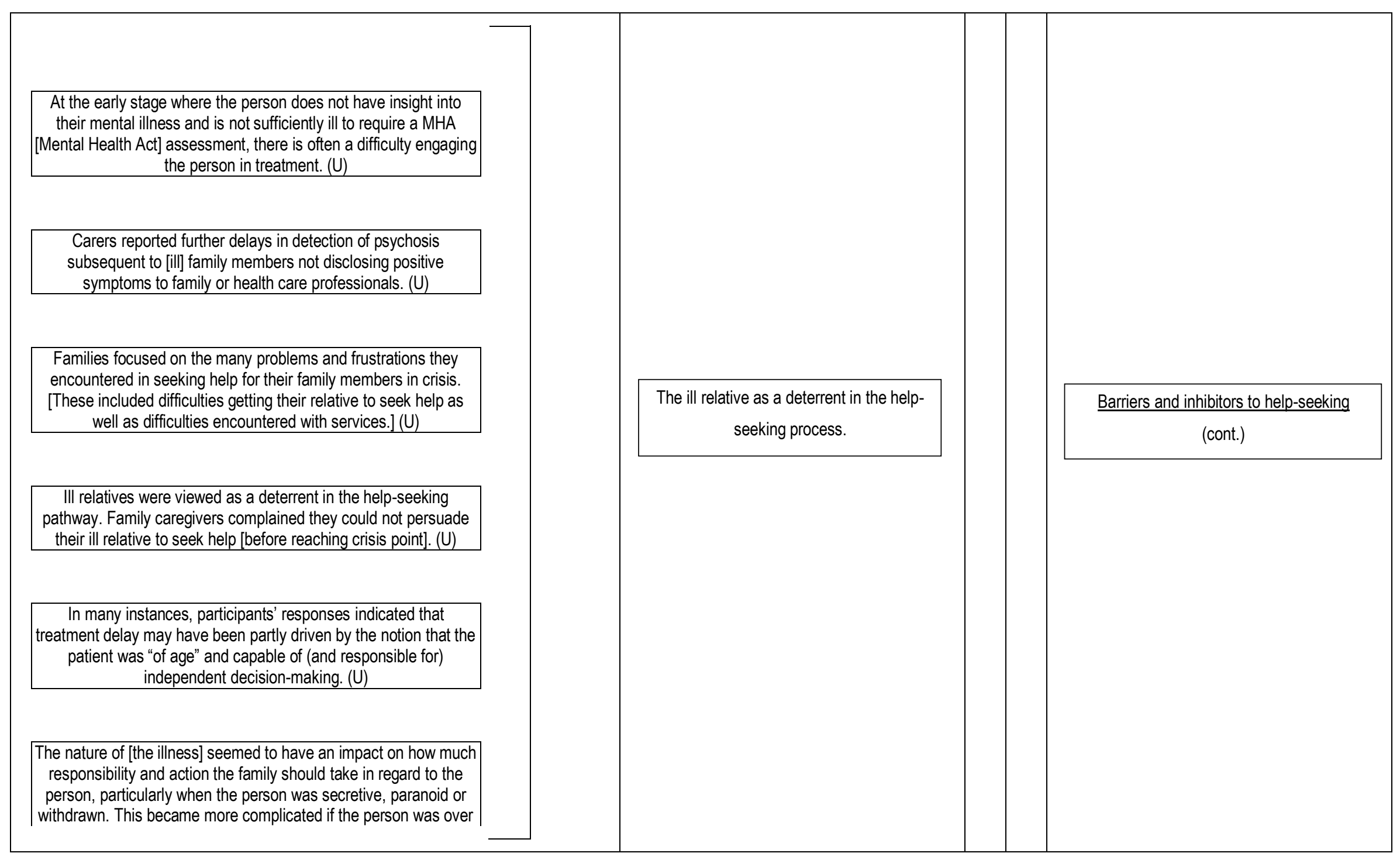




\begin{tabular}{|c|c|c|}
\hline 18 and unwilling to seek help. (U) & & \\
\hline \multicolumn{3}{|l|}{$\begin{array}{l}\text { There seems to be some difficulty with regard to the person with } \\
\text { psychotic symptoms admitting to having problems and asking for } \\
\text { help before being able to receive it. (U) }\end{array}$} \\
\hline $\begin{array}{l}\text { When the person denied their symptoms and/or refused help, this } \\
\text { was the most pressurising situation for relatives. This also } \\
\text { interfaced with professionals being unable or unwilling to see the } \\
\text { person without their consent. (C) }\end{array}$ & $\begin{array}{l}\text { The ill relative as a deterrent in the help- } \\
\text { seeking process. }\end{array}$ & $\frac{\text { Barriers and inhibitors to help-seeking }}{\text { (cont.) }}$ \\
\hline $\begin{array}{c}\text { [Accessing psychiatric services] can become extremely difficult for } \\
\text { relatives, as medical treatment cannot commence if the affected } \\
\text { person refuses to recognise his or her illness and if there is no } \\
\text { evidence of the patient endangering either himself or herself or a } \\
\text { third person. }(U)\end{array}$ & & \\
\hline
\end{tabular}




\section{Synthesised finding 2:}

The predominant barriers to seeking help were the perceived stigma of having a mental illness and reluctance of the ill relative to participate in the help-seeking process. Lack of knowledge of treatment options, and the ill individuals' wider social context and informal networks may also inhibit help-seeking.

The second synthesised finding was derived from four categories with a total of 43 findings. A few key findings with their supporting illustrations will be presented within a summary of each category.

Category: Lack of knowledge of treatment and service options available delayed help-seeking.

Carers reported they were unaware of where to access help $28,31,47,59$ and how to negotiate access $^{47}$ as demonstrated by the following finding and illustration:

Carers reported having insufficient knowledge about mental health services and feeling uncertain where to seek help:28

"I have a feeling I did try. I mean I spoke to friends about it. I didn't even think to go to a psychiatrist; I wouldn't even have known where to go. I mean I didn't know this place [CIEIS] here existed. Had I known about it and had they had a helpline or something, I might have done that and I think that would be very, very good if they had a helpline for confused and worried parents or parents-in-law or friends". (Carer; mother-in-law, 68, White British) (Additional File 3, 3.4)

Category: Relatives' informal networks and the individuals' wider context did not promote helpseeking.

One paper ${ }^{28}$ reported findings whereby the carers' informal contacts either actively discouraged contact with mental health services or were noted as not advocating for or facilitating helpseeking. Informal networks included family members, relatives and friends as well as people in the individuals' wider context including employers, educators and religious bodies. 
Tanskanen et al28 found that one third of carers described unhelpful responses from those in their social network which had delayed or discouraged contact with mental health services:

"My mother would often get very irritated and say 'what do you want us to do - put her in a mental asylum?' like that was the most horrible thing one could say. [...] My father used to say 'oh let her go out into the world, she'll soon be put in her place or something..."' (Carer; sister, 33, White British)(p.6)

The most frequently identified barrier to seeking help was stigma.

Category: Stigma associated with having a mental illness and of mental health services and treatment delayed help-seeking.

Relatives struggled with the stigma attached to their relative having, or possibly having, a mental illness. This was at both an individual level and perceived community level and included the relatives' perception of mental health services and treatment.

Stigma was a major concern: 46

One mother said: "The S word- schizophrenia. I'm going to deal with it for the rest of my life". (p.313)

Stigma was reported to be of significant concern in eleven of the included studies. $28,31,46,59-62,64$, $65,70,72$ One of the papers, Franz et al ${ }^{62}$ was specifically concerned with participants' perceptions regarding the impact of stigma on treatment delay. Of the 24 findings in this systematic review related to stigma, ten were from this study. Stigma was reported at various levels including: carers' own perceptions of stigma regarding mental illness;28, 62, 70,72 carers' perceived perception of others' views regarding mental illness; ${ }^{31,62}$ carers' views of mental health services and treatment $28,62,70,72$ and the ill individuals' concerns about stigma. ${ }^{28}$ Stigma was reported to have an impact on carers recognising and acknowledging their relative may be ill62,70 as well as how they managed the symptoms e.g. secrecy. ${ }^{62}$ 
Participants refrained from labelling their relatives as having a mental illness, and acknowledged that a formal diagnosis would result in an official label, associated with negative stereotypes: 62

"I guess they think they're different, but they're not. They're people too. They just got some kind of dis - um, no not disease - but some kind of problem". (p.6)

"I didn't want him to think that, ya know, we were trying to tell him that he was crazy or something like that, but just that he needed to talk to someone who could probably explain to him better than I could what he was experiencing".(p.6)

Monterio et al ${ }^{70}$ reports that carers' own negative views about mental illness meant that they did not consider observed behavioural changes in their relative as being signs of a mental illness. Fear of labelling or fear of psychiatric services, was also reported as negatively impacting upon the decision to seek help, as carers responded with secrecy. ${ }^{60,62}$

Category: The ill relative as a deterrent in the help-seeking process.

The ill relatives themselves were frequently viewed as a deterrent in the help-seeking process. The cause of this was multi-factorial. Some relatives described not wanting to be overlyintrusive. ${ }^{64}$

In many instances, participants' responses indicated that treatment delay may have been partly driven by the notion that the patient was "of age" and capable of (and responsible for) independent decision-making:49

"A lot of times unless they are showing suicidal signs or are gonna hurt someone else, there's really nothing you can do. You know, it's like that person is of age and they have to be the one, you know, to initiate care". (p.6)

"I just kinda let him make his own decisions, ya know. I usually try to help him make decisions, but he says I treat him like a little boy". (p.6)

Various carers stated that the nature of the illness including paranoia, tendency to withdraw, ${ }^{64}$ 
poor insight, denial of symptoms ${ }^{28}$ and the ill individuals' fear of stigma can delay accessing treatment. ${ }^{28,66}$ Some carers had tried to convince their relatives to seek help but were unsuccessful. ${ }^{28,46,73}$ Carers reported being unable to successfully access help due to lack of assessed risk, ${ }^{72}$ lack of informed consent ${ }^{65}$ or lack of disclosure of symptoms. ${ }^{64}$

\begin{tabular}{|l|l|l|l|}
\hline Category & Unequivocal & Credible & Total \\
\hline $\begin{array}{l}\text { No knowledge of } \\
\text { treatment options }\end{array}$ & 5 & 0 & 5 \\
\hline Informal networks & 2 & 1 & 3 \\
\hline Stigma & 19 & 5 & 24 \\
\hline III relative & 8 & 3 & 11 \\
\hline Total & 34 & 9 & 43 \\
\hline
\end{tabular}

TABLE 5: Summary of evidence of credibility; Synthesised finding 2. 


\section{Synthesised Finding 3}

Crises, or overt psychotic symptoms, were the main promoters of active help-seeking and facilitators to accessing services. Relatives' informal networks often served to assist in this process.

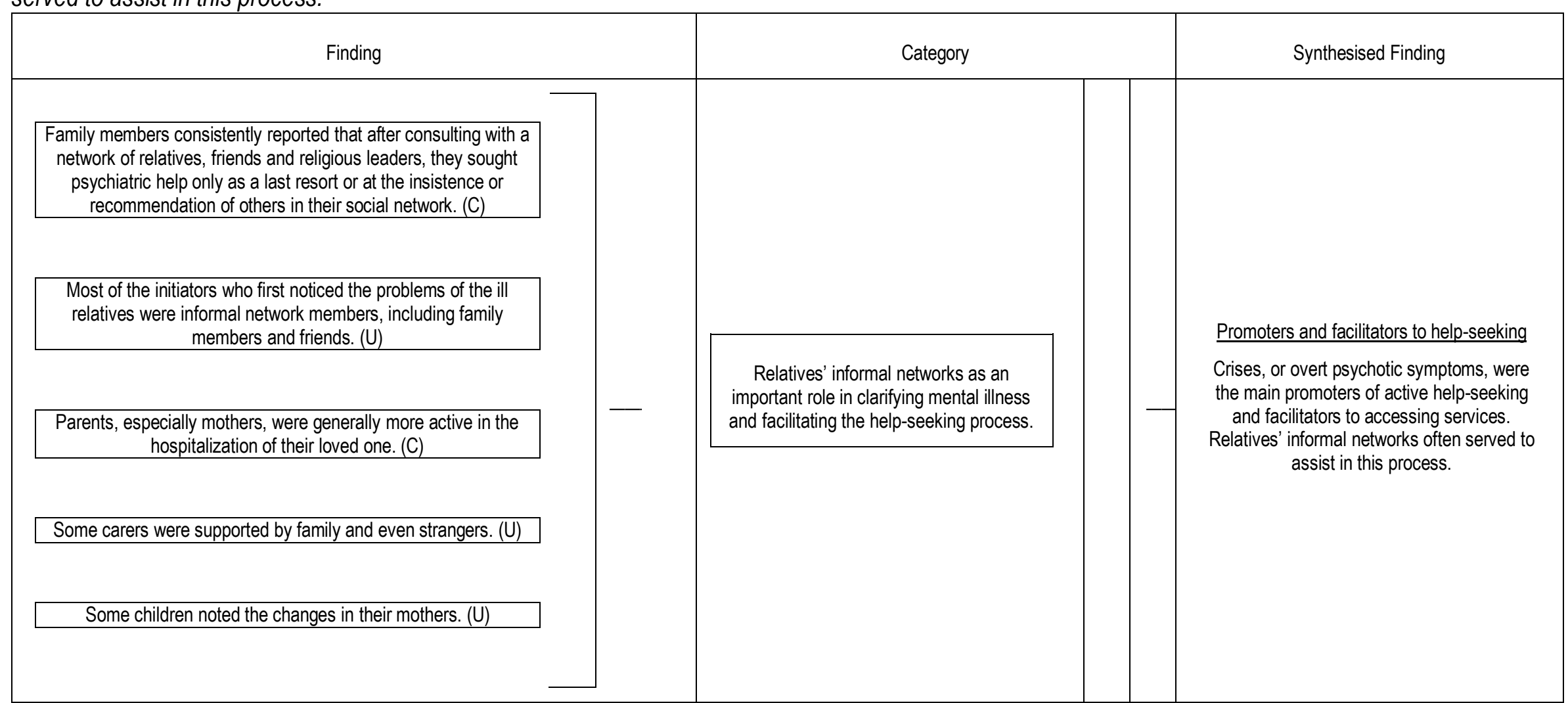




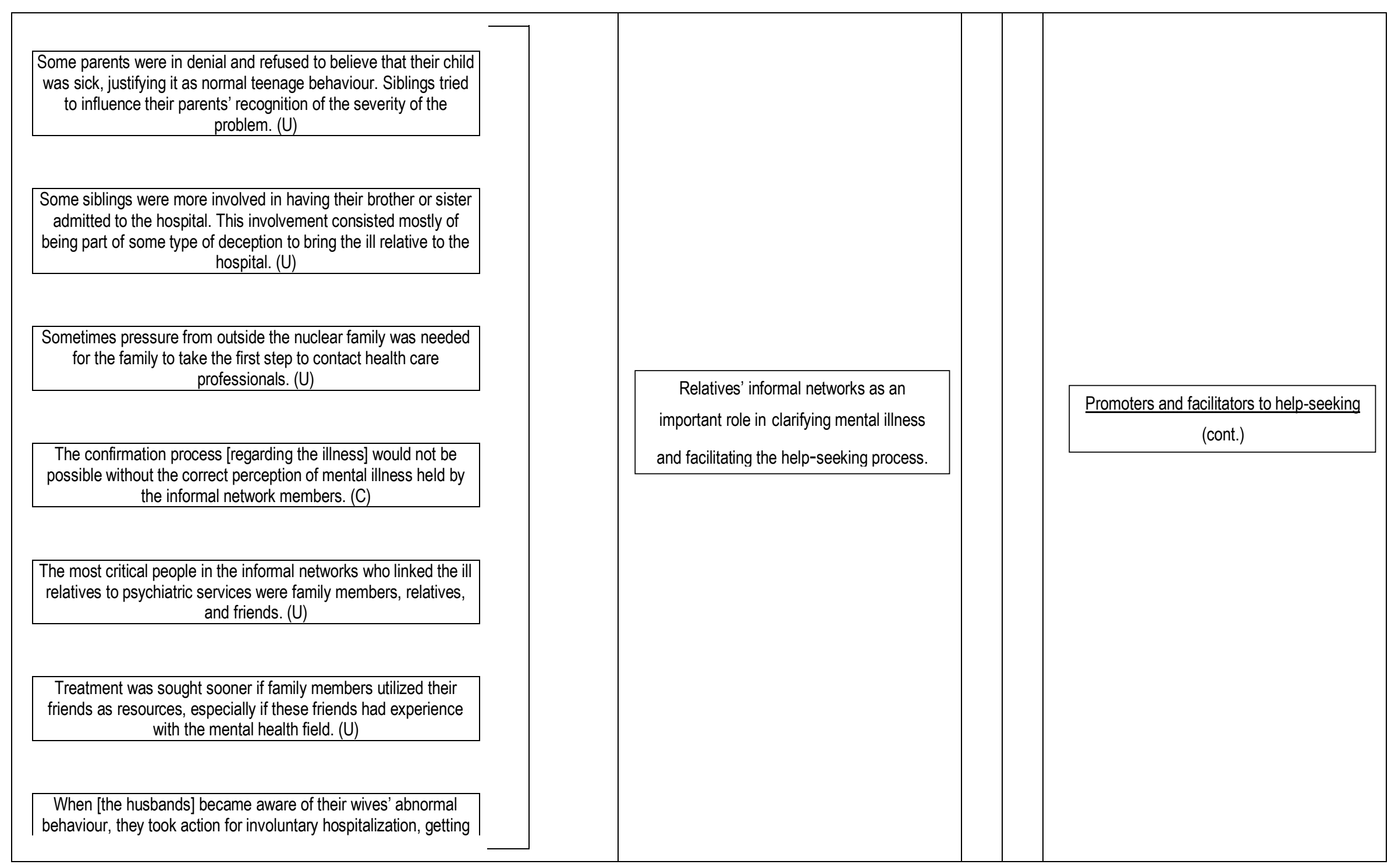




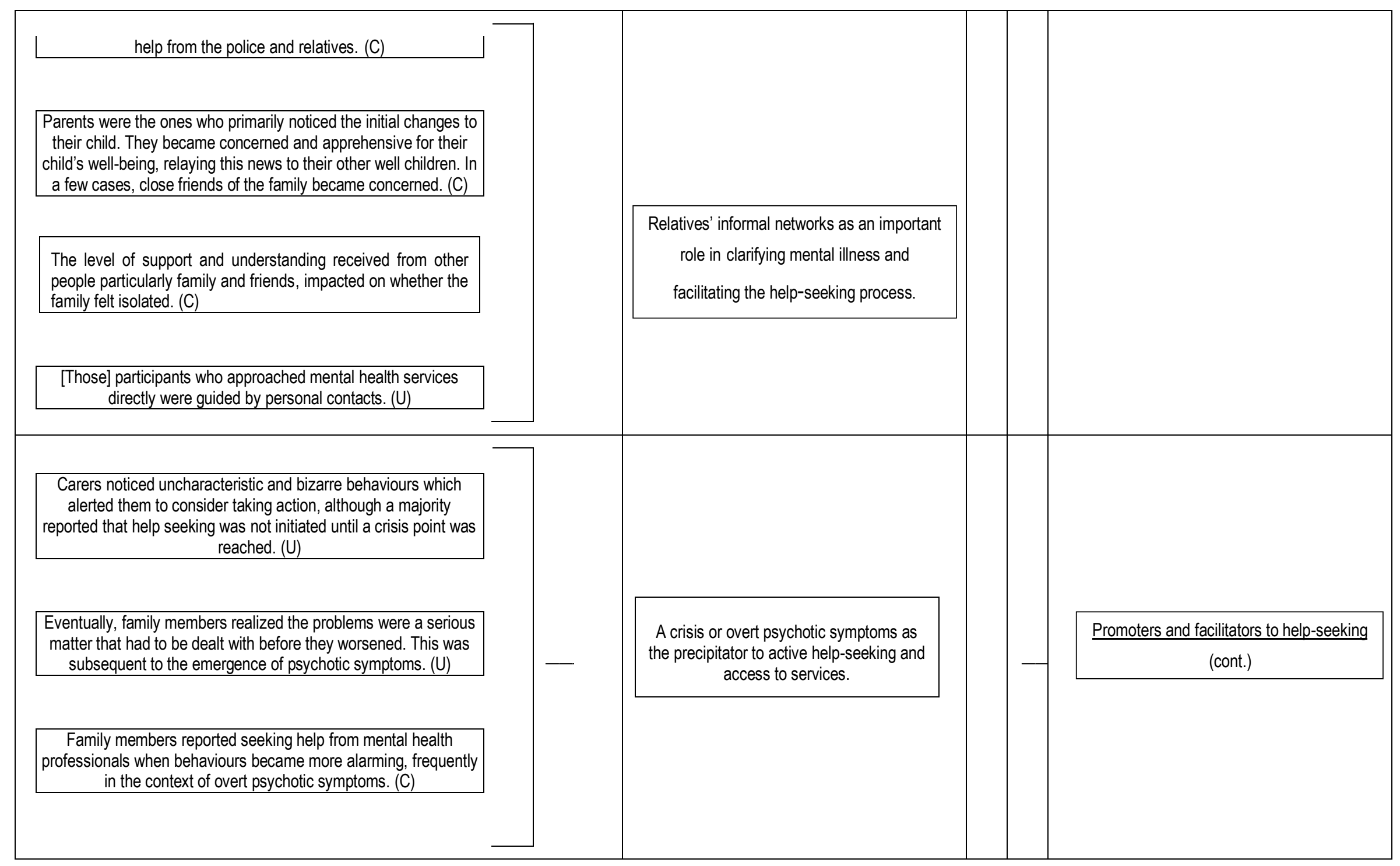




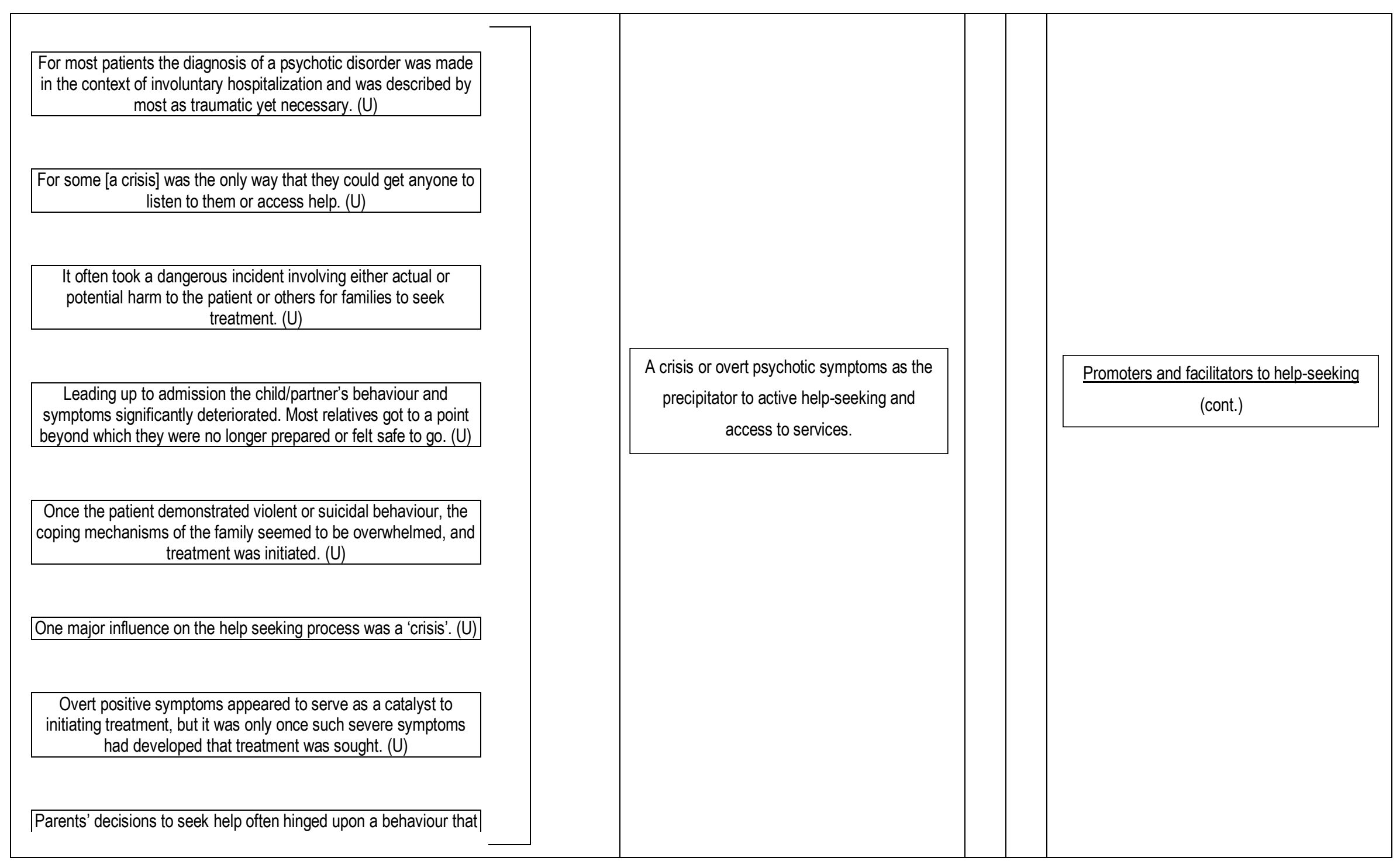




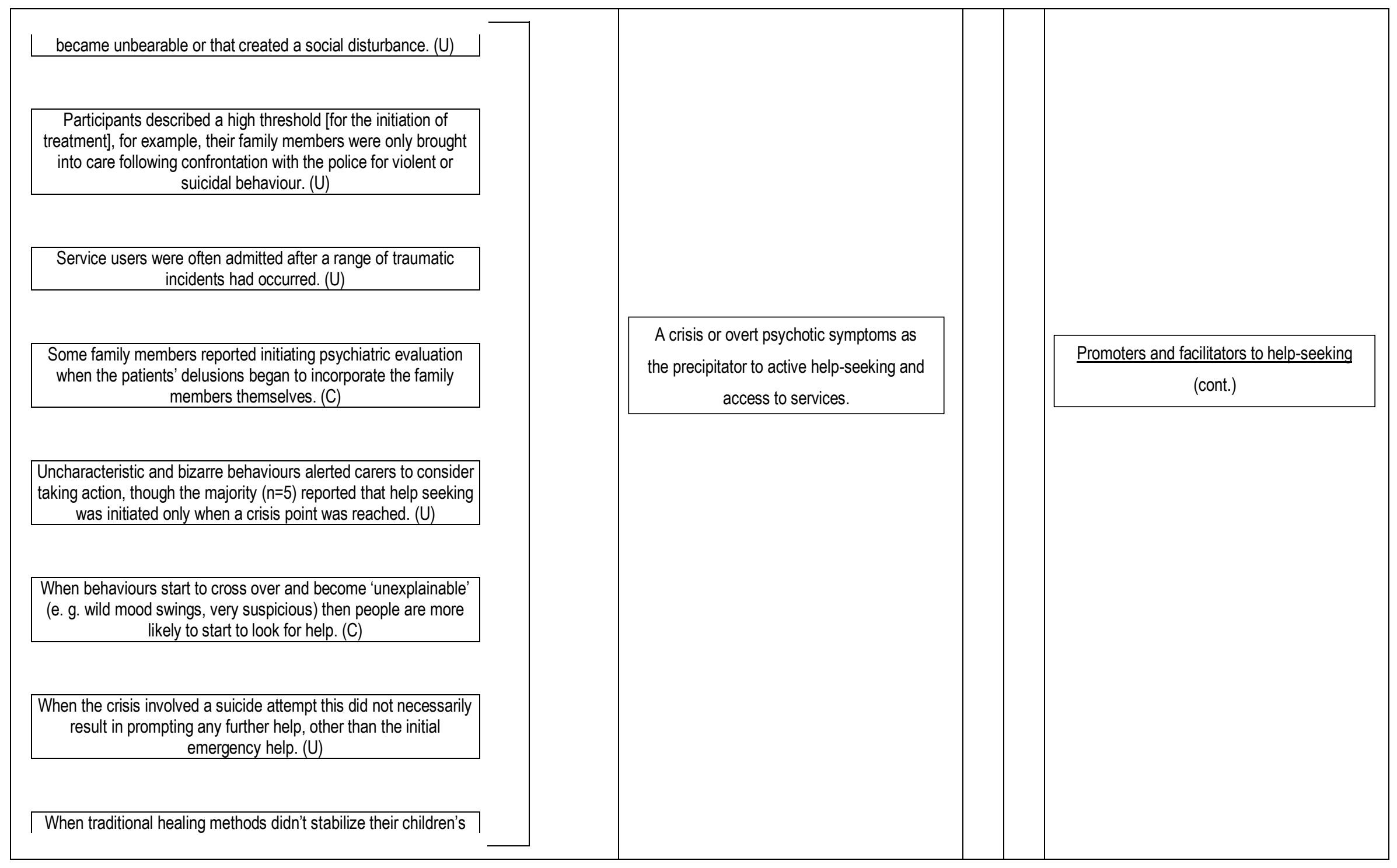




\begin{tabular}{|c|c|c|}
\hline $\begin{array}{l}\text { psychotic behaviours, the participants in the study were faced with } \\
\text { a crisis. At this turning point, the parents began to realize the } \\
\text { seriousness of their children's illness. They recognized the need to } \\
\text { expand their help seeking. (U) }\end{array}$ & $\begin{array}{l}\text { A crisis or overt psychotic symptoms as } \\
\text { the precipitator to active help-seeking } \\
\text { and access to services. }\end{array}$ & $\frac{\text { Promoters and facilitators to help-seeking }}{\text { (cont.) }}$ \\
\hline $\begin{array}{c}\text { [Some] carers identified a crisis point that prompted them to } \\
\text { approach services for help. (U) }\end{array}$ & & \\
\hline
\end{tabular}




\section{Synthesised finding 3:}

Crises, or overt psychotic symptoms, were the main promoters of active help-seeking and facilitators to accessing services. Relatives' informal networks often served to assist in this process.

The third synthesised finding was derived from two categories with a total of 34 findings. A few key findings with their supporting illustrations will be presented within a summary of each category.

Category: Relatives' informal networks as an important role in clarifying mental illness and facilitating the help-seeking process.

Family members consistently reported that after consulting with a network of relatives, friends and religious leaders, they sought psychiatric help only as a last resort or at the insistence or recommendation of others in their social network: 46

"My friend tells me my son is very upset. I brought him to the hospital". (p.312)

"I go to my friend who told me, "take her to the clinic". (p.312)

"The priest said we should take her to see a psychiatrist". (p.312)

Relatives' informal networks played an important role in facilitating the help-seeking process and were frequently the first line of contact for carers.

Most of the initiators who first noticed the problems of the ill relatives were informal network members, including family members and friends: ${ }^{73}$

"I knew something was wrong with my son. I did not know what to do, and so I asked my sister-in-law about it. She thought that my son might have a mental illness". (p.130)

Initial detection of problems, ${ }^{73}$ clarification of the seriousness of problems ${ }^{68}$ and encouragement to seek help ${ }^{46}$ was often from within carers' informal networks. Various relations who may have a role as facilitator are described within these findings including parents, ${ }^{68}$ siblings, ${ }^{68}$ children, ${ }^{74}$ 
family members, relatives, friends ${ }^{73}$ and religious leaders. ${ }^{46}$ The informal network also provides invaluable support to carers. ${ }^{31}$

Category: A crisis or overt psychotic symptoms as the precipitator to active help-seeking and access to services.

Carers start to actively seek help when coping mechanisms become overwhelmed, ${ }^{59}, 62$ traditional healing methods become viewed as ineffective, ${ }^{60}$ or they are presented with a crisis.

Carers noticed uncharacteristic and bizarre behaviours which alerted them to consider taking action, although a majority reported that help-seeking was not initiated until a crisis point was reached: 28

"It took me quite a long time to understand that there was a mental issue there but it wasn't until she started to become very ill. She actually had a crisis". (Carer; mother-inlaw, 68, White British)(Additional File 2, 2.3)

Many findings from the included studies implied that carers had been managing observed behavioural and mood changes in their relative over a prolonged period of time, and demonstrated a high threshold before seeking treatment. 28, 46, 49, 59, 62, 66, 68 Help-seeking was experienced by some as being an expanding process whereby alternative sources of help were sought after initial sources were exhausted. Crises that involved violence or suicidal behaviour ${ }^{49}$ 62 and overtly positive symptoms ${ }^{49,59}$ prompted carers to initiate help-seeking. In one instance whilst suicidal behaviour was reported to prompt help-seeking, it resulted in emergency help only, rather than ongoing help. ${ }^{64}$

\begin{tabular}{|c|c|c|c|}
\hline Category & Unequivocal & Credible & Total \\
\hline Informal networks & 9 & 6 & 15 \\
\hline Crisis & 16 & 3 & 19 \\
\hline Total & 25 & 9 & 34 \\
\hline
\end{tabular}

TABLE 7: Summary of evidence of credibility; Synthesised finding 3. 


\section{Synthesised Finding 4}

Service response to relatives' help-seeking was often viewed as a barrier to accessing services, whilst contacts made with formal networks could either facilitate or inhibit the help-seeking process.

\begin{tabular}{|c|c|c|}
\hline Finding & Category & Synthesised Finding \\
\hline
\end{tabular}

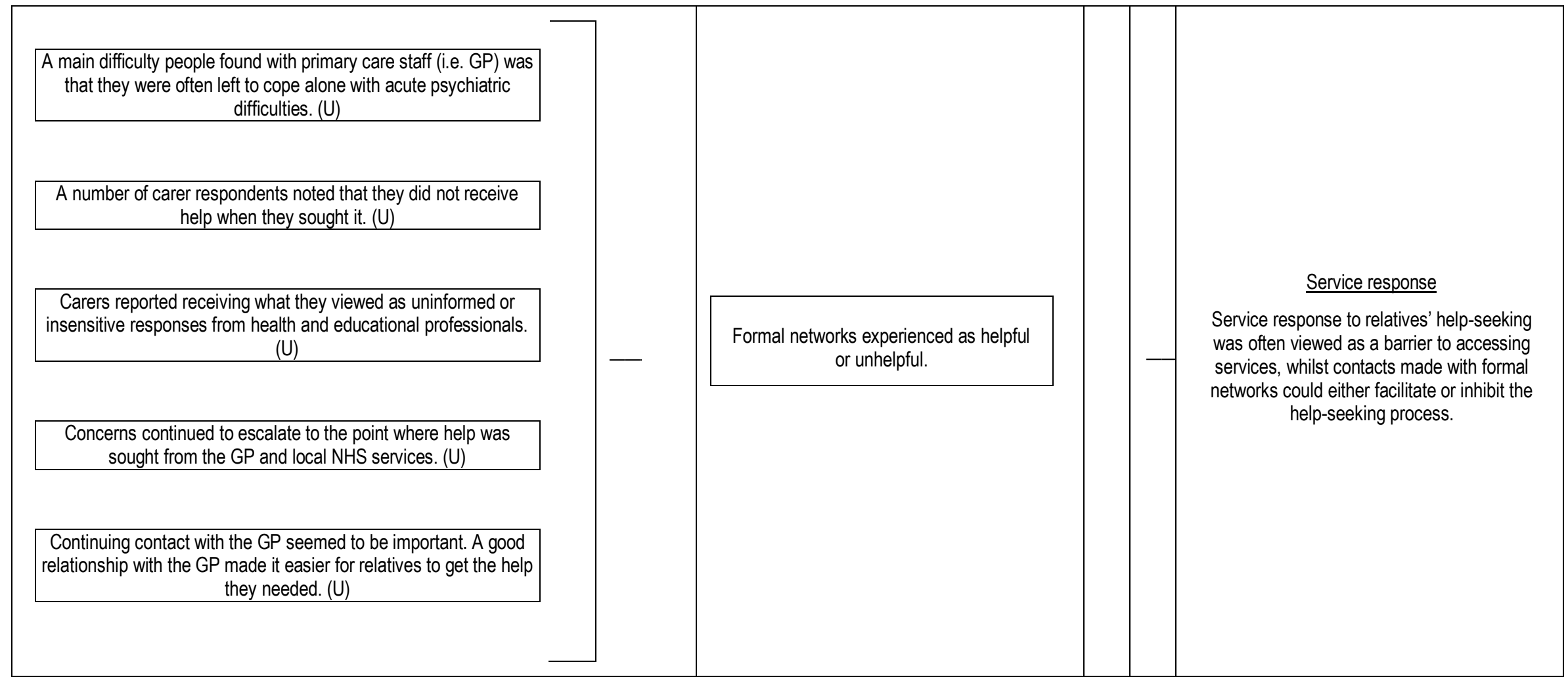




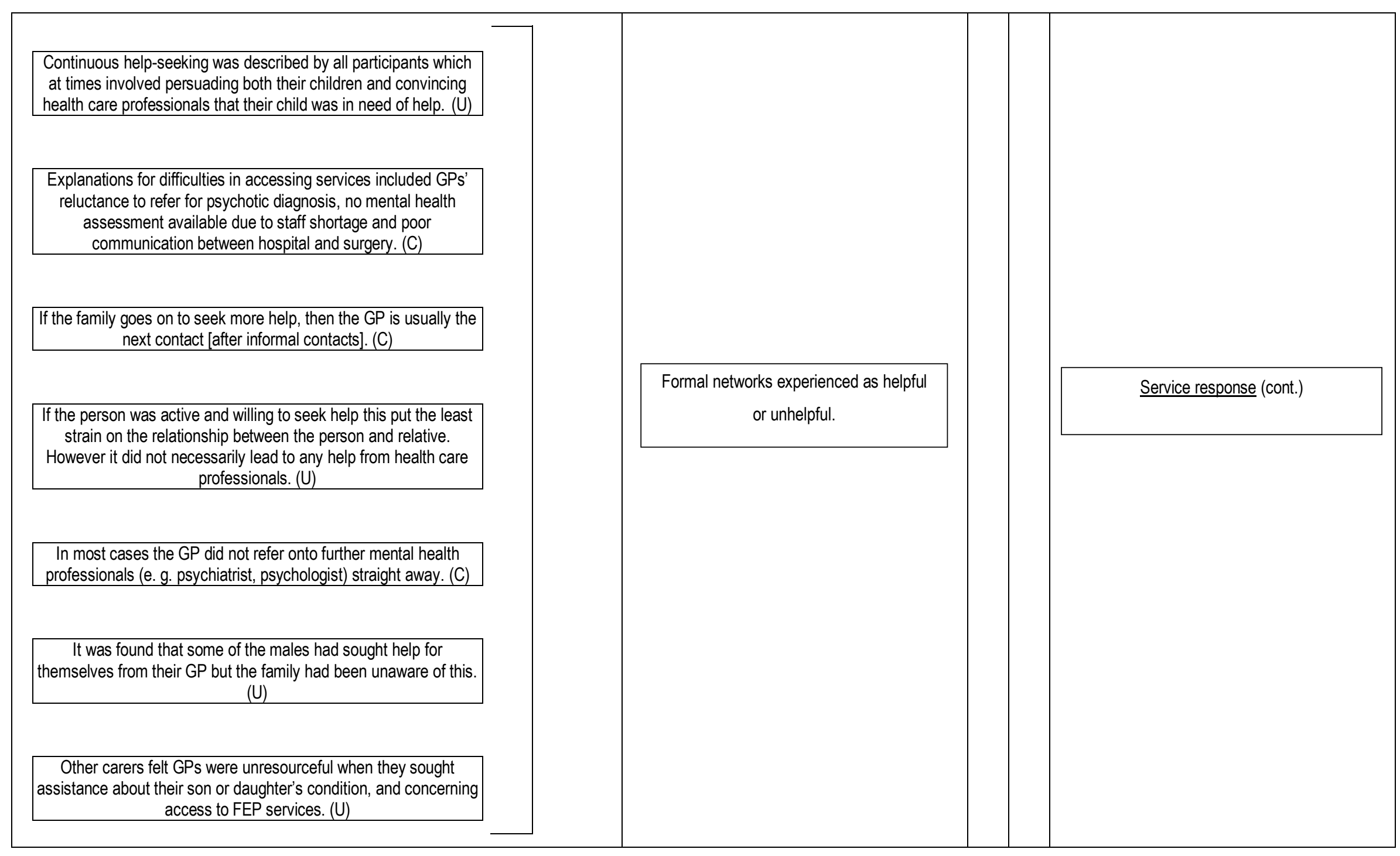




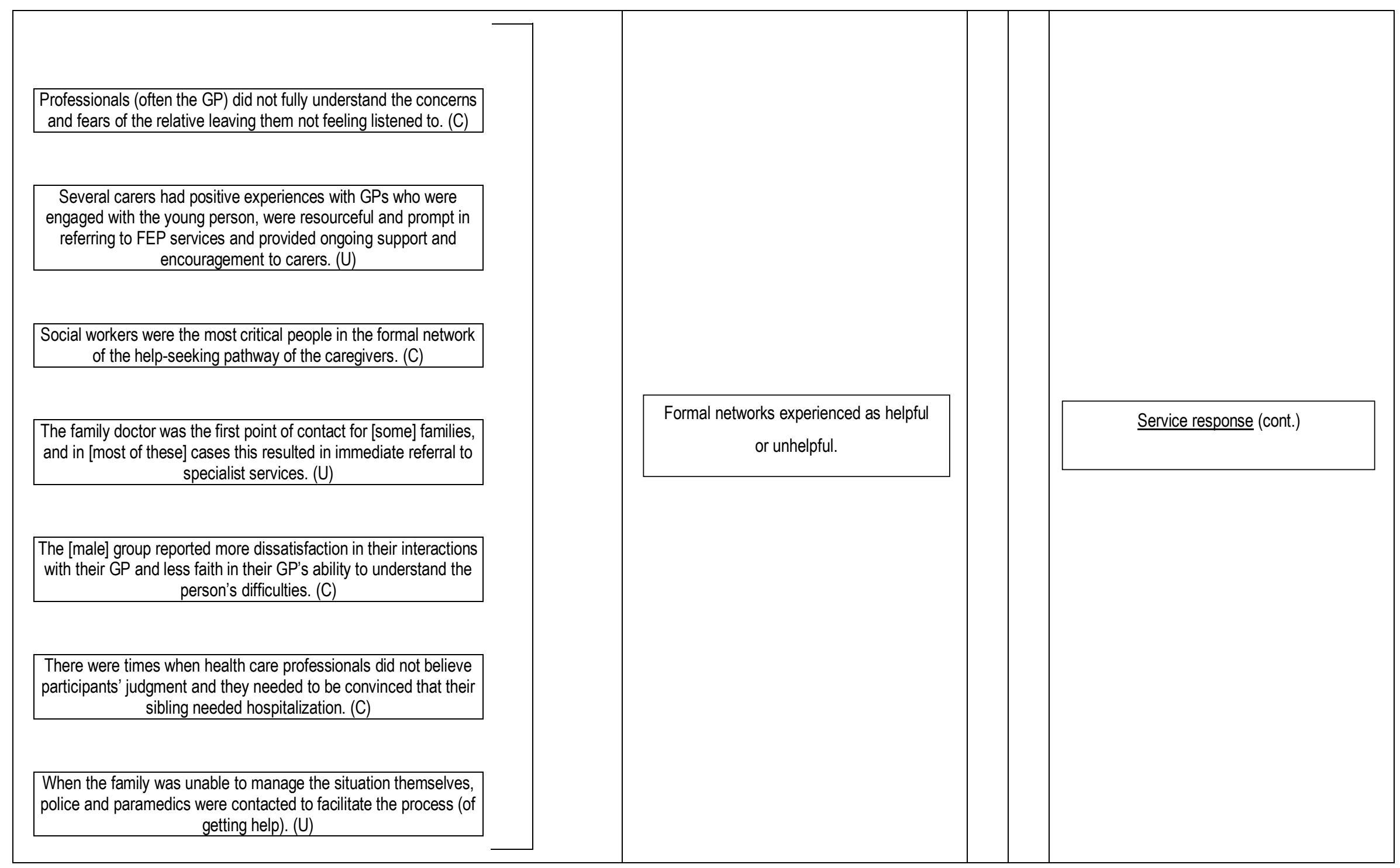




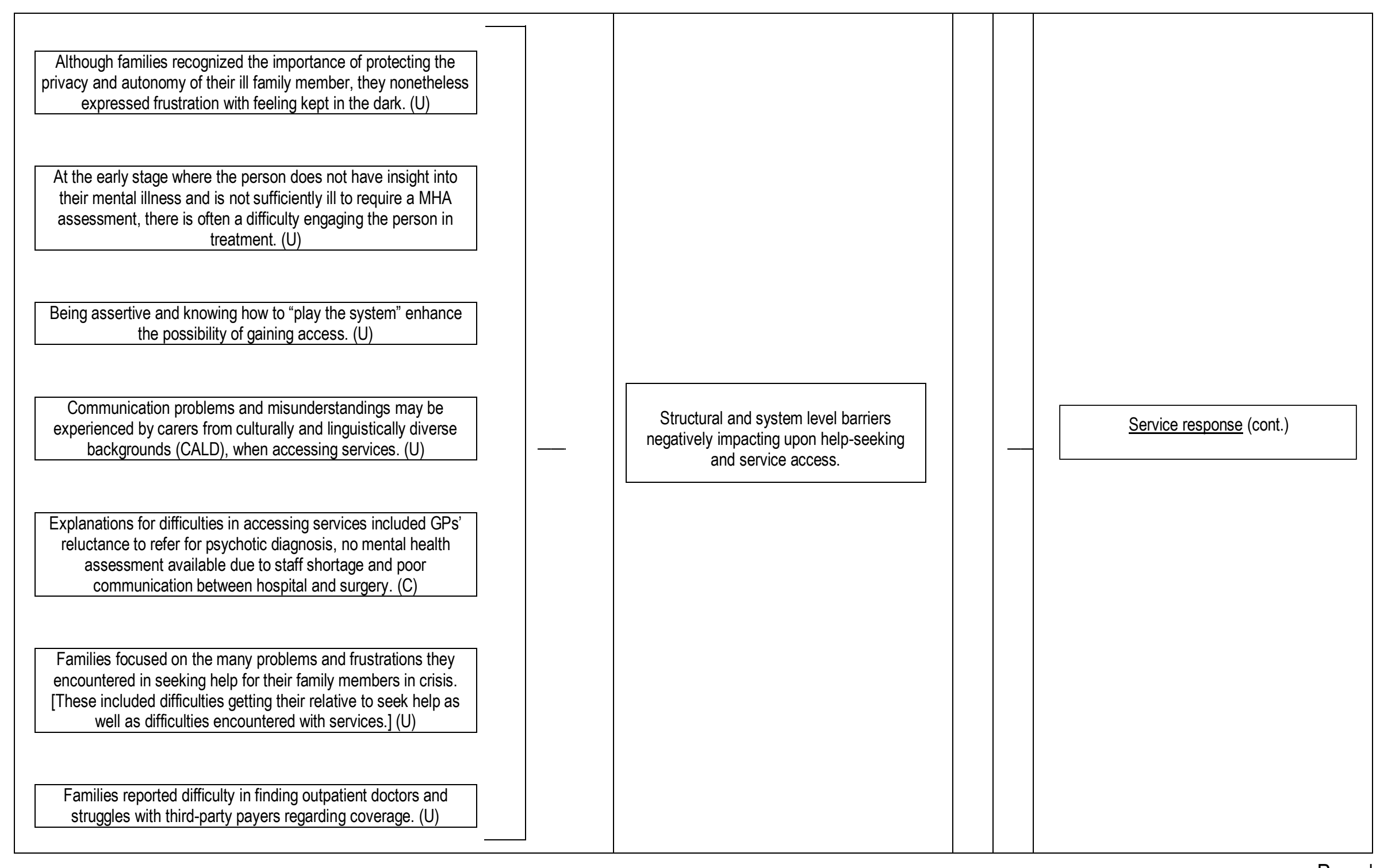




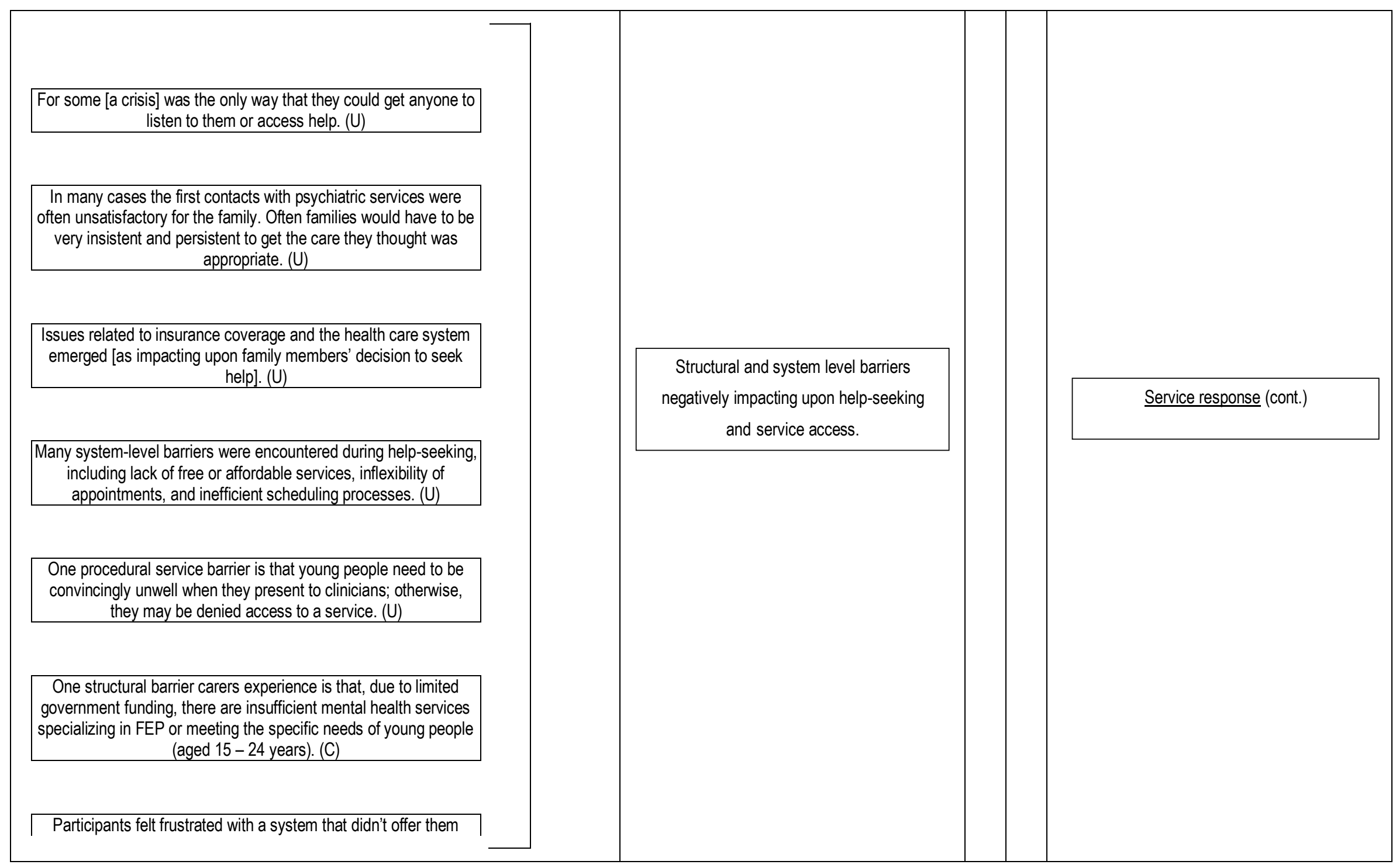




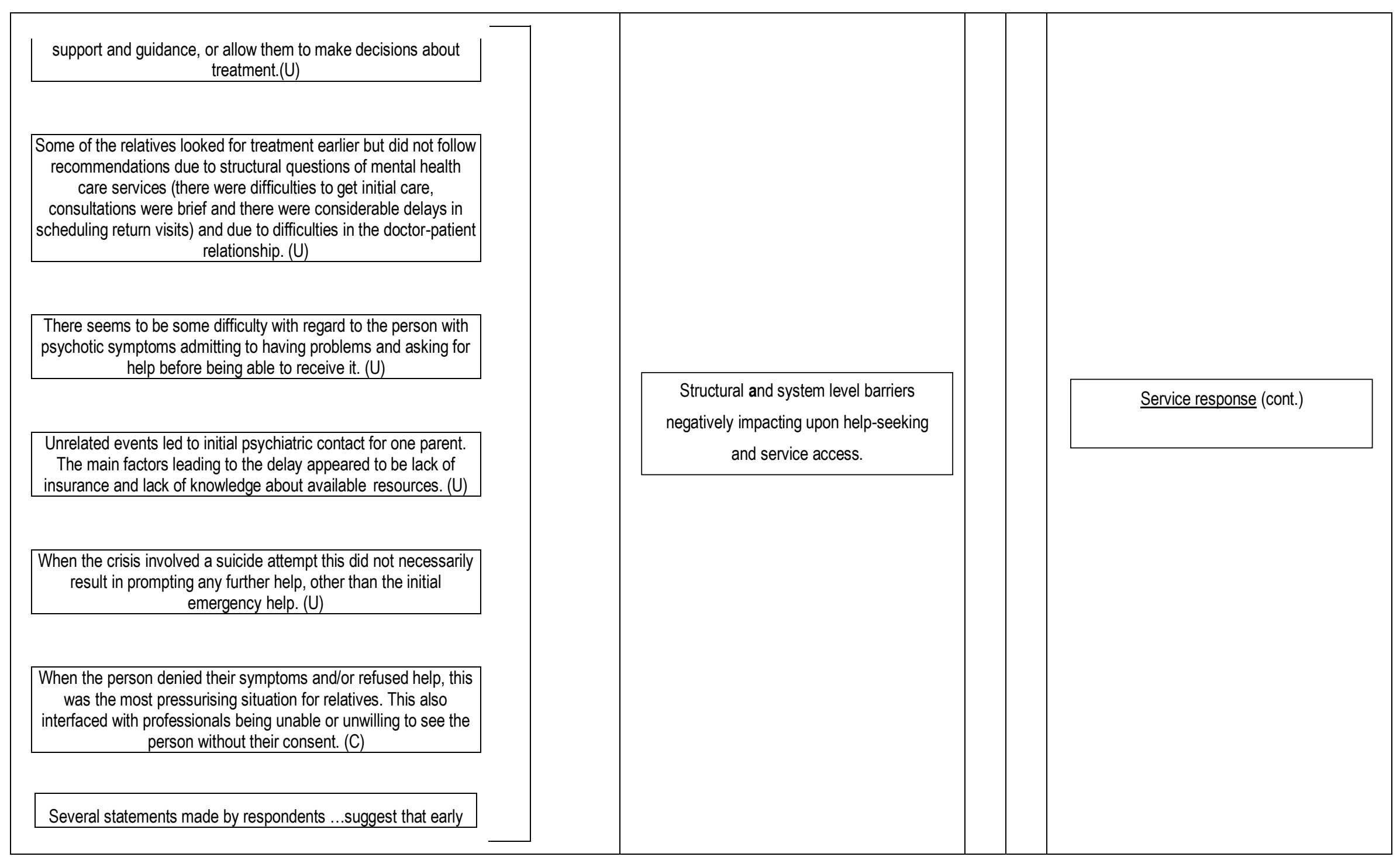




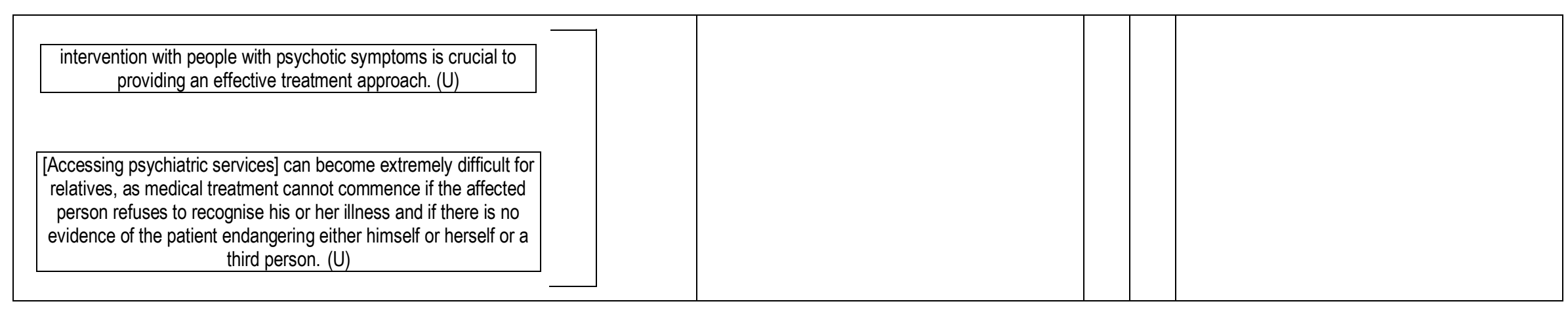




\section{Synthesised finding 4:}

Service response to relatives' help-seeking was often viewed as a barrier to accessing services, whilst contacts made with formal networks could either facilitate or inhibit the helpseeking process.

The fourth synthesised finding was derived from two categories with a total of 40 findings. A few key findings with their supporting illustrations will be presented within a summary of each category.

Category: Formal networks experienced as helpful or unhelpful.

Relatives reported conflicting responses when seeking help from formal networks e.g. General Practitioners (GPs'), Social Workers, Counsellors. Some were viewed as helpful and others unhelpful in facilitating the help-seeking process.

Carers sought help from outside the family when they were no longer able to manage the situation themselves. ${ }^{68}$ The majority of the findings regarding contacting more formal networks for help were related to GP's. Eight findings described GP's as unhelpful as they did not facilitate referral to specialist mental health services and showed a lack of understanding and support. $28,64-66$

Carers reported receiving what they viewed as uninformed or insensitive responses from health and educational professionals: 28

"So I brought him along to our local GP and told her what I felt was really wrong with him and she kind of dismissed it and said 'no, I think he just needs to sleep, he needs some sleeping tablets and he needs to sleep' [...] She [GP] said 'No, no give him these tablets and he'll be fine'. And his situation got worse". (Carer; mother, 51, Black Caribbean)(p.7)

Four findings described GP's as helpful in facilitating referral to services and providing support. ${ }^{31}$, $47,64,66$ 
Several carers had positive experiences with GPs who were engaged with the young person, were resourceful and prompt in referring to FEP services and provided ongoing support and encouragement to carers: 47

"Our GP has been fantastic. His relationship is such that . . . (carer's son) actually went to him when he was first ill. So that's a huge bonus I think, and he referred . . . (carer's son) to our local hospital and he rang them and organised for them to accept . . . (carer's son) as a way of referring him on to Orygen . . . , because he knew that he needed that. My GP's gives ongoing support; I suppose by him just encouraging us to keep going, because he tells us, 'you are a good mum'”. (Interviewee 5)(p.158)

Czuchta and McCay ${ }^{30}$ described a process of "continuous help-seeking" and the need for carers to convince health care professionals that their child was in need of help. Other formal contacts mentioned in the findings included: paramedics; police; psychiatrists; social workers and emergency department staff.

Category: Structural and system level barriers negatively impacting upon help-seeking and service access.

Many different structural and system level barriers were reported by carers when trying to access services for the first time.

Families focused on the many problems and frustrations they encountered in seeking help for their family members in crisis. [These included difficulties getting their relative to seek help as well as difficulties encountered with services]: 46

Three describe protracted efforts to schedule appointments with mental health professionals. (p.312)

Four could not persuade their symptomatic children to attend appointments, as they were ambivalent or hostile to their efforts to seek help. Consequently, treatment often began with emergency services and inpatient hospitalization, which four family members described explicitly as 'traumatic'. (p.312) 
Three family members described inpatient psychiatrists as insensitive or unavailable, providing little information. (p.312)

Various findings alerted to the ill relative needing to present as convincingly unwell, in crisis, at risk of harming themselves or others, or at least willing to engage in treatment in order to gain access to services. ${ }^{47,64-66,72}$ Staff shortages, ${ }^{65}$ poor communication, $, 65,67,70$ lack of free or affordable services, ${ }^{49}$ difficulties with insurance, ${ }^{59,61}$ inflexibility and poor scheduling of appointments ${ }^{49,70}$ were additional barriers identified by carers. Some carers reported managing these barriers by being persistent, ${ }^{64}$ assertive and learning how to "play the game". ${ }^{47}$ Whilst carers acknowledged the importance of privacy for the ill individual they struggled with the lack of information ${ }^{61}$ and support received from services at initial contact. ${ }^{67}$

\begin{tabular}{|c|c|c|c|}
\hline Category & Unequivocal & Credible & Total \\
\hline Formal networks & 12 & 7 & 19 \\
\hline Service barriers & 18 & 3 & 21 \\
\hline Total & 30 & 10 & 40 \\
\hline
\end{tabular}

TABLE 9: Summary of evidence of credibility; Synthesised finding 4. 


\section{Synthesised Finding 5}

There is a significant impact on relatives of individuals with a psychotic illness during the early stages of illness development, recognition, management and help-seeking. The impact for each family member may be different.

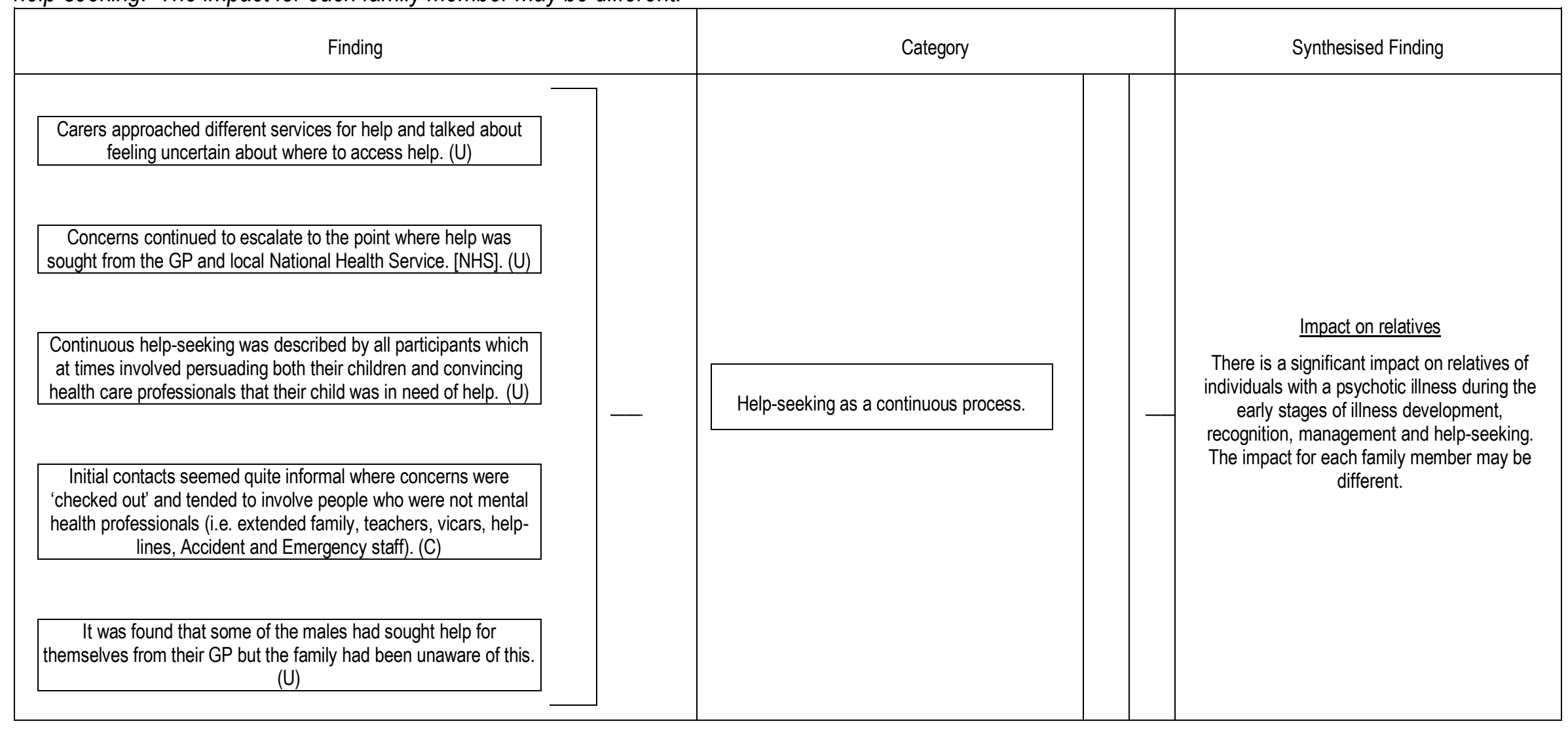




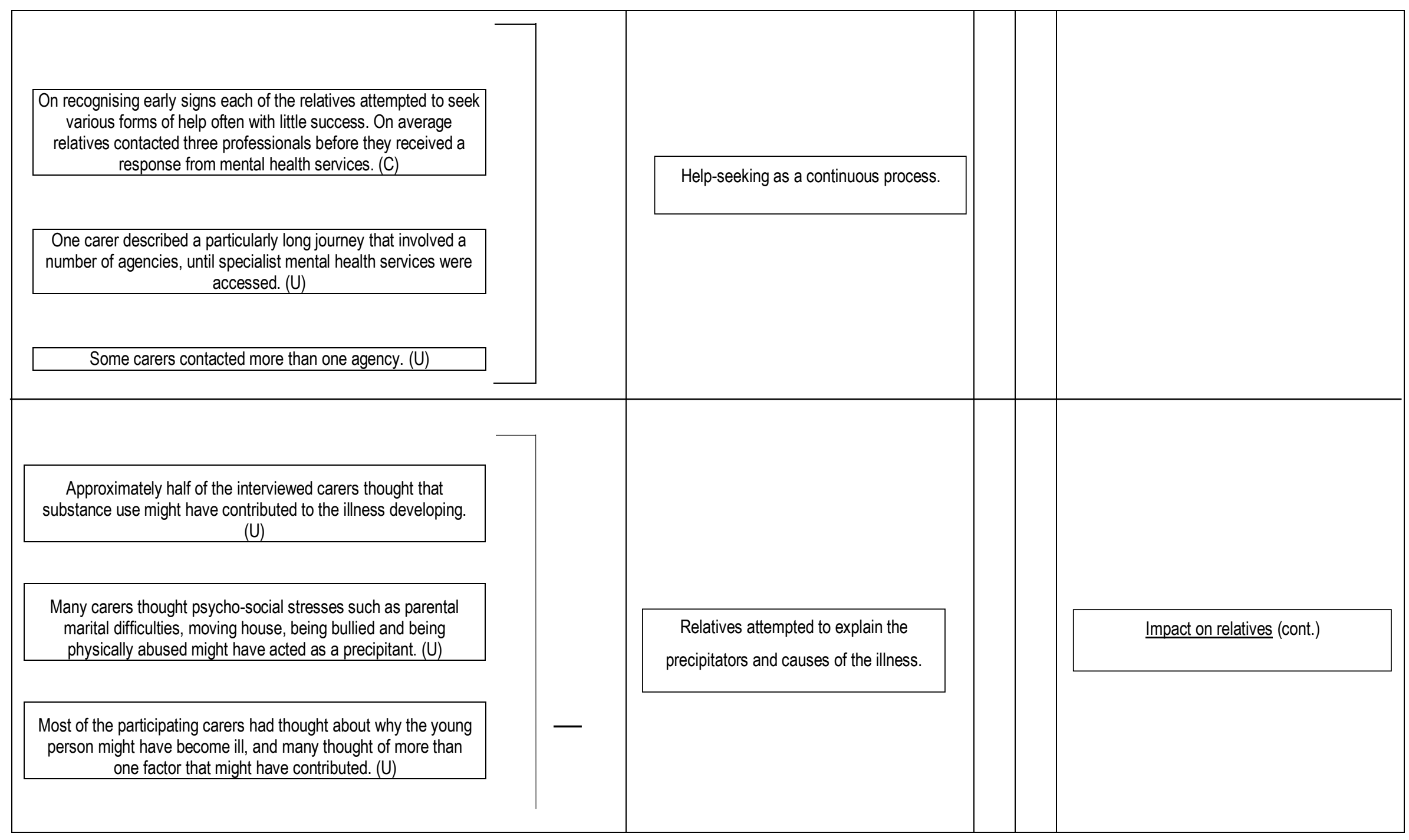




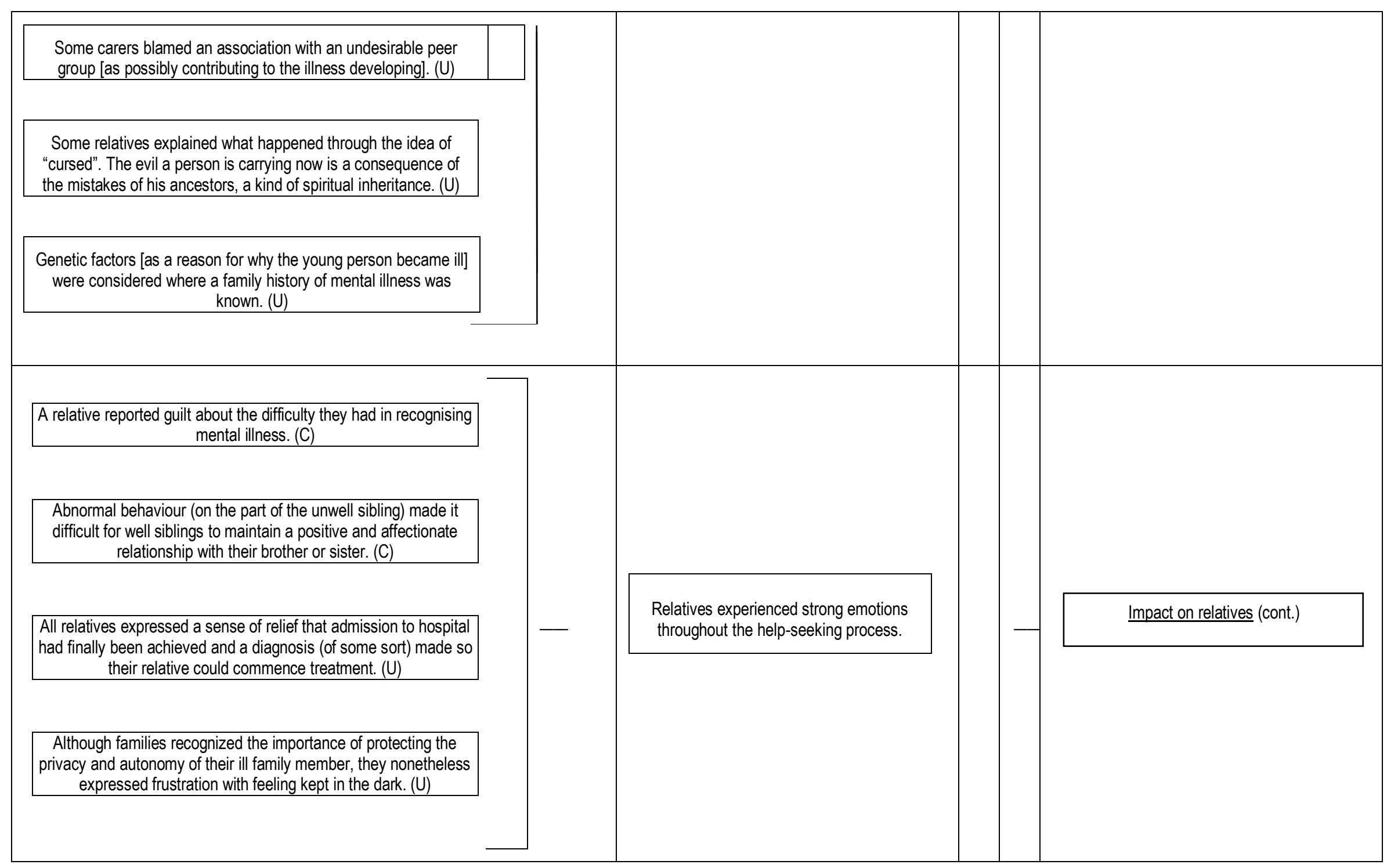




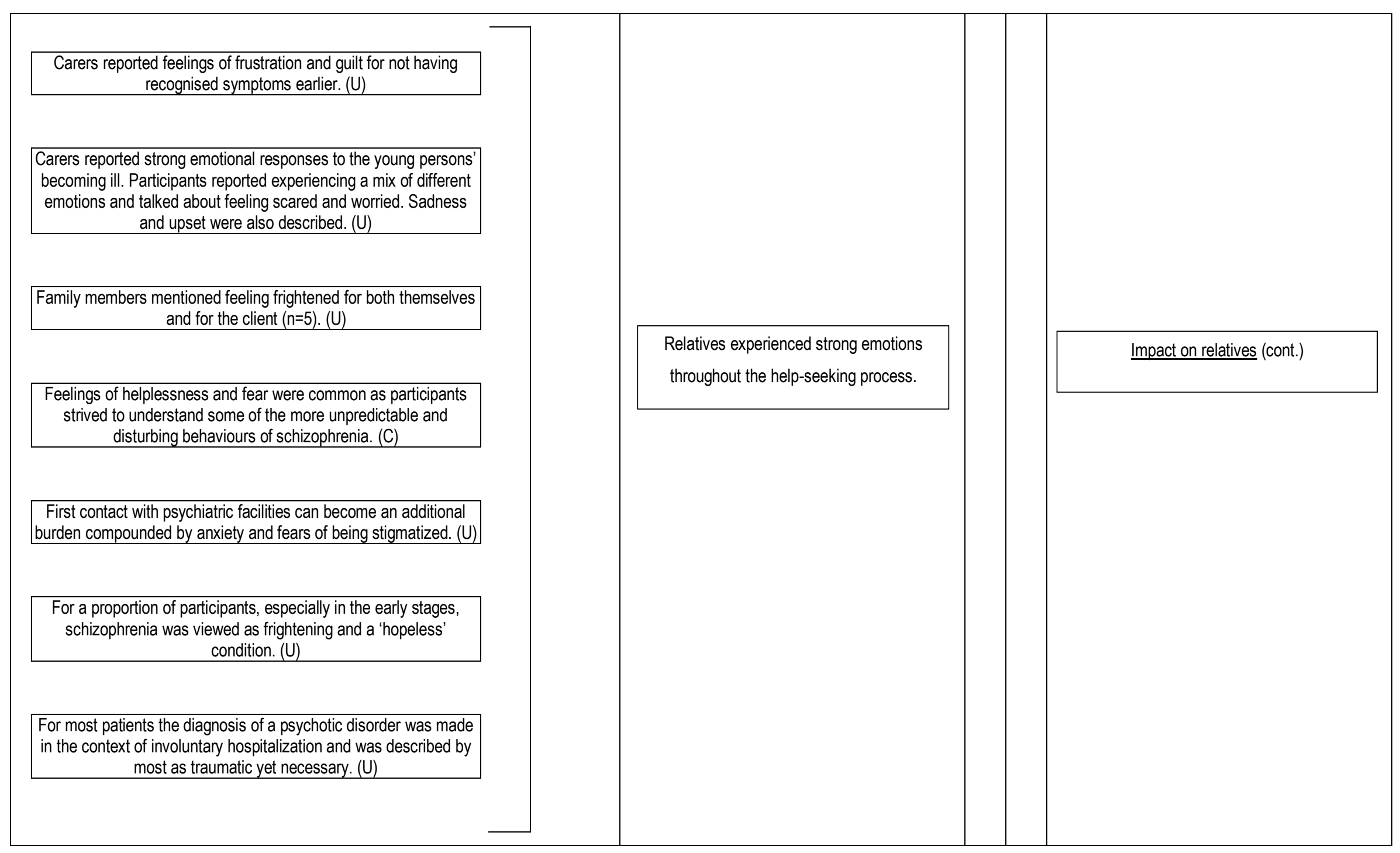




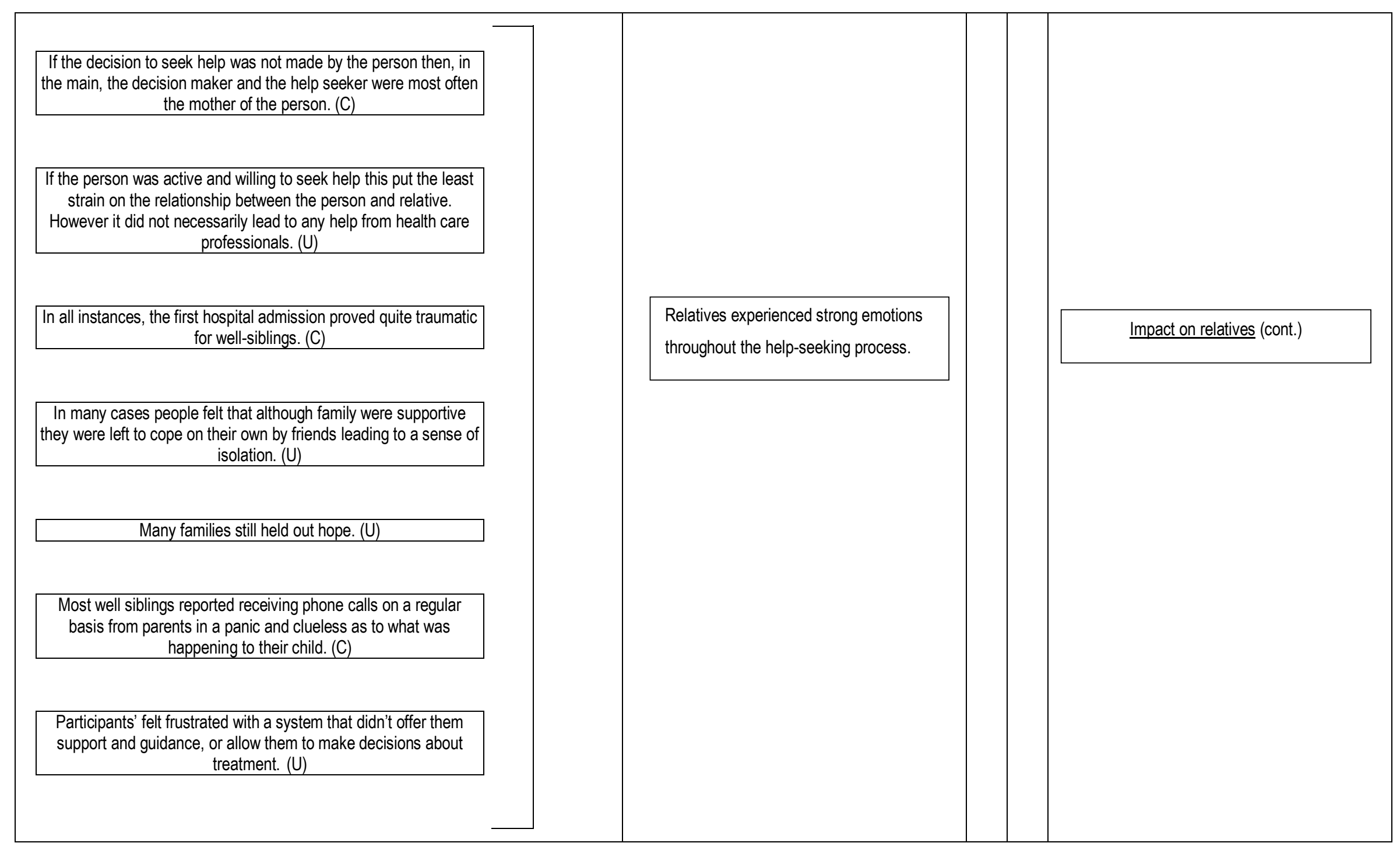




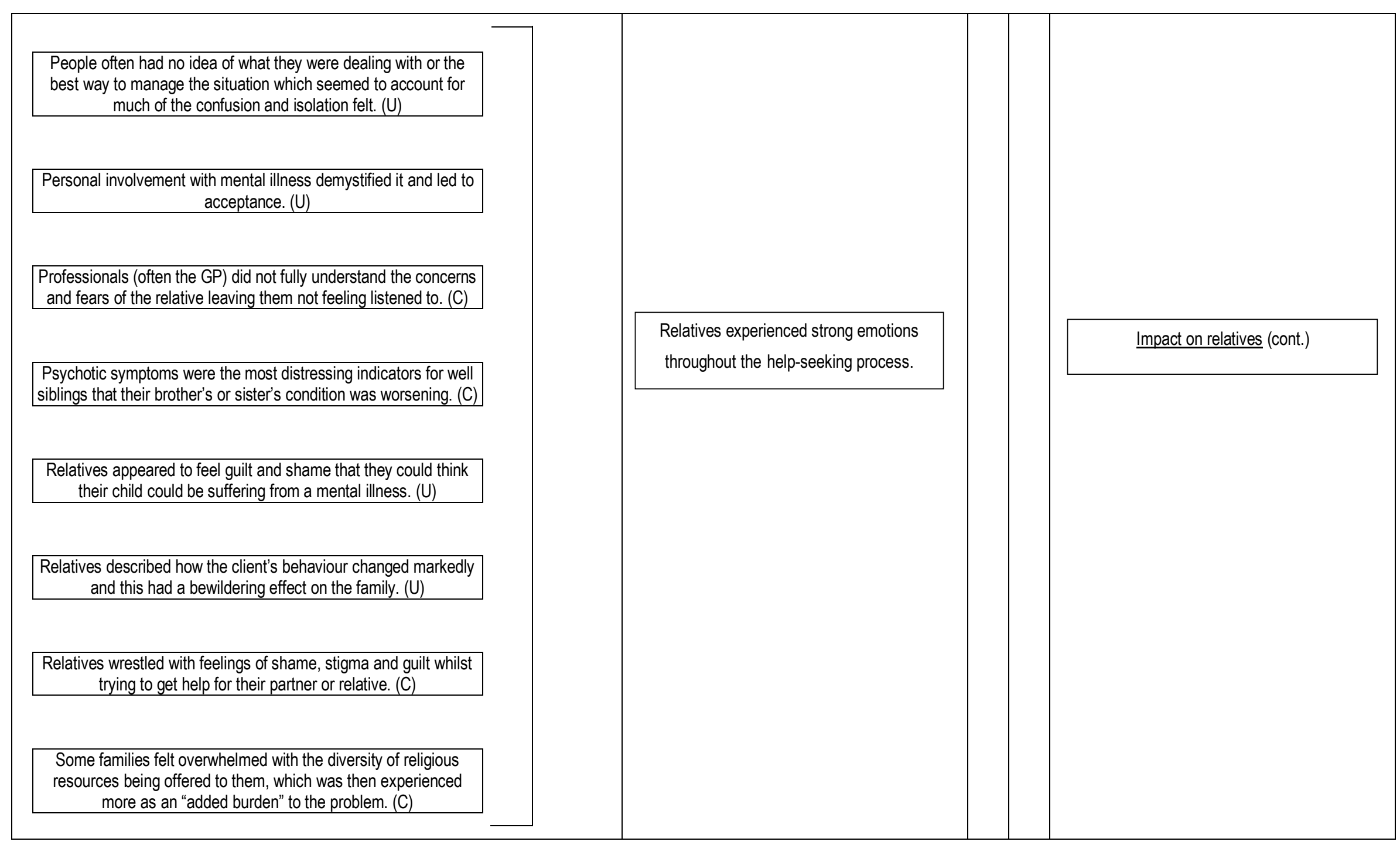




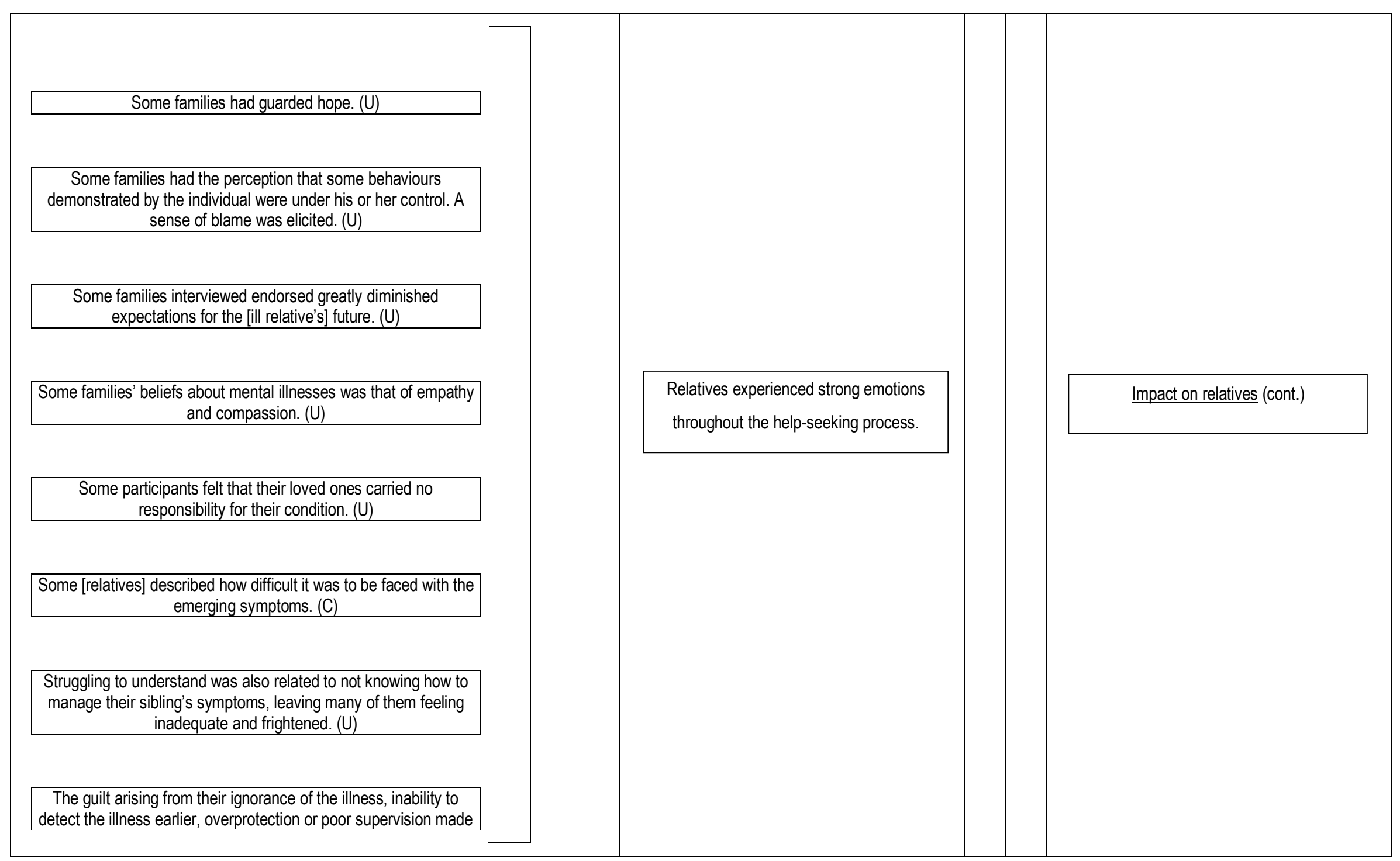




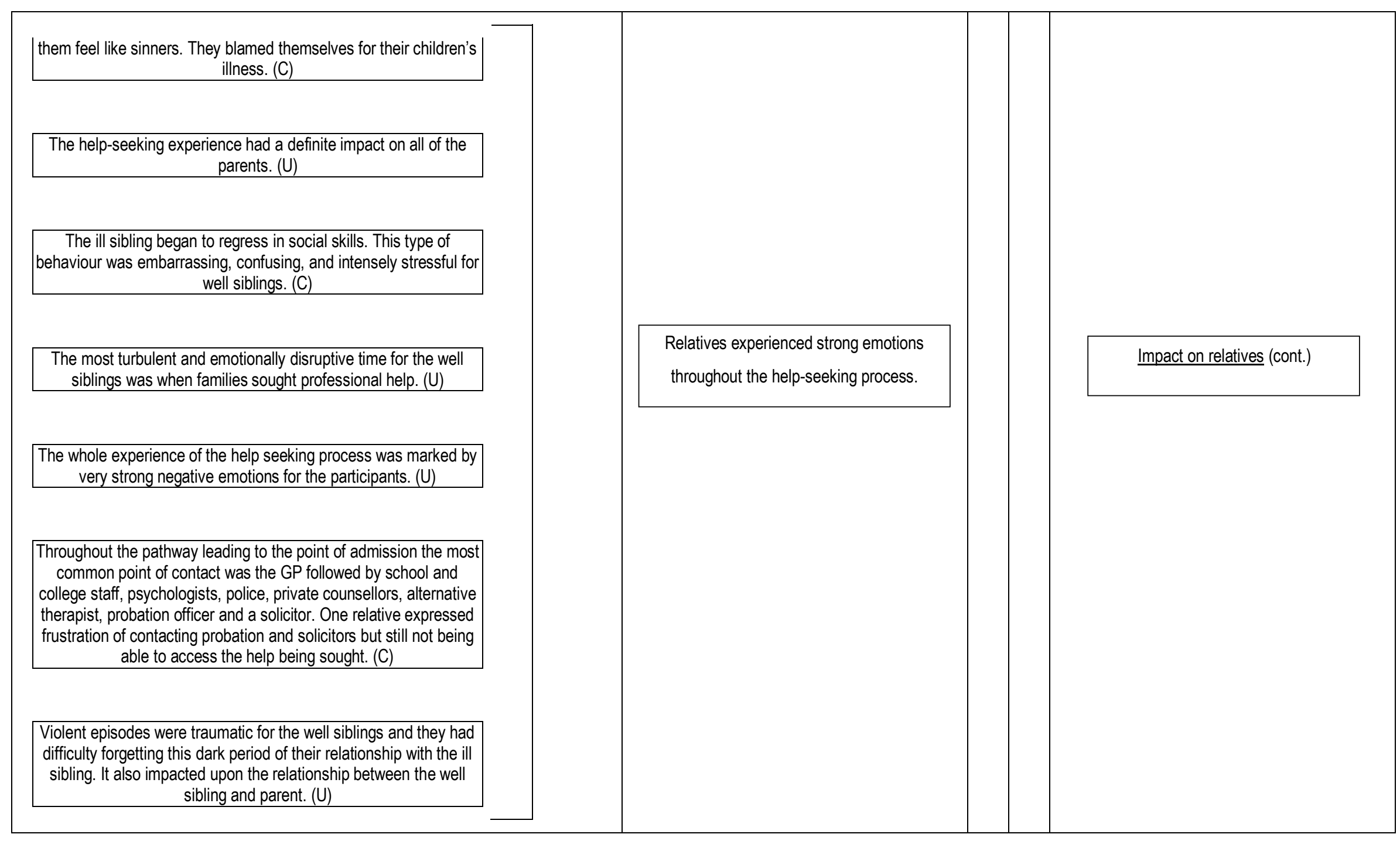




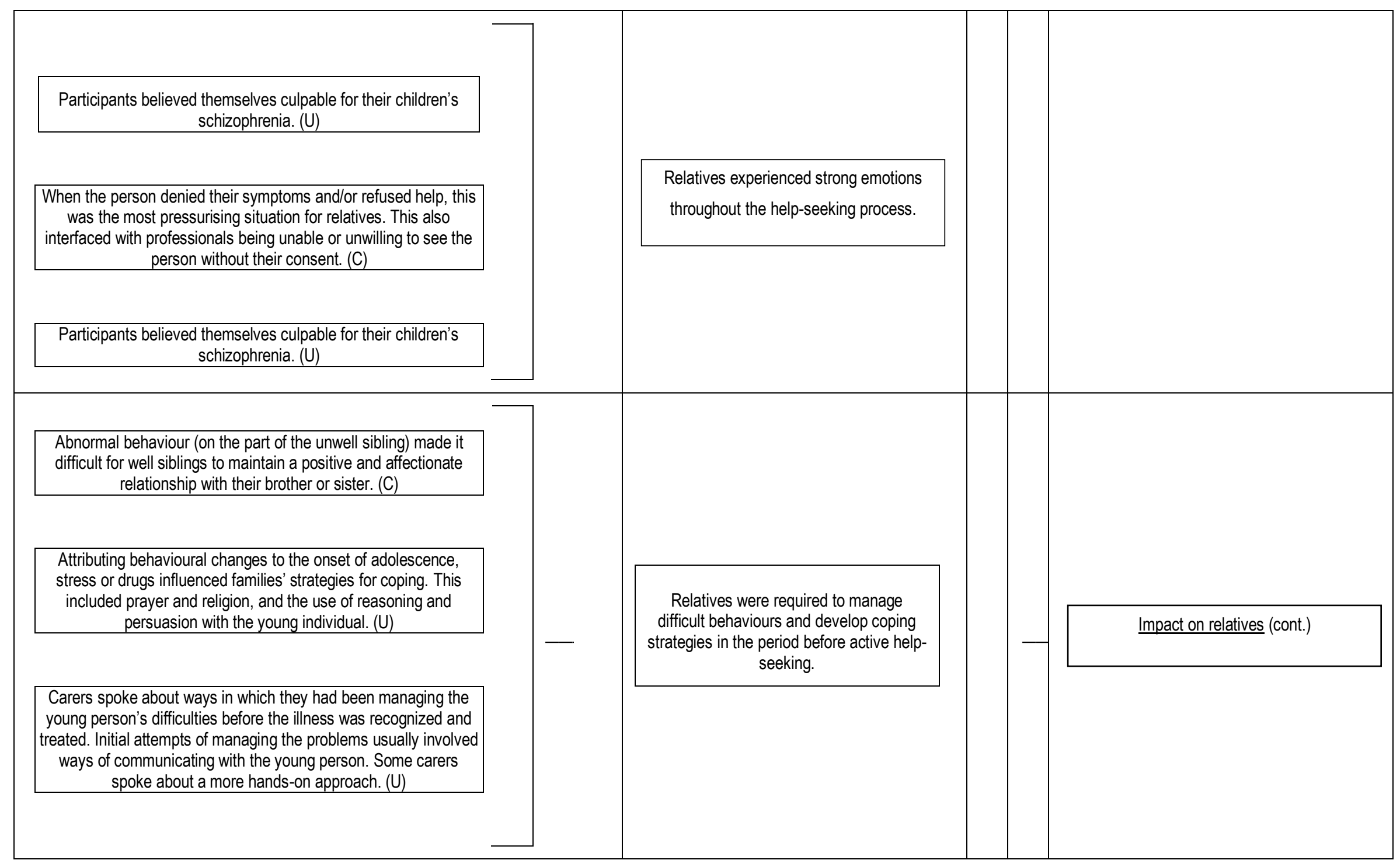




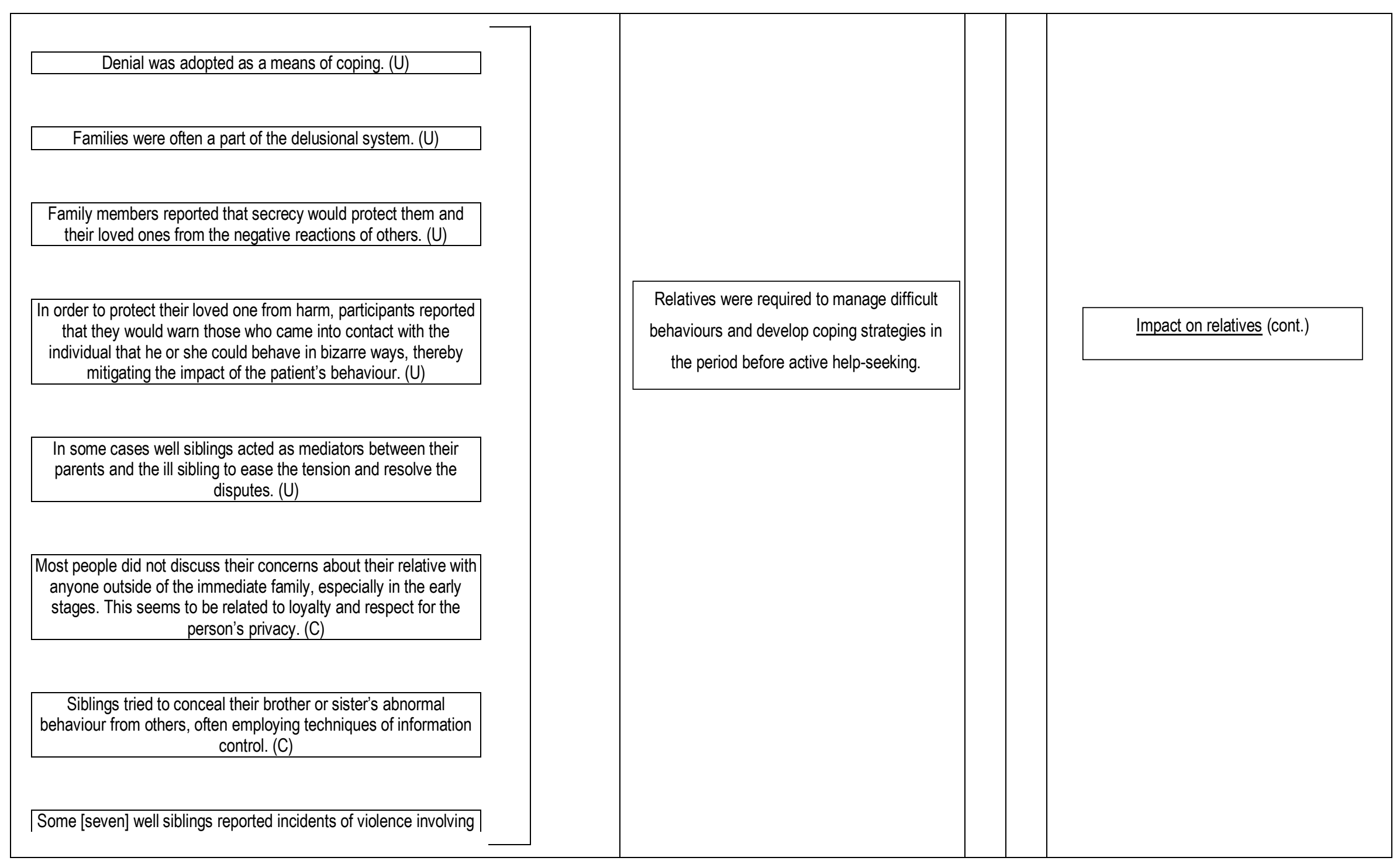




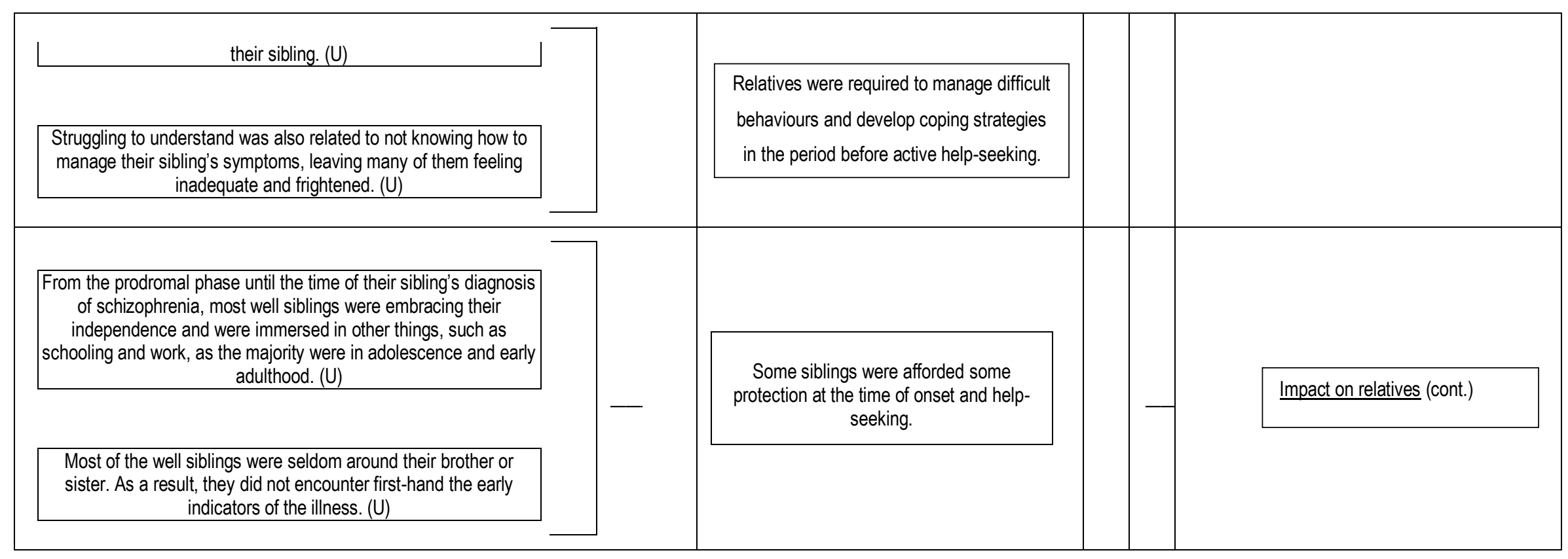




\section{Synthesised finding 5 :}

There is a significant impact on relatives of individuals with a psychotic illness during the early stages of illness development, recognition, management and help-seeking. The impact for each family member may be different.

The fifth synthesised finding was derived from five categories with a total of 69 findings. A few key findings with their supporting illustrations will be presented within a summary of each category.

Category: Help-seeking as a continuous process.

Help-seeking was often a continuous process requiring multiple attempts on behalf of the relative and sometimes ill individual, to get appropriate help. ${ }^{31,66}$ Czuchta and McCay ${ }^{30}$ summarized the situation well in one of their findings:

Continuous help-seeking was described by all participants which at times involved persuading both their children and convincing health care professionals that their child was in need of help: ${ }^{30}$

One parent described trying to convince health care professionals for over 1 year that her son needed help for his psychiatric illness. After a number of attempts to get help, she recalled an incident where her son was found by a girl along the side of a road after being missing in the woods for 11 days. The police brought her son to the emergency department so that he could be physically stabilized. After he was physically stable the staff were about to discharge him, which greatly concerned his parents. (p.167)

Category: Relatives attempted to explain the precipitators and causes of the illness.

During the first stage of illness recognition relatives attempted to make sense of the ill individuals' changed presentation. This has been explored in detail within the first synthesised finding. After clarification that an illness was present relatives reported trying to understand what may have triggered or caused the illness. ${ }^{31,70}$ 
Most of the participating carers had thought about why the young person might have become ill, and many thought of more than one factor that might have contributed: 31

"I think that's the hardest thing, you can't! You can't actually get a concrete answer. You know, there are just all these ideas out there, lots and lots of ideas. Nothing says, 'well yeah, it's definitely that'”. (p.88)

Approximately half of the interviewed carers thought that substance use might have contributed to the illness developing: ${ }^{31}$

"I tend to feel that just the combination of those years of drug taking probably had a significant effect". (p.88)

Some relatives explained what happened through the idea of "cursed". The evil a person is carrying now is a consequence of the mistakes of his ancestors, a kind of spiritual inheritance: ${ }^{70}$

"That's the way it is, suddenly someone in my family, from my ancestors who were involved in something, black magic or something, that goes on from generation to generation. So for three or four generations nothing happens, but suddenly in the fifth generation something can happen, [...] First the people from the church said that this came from my mother's womb, and could have been anyone, even more so the last daughter, so it came out in her. So it's like that, if some family goes into something wrong, or black magic, it may not come out in that generation, but in future generations; someone can, I don't know, get sick or have an attack and die".(p.108)

Category: Relatives experienced strong emotions throughout the help-seeking process.

The largest number of findings in any category was regarding the emotional impact on carers throughout the help-seeking process.

Carers reported strong emotional responses to the young persons' becoming ill. Participants reported experiencing a mix of different emotions and talked about feeling scared and worried. 
Sadness and upset were also described: ${ }^{31}$

Several carers cried during their interview. (Observation reported on p.88)

"Um, it was scary, it was really scary, 'cause there was nothing, there was nothing I could say, nothing anyone could do". (Appendix 3 p.97)

"I didn't stop feeling concerned, and I still haven't stopped feeling concerned". (Appendix $3 p .97)$

"I just couldn't stop crying. It was horrible, I had to go to work, l'd go to work in tears, you know". (Appendix 3 p.97)

"I was quite upset because I thought what's wrong with him, why is he saying all these strange things?" (Appendix 3 p.97)

"I really want him to have a better quality of life - l've seen his struggles - I just really want him to be well again, well enough for him, as well as he can be, comfortable with who he is". (Appendix 3 p.97)

The majority of findings were carers expressing difficult emotions ranging from fear, ${ }^{31}, 63,67$ sadness, ${ }^{31}$ helplessness, ${ }^{67}$ hopelessness, ${ }^{46}$ and isolation. ${ }^{64}$ Carers expressed guilt at not recognising signs of the illness earlier. ${ }^{28,66,71}$ Some expressed feeling distressed, embarrassed and confused when confronted with psychotic symptoms ${ }^{68}$ and behavioural changes. ${ }^{63,68}$

Some families interviewed endorsed greatly diminished expectations for the future: 46

One family member felt "it is all over" One parent wondered if her son could ever get married and have children, and another mother worried what would happen to her child when she eventually died. (p.312-313)

The active help-seeking period was described as being disruptive, ${ }^{64}$ stressful66, 68 and overwhelming. ${ }^{69}$ Shame, stigma and guilt were emotions used to further describe this 
experience for carers. ${ }^{66,68}$ At the point of contact with services, mixed emotions were described. Some carers described feeling relief that their relative was receiving care ${ }^{66}$ whilst others expressed frustration with service contact and response 61,67 or fear of stigma. ${ }^{72}$ It is important to note that at this early stage, some carers had a sense of acceptance ${ }^{31}$ and continued to hold out hope for their relative and their future ${ }^{46,61}$ as illustrated with the following finding:

Many families still held out hope:61

One family member said, "I want any parent who has to hear for the first time that their beloved son or daughter is developing this illness ... [to know,] yes, they can become well". (p.814)

Category: Relatives were required to manage difficult behaviours and develop coping strategies before active help-seeking.

Before active help-seeking had commenced, problems were becoming evident, and carers were often required to manage difficult behaviours and develop coping strategies. Coping strategies employed were related to the carers' interpretation of the cause of the presenting problems. ${ }^{31,46}$

Attributing behavioural changes to the onset of adolescence, stress or drugs influenced families' strategies for coping. This included prayer and religion, and the use of reasoning and persuasion with the young individual: 46

One woman prayed to understand why her son had become like a stranger, and to gain understanding as to how she could help him. Another mother sent her daughter to a church retreat, and tried to push her to find a job. The elder brother of one patient remembers, "I told him to go get a job and don't sleep too much ... He was just taking his sweet time finding a job and I remember screaming at him sometimes". (p.312)

An African-American woman tried to reason with her daughter who had begun to hear voices: "The windows are closed. How are you going to hear somebody talking about you outside?" She sought help from a priest for blessings and holy water, and tried saying prayers to "see if we could help her ourselves". The priest urged her to seek 
psychiatric care for her daughter. (p.312)

One girl started to believe that people were talking about her on the train and in her neighbourhood, and her mother advised her to simply ignore them. (p.312)

Carers' beliefs about mental illness also informed coping strategies utilised. ${ }^{62}$ Those who were fearful of negative reactions from others chose denial, ${ }^{62}$ or secrecy $62,64,68$ as coping strategies.

Denial was adopted as a means of coping:62

"There was nothing I could really do to try to make him come together, so I kinda ignored it completely. I just forgot about it". (p.6)

Other strategies employed included communication, ${ }^{31}$ reasoning and religion. ${ }^{46}$ Even at this early stage, difficult behaviours caused disruption within family relations. Some siblings reported acting as mediators between their ill sibling and parents. ${ }^{68}$ Carers also reported being left feeling fearful and inadequate when they found themselves unable to manage difficult behaviours. ${ }^{67}$

Category: Some siblings were afforded some protection at the time of onset and help-seeking.

In a study exploring siblings' experiences, Dodge ${ }^{68}$ noted that some protection was afforded to well siblings at the time of onset of illness as they were often immersed in their own life events.

From the prodromal phase until the time of their sibling's diagnosis of schizophrenia, most well siblings were embracing their independence and were immersed in other things, such as schooling and work, as the majority were in adolescence and early adulthood:68

"To be honest I was totally focused on my own life and didn't even have much of a relationship with Isaac at that time (when the illness was emerging)". Similarly, when Chloe began to experience difficulties in her work, Ethan recalled "I probably just didn't pay that much attention". In Sienna's case, she stated: "At that age, I just sort of distanced myself from him, I didn't know how to take it. So I lived my life apart from him and I really didn't want to have him a part of my life and I wasn't involved in his life at all'. 
(p.59-60)

\begin{tabular}{|c|c|c|c|}
\hline Category & Unequivocal & Credible & Total \\
\hline Continuous process & 6 & 2 & 8 \\
\hline $\begin{array}{c}\text { Precipitators and } \\
\text { causes }\end{array}$ & 6 & 0 & 6 \\
\hline Impact & 28 & 13 & 41 \\
\hline Coping strategies & 9 & 3 & 12 \\
\hline Siblings & 2 & 0 & 2 \\
\hline Total & 51 & 18 & 69 \\
\hline
\end{tabular}

TABLE 11: Summary of evidence of credibility; Synthesised finding 5.

\section{Conclusion}

Twenty-two studies were identified following appraisal that considered carers' experiences of help-seeking for a relative with a first-episode psychosis. Ten different countries were represented and the voices of many different relations to the ill individual. Five synthesised findings were derived from 16 categories and 213 findings.

Delays often began at the stage of illness recognition. The main barriers to seeking help were fear of stigma and reluctance of the ill relative to participate in the process. A crisis and overt psychotic symptoms were the main promoters of active help-seeking and facilitators to accessing services. Service response was often viewed as a barrier to service access. A significant negative impact on carers of individuals with a psychotic illness was reported during the early stages of illness development, recognition, management and help-seeking, however the impact for each family member may differ. 


\section{Chapter 5: Discussion}

\section{Introduction}

The objective of the systematic review presented in this thesis was to synthesise the best available evidence on the lived experience of carers of a relative with a first-episode psychosis (FEP) and in particular their experience preceding and of seeking help. The literature in this field indicates that delays in accessing appropriate treatment arise at various levels including: illness recognition; help-seeking and service response. The findings from this systematic review are congruent with this view and additionally found there was an association between each of these areas, as well as a significant impact on carers at each of these stages. This Discussion section will detail the relationships between the synthesised findings as depicted by the formulated model, see Figure 2 below, as well as explore commonalities and differences between studies.

Two separate frameworks have been drawn upon to formulate a model to summarise the findings of this review, and thereby describe carers' experiences of seeking help for relatives with a FEP. The first framework was from Lincoln and McGorry (1995) ${ }^{48}$ who conducted a literature review to understand pathways to care for young people experiencing a FEP. The review was structured around the three areas of illness recognition, help-seeking and referral pathways. The authors acknowledged that reasons for delays at each of these stages were complex and proposed talking to consumers and carers as a way forward in clarifying pathways to care. At the time of this paper in 1995, no qualitative research specific to this had been identified. The second framework was from Jorm (2012) ${ }^{41}$ who, drawing on his own earlier research, discusses the importance of mental health literacy as a way forward to improving management of mental disorders at a community level. The components of mental health literacy include: "knowledge of how to prevent disorders; recognition that a disorder is developing; knowledge of help-seeking options and treatments available; knowledge of effective self-help strategies for milder problems and first aid skills to support others who are developing a mental disorder". ${ }^{41 p .231}$

These two papers were utilised, alongside the synthesised findings of this review, to inform the development of the following model: 


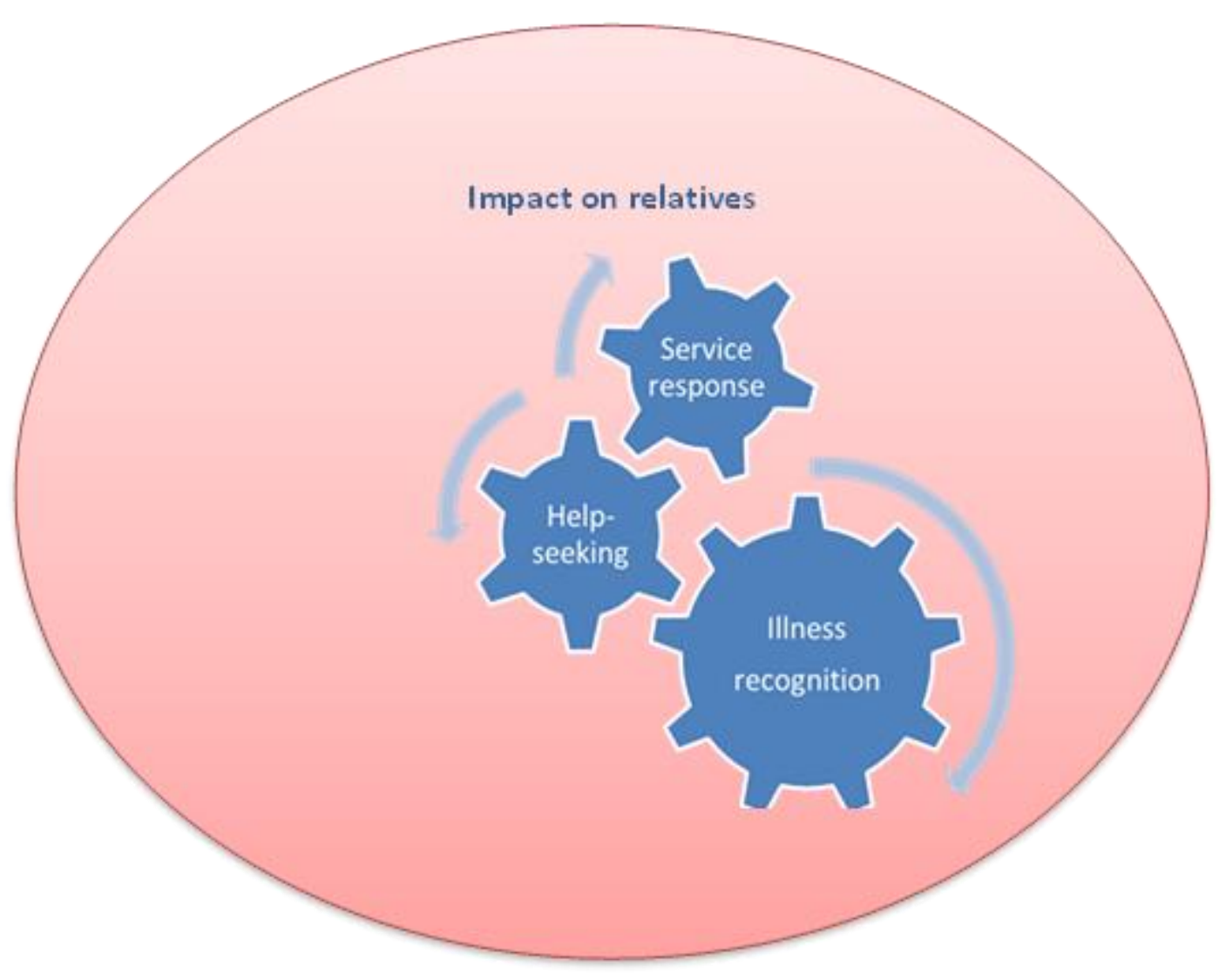

Figure 2: Model depicting the interrelated processes involved in carers' help-seeking for a relative with a FEP and the subsequent impact on carers throughout this process.

\section{IIIness Recognition}

Recognising an illness is developing and that the person is in need of help is often delayed. Beliefs about mental illness further impact upon the timing as well as type of help sought. (Synthesised finding 1)

The link between illness recognition and help-seeking is clear. Recognition that a disorder is developing and that the person is in need of help must occur before help-seeking will be considered or initiated. ${ }^{41}$ In the early stages of a psychotic illness symptoms can be vague ${ }^{28,31}$ and subtle and are commonly interpreted as typical adolescent behaviour $31,46,68$ or as a response to stress or illicit drugs. $28,46,70$ Even if help-seeking is initiated at this early stage, health professionals may miss signs of a more serious illness. This link demonstrates the potential interrelatedness of illness recognition with service response. It could be supposed that a 'missed diagnosis' by health professionals at this stage could undermine carers' perceptions that there was "something not quite right" and thereby inadvertently confirm any misattributions 
family members may have made of the signs of illness, and potentially lead to further delays in future help-seeking.

After acknowledging a problem, carers' beliefs and knowledge about mental illness continue to impact on their pattern of help-seeking. This includes the type of help sought, which may for example be religious sources, ${ }^{60,69-71}$ as well as timing. When the concept of having an illness was viewed negatively further delays in acknowledging an illness or in seeking help occurred. ${ }^{62}$ 70, 71 Often a high threshold of difficulties was reported to be reached before help-seeking was initiated. Two of the main reasons for this delay were concerns about stigma ${ }^{62}$ and misattribution of symptoms. ${ }^{28,} 31,46,68,70$ Even at this early stage carers were often under considerable stress. ${ }^{31}$ 63,68

\section{Help-seeking}

Two synthesised findings were combined to describe the help-seeking process, and more specifically the identified promoters and inhibitors.

Inhibitors-

The predominant barriers to seeking help were the perceived stigma of having a mental illness and reluctance of the ill relative to participate in the help-seeking process. Lack of knowledge of treatment options, and the ill individuals' wider social context and informal networks may also inhibit help-seeking. (Synthesised finding 2)

A further link between illness recognition and help-seeking is resultant from fears of stigma. Stigma was the most frequently reported inhibitor to seeking help, contributing to delays in carers even recognising and acknowledging their relative may be ill.62, 70 In a systematic review regarding pathways to care during a FEP, Singh and Grange ${ }^{25}$ noted there is a delay in relatives seeking help even after a problem has become evident. After acknowledging an illness was present, stigma led to further delays in help-seeking due to carers' fears of their relative being labelled as having a mental illness, ${ }^{31,62}$ as well as fears about treatment and stigmatisation resulting from association with psychiatric services. ${ }^{28,62,70,72}$ Additionally, those carers that were fearful of stigma often employed secrecy as a coping strategy, ${ }^{60,62}$ thereby losing the invaluable support provided by their informal networks.

When the ill relative was unwilling to seek help or acknowledge there was a problem, this impacted upon both the carer and 'service response' during the help-seeking process. Carers 
frequently reported the ill individual as a deterrent in the help-seeking process and reported being unable to successfully access help due to lack of risk as assessed by health professionals, ${ }^{72}$ lack of informed consent ${ }^{65}$ or lack of disclosure of symptoms. ${ }^{64}$ Whilst carers reported trying to convince their relative to seek help $28,46,73$ they also acknowledged the tension related to this due to the perception that the ill individual was of an age to make independent decisions. ${ }^{49}$ Being 'of age' was reported to both inhibit the carers seeking help as well as impact on service response. Health professionals are required to provide confidential services to the 'client' and follow service directions and policy regarding criteria for access to secondary mental health services. It is possible that a negative or unhelpful response from services or health professionals may again contribute to further delays in future help-seeking.

Promoters-

Crises, or overt psychotic symptoms, were the main promoters of active help-seeking and facilitators to accessing services. Relatives' informal networks often served to assist in this process. (Synthesised finding 3)

Carers' informal networks, particularly family and friends, were often the first to be contacted in the help seeking process. Informal contacts provided help with confirming there was a problem, ${ }^{68}$ facilitating help-seeking ${ }^{46,73}$ and providing emotional support. ${ }^{31,68}$

The main interface when considering the promoters of help-seeking was with service response. Help-seeking extended to more formal contacts, particularly GP's, and became an expanding process, beyond immediate family. Alternative sources of help were sought after initial sources were exhausted 68 or the family became unable to manage disruptive behaviour. ${ }^{59}$ Typically a crisis or overt psychotic symptoms were reported to be the main precipitators for carers to seek help more broadly.49, 59, 62, 64 Crises and clear psychotic symptoms were also reported as facilitators in accessing appropriate services. This is synonymous with some of the findings in quantitative studies. Addington et al ${ }^{4}$ found that individuals presenting with psychotic symptoms including delusional thinking and hallucinations had the most success in gaining appropriate help.

\section{Service response}

Service response to relatives' help-seeking was often viewed as a barrier to accessing services, whilst contacts made with formal networks could either facilitate or inhibit the help-seeking 
process. (Synthesised finding 4)

Service response interfaces with both illness recognition and help-seeking. Whilst this systematic review was interested in the perceived barriers and facilitators to accessing services during a FEP, the findings reported here overwhelmingly identified barriers. Some of the findings, such as those describing difficulties relating to insurance ${ }^{59,61}$ and lack of free or affordable services, ${ }^{49}$ were specific to the country that the research was located within. The three aforementioned studies were all conducted within the USA. However, carers from a range of countries where access to free health care services is available also reported difficulties accessing services including: Australia; ${ }^{47} \mathrm{UK} ;{ }^{64-66}$ Canada; 67 Brazil ${ }^{70}$ and Germany. ${ }^{72}$

Successful entry to secondary mental health services was often within the context of the ill individual presenting with overt psychotic symptoms or at significant risk of harming themselves or others, as discussed under facilitators to help-seeking. It was at this point carers were most likely to seek help from formal networks and services. Formal networks, mainly the GP, were described as being helpful 31,47 by some carers and unhelpful by others. ${ }^{47}$ As the studies explored the carers' perspective only, it is not always possible to ascertain why some GP's did not facilitate referral to more specialist services. It could be postulated that delayed referral could be related to the difficulty of making an early diagnosis, misattribution of symptoms, missed diagnosis or responding with an appropriate 'watch and wait'.

Johannsen et al75p.24 reported that the delays to early detection and intervention are related to "the patients themselves; the patients' families; the primary health care system and the specialised psychiatric services". The findings of this systematic review support this view. McCann et al ${ }^{47}$ explored carers' experiences with GP's in the pathway to care and subsequently made recommendations to provide increased support to GP's around referral to mental health services to address identified gaps.

\section{Impact on relatives}

There is a significant impact on relatives of individuals with a psychotic illness during the early stages of illness development, recognition, management and help-seeking. The impact for each family member may be different. (Synthesised finding 5)

There was a significant negative impact on carers throughout each of the three stages of illness recognition, help-seeking and service response, with many of the allocated findings overlapping 
with these areas. At the stage of illness recognition carers reported various feelings including fear, ${ }^{31,63,67}$ sadness, ${ }^{31}$ helplessness ${ }^{67}$ and distress. ${ }^{31}$ Some expressed guilt for not having detected an illness earlier. ${ }^{28,66,71}$ People's beliefs about mental illness, particularly if they were negative, were noted to add additional concerns relating to stigma. ${ }^{62}$ Conflict between family members arose subsequent to lack of disclosure by one person of knowledge of a family history or denial of the illness. ${ }^{68}$ The stage of help-seeking resulted in ongoing disruption ${ }^{64}$ and stress ${ }^{66}$, 68 for carers and further frustration was often reported at first contact with services. ${ }^{61,} 67$ Closely related to the emotional impact on carers was the requirement on them to manage difficult behaviours. ${ }^{31}$

Whilst the majority of findings were related to difficult emotions, the effect of positive support was mentioned by some carers. This typically came from within the carers' informal network, ${ }^{31}$ GP's ${ }^{47}$ and religious groups. ${ }^{69}$ Relief was also expressed by some when treatment was accessed. 66

The impact on each family member may vary depending on their relation to the ill individual. Mizuno et al ${ }^{74}$ identified that in some cases children were the ones to detect their mothers' illness, which then alerted the fathers to seek help. As the study was concerned with the husband's experience specifically, there was no detail of the impact on the children, though it could be presumed that there would be significant emotional and practical consequences for the children in this scenario. Various studies reported siblings' experiences with some taking a more active role ${ }^{67,68}$ and others afforded more protection due to living away from home at the time of illness onset, or being less involved in their siblings' day-to-day life. 68

The impact on carers, of course, goes beyond the early phase of illness detection and helpseeking with some carers expressing concerns for the future ${ }^{31}$ and others a sense of hope. ${ }^{46,61}$

\section{Commonalities and Difference}

The voices of a wide variety of participants, meeting the definition of 'carer', were covered in the papers including: mothers; fathers; partners; siblings and extended family members. Perhaps a surprising observation was the commonality of experience across participants regardless of the nature of their relationship to the ill individual. Most studies did not distinguish to whom the particular participant quotes belonged, and as the majority of participants were mothers, this will likely also contribute to the congruity. This could be viewed as a limitation within studies as it 
possibly did not allow for differences or non-congruency to be reported. Those studies that focussed on a specific relation to the ill individual did produce more variety and difference in reported experience. Dodge ${ }^{68}$ explored well siblings' experience and reported a variety of findings relating to their role and experience. Well siblings acted as mediator between the ill sibling and parents, took on a supportive role for parents but also apportioned blame towards their parents. They discussed their changed relationship to their ill sibling and difficulty forgetting traumatic incidents.

Differences regarding the year the study was conducted, the setting of the study and the variation in time since onset of illness did not contribute to any significant variation in findings. The exception was Wong ${ }^{73}$ where the study setting was child and adolescent mental health services in Hong Kong. In this study it is likely that in addition to the service setting, the cultural context also contributed to the difference in findings. Wong ${ }^{73}$ reported that Chinese families take responsibility for initiating treatment for ill children when young, as well as for unmarried adult children. There seemed to be less of an issue that the child was of an age of independent decision-making regarding help-seeking, as found in other studies. ${ }^{64}$ Wong $^{73}$ also reported social workers as having a key role in facilitating service referral, pointing to differences in pathways dependent on the studies' country of origin. Studies, for instance, situated in the UK ${ }^{28,}$ 64-66 and Australia ${ }^{47}$ referred to the GP as having a key role in the care pathway.

Some of the included studies explored both the consumers' and carers' views and generally reported similarity in findings. ${ }^{28,31}$ Cadario et al ${ }^{31}$ looked at the experiences of adult carers and adolescent consumers and stated that the concordance of themes between these two participant groups supported working conjointly with parents and adolescents. This finding could also be considered by clinicians working in adult settings. A recent qualitative study exploring the helpseeking experiences of adolescents with FEP provides further evidence of congruity in findings. ${ }^{76}$ Anderson et $\mathrm{al}^{76}$ found self-stigma and lack of knowledge of symptoms of psychosis and availability of services were significant barriers to help-seeking. Regarding facilitators to the helpseeking process, the young people in the study highlighted the crucial role of significant others, particularly parents, in initiating the process. ${ }^{76}$ The above findings, regarding perceived barriers and facilitators to accessing services during a FEP, are supported by the synthesised findings from the review presented in this thesis. 
The main difference in findings was regarding participants' responses to mental illness. Monterio et al70 discuss the importance of the cultural and social meanings given to symptoms of mental illness on informing help-seeking as well as identification of illness: "it is through the lens of culture that people define health and illness and perceive and respond to health messages."77 s123 Culture will affect how symptoms are described, from whom help is sought and how treatment options are viewed. ${ }^{77}$ Jorm ${ }^{78}$ found that stigmatising attitudes toward mental illness were barriers to help-seeking, and that specifically, those who viewed the ill person as having negative attributes were less likely to encourage professional help-seeking. Findings from this review supported this. Franz et al 62 reported carers delaying help-seeking due to fear of stigma. In some instances carers' own extreme negative views of mental illness meant they did not recognise their own relatives' experience as signifying illness, resulting in delayed recognition. ${ }^{70}$

Various studies reported a culturally diverse group of participants and did not allude to any differences regarding impact of beliefs on illness recognition or help-seeking. These included Champion ${ }^{66}$ (UK), Tanskanen et al ${ }^{28}$ (UK), Gerson et al61 (USA) and Cadario et al ${ }^{31}$ (NZ). Whilst it is possible that the collection and analysis of data in these studies was less sensitive to these issues, one paper, Cadario et al, ${ }^{31}$ explicitly referred to participants' beliefs, acknowledging that spiritual help was sought by both Maori and non-Maori families. Other studies reported extremely negative views held by carers. These included Franz et al62 (USA), Monterio et al70 (Brazil) and Jung ${ }^{71}$ (Korea). Perhaps the most extreme was found within Jung's ${ }^{71}$ study conducted in Korea. In this study the mothers interviewed described the illness as a "dirty illness", a "shameful illness" and an "illness causing pain to all the family members." $71 p .88$ Donnelly 60 recruited immigrant Korean-American parents in a study conducted in the USA. These participants also reported feeling "guilt" and "shame" at having a mentally ill child. The negative beliefs regarding mental illness identified by the participants in Jung, ${ }^{71}$ Donnelly60 and Monterio et al ${ }^{70}$ appeared to be strongly linked to the participants' cultural and religious beliefs.

Individuals' beliefs impacted on their interpretation of the presenting problems and influenced the choice of help sought. Donnelly60 found that Korean American families initially attributed changes in their relative to unbalanced Chi energy or the Devil, so sought treatment through traditional healing methods or religion. Families expanded their help-seeking to include psychiatric services when the above methods did not lead to resolution and the problems worsened. Monterio et al ${ }^{70}$ (Brazil) reported that participants' negative beliefs about mental 
illness contributed to delayed illness recognition as well as impacted on the type of help sought. They found that whilst seeking religious help did not usually exclude seeking medical treatment "in two cases relatives saw the patient's problem as exclusively spiritual and concerned themselves solely with the spiritual question for a period of one to three years". ${ }^{70 p .108}$

Franz et al 62 were concerned about determining if perceived stigma was a potential factor in treatment delay and prolonged DUP. All participants in the study were African-American and significant concerns regarding stigma were uncovered. Franz et al 62 also referred to the impact of race on stigma. Compton et a $1{ }^{59}$ were concerned with exploring parent/family factors that may impact upon pathways to care. In this study, one of the African-American carers explicitly referred to fears of a negative response from others that they were causally relating to racial discrimination. Ethnicity as a determinant of the pathway to care for people with a FEP was explored within a systematic review conducted by Anderson et al39 in 2010. The authors concluded the various studies identified on this topic were limited in their power to sufficiently explore this determinant. Of the seven papers identified that met criteria for the above review specific to exploring racial determinants, three were found to have no evidence of ethnic difference. The remaining four papers reported variations of increased police involvement, longer treatment-delays and increased compulsory admissions. Anderson et al ${ }^{39}$ suggested further research was warranted to examine the socio-demographic determinants of the pathway to care for individuals with a FEP.

In summary, it is interesting to briefly compare the findings from this review, which primarily includes studies conducted since 2006, to some of the findings from the Northwick Park Study conducted in 1986, almost three decades ago.44 Johnstone et al (1986) ${ }^{44}$ collected data from patients with a first episode of schizophrenia presenting for admission at nine medical centres around London, UK. They found there was often a significant delay between illness onset and treatment and that "the patient whose assessment and admission had gone smoothly was exceptional".44 p.120 Families' lack of knowledge of services, in addition to some health professionals being unsure of appropriate courses of action when the ill relative refused to be seen for assessment, were reported as negatively impacting upon help-seeking and service access. $^{44}$ Perhaps the latter could explain some of the difficulties that continue to be encountered by families when interfacing with health professionals on first contact with services. Some families reported making multiple contacts before successfully accessing appropriate 
treatment for their relative, ${ }^{44}$ which again mirrors the experience of many of the relatives in this review. The above findings are also supported by more recent quantitative studies. ${ }^{45}$ Norman et al $(2004)^{45}$ examined pathways to care for individuals presenting with a FEP in London, Canada, and found that delays in receiving treatment occurred as a result of both delayed help-seeking by the family and delays after contact with a clinician had been established.

The Northwick Park Study acknowledged that the difficulties, for clients presenting with a FEP, in accessing services may in part be due to the nature of the patient's condition. ${ }^{44}$ This statement would relate to the many findings concerned with illness recognition in this review. In conclusion, Johnstone et al ${ }^{44}$ commented that the distress experienced by relatives and the inexperience of health professionals should cause serious concern to those responsible for service provision.

Whilst some of the findings from this review may still align with the Northwick Park study, thirty years forward the information available to explain the early findings is much more detailed, and it is from this detail that recommendations can be made with the hope of minimising the distress experienced by carers and their ill relative during the early stages of help-seeking. It will always be difficult to accurately identify psychotic illness, as highlighted by the common misinterpretations under illness recognition in this review. However it is possible to provide education so that psychotic illness may at least be considered, as well as encourage clinicians to be more proactive in areas of assessment and referral to alternative sources of help if the client does not meet criteria for secondary mental health care.

\section{Conclusion}

The 22 papers included in this review have provided rich textual illustrations of carers' experiences of help-seeking for relatives with a FEP. Two-hundred and thirteen findings were extracted from these papers which formed the basis for the meta-aggregation into the five synthesised findings. Delays in accessing services, as experienced by carers of a relative with a FEP, were found to be at various stages of the help-seeking process including illness recognition, help-seeking and services response. These stages were found to be interrelated and the impact on carers throughout the process was significant. These synthesised findings have been used to inform development of recommendations for clinical practice, research, education and policy development. Each recommendation is assigned a level of credibility 
based on the JBI levels of evidence (Appendix IV). The recommendations detailed below are all considered to be level 2 evidence.

\section{Implications for practice}

- Clinicians need to be more aware of, and sensitive to, carers' beliefs about mental illness to facilitate engagement and inform psycho-education.

- When taking a history from relatives to inform provisional diagnosis and an intervention plan, it is recommended that clinicians ask about the pathway to care and acknowledge the frequent difficulty in recognising early symptoms of a psychotic illness. This is to reduce self-blame frequently reported by relatives.

- If carers present with significant concerns about a relative, but there is no significant evidence of an illness at assessment, it is recommended that clinicians, including GP's, Emergency Department staff and mental health practitioners, give information on signs of a developing psychotic mental illness and other high prevalence mental disorders and encourage further help-seeking if the relatives' concerns persist. Various web-based sites could be utilised for information.

- Assessment needs to be offered for individuals whose relatives are concerned that they may have a developing mental illness. This may be at the primary health care level.

- Clinicians need to offer referral to services that are able to offer support to vulnerable individuals who may not meet the criteria for mental health services. In order to do this clinicians will need to be more aware of available services.

- Services need to offer flexible appointment options, considering time and place, to promote easy access for assessment.

- The emotional and practical impact on carers of a relative with a psychotic illness needs to be acknowledged and assessed individually. Assessment should be offered at initial contact as well as throughout contact with services. Referrals to specialist carer workers and family educational and support groups need to be considered.

- Clinicians need to consider all family member needs and provide assessment and support as appropriate to each individual. This includes those who may not be perceived as having an active caring role, including siblings and children.

- Clinicians need to promote working conjointly with carers and the ill relative from first contact with services. 
- Clinicians need to be aware of carers' 'rights' under their own country's mental health act and be creative regarding how to give information and include the carer so that they feel informed and supported without breaking confidentiality of the ill relative. The aim is to preserve confidentiality of the consumer but still work with and support the family. The clinician could consider referring to carer support agencies, carer forums, or a co-worker within the mental health service.

- GP's need to take an active and primary role in facilitating service access for people with a psychotic illness.

\section{Implications for research}

- Research is needed to review the most effective strategies of reducing stigma relating to mental illness.

- Research to explore the experiences of groups of carers who are 'less heard', including men and children is warranted.

- Research to explore clinicians' responses to those presenting for assessment with a FEP. This could be conducted in various settings e.g. Emergency departments, GP practices and mental health care settings.

- Research on the impact of initial help-seeking experiences and pathways to care on engagement with services and future help-seeking for carers and individuals with a FEP.

\section{Implications for education}

- Community education about possible indicators of a mental illness and where and how to access help is advisable. This should be targeted at high interface places for young people as well as more widely. This could include schools, tertiary educational institutions, sporting clubs and religious organisations. Education strategies should encourage a reduced threshold for seeking help. Education could be face to face, via mainstream media or web-based. Carer and consumer advocates and mental health practitioners could be involved in face to face educational strategies.

- It is recommended carer specialists are involved in providing education to trainee clinicians, MHS, GP's and Emergency Departments regarding the impact experienced 
by relatives of individuals with a psychotic illness.

\section{Implications for policy}

- Funding is required for services that offer a reduced threshold for engaging and working with individuals deemed 'at risk' of developing an illness.

- Carer groups need to be involved in developing policies relating to provision of care for people with a psychotic illness, as well as service development and review of mental health services.

- Greater equity is needed in service provision for individuals experiencing a FEP who are unable to access specialist services, due to age restrictions or lack of availability.

\section{Conflict of Interest}

There are no conflicts of interest.

\section{Limitations}

It is noted that many papers refer to family members as 'relative' rather than 'carer'. Certainly in the early stages of experiencing a family member developing a psychotic illness, it is unlikely that people would identify with the term 'carer'. A broad range of alternatives to carer was included in the logic grids for each search engine used to identify relevant literature for this review. This should mean the majority of relevant studies were identified during the search; however it is still possible the search may have missed some studies. In hindsight, the author may have chosen 'relative' in place of 'carer' when writing the report as this would perhaps speak more directly to a broader range of participants. The terms have been used interchangeably throughout the paper with the author attempting to remain true to how each paper described their participants. The limitation however is really one of semantics.

Many of the studies, both included and excluded from this review, explored the experience of carers after accessing services. This was outside the scope of this study, though the importance of first contact with services on engagement and future help-seeking is acknowledged. Many 
people with a psychotic illness will have further episodes so first contact experiences are likely to inform future help-seeking and engagement with mental health services.

A further limitation relates to the studies considered for inclusion in this review being those written in English only. This may mean some studies were missed, though a broad representation of countries was still obtained for this systematic review. 


\section{References}

1. Jablensky A, Sartorius N, Ernberg G, Anker M, Korten A, Cooper JE, Day R, Bertelsen A. Schizophrenia: manifestations, incidence and course in different cultures. A World Health Organization ten-country study. Psychological Medicine Monograph Supplement 1992; 20:1-97.

2. Morgan VA, Waterreus A, Jablensky AV, Mackinnon A, McGrath J, Carr V, Bush R, Castle D, Cohen M, Harvey C, Galletly C, Stain H, Neil A, McGorry P, Hocking B, Shah S, Saw S. People living with psychotic illness 2010. Report on the second Australian national survey. Australian Government. Department of Health and Ageing. [cited May 12 2012]. Available from: http://health.gov.au/internet/main/publishing.nsf/Content/mental-pubs-p-psych10

3. Marshall M, Lewis S, Lockwood A, Drake R, Jones P, Croudace T. Association between duration of untreated psychosis and in cohorts of first-episode outcome patients - a systematic review. Archives of General Psychiatry 2005; 62 (9): 975-983.

4. Addington J, Van Mastrigt S, Hutchinson J, Addington D. Pathways to care: help seeking behaviour in first episode psychosis. Acta Psychiatrica Scandinavica 2002; 106(5): 358-364.

5. Birchwood M, Todd $P$, Jackson C. Early intervention in psychosis: the critical-period hypothesis. International Clinical Psychopharmacology 1998; 13. S31-S40.

6. Carr VJ, Neil AL, Halpin SA, Holmes S, Lewin TJ. Costs of schizophrenia and other psychoses in urban Australia: Findings from the Low Prevalence (Psychotic) Disorders Study. Australian and New Zealand Journal of Psychiatry 2003; 37(1):31-40.

7. Ten year roadmap for national mental health reform: draft. 2012. Australian Government. Department of Health and Ageing. [cited May 12 2012]; Available from: http://www.health.gov.au/internet/main/publishing.nsf/Content/mental-pubs-t-roadmap.

8. McGorry P, Killackey E, Lambert T, Lambert M, Jackson H, Codyre D, Codyre D, James N, Pantelis C, Pirkis J, Jones P, Durie MA., McGrath J, McGlashan T, Malla A, Farhall J, Hermann $\mathrm{H}$, Hocking B. Royal Australian and New Zealand College of Psychiatrists clinical practice 
guidelines for the treatment of schizophrenia and related disorders. The Australian and New Zealand Journal of Psychiatry. 2005; 39(1-2):1-30.

9. NICE Clinical Guidelines for Schizophrenia. Core interventions in the treatment and management of schizophrenia in adults in primary and secondary care. UK. 2009. [cited May 12 2012]. Available from: http://www.nice.org.uk/CG82

10. Addington J, Amminger AG, Barbato A, Catts S, Chen E, Chhim S, Chong SA, Cullberg J, Edwards J, Grosso L, Louzã M, Hambrecht M, Keshavan M, Johannessen JO, Johnson DL, Lewis S, Lieberman J, MacEwan W, Malla A, May R, McGlashan TH, McGorry P, Merlo MG, Nordentoft M, Nightingale S, Perkins D, Thara R, Yamamoto K, Yung A. International clinical practice guidelines for early psychosis. International Early Psychosis Association Writing Group. The British Journal of Psychiatry. 2005;187:s120-s124.

11. The Joanna Briggs Institute 2011. The Joanna Briggs Institute Reviewers' Manual 2011 Edition, Adelaide, The Joanna Briggs Institute.

12. Pearson A, Wiechula R, Court A, Lockwood C. The JBI model of evidence-based healthcare. International Journal of Evidence Based Healthcare 2005; 3:207-15.

13. Sackett DL, Rosenberg WM, Gray JA, Haynes RB, Richardson WS. Evidence based medicine: what it is and what it isn't. 1996. Clinical Orthopaedics and Related Research 2007; 455:3-5.

14. Noyes J. Never mind the qualitative feel the depth! The evolving role of qualitative research in Cochrane intervention reviews. Journal of Research in Nursing. 2010; 15(6):525-34.

15. Lockwood C. Critiquing the contested nature of aggregation in qualitative evidence synthesis: an examination of the dominant vies on Interpretivism. Unpublished thesis 2011:1-168.

16. American Psychiatric Association. Diagnostic and statistical manual of mental disorders fourth edition- text revision. 2000. 
17. Yung AR, McGorry PD. The initial prodrome in psychosis: descriptive and qualitative aspects. The Australian and New Zealand Journal of Psychiatry 1996; 30(5):587-99.

18. McGorry PD, Yung AR, Phillips LJ. The "close-in" or ultra high-risk model: a safe and effective strategy for research and clinical intervention in prepsychotic mental disorder. Schizophrenia Bulletin 2003; 29(4):771-90.

19. Harris A, Brennan J, Anderson, J, Taylor A, Sanbrook M, Fitzgerald D, Lucas S, RedobladoHodge A, Gomes L, Gordon E. Clinical profiles, scope and general findings of the Western Sydney first episode psychosis project. Australian and New Zealand Journal of Psychiatry 2005; 39(1-2): 36-43.

20. Castle DJ. The truth, and nothing but the truth, about early intervention in psychosis. The Australian and New Zealand Journal of Psychiatry 2012; 46(1):10-3.

21. Harrison G, Hopper K, Craig T, Laska E, Siegel C, Wanderling J, Dube KC, Ganev K, Giel R, An der Heiden W, Holmberg SK, Janca A, Lee PWH, Leon CA., Malhotra S, Marsella AJ, Nakane Y, Sartorius N, Shen Y, Skoda C, Thara R, Tsirkin SJ, Varma VK, Walsh D, Wiersma D. Recovery from psychotic illness: a 15- and 25-year international follow-up study. The British Journal of Psychiatry 2001; 178: 506-517.

22. Organization WH. The World Health Report: Mental Health: new understanding, new hope. 2001. [cited Aug 8 2013] Available from: http://www.who.int/whr/2001/en/

23. Reading B, Birchwood M. Early intervention in psychosis - rationale and evidence for effectiveness. Disease Management \& Health Outcomes 2005; 13(1):53-63.

24. Orygen Youth Health Research Centre. Early psychosis feasibility study report. Australian Government. Department of Health and Ageing.; 2011 [cited 2012 May 12] Available from: http://www.health.gov.au/internet/main/publishing.nsf/Content/mental-pubs-e-earlypsy.

25. Singh SP, Grange T. Measuring pathways to care in first-episode psychosis: a systematic review. Schizophrenia Research 2006; 81(1):75-82. 
26. Joa I, Johannessen JO, Auestad B, Friis S, McGlashan T, Melle I, Opjordsmoen S, Simonsen E, Vaglum $P$, Larsen TK. The key to reducing duration of untreated first psychosis: information campaigns. Schizophrenia Bulletin 2008; 34(3):466-72.

27. Hegelstad W, Larsen TK, Auestad B, Evensen J, Haahr U, Joa I, Johannesen JO, Langeveld J, Melle I, Opjordsmoen S, Rossberg JI, Rund BR, Simonsen E, Sundet K, Vaglum P, Friis S, McGlashan T. Long-term follow-up of the TIPS early detection in psychosis study: effects on 10-year outcome. The American Journal of Psychiatry 2012; 169(4):374-80.

28. Tanskanen S, Morant N, Hinton M, Lloyd-Evans B, Crosby M, Killaspy H, Raine R, Pilling S, Johnson S. Service user and carer experiences of seeking help for a first episode of psychosis: a UK qualitative study. BMC Psychiatry 2011; 11: 157.

29. Addington J, Coldham EL, Jones B, Ko T, Addington D. The first episode of psychosis: the experience of relatives. Acta Psychiatrica Scandinavica 2003; 108(4):285-9.

30. Czuchta DM, McCay E. Help-seeking for parents of individuals experiencing a first episode of schizophrenia. Archives of Psychiatric Nursing 2001;15(4):159-70.

31. Cadario E, Stanton J, Nicholls P, Crengle S, Wouldes T, Gillard M, Merry SN. A qualitative investigation of first-episode psychosis in adolescents. Clinical Child Psychology and Psychiatry 2012; 17(1):81-102.

32. Melle I, Johannessen JO, Friis S, Haahr U, Joa I, Larsen TK., Opjordsmoen S, Rund BR, Simonsen E, Vaglum P, McGlashan T. Course and predictors of suicidality over the first two years of treatment in first-episode schizophrenia spectrum psychosis Archives of Suicide Research 2010; 14 (2): 158-170.

33. Hawton K, Sutton L, Haw C, Sinclair J, Deeks JJ. Schizophrenia and suicide: systematic review of risk factors. The British Journal of Psychiatry 2005; 187:9-20. 
34. Gerson R, Wong C, Davidson L, Malaspina D, McGlashan T, Corcoran C. Self-reported coping strategies in families of patients in early stages of psychotic disorder: an exploratory study. Early Intervention in Psychiatry 2011; 5(1):76-80.

35. Fortune DG, Smith JV, Garvey K. Perceptions of psychosis, coping, appraisals, and psychological distress in the relatives of patients with schizophrenia: an exploration using selfregulation theory. The British Journal of Clinical Psychology 2005; 44:319-31.

36. Amos A. Assessing the cost of early intervention in psychosis: A systematic review. Australian and New Zealand Journal of Psychiatry 2012; 46(8):719-34.

37. Marshall M. and Rathbone J. Early intervention for psychosis. Cochrane Database of Systematic Reviews 2011. [cited 2012 Apr 4]. Available from: http://onlinelibrary.wiley.com/doi/10.1002/14651858.CD004718.pub3/abstract;jsessionid=4082C D37A89D63FBF033852CAA918188.d03t01

38. Singh SP. Outcome measures in early psychosis - relevance of duration of untreated psychosis. The British Journal of Psychiatry 2007; 191:S58-S63.

39. Anderson KK, Fuhrer R, Malla AK. The pathways to mental health care of first-episode psychosis patients: a systematic review. Psychological Medicine 2010; 40(10):1585-97.

40. Rickwood D, Deane FP, Wilson CJ, Ciarrochi J. Young people's help-seeking for mental health problems. Australian e-Journal for the Advancement of Mental Health 2005; 4(3).

41. Jorm AF. Mental health literacy: empowering the community to take action for better mental health. American Psychologist 2012; 67(3):231-43.

42. O'Callaghan E, Turner N, Renwick L, Jackson D, Sutton M, Foley SD, McWilliams S, Behan C, Fetherstone A, Kinsella A. First episode psychosis and the trail to secondary care: helpseeking and health-system delays. Social Psychiatry and Psychiatric Epidemiology 2010; 45(3):381-91. 
43. Wilson CJ, Bushnell JA, Caputi P. Early access and help seeking: practice implications and new initiatives. Early Intervention in Psychiatry 2011; 5:34-9.

44. Johnstone EC, Crow TJ, Johnson AL, Macmillan JF. The Northwick Park Study of 1st Episodes of Schizophrenia. 1. Presentation of the illness and problems relating to admission. British Journal of Psychiatry 1986; 148:115-20.

45. Norman RM, Malla AK, Verdi MB, Hassall LD, Fazekas C. Understanding delay in treatment for first-episode psychosis. Psychological Medicine 2004; 34(2):255-66.

46. Corcoran C, Gerson R, Sills-Shahar R, Nickou C, McGlashan T, Malaspina D, Davidson, L. Trajectory to a first episode of psychosis: a qualitative research study with families. Early Intervention in Psychiatry 2007; 1(4):308-15.

47. McCann TV, Lubman DI, Clark E. First-time primary caregivers' experience accessing firstepisode psychosis services. Early Intervention in Psychiatry 2011; 5(2):156-62.

48. Lincoln CV, McGorry P. Who cares? - pathways to psychiatric-care for young-people experiencing a first episode of psychosis. Psychiatric Services 1995; 46(11):1166-71.

49. Bergner E, Leiner AS, Carter T, Franz L, Thompson NJ, Compton MT. The period of untreated psychosis before treatment initiation: a qualitative study of family members' perspectives. Comprehensive Psychiatry 2008; 49(6):530-6.

50. Judge AM, Estroff SE, Perkins DO, Penn DL. Recognizing and responding to early psychosis: a qualitative analysis of individual narratives. Psychiatric Services 2008; 59(1):96-9.

51. lenciu M, Romosan F, Bredicean C, Romosan R. First episode psychosis and treatment delay- causes and consequences. Psychiatria Danubina 2010; 22(4):540-3.

52. Pearson A, Jordan, Z., Munn, Z. Translational Science and Evidence-Based Healthcare: A Clarification and Reconceptualization of How Knowledge Is Generated and Used in Healthcare. Nursing Research and Practice 2012: (2012)1-6. 
53. Breitborde NJK, Srihari VH, Woods SW. Review of the operational definition for firstepisode psychosis. Early Intervention in Psychiatry 2009; 3(4):259-65.

54. NHS Choices. All about caring [cited 12/08/13]. Available from: http://www.nhs.uk/CarersDirect/carerslives/aboutcaring/Pages/Whatisacarer.aspx

55. Carers Australia. About carers. [cited 12/08/13]. Available from: http://www.carersaustralia.com.au/about-carers/

56. Bero LA, Grilli R, Grimshaw JM, Harvey E, Oxman AD, Thomson MA. Getting research findings into practice. Closing the gap between research and practice: An overview of systematic reviews of interventions to promote the implementation of research findings. British Medical Journal 1998; 317(7156):465-8.

57. Hannes K, Lockwood, C., Pearson, A. A Comparative Analysis of Three Online Appraisal Instruments' Ability to Assess Validity in Qualitative Research. Qualitative Health Research 2010:1-8.

58. The Joanna Briggs Institute. SUMARI User Manuel: Version 5.0 System for the Unified Management, Assessment and Review of Information. 2011. Adelaide, The Joanna Briggs Institute.

59. Compton MT, Kaslow NJ, Walker EF. Observations on parent/family factors that may influence the duration of untreated psychosis among African American first-episode schizophrenia-spectrum patients. Schizophrenia Research 2004; 68(2-3):373-85.

60. Donnelly PL. Mental health beliefs and help seeking behaviors of Korean American parents of adult children with schizophrenia. Journal of Multicultural Nursing \& Health 2005; 11(2):23-34.

61. Gerson R, Davidson L, Booty A, Wong C, McGlashan T, Malespina D, et al. Families' experience with seeking treatment for recent-onset psychosis. Psychiatric Services. 2009;60(6):812-6. 
62. Franz L, Carter T, Leiner AS, Bergner E, Thompson NJ, Compton MT. Stigma and treatment delay in first-episode psychosis: A grounded theory study. Early Intervention in Psychiatry 2010; $4(1): 47-56$.

63. Barker S, Lavender T, Morant N. Client and family narratives on schizophrenia. Journal of Mental Health 2001; 10(2):199-212.

64. Pearse WA. A qualitative study exploring relatives' experience of seeking help for a person during the early stages of schizophrenia. Unpublished thesis 1998; Open University (United Kingdom)(1):1-100.

65. McKenzie LH. Service users and carers' experiences of a psychosis service. Journal of Psychiatric and Mental Health Nursing 2006; 13(6):636-40.

66. Champion S. Exploring the pathways into care for young people aged $14--35$ years with a first episode psychosis. Unpublished thesis 2007; University of Essex (United Kingdom)(1):1100.

67. Barnable A, Gaudine A, Bennett L, Meadus R. Having a sibling with schizophrenia: a phenomenological study. Research and Theory for Nursing Practice 2006; 20(3):247-64.

68. Dodge CE. Caregiving and Schizophrenia: The Well Siblings' Perspective. Unpublished thesis. 2011; University of Victoria (Canada)(1):1-100.

69. Redko C. Religious construction of a first episode of psychosis in urban Brazil. Transcultural Psychiatry 2003; 40(4):507-30.

70. Monteiro VBM, Dos Santos JQ, Martin D. Patients' relatives delayed help seeking after a first psychotic episode. Revista Brasileira de Psiquiatria. 2006; 28(2):104-10.

71. Jung M. Lives of two Korean mothers of children with schizophrenia: An interpretive approach. Journal of the American Psychiatric Nurses Association 2000; 6(3):87-92. 
72. Jungbauer J, Angermeyer MC. Living with a schizophrenic patient: A comparative study of burden as it affects parents and spouses. Psychiatry-Interpersonal and Biological Processes 2002; 65(2):110-23.

73. Wong DFK. Crucial individuals in the help-seeking pathway of Chinese caregivers of relatives with early psychosis in Hong Kong. Social Work 2007; 52(2):127-35.

74. Mizuno E, Iwasaki M, Sakai I. Subjective experiences of husbands of spouses with schizophrenia: an analysis of the husbands' descriptions of their experiences. Archives of Psychiatric Nursing 2011; 25(5):366-75.

75. Johannessen JO, Larsen TK, Joa I, Melle I, Friis S, Opjordsmoen S, Rund, BR, Simonsen, E, Vaglum, P, McGlashan, TH . Pathways to care for first-episode psychosis in an early detection healthcare sector: part of the Scandinavian TIPS study. The British Journal of Psychiatry Supplement 2005; 48:s24-8.

76. Anderson KK, Fuhrer R, Malla AK. "There are too many steps before you get to where you need to be": Help-seeking by patients with first-episode psychosis. Journal of Mental Health 2013; 22(4):384-95.

77. Andrulis DP, Brach C. Integrating literacy, culture, and language to improve health care quality for diverse populations. American Journal of Health Behavior 2007; 31(SUPPL. 1):s122s33.

78. Jorm AF, Blewitt KA, Griffiths KM, Kitchener BA, Parslow RA. Mental health first aid responses of the public: results from an Australian national survey. BMC Psychiatry. 2005; 5:9. 


\section{Appendices}

\section{Appendix I: Search strategy}

\section{PubMed Search Strategy}

\begin{tabular}{|c|c|}
\hline String 1 & $\begin{array}{l}\text { Caregivers[mh] OR Caregiver*[tw] OR (Care Giver*)[tw] OR (Care-giver*)[tw] OR Carer*[tw] OR } \\
\text { Family[mh] OR Family[tw] OR Families[tw] OR Spouse*[tw] OR Sibling*[tw] OR Brother*[tw] OR } \\
\text { Sister*[tw] OR Husband*[tw] OR Wife[tw] OR Wives[tw] OR relative*[tw] OR parents[tw] }\end{array}$ \\
\hline \multicolumn{2}{|l|}{ AND } \\
\hline String 2 & $\begin{array}{l}\text { Schizophrenia and disorders with psychotic features[mh] OR Psychotic[tw] OR Psychosis[tw] OR } \\
\text { Schizoph^־tw] }\end{array}$ \\
\hline
\end{tabular}

AND

\begin{tabular}{|c|c|}
\hline String 3 & $\begin{array}{l}\text { Qualitative research[mh] OR qualitative[tw] OR (Grounded theory)[tw] OR Phenomenol*[tw] OR } \\
\text { Ethnog*[tw] OR (Action research)[tw] OR (Mixed-methods) [tw] OR (mixed methods)[tw] OR narrative*[tw] } \\
\text { OR experience* }{ }^{*} \text { tw] OR interview*[tw] OR (discourse analysis)[tw] OR (focus group*)[tw] OR descript*[tw] } \\
\text { OR opinion*[tw] OR attitude*[tw] }\end{array}$ \\
\hline
\end{tabular}

\section{CINAHL Search Strategy}

\begin{tabular}{|l|l|}
\hline String 1 & MH Caregiver+ OR TI Caregiver* OR AB Caregiver* OR MH Family+ OR TI Family OR AB Family OR TI \\
Families OR AB Families OR TI Sibling* OR AB Sibling* OR MH Parents OR TI Parents OR AB Parents \\
OR TI Spouse* OR AB Spouse* OR TI Brother* OR AB Brother* OR TI Sister* OR AB Sister* OR TI \\
Husband* OR AB Husband* OR TI Wife OR AB Wife OR TI Wives OR AB Wives OR TI Relatives OR AB \\
Relatives OR TI "care-giver” OR AB "care-giver" OR TI "Care giver”" OR AB "Care giver”" OR AB carer* \\
OR TI carer*
\end{tabular}

AND

\begin{tabular}{|l|l|}
\hline String 2 & $\begin{array}{l}\text { MH Psychotic disorders OR TI Psychosis OR AB Psychosis OR TI Psychotic OR AB Psychotic OR TI } \\
\text { Schizophr* OR AB Schizophr* }\end{array}$ \\
\hline
\end{tabular}

\section{AND}

\begin{tabular}{|l|l|}
\hline String 3 & $\begin{array}{l}\text { MH Qualitative studies+ OR TI Qualitative OR AB Qualitative OR TI experience* OR AB Experience* OR } \\
\text { TI 'Mixed-methods' OR AB 'Mixed- Methods' OR TI 'mixed methods' OR AB 'mixed methods' OR TI } \\
\text { narrative* OR AB narrative*OR TI interview* OR AB interview* OR TI 'discourse analysis' OR AB } \\
\text { 'discourse analysis' OR TI " focus group*" OR AB "focus group" OR TI descript* OR AB descript* OR TI } \\
\text { opinion* OR AB opinion*OR TI attitude* OR AB attitude* OR TI phenomenol* OR AB phenomenol* OR TI } \\
\text { ethnog* OR AB ethnog* OR TI "action research" OR AB "action research" OR TI "grounded theory" OR AB } \\
\text { "grounded theory" }\end{array}$ \\
\hline
\end{tabular}




\section{Scopus Search Strategy}

\begin{tabular}{|c|c|}
\hline String 1 & 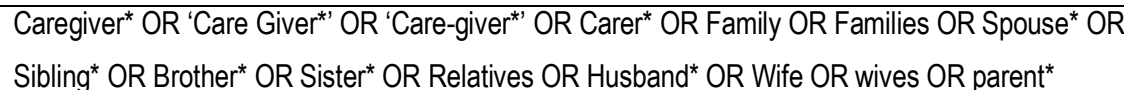 \\
\hline
\end{tabular}

AND

String 2 Schizophrenia OR Psychotic OR Psychosis OR Schizophr ${ }^{*}$

AND

String 3

'Qualitative research' OR Qualitative OR ‘Grounded theory' OR Phenomenol` OR Ethnog* OR 'Action research' OR 'Mixed-methods' OR 'mixed methods' OR Experience* OR narrative* OR interview* OR 'discourse analysis' OR 'focus group*' OR descript* OR opinion* OR attitude*

\section{Embase Search Strategy}

\begin{tabular}{|l|l|}
\hline String 1 & Caregiver:ti,ab,de OR “Caregiver burden":ti,ab,de OR "care giver":ti,ab OR "care givers":ti,ab OR \\
& Family:ti,ab,de OR Families:ti,ab OR Spouse:ti,ab,de OR Spouses:ti,ab OR Sibling:ti,ab,de OR \\
& $\begin{array}{l}\text { siblings:ti,ab OR Brother:ti,ab OR Brothers:ti,ab OR Sister:ti,ab OR sisters:ti,ab OR Husband:ti,ab OR } \\
\text { husbands:ti,ab OR Wife:ti,ab OR Wives:ti,ab OR Parents:ti,ab }\end{array}$ \\
\hline
\end{tabular}

AND

\begin{tabular}{|l|l|}
\hline String 2 & Psychosis:ti,ab,de OR Schizophrenia:ti,ab,de OR schizophreniform:ti,ab OR psychotic:ti,ab
\end{tabular}

AND

\begin{tabular}{|l|l|}
\hline String 3 & "Qualitative research":ti,ab,de OR “Grounded theory":ti,ab,de OR Phenomenology :ti,ab,de OR \\
& Ethnography:ti,ab,de OR "Action research":ti,ab,de OR "Mixed-methods":ti,ab OR "mixed methods":ti,ab \\
& OR narrative:ti,ab,de OR narratives:ti,ab OR Experience:ti,ab,de OR experiences:ti,ab OR interview:ti,ab \\
& OR interviews:ti,ab OR "discourse analysis":ti,ab OR "focus group":ti,ab OR "focus groups":ti,ab OR \\
& Descriptions:ti,ab OR Opinions:ti,ab OR Attitude:ti,ab OR attitudes:ti,ab OR descriptive:ti,ab
\end{tabular}

\section{PsycINFO Search Strategy}

\begin{tabular}{|l|l|}
\hline String 1 & DE Caregivers OR TI Caregiver* OR AB Caregiver* OR DE Family OR TI Family OR AB Family OR DE \\
& Sibling OR TI Sibling* OR AB Sibling* OR DE Spouses OR TI Spouse* OR AB Spouse* OR TI relative* OR \\
& AB relative* OR TI Care-giver* OR AB Care-giver* OR TI care giver OR AB care giver OR TI Carer* OR \\
& AB Carer OR TI Families OR AB Families OR TI Sibling* OR AB Sibling* OR TI Brother* OR AB Brother* \\
& OR TI Sister* OR AB Sister* OR TI Husband* OR AB Husband* OR TI Wife OR AB Wife OR TI Wives OR \\
& AB Wives OR TI parents OR AB parents \\
\hline
\end{tabular}

AND

\begin{tabular}{|l|l|}
\hline String 2 & $\begin{array}{l}\text { DE Psychosis OR DE schizophrenia OR TI Psychotic OR AB Psychotic OR TI Psychosis OR AB Psychosis } \\
\text { OR TI Schizoph** OR AB Schizophr* }\end{array}$ \\
\hline
\end{tabular}


AND

\begin{tabular}{|l|l|}
\hline String 3 & DE "Experience level" OR TI Qualitative OR AB Qualitative OR DE "Qualitative research" OR DE \\
Phenomenology OR TI Phenomenol* OR AB Phenomenol* OR DE Ethnography OR TI Ethnog* OR AB \\
Ethnog* OR DE 'Action research' OR TI "Action research" OR AB "Action research" OR TI "Mixed-methods" \\
OR AB "Mixed-methods" OR TI "mixed methods" OR AB "mixed methods" OR TI narrative* OR AB \\
narrative* OR TI experience* OR AB experience* OR TI interview* OR AB interview* OR TI 'discourse \\
analysis' OR AB 'discourse analysis' OR TI "focus group* OR AB "focus group*" OR TI descript* OR AB \\
descript* OR TI opinion* OR AB opinion* OR TI attitude* OR AB attitude* OR TI "grounded theory" OR AB \\
"grounded theory"
\end{tabular}

\section{ProQuest Search Strategy}

(caregiver ${ }^{*}$ OR relatives OR carer*) AND (psychosis OR schizophrenia) AND (experience* OR qualitative OR opinion* OR attitude*) - abstract

\section{MEDNAR Search Strategy}

(Caregiver* OR relatives OR carer*) AND (psychosis OR schizophrenia) AND ('help seeking')

\section{Trove Search Strategy}

Psychosis AND help seeking thesis

Psychosis AND experience AND caregiver* thesis 
Appendix II: Appraisal instruments

QARI Appraisal instrument

\section{JBI QARI Critical Appraisal Checklist for Interpretive \& Critical Research}

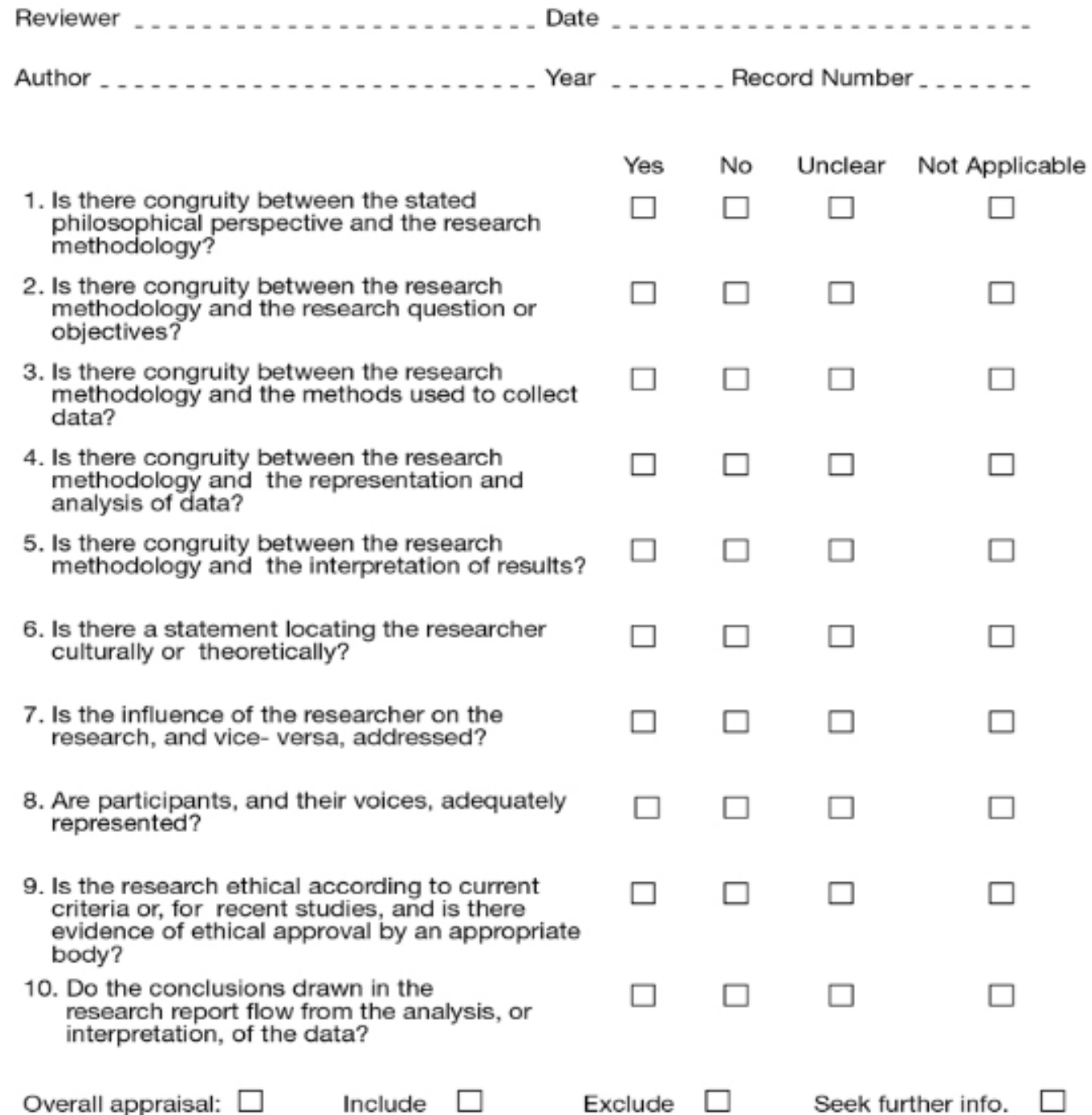

Comments (Including reason for exclusion) 
Appendix III: Data extraction instruments

QARI data extraction instrument

\section{JBI QARI Data Extraction Form for Interpretive \& Critical Research}

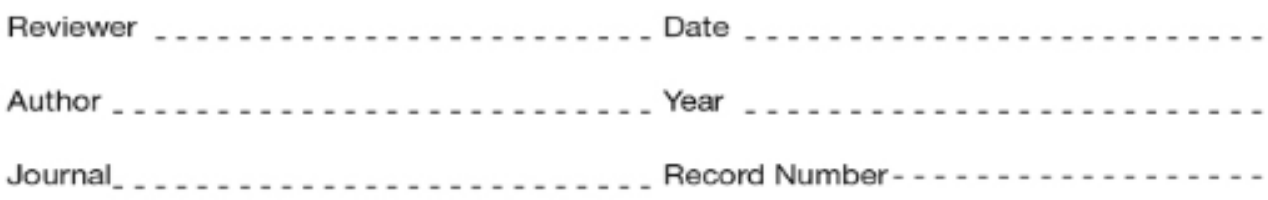

Study Description

Methodology

Method

Phenomena of interest

Setting

Geographical

Cultural

Participants

Data analysis

Authors Conclusions

Comments

Complete

Yes $\square$

No $\square$ 


\begin{tabular}{|l|l|l|l|l|}
\hline \multirow{2}{*}{ Findings } & \multirow{2}{*}{$\begin{array}{c}\text { Illustration from } \\
\text { Publication } \\
\text { (page number) }\end{array}$} & Unequivocal & Credible & Unsupported \\
\hline & & & & \\
\hline & & & & \\
\hline & & & & \\
\hline & & & & \\
\hline & & & & \\
\hline & & & & \\
\hline & & & & \\
\hline & & & & \\
\hline & & & & \\
\hline & & & & \\
\hline & & & & \\
\hline & & & & \\
\hline
\end{tabular}

Extraction of findings complete

Yes $\square$

No $\square$ 


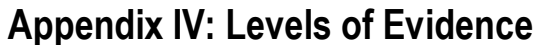 \\ Levels of Evidence FAME}

The Joanna Briggs Institute, its Collaborating Centres and Evidence Translation Groups currently assign a level of evidence to all conclusions drawn in JBI Systematic Reviews.

The JBI Levels of Evidence are:

\begin{tabular}{|c|c|c|c|c|c|}
\hline $\begin{array}{l}\text { Levels of } \\
\text { Evidence }\end{array}$ & Feasibility $F(1-4)$ & Appropriateness A(1-4) & Meaningfulness M(1-4) & Effectiveness $\mathrm{E}(1-4)$ & Economic Evidence \\
\hline 1 & $\begin{array}{l}\text { Metasynthesis of } \\
\text { research with } \\
\text { unequivocal synthesised } \\
\text { findings }\end{array}$ & $\begin{array}{l}\text { Metasynthesis of research } \\
\text { with unequivocal } \\
\text { synthesised findings }\end{array}$ & $\begin{array}{l}\text { Metasynthesis of research } \\
\text { with unequivocal } \\
\text { synthesised findings }\end{array}$ & $\begin{array}{l}\text { Meta-analysis(with homogeneity) of experimental } \\
\text { studies (eg RCT with concealed randomisation) } \\
\text { OR One or more large experimental studies with } \\
\text { narrow confidence intervals }\end{array}$ & $\begin{array}{l}\text { Metasynthesis (with homogeneity) of evaluations of } \\
\text { important alternative interventions comparing all clinically } \\
\text { relevant outcomes against appropriate cost measurement, } \\
\text { and including a clinically sensible sensitivity analysis }\end{array}$ \\
\hline 2 & $\begin{array}{l}\text { Metasynthesis of } \\
\text { research with credible } \\
\text { synthesised findings }\end{array}$ & $\begin{array}{l}\text { Metasynthesis of research } \\
\text { with credible synthesised } \\
\text { findings }\end{array}$ & $\begin{array}{l}\text { Metasynthesis of research } \\
\text { with credible synthesised } \\
\text { findings }\end{array}$ & $\begin{array}{l}\text { One or more smaller RCTs with wider confidence } \\
\text { intervals OR Quasi-experimental studies(without } \\
\text { randomisation) }\end{array}$ & $\begin{array}{l}\text { Evaluations of important alternative interventions comparing } \\
\text { all clinically relevant outcomes against appropriate cost } \\
\text { measurement, and including a clinically sensible sensitivity } \\
\text { analysis }\end{array}$ \\
\hline 3 & $\begin{array}{l}\text { a. Metasynthesis of } \\
\text { text/opinion with credible } \\
\text { synthesised findings } \\
\text { b. One or more single } \\
\text { research studies of high } \\
\text { quality }\end{array}$ & $\begin{array}{l}\text { a. Metasynthesis of } \\
\text { text/opinion with credible } \\
\text { synthesised findings } \\
\text { b. One or more single } \\
\text { research studies of high } \\
\text { quality }\end{array}$ & $\begin{array}{l}\text { a. Metasynthesis of } \\
\text { text/opinion with credible } \\
\text { synthesised findings } \\
\text { b. One or more single } \\
\text { research studies of high } \\
\text { quality }\end{array}$ & $\begin{array}{l}\text { a. Cohort studies (with control group) } \\
\text { b. Case-controlled } \\
\text { c. Observational studies(without control group) }\end{array}$ & $\begin{array}{l}\text { Evaluations of important alternative interventions comparing } \\
\text { a limited number of appropriate cost measurement, without } \\
\text { a clinically sensible sensitivity analysis }\end{array}$ \\
\hline 4 & Expert opinion & Expert opinion & Expert opinion & Expert opinion, or physiology bench research, or & Expert opinion, or based on economic theory \\
\hline
\end{tabular}




\begin{tabular}{|l|l|l|l|l|}
\hline & consensus \\
\hline
\end{tabular}

\section{History of Levels of Evidence}

From 2003-2004 The Joanna Briggs Institute used the levels of evidence from Australian National Health \& Medical Research Council - NHMRC Development, implementation and evaluation for clinical practice guidelines published in 1999. These levels assess the validity of recommendations for clinical guidelines and focuses, understandably, on the effectiveness of treatment. As The Joanna Briggs Institute has a broader definition of what constitutes evidence, a more inclusive approach to the development and grading of levels of evidence and implications for practice was later developed. Until 2003 the Institute used the levels of evidence as specified by the NHMRC 1995 Guidelines for the Development and Implementation of Clinical Practice Guidelines.

Available from: http://joannabriggs.org/Levels\%20of\%20Evidence\%20\%20FAME 


\section{Appendix V: Included studies}

\begin{tabular}{|c|c|c|c|c|c|}
\hline Study & Methods & Participants & Intervention & Outcomes & Notes \\
\hline $\begin{array}{c}\text { Barker, S., T. Lavender, T., } \\
\text { Morant, N., } 2001\end{array}$ & $\begin{array}{l}\text { Semi-structured face to face } \\
\text { interviews with open-ended } \\
\text { questions. Interviews were in } \\
\text { participants' homes, lasted } 40 \\
\text { to } 80 \text { minutes, were taped- } \\
\text { recorded and transcribed } \\
\text { verbatim. }\end{array}$ & $\begin{array}{l}\text { Eight clients of psychiatric } \\
\text { services and } 8 \text { close relatives. } \\
\text { The sample of clients } \\
\text { consisted of } 6 \text { men and } 2 \\
\text { women, aged 25-50, who had } \\
\text { a diagnosis of schizophrenia. } \\
\text { They were living in a hospital, } \\
\text { hostel or supported } \\
\text { accommodation. Relatives } \\
\text { included } 6 \text { mothers and } 2 \\
\text { fathers of clients. }\end{array}$ & $\begin{array}{l}\text { To explore the narratives used } \\
\text { by clients and family members } \\
\text { to explain the process of } \\
\text { developing schizophrenia. }\end{array}$ & $\begin{array}{l}\text { The narratives produced a } \\
\text { temporal model of the } \\
\text { experience of schizophrenia } \\
\text { over time. Four stages are } \\
\text { described: before the first } \\
\text { psychotic episode, the first } \\
\text { psychotic episode, first } \\
\text { hospital admission, and } \\
\text { current experiences. It is } \\
\text { suggested that clients and } \\
\text { family members need } \\
\text { continued support to develop } \\
\text { their understanding of a } \\
\text { complex process traditionally } \\
\text { dismissed as madness. } \\
\text { Implications for clinical work } \\
\text { and services are discussed. }\end{array}$ & $\begin{array}{l}\text { Good description of } \\
\text { methodology. Additional } \\
\text { findings were reported in the } \\
\text { study without data to support } \\
\text { which were therefore unable tc } \\
\text { be included in the review. }\end{array}$ \\
\hline $\begin{array}{c}\text { Barnable, A., Gaudine, A., } \\
\text { Bennett, L., Meadus, R., } 2006\end{array}$ & $\begin{array}{l}\text { A semi structured interview } \\
\text { guide was used and } \\
\text { participants described their } \\
\text { experience without }\end{array}$ & $\begin{array}{l}\text { Six adult siblings ( } 5 \text { females } \\
\text { and } 1 \text { male) who had a brother } \\
\text { or sister with schizophrenia } \\
\text { and met the following inclusion }\end{array}$ & $\begin{array}{l}\text { The lived experience of a } \\
\text { sibling who has a brother or } \\
\text { sister with schizophrenia. }\end{array}$ & $\begin{array}{l}\text { Four themes were identified: } \\
\text { struggling to understand; } \\
\text { struggling with the system; } \\
\text { caring for the sibling; and }\end{array}$ & $\begin{array}{l}\text { No cultural or socioeconomic } \\
\text { diversity. All participants were } \\
\text { white and predominantly } \\
\text { female, which was stated as a }\end{array}$ \\
\hline
\end{tabular}




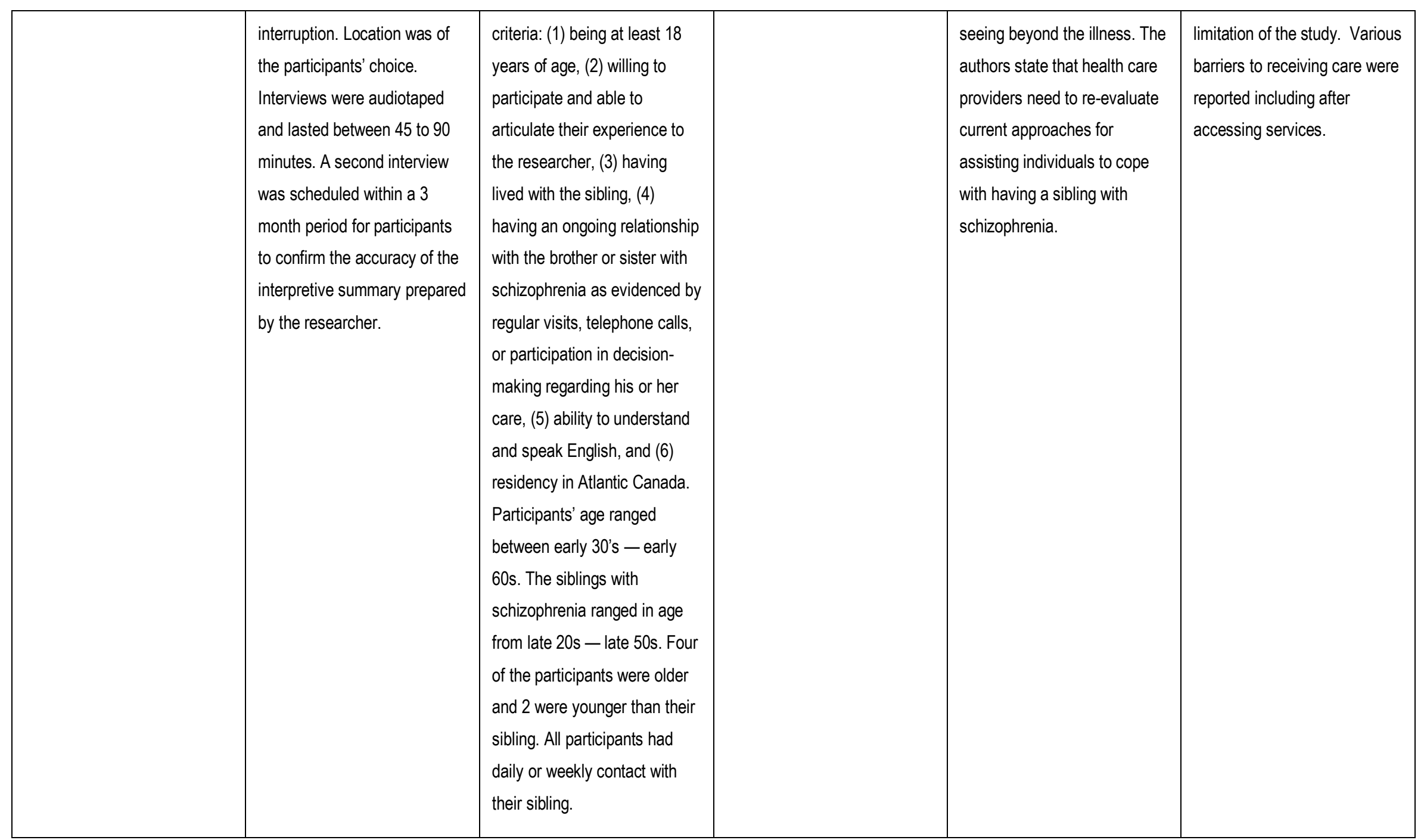




\begin{tabular}{|c|c|c|c|c|c|}
\hline $\begin{array}{c}\text { Bergner, E., Leiner, A. S., } \\
\text { Carter, T., Franz, L., } \\
\text { Thompson, N. J., Compton, M. } \\
\text { T., } 2008\end{array}$ & $\begin{array}{l}\text { Data on clinical status of } \\
\text { patients were obtained from: } \\
\text { Structured Clinical Interview } \\
\text { for DSM-IV Axis I Disorders, } \\
\text { Patient Version (SCID-I/P), the } \\
\text { Positive and Negative } \\
\text { Syndrome Scale (PANSS), } \\
\text { and the Global Assessment of } \\
\text { Functioning (GAF) scale. } \\
\text { Family members participated } \\
\text { in semi-structured interviews. } \\
\text { Interviews were audiotaped } \\
\text { and transcribed verbatim. }\end{array}$ & $\begin{array}{l}\text { Twelve family members } \\
\text { instrumental in seeking } \\
\text { treatment for } 10 \text { hospitalized } \\
\text { first-episode schizophrenia- } \\
\text { spectrum disorder patients. } \\
\text { Required to be } 18 \text { years or } \\
\text { older and able to speak } \\
\text { English... All participants were } \\
\text { African American, most (n=7) } \\
\text { reported religious affiliation } \\
\text { was Baptist. } 7 \text { were mothers, } 2 \\
\text { fathers, } 1 \text { sister, } 1 \\
\text { grandmother and } 1 \text { uncle. } \\
\text { Ages ranged from } 32-62 \\
\text { (mean } 47.8 \text { ) The } 10 \text { patients } \\
\text { were aged } 18-28 \text { years (mean } \\
22.0) .7 \text { patients were male } \\
\text { and } 3 \text { female. All patients were } \\
\text { African American. } 7 \text { were } \\
\text { diagnosed with schizophrenia } \\
\text { and } 3 \text { with schizophreniform } \\
\text { disorder. DUP ranged from } 2.3 \\
\text { weeks to } 204.4 \text { weeks } \\
\text { (median } 42.4 \text { weeks). }\end{array}$ & $\begin{array}{l}\text { To explore common themes } \\
\text { pertaining to the period of } \\
\text { untreated psychosis prior to } \\
\text { treatment initiation in } \\
\text { hospitalised, urban, African- } \\
\text { American, first-episode } \\
\text { psychosis patients. }\end{array}$ & $\begin{array}{l}\text { Family members encountered } \\
\text { numerous barriers when } \\
\text { seeking treatment, including } \\
\text { their own misattributions, the } \\
\text { nature of the patient's } \\
\text { symptoms, financial issues, } \\
\text { and system-level delays. }\end{array}$ & $\begin{array}{l}\text { Data from this study used in } \\
\text { Franz et al } 2010 \text { article, } \\
\text { included in this review. This } \\
\text { paper presents themes } \\
\text { specifically regarding families' } \\
\text { encounters with the mental } \\
\text { health system. }\end{array}$ \\
\hline Cadario, E., Stanton, J., & Combination of structured and & Eleven young people aged & The experience of first- & Lack of awareness of mental & The context for this study was \\
\hline
\end{tabular}




\begin{tabular}{|c|c|c|c|c|c|}
\hline $\begin{array}{c}\text { Nicholls, P., Crengle, S., } \\
\text { Wouldes, T., Gillard, M., } \\
\text { Merry, S. N., } 2012\end{array}$ & $\begin{array}{l}\text { unstructured face-face } \\
\text { interviews. The unstructured } \\
\text { portion invited participants to } \\
\text { tell the story of their (or their } \\
\text { child's) pathway to treatment. } \\
\text { The semi-structured part of the } \\
\text { interview comprised a topic } \\
\text { guide to ask the participant } \\
\text { about broad areas which were } \\
\text { identified from the } \\
\text { researchers' clinical } \\
\text { experience and from the } \\
\text { literature; however, these were } \\
\text { usually spontaneously covered } \\
\text { in the narrative. Interviews } \\
\text { were audio-recorded. }\end{array}$ & $\begin{array}{l}\text { between } 15-18 \text { years and their } \\
\text { primary carers' which included } \\
7 \text { mothers and } 2 \text { fathers. The } \\
\text { young person must have a } \\
\text { good command of English and } \\
\text { be identified by the treating } \\
\text { team as experiencing a FEP. } \\
\text { All participants had severe and } \\
\text { persistent symptoms. } 8 \text { had } \\
\text { schizophrenia and } 4 \text { bipolar } \\
\text { affective disorder. There was } \\
\text { a mix of ethnicity with } 7 \text { NZ } \\
\text { European, } 4 \text { NZ Maori and } 1 \\
\text { NZ Maori/Cook Island Maori } \\
\text { (parents and children not } \\
\text { distinguished). }\end{array}$ & $\begin{array}{l}\text { episode psychosis from two } \\
\text { perspectives, that of the } \\
\text { adolescents with the disorder } \\
\text { and that of their primary } \\
\text { caregivers. We explored how } \\
\text { young people with first- } \\
\text { episode psychosis and their } \\
\text { carers noticed they were ill, } \\
\text { and how they accessed } \\
\text { mental health services. We } \\
\text { obtained a description of the } \\
\text { meaning of the first psychotic } \\
\text { episode for the adolescent and } \\
\text { their primary caregiver, and } \\
\text { the experience of accessing } \\
\text { effective treatment. }\end{array}$ & $\begin{array}{l}\text { illness prevented access to } \\
\text { early treatment. Young people } \\
\text { relied on others to access help } \\
\text { and the emotional impact on } \\
\text { caregivers was great. } \\
\text { Experiences of services were } \\
\text { mixed and recommendations } \\
\text { were made for service } \\
\text { providers and service users. } \\
\text { There was significant } \\
\text { concordance in themes } \\
\text { between the carers' and young } \\
\text { persons' perspectives } \\
\text { supporting importance of } \\
\text { working conjointly. }\end{array}$ & child and adolescent services. \\
\hline Champion, S., 2007 & $\begin{array}{l}\text { Semi-structured interviews } \\
\text { lasting between } 40-90 \\
\text { minutes. Face to face in a } \\
\text { venue of the persons choice. }\end{array}$ & $\begin{array}{l}\text { Eleven groups of relatives: } 9 \\
\text { mothers; } 2 \text { fathers; } 1 \text { step } \\
\text { father; } 1 \text { male partner. Mean } \\
\text { age of relative with psychosis } \\
\text { was } 26.7 \text { years. } \\
\text { DUP- average of } 15 \text { months } \\
\text { with range of } 3 \text { months to } 37 \\
\text { months. }\end{array}$ & $\begin{array}{l}\text { To explore the experience of } \\
\text { service users and their } \\
\text { relatives and identify the } \\
\text { factors that may contribute to } \\
\text { a delay in seeking or } \\
\text { accessing care and within that } \\
\text { identify the relevance and } \\
\text { impact of substance use on } \\
\text { the pathway. }\end{array}$ & $\begin{array}{l}\text { Recommended robust } \\
\text { partnerships be developed } \\
\text { with schools and primary care } \\
\text { to provide more seamless care } \\
\text { and joined-up support; } \\
\text { importance of listening to } \\
\text { service users and their } \\
\text { relatives and ensuring } \\
\text { services are accessible and }\end{array}$ & $\begin{array}{l}\text { Findings could often be } \\
\text { attributed to a variety of } \\
\text { categories based on the } \\
\text { evidence, so the author kept to } \\
\text { what the initial researcher had } \\
\text { identified as the meaning of } \\
\text { the finding. }\end{array}$ \\
\hline
\end{tabular}




\begin{tabular}{|c|c|c|c|c|c|}
\hline & & & & responsive. & \\
\hline $\begin{array}{c}\text { Compton, M. T., Kaslow, N. J., } \\
\text { Walker, E. F., } 2004\end{array}$ & $\begin{array}{l}\text { Demographics sheet; an } \\
\text { interview on the duration of } \\
\text { untreated psychosis- } \\
\text { combination of probe and } \\
\text { specific questions; a } \\
\text { questionnaire containing } 6 \\
\text { items that assessed potential } \\
\text { barriers to seek psychiatric } \\
\text { evaluation using a } 7 \text { point } \\
\text { likert scale. }\end{array}$ & $\begin{array}{l}\text { One- three family members of } \\
6 \text { first-episode African } \\
\text { American patients with a } \\
\text { clinical diagnosis of a primary } \\
\text { psychotic illness. Eligibility } \\
\text { criteria for participating family } \\
\text { members included: (1) age 18- } \\
65, \text { (2) ability to speak English, } \\
\text { (3) at least monthly contact } \\
\text { with the patient over the past } \\
\text { year and (4) absence of } \\
\text { mental retardation or medical } \\
\text { conditions that could interfere } \\
\text { with participation. All } \\
\text { participants are African } \\
\text { American and were directly } \\
\text { involved in initiating psychiatric } \\
\text { evaluation and treatment. } \\
\text { Interviews were between days } \\
3-7 \text { of first hospitalization. }\end{array}$ & $\begin{array}{l}\text { To examine parent/family } \\
\text { factors that may influence } \\
\text { DUP in schizophrenia. }\end{array}$ & $\begin{array}{l}\text { Early psychotic symptoms } \\
\text { were often attributed to } \\
\text { depression, lack of motivation } \\
\text { or relational stressors. Family } \\
\text { members' decisions to seek } \\
\text { help often were solidified only } \\
\text { after the emergence of } \\
\text { unbearable psychotic } \\
\text { symptoms or socially } \\
\text { disruptive behaviours. Low } \\
\text { concordance among family } \\
\text { members' reports of the DUP } \\
\text { and perceived barriers to } \\
\text { accessing psychiatric services } \\
\text { were unexpected findings. }\end{array}$ & $\begin{array}{l}\text { Good discussion and } \\
\text { recommendations for further } \\
\text { research. Some data } \\
\text { regarding perceived barriers to } \\
\text { treatment was unable to be } \\
\text { included in findings as they } \\
\text { were reported in table format } \\
\text { and developed from a } \\
\text { questionnaire containing a } \\
\text { likert scale. } \\
\text { Interviews occurred at first } \\
\text { contact with services. }\end{array}$ \\
\hline $\begin{array}{c}\text { Corcoran, C., Gerson, R., } \\
\text { Sills-Shahar, R., Nickou, C., } \\
\text { McGlashan, T., Malaspina, D., }\end{array}$ & $\begin{array}{l}\text { Open-ended, retrospective, } \\
\text { audiotaped interviews of } 1 \text { - } 2 \\
\text { to hours. Participants were }\end{array}$ & $\begin{array}{l}\text { Nine mothers, } 3 \text { fathers, } 1 \\
\text { sibling and } 1 \text { aunt. Sample } \\
\text { was ethnically diverse }\end{array}$ & $\begin{array}{l}\text { To examine the perceptions of } \\
\text { family members of patients' } \\
\text { trajectory of symptoms over }\end{array}$ & $\begin{array}{l}\text { Understanding families' } \\
\text { explanatory models for } \\
\text { symptoms and behavioural }\end{array}$ & $\begin{array}{l}\text { Recent onset of illness- within } \\
1 \text { year prior to interview. } \\
\text { Same study as Gerson et al }\end{array}$ \\
\hline
\end{tabular}




\begin{tabular}{|c|c|c|c|c|c|}
\hline Davidson, L., 2007 & $\begin{array}{l}\text { asked to "tell their story" about } \\
\text { the patient. There was no semi } \\
\text { structured interview } \\
\text { framework, though family } \\
\text { members were queried in } \\
\text { specific areas of interest to the } \\
\text { study if they did not discuss } \\
\text { them spontaneously. }\end{array}$ & $\begin{array}{l}\text { (patients): 31\% Caucasian; } \\
38 \% \text { African-American; } 15 \% \\
\text { Hispanic; } 8 \% \text { East Asian; } 8 \% \\
\text { mixed. Diagnoses included: } \\
\text { Schizophrenia ( } n=6 \text { ); } \\
\text { schizoaffective disorder ( } n=1 \text { ) } \\
\text { and psychotic disorder not } \\
\text { otherwise specified ( } n=6) \text {. All } \\
\text { were recent onset, having } \\
\text { received treatment within the } \\
\text { last year. }\end{array}$ & $\begin{array}{l}\text { time and their impact on family } \\
\text { members, both in coping and } \\
\text { help-seeking patterns. }\end{array}$ & $\begin{array}{l}\text { changes, and their related } \\
\text { patterns of help-seeking, may } \\
\text { be useful for understanding } \\
\text { evolution of psychosis and for } \\
\text { the design of early intervention } \\
\text { programmes. Dissatisfaction } \\
\text { with hospitalisation supports } \\
\text { the mandate to improve } \\
\text { systems of care for recent- } \\
\text { onset psychosis patients, } \\
\text { including de-stigmatisation } \\
\text { and a focus on recovery. }\end{array}$ & $\begin{array}{l}\text { (2009), also included in the } \\
\text { review. } \\
\text { Many relevant findings } \\
\text { included within the review. }\end{array}$ \\
\hline $\begin{array}{c}\text { Czuchta, D. M. and McCay, } \\
\text { E., } 2001\end{array}$ & $\begin{array}{l}\text { For the qualitative component } \\
\text { of the study, semi-structured } \\
\text { interviews were used. } \\
\text { For the quantitative } \\
\text { component of this study, } \\
\text { correlational analysis was } \\
\text { used to examine the patterns } \\
\text { of association amongst the } \\
\text { variables, namely indicators of } \\
\text { help-seeking and perceived } \\
\text { stigma, caregiver burden, and } \\
\text { uncertainty in illness }\end{array}$ & $\begin{array}{l}\text { Twenty parents whose child } \\
\text { was hospitalized for a first } \\
\text { episode of schizophrenia, } \\
\text { schizophreniform, or } \\
\text { schizoaffective disorder. Five } \\
\text { family members were selected } \\
\text { for the qualitative component. } \\
\text { The majority of the sample } \\
\text { was female, mean age was } \\
49.7 \text { years. The majority of the } \\
\text { parents lived with the son or } \\
\text { daughter experiencing a first } \\
\text { episode of schizophrenia. The }\end{array}$ & $\begin{array}{l}\text { 1. What are the indicators of } \\
\text { parental help-seeking? } 2 . \\
\text { What is the level of perceived } \\
\text { stigma, caregiver burden, and } \\
\text { uncertainty in illness that } \\
\text { parents experience at the time } \\
\text { of their son's or daughter's } \\
\text { hospitalization for a FEP? } 3 \text {. } \\
\text { What is the association } \\
\text { between indicators of parental } \\
\text { help-seeking and the following } \\
\text { variables: perceived stigma, } \\
\text { caregiver burden, and }\end{array}$ & $\begin{array}{l}\text { Three overarching themes } \\
\text { emerged from the qualitative } \\
\text { component: } 1 \text {. Evolving } \\
\text { change: What does it mean? } \\
\text { 2. Continuous help-seeking, } \\
\text { and 3. The help-seeking } \\
\text { experience: Impact on } \\
\text { parents. } \\
\text { Findings from the quantitative } \\
\text { component indicated: } 1 \text {. As } \\
\text { stigmatized attitudes towards } \\
\text { mental illness and feelings of } \\
\text { ambiguity increased, so did }\end{array}$ & $\begin{array}{l}\text { Small qualitative section from } \\
\text { which to draw findings. } \\
\text { The author referred to a } \\
\text { further paper being published } \\
\text { detailing the qualitative } \\
\text { findings. This was unable to } \\
\text { be located despite thorough } \\
\text { searching and emailing the } \\
\text { authors. } \\
\text { Various subthemes were } \\
\text { reported but without } \\
\text { supporting illustrations. }\end{array}$ \\
\hline
\end{tabular}




\begin{tabular}{|c|c|c|c|c|c|}
\hline & & $\begin{array}{l}\text { participants had a mean age } \\
\text { of } 23.9 \text { years. Nineteen out of } \\
\text { the } 20 \text { children were male. }\end{array}$ & $\begin{array}{l}\text { uncertainty in illness? } 4 \text {. How } \\
\text { does a parent describe the } \\
\text { experience of help-seeking for } \\
\text { his/her son or daughter who } \\
\text { has experienced a first } \\
\text { episode of schizophrenia? }\end{array}$ & $\begin{array}{l}\text { burden; } 2 \text {. As parental } \\
\text { education increased, } \\
\text { uncertainty regarding their } \\
\text { child's illness decreased; } 3 \text {. As } \\
\text { the number of symptoms } \\
\text { causing distress increased so } \\
\text { did burden and lack of clarity } \\
\text { regarding the illness. A } \\
\text { significant amount of time } \\
\text { passed before parents were } \\
\text { able to access help. No } \\
\text { relationships were found } \\
\text { between indicators of parental } \\
\text { help-seeking and the study } \\
\text { variables. }\end{array}$ & \\
\hline Dodge, C. E., 2011 & $\begin{array}{l}\text { Individual in-depth semi- } \\
\text { structured interviews of one } \\
\text { hour duration. The researcher } \\
\text { also recorded their own } \\
\text { reactions, speculations, } \\
\text { feelings, problems, ideas, } \\
\text { hunches, impressions, and } \\
\text { prejudices. Follow-up } \\
\text { interviews were conducted to } \\
\text { verify analytical accounts of }\end{array}$ & $\begin{array}{l}\text { Ten adult siblings of people } \\
\text { with schizophrenia who met } \\
\text { the following inclusion criteria: } \\
\text { 1. Have a brother or sister } \\
\text { diagnosed with schizophrenia } \\
\text { based on the criteria outlined } \\
\text { in the DSM-IV; } 2 \text {. Have } \\
\text { contact with the brother or } \\
\text { sister as evidenced by at least } \\
\text { monthly contact; } 3 \text {. Be } 19\end{array}$ & $\begin{array}{l}\text { The primary research } \\
\text { questions are: } 1 \text {. How do well } \\
\text { siblings relate to the brother or } \\
\text { sister with schizophrenia? And } \\
\text { how has this relationship } \\
\text { evolved before and since the } \\
\text { onset of the illness? } 2 \text {. How do } \\
\text { well siblings understand the } \\
\text { meaning of the term } \\
\text { caregiving; and what kinds of }\end{array}$ & $\begin{array}{l}\text { The study explored the } \\
\text { evolution of the sibling } \\
\text { relationship over the course of } \\
\text { the illness. In summary, there } \\
\text { was a disruption in siblings' } \\
\text { relations during onset of } \\
\text { illness. Following diagnosis, } \\
\text { well siblings defined their ill } \\
\text { sibling in terms of illness. } \\
\text { Support provided (type and }\end{array}$ & $\begin{array}{l}\text { The study provides a good } \\
\text { description of the impact on } \\
\text { relationships in the family } \\
\text { network subsequent to a } \\
\text { sibling developing a psychotic } \\
\text { illness as seen from the well } \\
\text { siblings' perspective. More } \\
\text { direct quotes from the } \\
\text { interviews would have been } \\
\text { good as the primary }\end{array}$ \\
\hline
\end{tabular}




\begin{tabular}{|c|c|c|c|c|c|}
\hline & the first interview. & $\begin{array}{l}\text { years of age or older; and } 4 . \\
\text { Reside in Greater Vancouver. } \\
\text { Five males and } 5 \text { females } \\
\text { participated, age ranged from } \\
21 \text { to } 56 \text { years (mean=32.2). } \\
\text { The } 10 \text { participants identified } 6 \\
\text { brothers and } 2 \text { sisters } \\
\text { diagnosed with schizophrenia. } \\
\text { The ill siblings age ranged } \\
\text { from } 26 \text { - } 46 \text { years } \\
\text { (mean=32.5), were diagnosed } \\
\text { at an average age of } 20.5 \\
\text { years (range=14-27 years) } \\
\text { and had been ill for an } \\
\text { average of } 11.9 \text { years } \\
\text { (range=4-31 years). The } \\
\text { difference between } \\
\text { participants' estimates of the } \\
\text { age of onset of illness and } \\
\text { diagnosis was } 1.5 \text { years. }\end{array}$ & $\begin{array}{l}\text { activities do they consider as } \\
\text { caregiving activities? } 3 \text {. In } \\
\text { what way are well siblings } \\
\text { currently involved in } \\
\text { caregiving; and how does this } \\
\text { compare to the care their } \\
\text { parents provide? } 4 \text {. What } \\
\text { responsibilities do well siblings } \\
\text { feel they have in relation to the } \\
\text { affected brother or sister; and } \\
\text { how do they believe those } \\
\text { responsibilities will evolve as } \\
\text { parents age? }\end{array}$ & $\begin{array}{l}\text { nature of) was explored and } \\
\text { interestingly not viewed as a } \\
\text { source of burden. } \\
\text { Recommendations for further } \\
\text { research and clinical practice } \\
\text { based on the findings. }\end{array}$ & $\begin{array}{l}\text { researcher often reported } \\
\text { findings in a summarised } \\
\text { format, thereby missing some } \\
\text { of the richness obtained from } \\
\text { direct quotes. This also meant } \\
\text { that some of the findings were } \\
\text { required to be scored as } \\
\text { credible. } \\
\text { There was a large range of } \\
\text { time since illness onset (4-31 } \\
\text { years) which may impact on } \\
\text { the data collected. }\end{array}$ \\
\hline Donnelly, P. L., 2005 & $\begin{array}{l}\text { In-depth tape-recorded } \\
\text { interviews and field notes } \\
\text { lasting from } 1-5 \text { hours. } \\
\text { Interviews were conducted in } \\
\text { the participants' native Korean }\end{array}$ & $\begin{array}{l}\text { Seven mothers and } 3 \text { fathers } \\
\text { whose ages ranged from } 38 \text { - } \\
76, \text { with adult children with } \\
\text { schizophrenia ranging } 20-32 \\
\text { years of age. } 9 \text { of the } 10\end{array}$ & $\begin{array}{l}\text { To investigate mental health } \\
\text { beliefs of Korean American } \\
\text { parental caregivers of adult } \\
\text { children with schizophrenia } \\
\text { and the resulting impact on }\end{array}$ & $\begin{array}{l}\text { The study indicates the need } \\
\text { for culturally appropriate } \\
\text { community-based treatment } \\
\text { programmes with family } \\
\text { education. Raises awareness }\end{array}$ & $\begin{array}{l}\text { Study findings and } \\
\text { recommendations all } \\
\text { discussed within context of } \\
\text { extensive research regarding } \\
\text { cultural beliefs and }\end{array}$ \\
\hline
\end{tabular}




\begin{tabular}{|c|c|c|c|c|c|}
\hline & $\begin{array}{l}\text { language. Open ended } \\
\text { questions were used with } \\
\text { probing providing further } \\
\text { insight into thoughts and } \\
\text { feelings. Each participant was } \\
\text { interviewed twice to validate } \\
\text { and confirm findings. }\end{array}$ & $\begin{array}{l}\text { participants had spent } 5 \text { or } \\
\text { more years as the caregiver. }\end{array}$ & their help seeking behaviours. & $\begin{array}{l}\text { that cultural conceptions of } \\
\text { mental health determine help } \\
\text { seeking. }\end{array}$ & $\begin{array}{l}\text { interpretations of mental } \\
\text { illness. Good clinical } \\
\text { recommendations. }\end{array}$ \\
\hline $\begin{array}{l}\text { Franz, L., Carter, T., Leiner, } \\
\text { A. S., Bergner, E., Thompson, } \\
\text { N. J., Compton, M. T., } 2010\end{array}$ & $\begin{array}{l}\text { A semi-structured, in-depth } \\
\text { interview guide. The guide } \\
\text { largely utilized open-ended } \\
\text { questions to probe for } \\
\text { potential determinants of } \\
\text { treatment delay, but included a } \\
\text { final section that asked more } \\
\text { specifically about potential } \\
\text { effects of stigma. }\end{array}$ & $\begin{array}{l}\text { Twelve relatives of } 10 \text { first- } \\
\text { episode, first-hospitalization } \\
\text { patients with a schizophrenia- } \\
\text { spectrum disorder. All } \\
\text { participants were African } \\
\text { American. One or two family } \\
\text { members represented each } \\
\text { patient. } 7 \text { mothers, } 2 \text { fathers, } 1 \\
\text { sister, } 1 \text { grandmother and } 1 \\
\text { uncle participated. The mean } \\
\text { age of participants was } 47.8 \\
\text { years. All patients were } \\
\text { African American and had } \\
\text { been diagnosed with } \\
\text { schizophreniform disorder, } \\
\text { schizophrenia, schizoaffective } \\
\text { disorder or psychotic disorder } \\
\text { not otherwise specified. The }\end{array}$ & $\begin{array}{l}\text { The present study aimed to } \\
\text { develop a grounded theory } \\
\text { regarding a particular } \\
\text { postulated determinant of } \\
\text { DUP, stigma, as perceived by } \\
\text { family members. Thus, this } \\
\text { study addressed whether } \\
\text { family members' qualitative } \\
\text { reports of the process of } \\
\text { treatment initiation for } \\
\text { individuals with first-episode } \\
\text { psychosis reveal perceived } \\
\text { stigma as a potential factor in } \\
\text { treatment delay/DUP. }\end{array}$ & $\begin{array}{l}\text { The findings suggest that due } \\
\text { to fear of the official label of a } \\
\text { mental illness, certain coping } \\
\text { mechanisms may be adopted } \\
\text { by families, which may result } \\
\text { in a raised threshold for } \\
\text { treatment initiation, and } \\
\text { ultimately treatment delay. If } \\
\text { the relationships within the } \\
\text { grounded theory model are } \\
\text { confirmed by further qualitative } \\
\text { and quantitative research, } \\
\text { public educational programs } \\
\text { could be developed with the } \\
\text { aim of reducing this threshold, } \\
\text { ultimately decreasing DUP. }\end{array}$ & $\begin{array}{l}\text { Data for this article was taken } \\
\text { from same study as reported } \\
\text { by Bergner et al. Good } \\
\text { discussion around impact of } \\
\text { racial discrimination on stigma. }\end{array}$ \\
\hline
\end{tabular}




\begin{tabular}{|c|c|c|c|c|c|}
\hline & & $\begin{array}{l}\text { mean age of the patients was } \\
22.0 \text { years. } 7 \text { were male. } \\
\text { Medium DUP was } 42.4 \text { weeks } \\
\text { (range: } 2-204 \text { ). }\end{array}$ & & & \\
\hline $\begin{array}{c}\text { Gerson, R., Davidson, L., } \\
\text { Booty, A., Wong, C., } \\
\text { McGlashan, T., Malespina, D., } \\
\text { Pincus, H. A., Corcoran, C., } \\
2009\end{array}$ & $\begin{array}{l}\text { Open-ended, retrospective, } \\
\text { audiotaped interviews of 1-2 } \\
\text { hours duration. Participants } \\
\text { were asked to "tell their story" } \\
\text { about the patient. Questions } \\
\text { were asked for clarification or } \\
\text { elaboration. Family members } \\
\text { were queried about the } \\
\text { following areas if they did not } \\
\text { discuss them spontaneously: } \\
\text { What changes have you } \\
\text { perceived in the patient? What } \\
\text { has been helpful or not? What } \\
\text { are your expectations for the } \\
\text { future? }\end{array}$ & $\begin{array}{l}\text { Participating family members } \\
\text { included } 9 \text { mothers, } 3 \text { fathers, } \\
1 \text { brother, and } 1 \text { aunt. Patients } \\
\text { identified the family member } \\
\text { who they felt could best } \\
\text { describe them. The only } \\
\text { exclusion criterion was an } \\
\text { inability to speak English, on } \\
\text { the part of either the patient or } \\
\text { family member. Most of the } 13 \\
\text { inpatients were male ( } \mathrm{N}=10 \text {, } \\
77 \% \text { ). They were ethnically } \\
\text { diverse: } 5 \text { (38\%) were } \\
\text { Caucasian, } 4(31 \%) \text { were } \\
\text { Hispanic, } 3 \text { (23\%) were } \\
\text { African American, and } 1 \text { ( } 8 \% \text { ) } \\
\text { was East Asian and inpatients } \\
\text { ranging in age from } 16-24 \\
\text { (mean age, } 20.7) \text {. Diagnoses } \\
\text { included schizophrenia ( } \mathrm{N}=6 \text {, } \\
46 \% \text { ), schizoaffective disorder }\end{array}$ & $\begin{array}{l}\text { To understand the experience } \\
\text { of families of individuals with } \\
\text { recent-onset psychosis and } \\
\text { gain insight into how treatment } \\
\text { services for first-episode } \\
\text { psychosis could be improved. }\end{array}$ & $\begin{array}{l}\text { The upheaval that a first } \\
\text { episode of psychosis can } \\
\text { cause in families, with its } \\
\text { accompanying tragedy, grief, } \\
\text { anger, and sense of chaos is } \\
\text { revealed. There is a need for } \\
\text { need for broader } \\
\text { implementation of specialized, } \\
\text { accessible, affordable, and } \\
\text { integrated treatment programs } \\
\text { for patients with a first episode } \\
\text { of psychosis programs that } \\
\text { involve families and are } \\
\text { culturally sensitive. }\end{array}$ & $\begin{array}{l}\text { Data from the same study as } \\
\text { reported by Corcoran et al } \\
\text { 2007, included in the review. } \\
\text { Relatives in the study have a } \\
\text { recent onset- within last year. } \\
\text { Data was collected between } \\
\text { 1999-2002 but not published } \\
\text { until 2009. The findings are } \\
\text { discussed within the context of } \\
\text { the US healthcare system and } \\
\text { recommendations made by } \\
\text { the Institute of Medicine to } \\
\text { transform MH care in America } \\
\text { (published in 2003). }\end{array}$ \\
\hline
\end{tabular}




\begin{tabular}{|c|c|c|c|c|c|}
\hline & & $\begin{array}{l}(\mathrm{N}=1,8 \%) \text {, and psychotic } \\
\text { disorder not otherwise } \\
\text { specified }(\mathrm{N}=6,46 \%) \text {. All } \\
\text { patients had received first } \\
\text { treatment for psychosis within } \\
\text { the previous year. }\end{array}$ & & & \\
\hline Jung, M., 2000 & $\begin{array}{l}\text { Six-8 in-depth interviews } \\
\text { conducted over } 5 \text { months. } \\
\text { Interviews were conducted in } \\
\text { locations of the subject's } \\
\text { choice. A semi structured } \\
\text { format was used to facilitate } \\
\text { early interviews. Validation of } \\
\text { the interpretive analysis was } \\
\text { done throughout the interview } \\
\text { process with the participants. }\end{array}$ & $\begin{array}{l}\text { Two Korean mothers of } \\
\text { children with schizophrenia. } \\
\text { One mother was } 42 \text { years and } \\
\text { her daughter } 20 \text { years. The } \\
\text { other mother was } 52 \text { years } \\
\text { and her daughter } 26 \text { years. }\end{array}$ & $\begin{array}{l}\text { How mothers of children with } \\
\text { schizophrenia view and } \\
\text { express their caring } \\
\text { experiences, themselves and } \\
\text { their lives. }\end{array}$ & $\begin{array}{l}\text { Highlights the needs for } \\
\text { nurses to carefully assess and } \\
\text { intervene when working with } \\
\text { families of mentally ill persons, } \\
\text { and have an awareness of the } \\
\text { norms in a clients' culture and } \\
\text { design interventions that } \\
\text { address their cultural issues. }\end{array}$ & $\begin{array}{l}\text { The role of mother within } \\
\text { Korean culture explored and } \\
\text { the subsequent impacts on } \\
\text { mothers caring for children, in } \\
\text { this instance daughters, with } \\
\text { schizophrenia. }\end{array}$ \\
\hline Jungbauer, J., 2002 & $\begin{array}{l}\text { Face to face interviews. As } \\
\text { well as a narrative interview } \\
\text { regarding the biography and } \\
\text { living situation of the } \\
\text { participant, a questionnaire } \\
\text { enquiring into socio- } \\
\text { demographic data, financial } \\
\text { burden, and health }\end{array}$ & $\begin{array}{l}\text { One hundred and three } \\
\text { participants; } 52 \text { spouses and } \\
51 \text { mothers or fathers. The } \\
\text { spouses consisted of } 28 \text { male } \\
\text { and } 24 \text { female spouses, } \\
\text { average age was } 46 \text { years } \\
\text { (ranging } 22-72 \text { ). The parents } \\
\text { consisted of } 42 \text { mothers and } 9\end{array}$ & $\begin{array}{l}\text { A comparison of the burden } \\
\text { experienced by parents and } \\
\text { spouses of schizophrenic } \\
\text { patients. }\end{array}$ & $\begin{array}{l}\text { Parents and spouses perceive } \\
\text { the caregiver burden } \\
\text { differently, although there are } \\
\text { some similarities. The study } \\
\text { reveals that the symptoms the } \\
\text { disorder as well as different } \\
\text { family roles contribute to the } \\
\text { subjective burden of parents }\end{array}$ & $\begin{array}{l}\text { Authors gave good specific } \\
\text { examples of how clinicians } \\
\text { could better support } \\
\text { caregivers. }\end{array}$ \\
\hline
\end{tabular}




\begin{tabular}{|c|c|c|c|c|c|}
\hline & $\begin{array}{l}\text { impairments was completed. } \\
\text { All interviews were recorded } \\
\text { and transcribed. }\end{array}$ & $\begin{array}{l}\text { fathers; average age was } 60 \\
\text { years (ranging } 36-85 \text { ). } \\
\text { Patients had had } \\
\text { schizophrenia for an average } \\
\text { of } 11 \text { years. }\end{array}$ & & $\begin{array}{l}\text { and spouses. Supportive } \\
\text { assistance for caregivers } \\
\text { should address their particular } \\
\text { needs more adequately. }\end{array}$ & \\
\hline $\begin{array}{c}\text { McCann, T. V., Lubman, D. I., } \\
\text { Clark, E., } 2011\end{array}$ & $\begin{array}{l}\text { Semi structured, in-depth, } \\
\text { audio recorded interviews, } \\
\text { each lasting about } 1 \text { hour. }\end{array}$ & $\begin{array}{l}\text { Twenty first- time primary } \\
\text { caregivers. Inclusion criteria } \\
\text { were ; First-time primary } \\
\text { caregiver; Being in a } \\
\text { caregiving role for less than } 3 \\
\text { years; Fully engaged in the } \\
\text { standard treatment process } \\
\text { and; Able to communicate in } \\
\text { conversational English. } \\
\text { Exclusion criteria comprised: } \\
\text { Had received specialist family } \\
\text { interventions for FEP and } \\
\text { Personal history of serious } \\
\text { and persistent mental illness. } \\
\text { Most participants were female, } \\
\text { with a mean age of } 49 \text { years. } \\
\text { Most were parents, and almost } \\
\text { all resided in the same } \\
\text { households as the young } \\
\text { people with FEP. The mean }\end{array}$ & $\begin{array}{l}\text { To understand the lived } \\
\text { experience of first-time } \\
\text { primary caregivers of young } \\
\text { adults with FEP, with a focus } \\
\text { on examining how they access } \\
\text { specialist FEP clinical services } \\
\text { and how they overcome } \\
\text { potential barriers. }\end{array}$ & $\begin{array}{l}\text { This study highlights the } \\
\text { important contribution and } \\
\text { experience of first-time } \\
\text { primary caregivers and the } \\
\text { difficulties they face accessing } \\
\text { services. The findings suggest } \\
\text { access should be influenced } \\
\text { more by clinical need and less } \\
\text { by caregivers? Perseverance. } \\
\text { The findings also underline the } \\
\text { importance of providing clinical } \\
\text { training that acknowledges the } \\
\text { needs and contributions of } \\
\text { caregivers, as well as } \\
\text { interventions that meet the } \\
\text { unique challenges faced by } \\
\text { first-time caregivers accessing } \\
\text { services after the onset of } \\
\text { FEP. }\end{array}$ & $\begin{array}{l}\text { Good recommendations made } \\
\text { for practice. } \\
\text { Clear definition of caregiver. }\end{array}$ \\
\hline
\end{tabular}




\begin{tabular}{|c|c|c|c|c|c|}
\hline & & $\begin{array}{l}\text { duration of their contact with } \\
\text { the FEP service was } 14.5 \\
\text { months. }\end{array}$ & & & \\
\hline McKenzie, L. H., 2006 & $\begin{array}{l}\text { Two questionnaires were } \\
\text { designed for the adult survey, } \\
\text { one for service users and one } \\
\text { for carers. The questionnaires } \\
\text { comprised of tick box } \\
\text { responses, with an option for } \\
\text { additional comment, and } \\
\text { open-ended questions. } \\
\text { Respondents were offered } \\
\text { assistance with the completion } \\
\text { of their questionnaires from a } \\
\text { person independent of the } \\
\text { psychosis service. } \\
\text { Respondents were also invited } \\
\text { to take part in interviews } \\
\text { concerning their experiences } \\
\text { of the service. }\end{array}$ & $\begin{array}{l}\text { Inclusion criteria for the survey } \\
\text { sample were: service users } \\
\text { have a diagnosis of psychosis } \\
\text { and relatives. A total of } 82 \\
\text { questionnaires ( } 41 \text { service } \\
\text { user and } 41 \text { carer } \\
\text { questionnaires) were } \\
\text { distributed. Of these } 12 \text { of } \\
\text { each of the service user and } \\
\text { the carer questionnaires were } \\
\text { returned, a response rate of } \\
29 \% \text {. }\end{array}$ & $\begin{array}{l}\text { To examine the experiences of } \\
\text { people with psychosis and } \\
\text { their carers' in accessing and } \\
\text { receiving local mental health } \\
\text { services. }\end{array}$ & $\begin{array}{l}\text { A number of important issues } \\
\text { were highlighted. These } \\
\text { include } 1 \text {. The need for public } \\
\text { education (which may help to } \\
\text { reduce the delay which } \\
\text { currently occurs between } \\
\text { people seeking support and } \\
\text { receiving treatment); } 2 \text {. } \\
\text { Improved access to alternative } \\
\text { treatments, such as } \\
\text { psychosocial therapies (in } \\
\text { conjunction with } \\
\text { pharmacological treatment); } \\
\text { the provision of appropriate } \\
\text { psychiatric facilities; and } 3 \text {. } \\
\text { The inclusion of an early } \\
\text { intervention treatment } \\
\text { approach. }\end{array}$ & $\begin{array}{l}\text { A quantitative content analysis } \\
\text { identifying frequency of } \\
\text { themes limited data that could } \\
\text { be utilised for this review. } \\
\text { Service users and carers } \\
\text { reported feeling supported by } \\
\text { mental health professionals } \\
\text { and voluntary support } \\
\text { agencies, and included in the } \\
\text { treatment approach. This was } \\
\text { different to other studies } \\
\text { reporting primarily difficulties. } \\
\text { The results could not be } \\
\text { included as it was not within } \\
\text { the scope of this study. }\end{array}$ \\
\hline $\begin{array}{c}\text { Mizuno, E., Misuzu, I., Sakai, } \\
\text { I., } 2011\end{array}$ & $\begin{array}{l}\text { Semi structured interviews, of } \\
\text { about } 50 \text { minute's duration. }\end{array}$ & $\begin{array}{l}\text { Twelve husbands of spouses } \\
\text { with schizophrenia. The mean } \\
\text { age of the husbands was } 50.8\end{array}$ & $\begin{array}{l}\text { To describe and understand } \\
\text { the caregiving experiences of } \\
\text { husbands living with spouses }\end{array}$ & $\begin{array}{l}\text { Six major themes were } \\
\text { identified including: } \\
\text { acceptance of the disease by }\end{array}$ & $\begin{array}{l}\text { The authors emphasised the } \\
\text { importance of exploring and } \\
\text { considering the characteristics }\end{array}$ \\
\hline
\end{tabular}




\begin{tabular}{|c|c|c|c|c|c|}
\hline & & $\begin{array}{l}\text { years, ranging from } 27-77 \\
\text { years. Nine of the couples had } \\
\text { children. Four wives } \\
\text { developed schizophrenia after } \\
\text { marriage, and in three of them, } \\
\text { the onset of illness occurred } \\
\text { after childbirth. The mean age } \\
\text { of the wives was } 47.8 \text { years, } \\
\text { ranging from } 27-76 \text { years. } \\
\text { The mean duration of illness } \\
\text { was } 18.0 \text { years, ranging from } \\
7-41 \text { years. }\end{array}$ & $\begin{array}{l}\text { with schizophrenia through } \\
\text { exploring the descriptions of } \\
\text { husbands' experiences. }\end{array}$ & $\begin{array}{l}\text { the husbands; past and } \\
\text { present experience with wives } \\
\text { with schizophrenia; the roles } \\
\text { and burdens of husbands; } \\
\text { marital relationships and the } \\
\text { presence of the wife for } \\
\text { husbands; social resources, } \\
\text { participation in the community } \\
\text { and society, and perspectives } \\
\text { on the future. Husbands aimed } \\
\text { to share experiences with their } \\
\text { wives. }\end{array}$ & $\begin{array}{l}\text { of family members' } \\
\text { experiences according to their } \\
\text { relation to the ill person. This } \\
\text { is important for clinicians } \\
\text { working with families. }\end{array}$ \\
\hline $\begin{array}{c}\text { Monteiro, V. B. M., Dos } \\
\text { Santos, J. Q., Martin, D., } 2006\end{array}$ & $\begin{array}{l}\text { In-depth interviews lasting } \\
\text { between } 45-1 \text { hour } 50 \\
\text { minutes. A checklist was used } \\
\text { containing subjects } \\
\text { concerning: 1) perception of } \\
\text { the first symptoms or } \\
\text { behavioural changes in their } \\
\text { sick relative; } 2 \text { ) how these } \\
\text { were dealt with; 3) how they } \\
\text { were understood, and if help } \\
\text { was sought, what this help } \\
\text { was and what difficulties they } \\
\text { faced in getting it. The study }\end{array}$ & $\begin{array}{l}\text { Inclusion criteria for patients } \\
\text { whose relatives were } \\
\text { evaluated: 1) Having begun } \\
\text { treatment due to a first } \\
\text { psychotic episode defined by } \\
\text { the presence of at least one of } \\
\text { the typical symptoms 2) } \\
\text { Having a time of untreated } \\
\text { psychosis longer than six } \\
\text { months defined as the interval } \\
\text { between the start (as } \\
\text { perceived by the family) of } \\
\text { psychotic symptoms and the }\end{array}$ & $\begin{array}{l}\text { To explore why delays of more } \\
\text { than } 6 \text { months, to seek } \\
\text { psychiatric counselling, are a } \\
\text { common practice for relatives } \\
\text { of persons having suffered a } \\
\text { first psychotic episode, in the } \\
\text { Greater Sao Paulo area. }\end{array}$ & $\begin{array}{l}\text { Cultural factors may influence } \\
\text { the process of understanding } \\
\text { and seeking help for a FEP. } \\
\text { Thus mental health } \\
\text { professionals should evaluate } \\
\text { cultural and social meanings } \\
\text { that patients and relatives give } \\
\text { for symptoms and illnesses to } \\
\text { allow for more inclusive } \\
\text { evaluation of patients and their } \\
\text { diseases and of their family's } \\
\text { involvement. This will also } \\
\text { make it possible to propose }\end{array}$ & $\begin{array}{l}\text { Interesting exploration of } \\
\text { impact of culture and social } \\
\text { context on people's } \\
\text { experience. }\end{array}$ \\
\hline
\end{tabular}




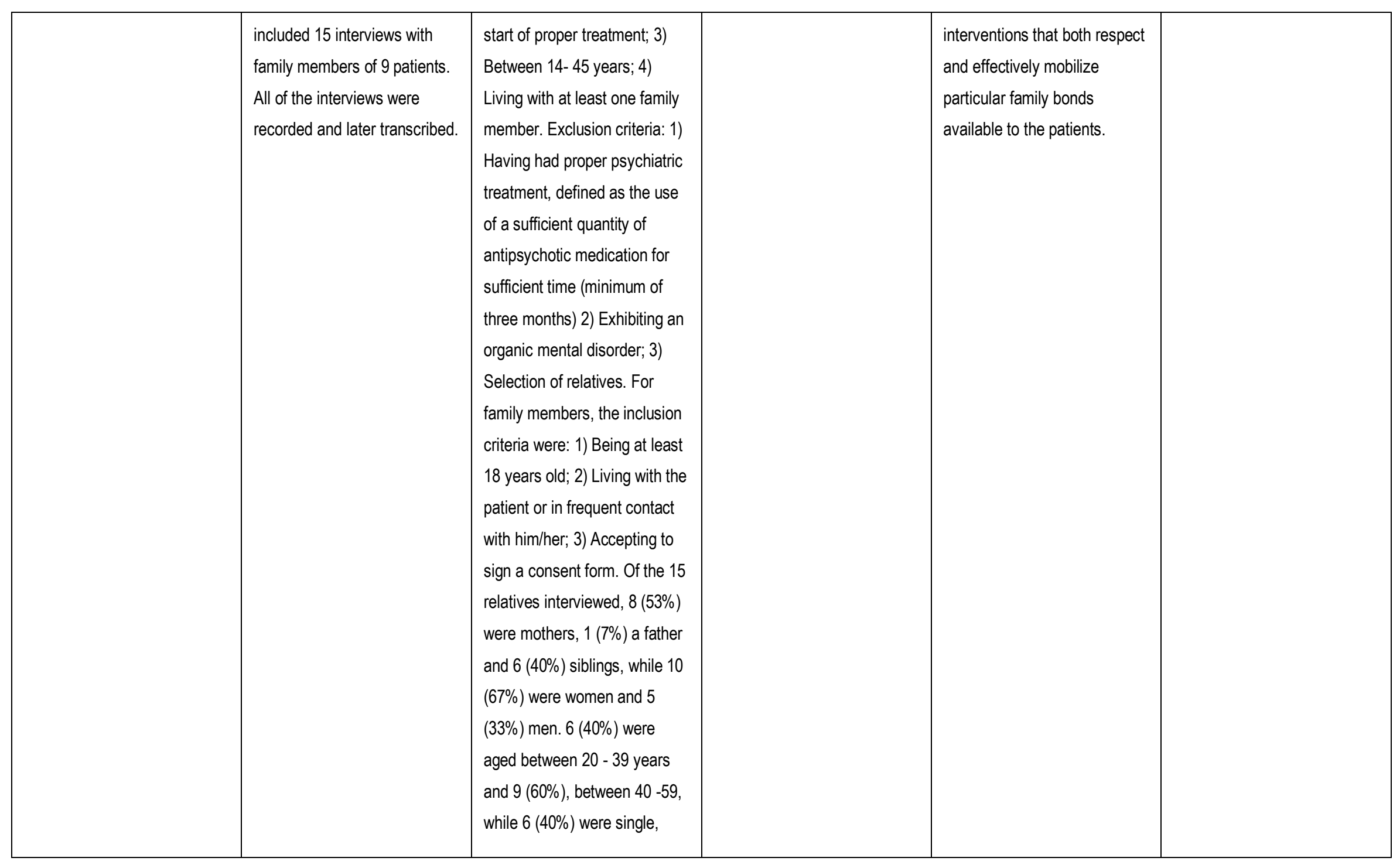




\begin{tabular}{|c|c|c|c|c|c|}
\hline & & $\begin{array}{l}6(40 \%) \text { were married, } 2(13 \%) \\
\text { were divorced or separated } \\
\text { and } 1(7 \%) \text { was a widower. } \\
\text { Regarding religion, } 8(53 \%) \\
\text { were Catholics, } 5(33 \%) \\
\text { Evangelists and } 2(14 \%) \text { were } \\
\text { Jews. }\end{array}$ & & & \\
\hline Pearse, W. A., 1998 & $\begin{array}{l}\text { Semi-structured interview } \\
\text { schedule of open-ended } \\
\text { questions. }\end{array}$ & $\begin{array}{l}\text { Sixteen participants. } 12 \\
\text { mothers; } 1 \text { husband; } 1 \text { sister; } \\
2 \text { fathers. Inclusion was based } \\
\text { on } 2 \text { criteria. 1) The client had } \\
\text { to have a diagnosis of some } \\
\text { form of schizophrenia or } \\
\text { schizoaffective disorder, } \\
\text { according to ICD-10 and have } \\
\text { experienced their initial } \\
\text { episode of schizophrenia } \\
\text { within the last } 15 \text { years. 2) The } \\
\text { participating relative had to } \\
\text { have been in contact with the } \\
\text { client at the time of the initial } \\
\text { episode. Length of illness } \\
\text { ranged from } 8 \text { months- } 12 \\
\text { years. }\end{array}$ & $\begin{array}{l}\text { To explore relatives' } \\
\text { experience of seeking help for } \\
\text { a person during the early } \\
\text { stages of schizophrenia. This } \\
\text { was to be considered in } \\
\text { general terms and with } \\
\text { particular reference to the } \\
\text { influence that the gender of } \\
\text { the person had on this } \\
\text { process. }\end{array}$ & $\begin{array}{l}\text { A theoretical framework for } \\
\text { understanding the process of } \\
\text { a relative's adjustment to their } \\
\text { experience was developed: } \\
\text { Normality; Explainable } \\
\text { Difference; Inexplicable } \\
\text { Difference; Mental Illness. }\end{array}$ & $\begin{array}{l}\text { Good descriptive data } \\
\text { reported. }\end{array}$ \\
\hline
\end{tabular}




\begin{tabular}{|c|c|c|c|c|c|}
\hline Redko, C., 2003 & $\begin{array}{l}12 \text { months of ethnographic } \\
\text { fieldwork. The first phase } \\
\text { consisted of the recruitment of } \\
\text { and observation with } 21 \text { young } \\
\text { people. The second phase of } \\
\text { fieldwork involved interviewing } \\
\text { these youths and their families } \\
\text { and following them in their } \\
\text { everyday lives for a period of } \\
\text { at least } 6 \text { months. Contact was } \\
\text { typically once every two } \\
\text { weeks. Initial interviews were } \\
\text { semi-structured. Interviews } \\
\text { were tape-recorded. }\end{array}$ & $\begin{array}{l}\text { Twenty-one young people } \\
\text { (aged 17-27 years) } \\
\text { experiencing a first episode of } \\
\text { psychosis and their families, } \\
\text { usually the mother but also } \\
\text { inclusive of brothers, sisters, } \\
\text { the father, neighbours, } \\
\text { boyfriends, girlfriends, cousins } \\
\text { and psychiatrists. }\end{array}$ & $\begin{array}{l}\text { Exploring how young people } \\
\text { suffering a first episode } \\
\text { psychosis in urban Brazil } \\
\text { resorted to religion and how } \\
\text { this framed the reactions of } \\
\text { their families and } \\
\text { communities. }\end{array}$ & $\begin{array}{l}\text { For young people, the } \\
\text { personal articulation of } \\
\text { religious idioms and signifiers } \\
\text { served to communicate, } \\
\text { elaborate and transform their } \\
\text { experience of psychosis. } \\
\text { Family members resorted to } \\
\text { religion as a source of healing, } \\
\text { complementary to psychiatric } \\
\text { treatment, as well as for } \\
\text { personal relief and comfort. } \\
\text { For youth, involvement with } \\
\text { religion worked in both } \\
\text { "progressive" and "regressive" } \\
\text { ways, to improve and, at } \\
\text { times, to diminish functioning } \\
\text { and well-being. }\end{array}$ & $\begin{array}{l}\text { Little distinguishing of various } \\
\text { family members voices. } \\
\text { Special attention was paid to } \\
\text { their direct or indirect contact } \\
\text { with religious settings in order } \\
\text { to understand how the youths } \\
\text { perceived their significance. }\end{array}$ \\
\hline $\begin{array}{l}\text { Tanskanen, S., Morant, N., } \\
\text { Hinton, M., Lloyd-Evans, B., } \\
\text { Crosby, M., Killaspy, H., } \\
\text { Raine, R., Pilling, S., Johnson, } \\
\text { S., } 2011\end{array}$ & $\begin{array}{l}\text { Semi-structured, face to face } \\
\text { interviews of } 1 \text { hour duration } \\
\text { were conducted in } \\
\text { respondent's homes. Topic } \\
\text { guides included: onset of } \\
\text { difficulties; main activities and } \\
\text { contact with community } \\
\text { organisations at the time }\end{array}$ & $\begin{array}{l}\text { Twenty-one service users and } \\
9 \text { carers. Carers' included } 6 \\
\text { mothers, } 1 \text { sister, } 1 \text { partner } \\
\text { and } 1 \text { mother-in-law; age } \\
\text { range between } 26-68 \text { years } \\
\text { with the majority ( } n=5 \text { ) aged } \\
\text { 49-59. } 5 \text { participants were } \\
\text { white British; } 2 \text { white other; } 1\end{array}$ & $\begin{array}{l}\text { An investigation of service } \\
\text { users' and carers' experiences } \\
\text { of the onset of psychosis and } \\
\text { help-seeking in two inner } \\
\text { inner-city London boroughs } \\
\text { with a particular focus on the } \\
\text { roles of relevant community } \\
\text { groups and non-health }\end{array}$ & $\begin{array}{l}\text { A range of psychosocial } \\
\text { factors cause delays in } \\
\text { provision of appropriate } \\
\text { treatment for young people } \\
\text { developing psychosis. The } \\
\text { distress reported by young } \\
\text { people and their families, even } \\
\text { in relatively brief periods of }\end{array}$ & $\begin{array}{l}\text { Rich descriptive data reported. } \\
\text { Results from the study } \\
\text { indicated that there were no } \\
\text { differences regarding stigma } \\
\text { concerns or service response } \\
\text { experienced by the ethnically } \\
\text { diverse participants. }\end{array}$ \\
\hline
\end{tabular}




\begin{tabular}{|c|c|c|c|c|c|}
\hline & $\begin{array}{l}\text { mental health problems } \\
\text { developed; respondents' } \\
\text { understanding of and } \\
\text { responses to symptoms; help- } \\
\text { seeking attempts; reactions } \\
\text { from social network to the } \\
\text { onset of illness; and } \\
\text { experiences of help-seeking } \\
\text { and service responses. } \\
\text { Additional probes were used } \\
\text { to elicit more information as } \\
\text { appropriate. }\end{array}$ & $\begin{array}{l}\text { black Caribbean; } 1 \text { mixed } \\
\text { race. Service users and carers } \\
\text { was purposively recruited: a) } \\
\text { service users who were in } \\
\text { contact with community } \\
\text { organisations at the time of } \\
\text { referral were prioritised; b) a } \\
\text { diverse group of participants } \\
\text { were sought in terms of age, } \\
\text { gender, ethnic group, } \\
\text { educational attainment, } \\
\text { employment history and DUP. } \\
\text { Participants were required to } \\
\text { understand and speak } \\
\text { adequate levels of English and } \\
\text { be able to give written } \\
\text { informed consent. }\end{array}$ & $\begin{array}{l}\text { professionals in pathways to } \\
\text { care. }\end{array}$ & $\begin{array}{l}\text { untreated psychosis, supports } \\
\text { prioritisation by early } \\
\text { intervention services of } \\
\text { promoting swift access to } \\
\text { treatment. People's immediate } \\
\text { support networks and involved } \\
\text { community organisations may } \\
\text { either encourage or deter } \\
\text { help-seeking. More research } \\
\text { is needed to establish how } \\
\text { mental health service } \\
\text { initiatives can promote prompt } \\
\text { help-seeking for people with } \\
\text { FEP and how young people } \\
\text { themselves, their families and } \\
\text { broader social networks can } \\
\text { be helped to play a more } \\
\text { effective role in this process. }\end{array}$ & \\
\hline Wong, D. F. K., 2007 & $\begin{array}{l}\text { A semi-structured interview } \\
\text { guide. The interview guide } \\
\text { contained open-ended } \\
\text { questions related to the help- } \\
\text { seeking behaviours of the } \\
\text { informant, were face-to-face } \\
\text { and in-depth. A pilot test was }\end{array}$ & $\begin{array}{l}\text { Fifty-eight relatives agreed to } \\
\text { be interviewed. More than } \\
80 \% \text { of the informants were } \\
\text { women, predominately } \\
\text { parents, between ages } 40- \\
68 . \text { The ill relative was aged } \\
\text { between } 15-25 \text {, average }\end{array}$ & $\begin{array}{l}\text { There were two objectives of } \\
\text { this study: } 1 \text {. To identify the } \\
\text { roles and functions played by } \\
\text { the key individuals in the help- } \\
\text { seeking pathway of Chinese } \\
\text { caregivers with relatives } \\
\text { suffering from early psychosis }\end{array}$ & $\begin{array}{l}\text { Whilst family caregivers } \\
\text { usually initiated the help- } \\
\text { seeking process, informal } \\
\text { network members were } \\
\text { instrumental in confirming the } \\
\text { presence of mental illness and } \\
\text { encouraged the caregivers to }\end{array}$ & $\begin{array}{l}\text { Same data as Wong, } 2007 \text {, } \\
\text { therefore data used from this } \\
\text { study only. The author } \\
\text { generated frequencies for the } \\
\text { content analysis which were } \\
\text { unable to be used, limiting the } \\
\text { qualitative data available. }\end{array}$ \\
\hline
\end{tabular}




\begin{tabular}{|l|l|l|l|l|}
\hline & $\begin{array}{l}\text { conducted on two cases, and } \\
\text { a refinement of the contents of } \\
\text { the interview guide and format } \\
\text { was made. Each interview } \\
\text { lasted for about an hour. }\end{array}$ & $\begin{array}{l}\text { age 19 years, had been } \\
\text { diagnosed with a functional } \\
\text { psychosis, known to the } \\
\text { mental health system for less } \\
\text { than } 6 \text { months and have } \\
\text { resided with the informant for } \\
\text { a period of 1 year prior to } \\
\text { receiving treatment. The ratio } \\
\text { of males to females in this } \\
\text { sample was about 1:2. 72\% } \\
\text { had DUP for less than six } \\
\text { months, 28\% had DUP from } 6 \\
\text { months- 2 years. }\end{array}$ & $\begin{array}{l}\text { in Hong Kong 2. To explore } \\
\text { the underlying factors } \\
\text { influencing the help-seeking } \\
\text { pelative suffering from early } \\
\text { psychosis. }\end{array}$ & $\begin{array}{l}\text { seek external help. School } \\
\text { social workers acted as a } \\
\text { bridge between the informal } \\
\text { and formal networks. It was } \\
\text { found that some of the ill } \\
\text { relatives did not recognize the } \\
\text { severity of their mental health } \\
\text { problems, which posed a } \\
\text { major obstacle to help } \\
\text { with an illness (under 20 } \\
\text { years) represented. The } \\
\text { authors referred to different, } \\
\text { less flexible, pathways to care } \\
\text { for adults which may impact } \\
\text { on experiences of carers' } \\
\text { during help-seeking. }\end{array}$ \\
\end{tabular}




\section{Appendix VI: Excluded studies}

[47] Etheridge, K., Yarrow, L., Peet, M., Pathways to care in first episode psychosis

Reason for exclusion: Unable to include in metasynthesis due to lack of detailed results.

[43] lenciu, M., Romosan, F., Bredicean, C., Romosan, R., First episode psychosis and treatment delay- causes and consequences

Reason for exclusion: Does not pass critical appraisal regarding quality of study.

[47] Wong, D. F., Uncovering sociocultural factors influencing the pathway to care of Chinese caregivers with relatives suffering from early psychosis in Hong Kong

Reason for exclusion: Same findings in both articles by author, therefore only one used for extraction purposes.

[47] de Haan, L., Welborn, K., Krikke, M., Linszen, D. H., Opinions of mothers on the first psychotic episode and the start of treatment of their child

Reason for exclusion: Did not meet quality for inclusion around methodology or participants voices being adequately represented.

\section{Appendix VII: List of study findings}

\begin{tabular}{|l|l|l|l|}
\hline Barker et al. & 2001 & Client and family narratives on schizophrenia & UK \\
\hline
\end{tabular}

\begin{tabular}{|c|c|}
\hline Finding1 & $\begin{array}{l}\text { Leading up to the first psychotic episode all relatives witnessed observable changes in the client which } \\
\text { marked a difference with their previous character and functioning. }\end{array}$ \\
\hline Illustration & "(x) started getting allergies, pain in the tummy and things went wrong at school". P. 203 \\
\hline Finding2 & Relatives discussed how their child had started to challenge parental boundaries and be "bad". \\
\hline Illustration & "He was beginning to stay out later than he was allowed to". P.203 \\
\hline Finding3 & $\begin{array}{l}\text { Family members found it harder to pinpoint when a change had occurred and described the process as } \\
\qquad \text { more gradual rather than occurring at a discrete time. }\end{array}$ \\
\hline Illustration & No data to support. \\
\hline Finding4 & $\begin{array}{l}\text { Relatives described how the client's behaviour changed markedly and this had a bewildering effect on the } \\
\text { family. }\end{array}$ \\
\hline
\end{tabular}




\begin{tabular}{|c|c|}
\hline Illustration & $\begin{array}{l}\text { "The last few days before he sent her to hospital, she started to tell me that the girl downstairs was talking } \\
\text { about her and I was a bit confused because I couldn't hear her". P.204 }\end{array}$ \\
\hline Finding5 & Some [relatives] described how difficult it was to be faced with the emerging symptoms. \\
\hline Illustration & $\begin{array}{l}\text { 'He said 'you're not my mum, you're an alien, they took my real mum. Someone has come in her } \\
\text { place'”.P.204 }\end{array}$ \\
\hline Finding6 & $\begin{array}{l}\text { Relatives discussed how they had attempted to make sense of the changing behaviour making attributions } \\
\text { to teenage stupidity ( } n=1) \text {, trying to impress people }(n=1) \text {, testing boundaries }(n=2) \text { or being lazy }(n=1) \text {. }\end{array}$ \\
\hline Illustration & No data to support. \\
\hline Finding7 & $\begin{array}{l}\text { Relatives acknowledged that at the time their knowledge and understanding was poor }(n=6) \text { and they had } \\
\text { attempted to engage services at this point. }\end{array}$ \\
\hline Illustration & No data to support. \\
\hline Finding8 & Family members mentioned feeling frightened for both themselves and for the client $(n=5)$. \\
\hline Illustration & $\begin{array}{l}\text { "I was so scared I used to try and lock my door with no lock on. I used to wedge it. I was so scared he } \\
\qquad \text { would come in". p.204 } \\
\text { "We were fearful that he may have come a cropper and been killed and just disposed of". P.204 }\end{array}$ \\
\hline Finding9 & Other common emotions were feeling despondent, guilty and immersed in the process $(n=4)$. \\
\hline Illustration & No data to support. \\
\hline
\end{tabular}

\section{\begin{tabular}{|l|l|l|l|}
\hline Barnable et al. & 2006 & Having a sibling with schizophrenia: a phenomenological study & Canada \\
\hline
\end{tabular}}

\begin{tabular}{|c|c|}
\hline Finding1 & $\begin{array}{l}\text { Initially participants described a time when they did not know what the disease was and they were } \\
\text { struggling to understand the symptoms and behaviours. }\end{array}$ \\
\hline Illustration & $\begin{array}{l}\text { "I thought she didn't communicate well ... she seemed to close herself off... she seemed to be losing } \\
\text { weight... she would be sitting there in the dark for hours . . . I would say, 'this isn't normal' and I realised } \\
\text { something was really wrong... but I didn't know what . . . She wouldn't come out of the house and I would } \\
\text { get mad and say, 'What's wrong with her?' and there would be a big argument and I would flair up". } \\
\text { (Participant 2)(p.252) }\end{array}$ \\
\hline Finding2 & $\begin{array}{l}\text { Struggling to understand was also related to not knowing how to manage their sibling's symptoms, leaving } \\
\text { many of them feeling inadequate and frightened. }\end{array}$ \\
\hline Illustration & $\begin{array}{l}\text { "We noticed signs of something being wrong ... he came to visit me on occasions and almost as if he was } \\
\text { looking for help and I didn't realize what he was looking for... not understanding the problem or situation ... } \\
\text { that was part of the frustration ... he was doing little things that weren't like him. Acting in a way like we }\end{array}$ \\
\hline
\end{tabular}




\begin{tabular}{|c|c|}
\hline & $\begin{array}{l}\text { have never seen him act before ... it was frustrating because we didn't know how to deal with what was } \\
\text { happening to him. We didn't know at that point that it was schizophrenia ... it was frustrating because we } \\
\text { were afraid of the unknown. We were not sure how to handle the situation". (Participant 4)(p.252) }\end{array}$ \\
\hline Finding3 & $\begin{array}{l}\text { Feelings of helplessness and fear were common as participants strived to understand some of the more } \\
\qquad \text { unpredictable and disturbing behaviours of schizophrenia. }\end{array}$ \\
\hline Illustration & $\begin{array}{l}\text { "We went through a series of not knowing where she went. She would hitchhike to the mainland. We didn't } \\
\text { know where she was for weeks. Sometimes we would have to go where she was and bring her back. } \\
\text { Sometimes she would end up in jail and we would have to bail her out". (Participant 5)(p.253) }\end{array}$ \\
\hline Finding4 & $\begin{array}{l}\text { Participants' felt frustrated with a system that didn't offer them support and guidance, or allow them to } \\
\text { make decisions about treatment. }\end{array}$ \\
\hline Illustration & $\begin{array}{l}\text { "It was difficult to get help for him. That was frustrating. He wouldn't go along with our suggestions and see } \\
\text { a doctor. We were frustrated knowing there was a problem and not being able to get the professional help } \\
\text { he needed". (Participant 4) (p.255) }\end{array}$ \\
\hline Finding5 & $\begin{array}{l}\text { There were times when health care professionals did not believe participants' judgment and they needed } \\
\text { to be convinced that their sibling needed hospitalization. }\end{array}$ \\
\hline Illustration & $\begin{array}{l}\text { "I said, 'something has to be done ... you can't let her die.' I yelled at the doctor and I said . . .'don't worry } \\
\text { about the legal implications... let it come down on me'. I would go to jail. I would do anything to get her } \\
\text { help." (Participant 3)(p.255) }\end{array}$ \\
\hline
\end{tabular}

\begin{tabular}{|c|c|c|c|}
\hline $\begin{array}{c}\text { Bergner et } \\
\text { al. }\end{array}$ & 2008 & $\begin{array}{c}\text { The period of untreated psychosis before treatment initiation: a qualitative study of } \\
\text { family members' perspectives }\end{array}$ & USA \\
\hline
\end{tabular}

\begin{tabular}{|c|c|}
\hline Finding1 & $\begin{array}{c}\text { In many instances, participants' responses indicated that treatment delay may have been partly driven by } \\
\text { the notion that the patient was "of age" and capable of (and responsible for) independent decision-making. }\end{array}$ \\
\hline Illustration & $\begin{array}{c}\text { "A lot of times unless they are showing suicidal signs or are gonna hurt someone else, there's really } \\
\text { nothing you can do. You know, it's like that person is of age and they have to be the one, you know, to } \\
\text { initiate [care]". (p.6) }\end{array}$ \\
\hline Finding2 & $\begin{array}{c}\text { I just kinda let him make his own decisions, ya know. I usually try to help him make decisions, but he says } \\
\text { Ivert positive symptoms appeared to serve as a catalyst to initiating treatment, but it was only once such } \\
\text { severe symptoms had developed that treatment was sought. }\end{array}$ \\
\hline Illustration & $\begin{array}{l}\text { A patient's sister describes this: "I started noticing them more on a regular basis. Um, just like I said ya } \\
\text { know, I have small kids and he's uncle to them. So he's sitting there laughing at stuff and they're smaller } \\
\text { and they're not laughing. So they're wondering what he is laughing at; it's not even funny. So, just being } \\
\text { around him more, because he started coming around me more [helped me realize that he needed }\end{array}$ \\
\hline
\end{tabular}




\begin{tabular}{|c|c|}
\hline & treatment]". (p.5) \\
\hline Finding3 & $\begin{array}{l}\text { It often took a dangerous incident involving either actual or potential harm to the patient or others for } \\
\text { families to seek treatment. }\end{array}$ \\
\hline Illustration & $\begin{array}{l}\text { "We were just really trying to get [him] to a doctor or anybody, whoever we thought, such as the disability } \\
\text { office. Until that happened, I hate to say it, but that's the only thing that helped him, when he came up with } \\
\text { that gun". (p.5) } \\
\text { "I was giving benedryl to put her to sleep, I'm serious. 'Here, take these benedryl. Go lie down. You need } \\
\text { to lie down. Just lie down'. So, this time, it [became] dangerous. It was dangerous for her jumping out of } \\
\text { the car when she was with her dad, while they were on the expressway, and that was last fall". (p.5) }\end{array}$ \\
\hline Finding4 & $\begin{array}{l}\text { Most family members misattributed the patient's symptoms to either another mental disorder, most } \\
\text { commonly depression, or a response to stress. }\end{array}$ \\
\hline Illustration & $\begin{array}{l}\text { "He used to say he was all stressed out, ya know. I was saying 'Why are you so stressed out?' I guess } \\
\text { cause he's so, ya know, he says he's so depressed, and I don't know what he was so depressed about". } \\
\text { (p.4) }\end{array}$ \\
\hline Finding5 & $\begin{array}{l}\text { In addition to depression, family members tended to initially blame the possible use of illicit drugs for the } \\
\text { patients' odd behaviours and declining role performance. }\end{array}$ \\
\hline Illustration & $\begin{array}{l}\text { "A lot of people would ask him what's wrong, and they would ask me, 'What's wrong with your brother?' } \\
\text { and 'Why is he acting like that?' So, ya know, initially you're gonna think, okay, it has something to do with } \\
\text { drugs or something, but that's not what it was". (p.4-5) }\end{array}$ \\
\hline Finding6 & $\begin{array}{l}\text { Family members frequently viewed the changes they observed in their loved one as a passing } \\
\text { developmental phase, or simply a function of growing up or rebelling against their family. }\end{array}$ \\
\hline Illustration & $\begin{array}{l}\text { A mother of a patient stated the following: "I thought it was, ya know,"she was mad" cause she didn't get to } \\
\text { stay out as late as she wanted to. And since I was upset she stayed out late, we fought. I mean, I thought } \\
\text { it was just, ya know, that I thought she was going through an adolescent stage". (p.5) }\end{array}$ \\
\hline Finding7 & $\begin{array}{l}\text { Patients' functional decline and symptoms were sometimes viewed as personal or developmental } \\
\qquad \text { experiences that they had to go through on their own. }\end{array}$ \\
\hline Illustration & $\begin{array}{l}\text { "I always felt from the beginning, that this is something she's just gotta go through. Through her own } \\
\text { experience, ya know, the bad with the good? Cause my telling her, ya know, and saying, "You don't need } \\
\text { to do this", the best lesson is your own experience. I knew she had to go through that and I knew she had } \\
\text { to hit rock bottom to open up her eyes to some changes that, ya know, that need to be made". (p.6) }\end{array}$ \\
\hline Finding8 & $\begin{array}{l}\text { Treatment was sought sooner if family members utilized their friends as resources, especially if these } \\
\text { friends had experience with the mental health field. }\end{array}$ \\
\hline Illustration & $\begin{array}{l}\text { "I called a friend of mine who was a psychiatrist and she connected me with someone else who was, ya } \\
\text { know, who deals with that. They kinda told me what I needed to do and they gave me, ya know, referrals }\end{array}$ \\
\hline
\end{tabular}




\begin{tabular}{|c|c|}
\hline & and my wife and I went on the internet and we checked different places". (p.6) \\
\hline Finding9 & $\begin{array}{l}\text { Many system-level barriers were encountered during help-seeking, including lack of free or affordable } \\
\text { services, inflexibility of appointments, and inefficient scheduling processes. }\end{array}$ \\
\hline Illustration & $\begin{array}{l}\text { A father gave the following account of perceived financial constraints, despite the fact that the patient was } \\
\text { ultimately admitted to the unit that provides care to patients with no private or public-sector insurance: "I } \\
\text { mean we were just watching him deteriorate and couldn't do anything about it, we just didn't have the } \\
\text { money, there's just nothing we could do". (p.6) } \\
\text { "It took a while because no one responded. No one was there, and I had to leave a message. I was told } \\
\text { they would call me, and no one ever called back, or they weren't in, so, that was the main thing. [They } \\
\text { should] just call back. Ya know, if I'm calling, ya know, telling you something is going on with my brother, } \\
\qquad \text { just call back". (p.6) } \\
\text { "Even if you present at the mental health centre stating, 'I got a problem, I really need to see somebody', } \\
\text { you have to go to the phone. You have to call over to their intake place. They give you an appointment, } \\
\text { and then you have to come back. Then when you come back they do the paperwork. They do the intake, } \\
\text { like your insurance and stuff like that, and you may see the worker then, the social worker, or whoever's } \\
\text { gonna be like working as your case manager, or then they may do some history stuff with you. Then you } \\
\text { leave there with another appointment to come see the doctor, so with that, I think that's just crazy". (p.6) }\end{array}$ \\
\hline
\end{tabular}

\section{\begin{tabular}{|l|l|l|l|} 
Cadario et al. & 2012 & A qualitative investigation of first-episode psychosis in adolescents & NZ \\
\hline
\end{tabular}}

\begin{tabular}{|c|c|}
\hline Finding1 & $\begin{array}{l}\text { Carers described a broad range of symptoms that alerted them to the young person having a problem. } \\
\text { Symptoms included behavioural changes, social withdrawal and self-harm. Behavioural problems were } \\
\text { especially noticed when they were unusual for the individual, or led to conflict with the law. }\end{array}$ \\
\hline Illustration & $\begin{array}{l}\text { "Like he threw an egg at a teacher and things like that, that were slightly out of character". (p.85) } \\
\text { "It went from her just being a relatively normal kid to with no talking or anything to us". (p.85) }\end{array}$ \\
\hline Finding2 & $\begin{array}{l}\text { Somatic symptoms, especially loss of appetite, weight loss and sleep disturbance were commonly } \\
\text { observed. }\end{array}$ \\
\hline Illustration & $\begin{array}{l}\text { "He wouldn't eat. Normally he's a really good eater". (Appendix } 1 \text { p.95) } \\
\text { "He ended up staying up all that night and wouldn't sleep and I could hear him walking around the house". } \\
\text { (Appendix } 1 \text { p.95) }\end{array}$ \\
\hline Finding3 & $\begin{array}{l}\text { Carers noticed mood changes and anxiety and symptoms that were difficult to understand, such as } \\
\text { strange talk, bizarre ideas, hearing voices and seeing things the carers didn't see. }\end{array}$ \\
\hline Illustration & $\begin{array}{l}\text { "He was upset. He was tearful and miserable. Isolated, lonely and miserable". (Appendix } 1 \text { p.95) } \\
\text { "Her body language and her mind and her mood swings were changing rapidly prior, two and a half weeks } \\
\text { before she got admitted". (Appendix } 1 \text { p.95) } \\
\text { "He got more anxious, you couldn't leave him on his own". (Appendix } 1 \text { p.95) } \\
\text { "She did drastic things like she went up the road and broke into somebody's house looking for somebody }\end{array}$ \\
\hline
\end{tabular}




\begin{tabular}{|c|c|}
\hline & $\begin{array}{l}\text { that didn't exist". (Appendix } 1 \text { p.95) } \\
\text { "And the next morning, when I got up, he was talking quite strangely". (Appendix } 1 \text { p.95) } \\
\text { "He was standing out on the balcony talking to somebody but there was no one there". (Appendix } 1 \text { p.95) } \\
\text { "Everywhere he looked he could see all these dead people on the floor. It was quite bizarre really". } \\
\text { (Appendix } 1 \text { p.95) }\end{array}$ \\
\hline Finding4 & [Some] carers identified a crisis point that prompted them to approach services for help. \\
\hline Illustration & $\begin{array}{l}\text { "He was suspended from school for a few weeks and it was then, he just dropped and went on an almighty } \\
\qquad \text { low and that was when he tried to commit suicide then". (p.85) } \\
\text { "And he got obsessed by that one girl. It's only really till he literally cracked up on Friday afternoon, that I } \\
\text { took it on board..."(p.86) }\end{array}$ \\
\hline Finding5 & Carers sometimes only realized the presence of particular difficulties in retrospect. \\
\hline Illustration & "I do recall saying things like, you know, "you should make sure you get enough sleep". (p.86) \\
\hline Finding6 & $\begin{array}{l}\text { Half of the interviewed caregivers reported being uncertain as to whether the young person's difficulties } \\
\qquad \text { were signs of an illness. }\end{array}$ \\
\hline Illustration & $\begin{array}{l}\text { "And you never dreamed it was a medical condition I suppose; we just thought it was becoming more and } \\
\text { more out of character, for him". (p.86) }\end{array}$ \\
\hline Finding7 & Parents spoke about attributing the symptoms to teenage behaviour. \\
\hline Illustration & $\begin{array}{l}\text { "I just sort of thought that this was sort of an extension of his personality, just a little bit sort of } \\
\qquad \text { exaggerated". (p.86) } \\
\text { "But you think, kids do play up, it's that age, you know". (p.86) }\end{array}$ \\
\hline Finding8 & Some parents perceived the symptoms as subtle and hence difficult to notice. \\
\hline Illustration & "Yeah, little strange things that unfortunately, when you look back, it all added up". (p.86) \\
\hline Finding9 & $\begin{array}{l}\text { Carers approached different services for help and talked about feeling uncertain about where to access } \\
\text { help. }\end{array}$ \\
\hline Illustration & $\begin{array}{l}\text { "I felt a sense of not knowing what, really where to go first. Um, it's not like a normal illness where you can } \\
\text { say, "oh well I'll go to the doctor", or "l'll go to a homeopath", or something like that". (p.87) } \\
\text { "It was pretty hard figuring out who to take her to". (p.87) } \\
\text { "After we went to the spiritualist we said bugger this, we're taking her to our family doctor". (p.87) } \\
\text { "I put him in the car, and drove him up to [local hospital]". (Appendix } 3 \text { p.96) }\end{array}$ \\
\hline Finding10 & $\begin{array}{l}\text { The family doctor was the first point of contact for [some] families, and in [most of these] cases this } \\
\text { resulted in immediate referral to specialist services. }\end{array}$ \\
\hline Illustration & $\begin{array}{l}\text { "Initially we contacted our GP. She referred [young person] straight on". (Appendix } 3 \text { p.96) } \\
\text { "So we ended up going to the GP, and talking to her about it and she referred us". (Appendix } 3 \text { p.96) }\end{array}$ \\
\hline
\end{tabular}




\begin{tabular}{|c|c|}
\hline Finding11 & Some carers contacted more than one agency. \\
\hline Illustration & $\begin{array}{l}\text { "We saw one psychologist, school, before he got suspended. And we only went to a GP, the doctor, after } \\
\qquad \text { his suspension". (Appendix } 3 \text { p.96) } \\
\text { "So we went back to the doctor again, we rung the doctor and then the doctor's wife spent the whole day } \\
\text { ringing around different services and nobody would take him. And so by the time it came to the end of the } \\
\text { day she just said "go to [local hospital] A\&E and just sit there and someone does something about it, don't } \\
\text { leave". (Appendix } 3 \text { p.96) }\end{array}$ \\
\hline Finding12 & [Those] participants who approached mental health services directly were guided by personal contacts. \\
\hline Illustration & $\begin{array}{l}\text { "Because she [personal contact] works as an operator at the hospital, and she just rang up, what was it? } \\
\text { The Mental Health Line". (Appendix } 3 \text { p.96) } \\
\text { "My sister-in-law, she works in the hospital. She went to work and spoke to the nurses there, so they gave } \\
\text { the phone numbers to call the doctors. So we thought we better ring up the hospital and ask some doctors } \\
\text { to come and see her. So we rang up and then a doctor came in the night". (Appendix } 3 \text { p.96) }\end{array}$ \\
\hline Finding13 & Spiritual help was sought by families of both non-Maori and Maori ethnicity. \\
\hline Illustration & $\begin{array}{l}\text { "I said to my son, I said oh I think she [daughter]'s not well, you get ready, and we go and see the priest". } \\
\text { (p.87) }\end{array}$ \\
\hline Finding14 & $\begin{array}{l}\text { One carer described a particularly long journey that involved a number of agencies, until specialist mental } \\
\text { health services were accessed. }\end{array}$ \\
\hline Illustration & $\begin{array}{l}\text { "When I found out that he had been smoking marijuana, I got him into [addictions treatment centre] day } \\
\text { programme to try and get treatment for him. He'd been detained in [suburb] residential. Youth justice was } \\
\text { involved and um, like I kept telling people that there's something wrong with him. They actually had to call } \\
\text { in the CAT [Crisis] team [Name] from the youth justice and other people that were at the family meeting, } \\
\text { group conference, decided that maybe [young person] should be checked by somebody from CL [Consult } \\
\text { Liaison Team], yeah, just to make sure that um, it wasn't only because of the drugs. And so from then, } \\
\text { CL, workers at CL decided to have [young person] admitted into [local hospital], for further assessment". } \\
\text { (Appendix } 3 \text { p.97) }\end{array}$ \\
\hline Finding15 & $\begin{array}{l}\text { Carers spoke about ways in which they had been managing the young person's difficulties before the } \\
\text { illness was recognized and treated. Initial attempts of managing the problems usually involved ways of } \\
\text { communicating with the young person. Some carers spoke about a more hands-on approach. }\end{array}$ \\
\hline Illustration & $\begin{array}{l}\text { "I was challenging him about his dope smoking and his smoking and just his lifestyle generally because it } \\
\qquad \text { just seemed so incredibly frenetic". (Appendix } 3 \text { p.97) } \\
\text { "So we caught her and I said "come on love, come inside. I'm your mother. Should be with your mother } \\
\text { and talk." And then she was all right. She talked to me". (Appendix } 3 \text { p.97) } \\
\text { "And at night time, that's why you sleep with him so you'd actually hold him in the bed". (p.88) }\end{array}$ \\
\hline Finding16 & Some carers were supported by family and even strangers. \\
\hline
\end{tabular}




\begin{tabular}{|c|c|}
\hline Illustration & $\begin{array}{l}\text { "A guy turned up and started talking to him about Christianity and that sort of thing, and, in a way that was } \\
\qquad \text { probably the best thing at the time". (p.88) }\end{array}$ \\
\hline Finding17 & $\begin{array}{l}\text { Carers reported strong emotional responses to the young persons' becoming ill. Participants reported } \\
\text { experiencing a mix of different emotions and talked about feeling scared and worried. Sadness and upset } \\
\text { were also described. }\end{array}$ \\
\hline Illustration & $\begin{array}{l}\text { Several carers cried during their interview. (Observation reported on p.88) } \\
\text { "Um, it was scary, it was really scary, cause there was nothing, there was nothing I could say, nothing } \\
\text { anyone could do". (Appendix } 3 \text { p.97) } \\
\text { "I didn't stop feeling concerned, and I still haven't stopped feeling concerned". (Appendix } 3 \text { p.97) } \\
\text { 'I just couldn't stop crying. It was horrible, I had to go to work, I'd go to work in tears, you know". (Appendix } \\
\qquad 3 \text { p.97) } \\
\text { "I was quite upset because I thought what's wrong with him, why is he saying all these strange things." } \\
\text { (Appendix } 3 \text { p.97) } \\
\text { "I really want him to have a better quality of life, I've seen his struggles, I just really want him to be well } \\
\text { again, well enough for him, as well as he can be, comfortable with who he is". (Appendix } 3 \text { p.97) }\end{array}$ \\
\hline Finding18 & $\begin{array}{l}\text { Most of the participating carers had thought about why the young person might have become ill, and many } \\
\text { thought of more than one factor that might have contributed. }\end{array}$ \\
\hline Illustration & $\begin{array}{l}\text { "I think that's the hardest thing, you can't! You can't actually get a concrete answer. You know, there are } \\
\text { just all these ideas out there, lots and lots of ideas. Nothing says, 'well yeah, it's definitely that". (p.88) }\end{array}$ \\
\hline Finding19 & $\begin{array}{l}\text { Approximately half of the interviewed carers thought that substance use might have contributed to the } \\
\qquad \text { illness developing. }\end{array}$ \\
\hline Illustration & $\begin{array}{l}\text { "I tend to feel that just the combination of those years of drug taking probably had a significant effect". } \\
\qquad(\text { p.88) }\end{array}$ \\
\hline Finding20 & $\begin{array}{l}\text { Many carers thought psycho-social stresses such as parental marital difficulties, moving house, being } \\
\text { bullied and being physically abused might have acted as a precipitant. }\end{array}$ \\
\hline Illustration & $\begin{array}{l}\text { "So I sort of thought, well [father] and our break-up, um, moving house, moving away from [city], cause } \\
\text { that was the place he really identified with and really liked. Um, maybe changing schools". (Appendix } 4 \\
\text { p.98) } \\
\text { "I think that was the beginning of [young person]'s end, you know, the girlfriend dropping him". (Appendix } 4 \\
\text { p.98) } \\
\text { "I think he got into a vicious circle where he was doing too much, like he had two jobs, he was doing } \\
\text { bursary which, he was doing subjects that took heaps and heaps of work". (Appendix } 4 \text { p.98) }\end{array}$ \\
\hline Finding21 & $\begin{array}{l}\text { Some carers blamed an association with an undesirable peer group [as possibly contributing to the illness } \\
\text { developing]. }\end{array}$ \\
\hline Illustration & $\begin{array}{l}\text { "And then they teased him, called him Dumbo and handicap, handi, clap, clap for the handicapped. Made } \\
\qquad \text { him crack up too, he hated it". (Appendix } 4 \text { p.98) }\end{array}$ \\
\hline
\end{tabular}




\begin{tabular}{|c|c|}
\hline & "A lot of it I put down, he was hanging around with the wrong sort of people".(Appendix 4 p.98) \\
\hline Finding22 & $\begin{array}{l}\text { Genetic factors [as a reason for why the young person became ill] were considered where a family history } \\
\text { of mental illness was known. }\end{array}$ \\
\hline Illustration & "Her father's family have got a huge history of it". (Appendix 4 p.98) \\
\hline Finding23 & $\begin{array}{l}\text { One participant had prior knowledge of mental illness and reported that this shortened the time to illness } \\
\qquad \text { recognition and help seeking. }\end{array}$ \\
\hline Illustration & $\begin{array}{l}\text { "Well you see her father, he's got schizophrenia basically. And that's why I was sort of so freaked out as } \\
\text { well. That's why I did what we did straight away basically [taking her to our family doctor]. I thought, my } \\
\text { God, you know. Is that the start of it?" (Appendix } 6 \text { p.100) }\end{array}$ \\
\hline Finding24 & $\begin{array}{l}\text { Most carers highlighted a lack of knowledge about mental illness before they experienced the young } \\
\text { person's illness. }\end{array}$ \\
\hline Illustration & $\begin{array}{l}\text { "I really didn't know anything about it, nothing. I never had anything to do with it".(p.91) } \\
\text { "It's not something we're, you know, we thought would happen to us". (p.91) }\end{array}$ \\
\hline Finding25 & $\begin{array}{l}\text { Stigma, contributed to by unhelpful portrayal of mentally ill people by the media, was mentioned as a } \\
\text { significant issue. }\end{array}$ \\
\hline Illustration & "In the media, you hear the bad stuff, the court issues". (p.91) \\
\hline Finding26 & Personal involvement with mental illness demystified it and led to acceptance. \\
\hline Illustration & $\begin{array}{l}\text { "It can happen to anyone". (p.91) } \\
\text { "I don't have a problem with it, but I think other people do". (p.91) }\end{array}$ \\
\hline Finding27 & $\begin{array}{c}\text { Carers reported strong emotional responses to the young persons' becoming ill. They reported } \\
\text { experiencing a mix of different emotions and talked about feeling scared and worried. Sadness and upset } \\
\text { were also described. }\end{array}$ \\
\hline Illustration & $\begin{array}{l}\text { Several carers cried during their interview. (Observation reported on p.88) } \\
\text { "Um, it was scary, it was really scary, cause there was nothing, there was nothing I could say, nothing } \\
\text { anyone could do". (Appendix } 3 \text { p.97) } \\
\text { "I didn't stop feeling concerned, and I still haven't stopped feeling concerned". (Appendix } 3 \text { p.97) } \\
\text { "I just couldn't stop crying. It was horrible, I had to go to work, I'd go to work in tears, you know". (Appendix } \\
\qquad 3 p .97 \text { ) } \\
\text { "I was quite upset because I thought what's wrong with him, why is he saying all these strange things". } \\
\text { (Appendix } 3 \text { p.97) } \\
\text { "I really want him to have a better quality of life. I've seen his struggles. I just really want him to be well } \\
\text { again, well enough for him, as well as he can be, comfortable with who he is". (Appendix } 3 \text { p.97) }\end{array}$ \\
\hline
\end{tabular}




\begin{tabular}{|c|c|c|c|}
\hline Champion & 2007 & $\begin{array}{c}\text { Exploring the pathways into care for young people aged 14-35 years with a first episode } \\
\text { psychosis }\end{array}$ & UK \\
\hline
\end{tabular}

\begin{tabular}{|c|c|}
\hline Finding1 & $\begin{array}{l}\text { Whilst there were difficulties in identifying a mental illness, most relatives were aware of behavioural } \\
\text { changes giving cause for concern for longer than } 3 \text { years. These included changes in behaviour with } \\
\text { friends, increased concerns registered by schools, inability to hold down jobs and employers making } \\
\text { comments or concerns regarding performance. }\end{array}$ \\
\hline Illustration & $\begin{array}{l}\text { "I would say there has always been something wrong with Barry that you couldn't quite put your finger on. } \\
\text { He has always had a number of problems, dyslexia, dysphasia, glue ear. He would often get very angry, } \\
\qquad \text { slam doors or walk out". (Sue) (p.71) } \\
\text { "He was } 15 \text { or } 16 \text { when we started to get calls from college that he was having panic attacks. At sixth form } \\
\text { he couldn't sit in a class room but they didn't help him. He's tried to go into employment but things keep } \\
\text { going wrong and he loses the job". (Maxine) (p.71) }\end{array}$ \\
\hline Finding2 & $\begin{array}{l}\text { On recognising early signs each of the relatives attempted to seek various forms of help often with little } \\
\text { success. On average relatives contacted three professionals before they received a response from mental } \\
\text { health services. }\end{array}$ \\
\hline Illustration & $\begin{array}{l}\text { "At the college they have what's called, mother hens, who look after new students who come in. I phoned } \\
\text { her up several times and said he is having these panic attacks, will you help me and there was nothing". } \\
\text { (Maxine) (p.73) }\end{array}$ \\
\hline Finding3 & Relatives struggled to manage drug taking behaviour. \\
\hline Illustration & $\begin{array}{l}\text { "It was a battle with alcohol and food. He started to understandably control himself, from what was coming } \\
\text { up inside him. He was trying to get a grip on things, it was probably the cannabis but without proof it is } \\
\qquad \text { easy to put it down to that". (Jo and Sid) (p.72) }\end{array}$ \\
\hline Finding4 & $\begin{array}{l}\text { Families struggled in trying to separate out what was "normal teenage" experimentation from what might } \\
\text { be mental illness. }\end{array}$ \\
\hline Illustration & $\begin{array}{l}\text { "At the same time I managed to get Sarah to go to Drug Watch to try and sort of get over the things that } \\
\text { were going on. Nothing seemed to work, nothing was happening and it just wasn't doing anything and I } \\
\text { don't know if she was, I don't really know if I felt she was mentally ill... just felt she was a really naughty } \\
\text { teenager experimenting with drugs, testing me". (Helen) (p.73) } \\
\text { "I went to M who was my friend and asked her advice about it. She advised us to take the cannabis first to } \\
\text { the police station to identify it which we did and they said to bring George to the police station after school } \\
\text { which we did. He was locked in a cell with his dad waiting outside really I think to frighten him. It didn't } \\
\text { really have an effect on George as he continued to use cannabis". (Jean) (p.72) }\end{array}$ \\
\hline Finding5 & $\begin{array}{l}\text { Throughout the pathway leading to the point of admission the most common point of contact was the GP } \\
\text { followed by school and college staff, psychologists, police, private counsellors, alternative therapist, } \\
\text { probation officer and a solicitor. One relative expressed frustration of contacting probation and solicitors } \\
\text { but still not being able to access the help being sought. }\end{array}$ \\
\hline
\end{tabular}




\begin{tabular}{|c|c|}
\hline Illustration & $\begin{array}{l}\text { "She went on this May Day march and ended up going to prison. I knew nothing about it because at that } \\
\text { stage she was living with friends. From that she was put on probation. I managed to track down this } \\
\text { solicitor and said I am really worried about her but they didn't seem to care that she might be ill. She } \\
\text { wasn't engaging with the service. I kept getting in touch with these professional people who were involved } \\
\text { in her life and it went on for about a year. We tried talking to Sarah about it but she always said that there } \\
\text { was nothing wrong with her". (Helen) (p.74) }\end{array}$ \\
\hline Finding6 & $\begin{array}{l}\text { At the early stage where the person does not have insight into their mental illness and is not sufficiently ill } \\
\text { to require a MHA assessment, there is often a difficulty engaging the person in treatment. }\end{array}$ \\
\hline Illustration & $\begin{array}{l}\text { This young woman aged } 21 \text { years, had a DUP of more than } 37 \text { months and significant history of substance } \\
\text { abuse and involvement with the criminal justice system all of which failed to detect her mental illness and } \\
\text { offer appropriate treatment. The mother reflects: "I don't think you should be allowed to be sent to prison } \\
\text { until you've had a psychiatric assessment, I think it's absolutely abysmal you know to do with the courts. } \\
\text { There should be someone from mental health attached (to the courts) or a referral system in place. It's } \\
\text { very difficult if people think they are mentally ill they are not going to ask for that sort of help". (Helen) } \\
\text { (p.75) }\end{array}$ \\
\hline Finding7 & $\begin{array}{l}\text { Relatives' personal life experiences impacts upon the point in time when they make contact with services } \\
\text { and the persons chosen for this contact. }\end{array}$ \\
\hline Illustration & $\begin{array}{l}\text { "I was brought up in a very poor family and I can remember all the years and trying to cope with everything } \\
\text { on my own. Life was hard really when I look back on it now...and what happened, getting married and my } \\
\text { (first) husband dying and being on my own always really affected me in a sense with life, married life and } \\
\text { bringing up children, I never wanted him (2nd husband) to get angry because I would be scared if he got } \\
\text { angry. I began to think it (son's mental illness) was my fault". (Jean) (p.75) }\end{array}$ \\
\hline Finding8 & $\begin{array}{l}\text { Whilst relatives were actively seeking help they were still reluctant to acknowledge a potentially severe } \\
\text { mental illness and were seeking alternatives to the mental health services. }\end{array}$ \\
\hline Illustration & $\begin{array}{l}\text { "When he first presented and I knew he was unwell, I mean my immediate feeling then was, you know, I } \\
\text { didn't want to blot his copy book. I didn't want people to know about this, I wanted to manage this in- } \\
\text { house. We talked to a psychologist at one point...to get help dealing with difficult behaviour". (Sheila)(p.76) } \\
\text { "At this point we started to think about therapy, I really did not want to go for a diagnosis. I thought Oliver } \\
\text { should see a clinical psychologist. I have a friend who is a schizophrenic and I would think sometimes that } \\
\text { Oliver does remind me of my friend but I didn't really want to face this. We paid for him to see and } \\
\text { alternative therapist". (Jo \&amp; Sid) (p.76) }\end{array}$ \\
\hline Finding9 & Concerns continued to escalate to the point where help was sought from the GP and local NHS services. \\
\hline Illustration & $\begin{array}{l}\text { "Eventually Sarah went to the GP because when she gets mentally very unwell she focuses on her periods } \\
\text { and things. He realised she was extremely mentally ill and instigated the referral and later she had to be } \\
\qquad \text { admitted under the Mental health Act". (Helen) (p.77) }\end{array}$ \\
\hline Finding10 & Professionals (often the GP) did not fully understand the concerns and fears of the relative leaving them \\
\hline
\end{tabular}




\begin{tabular}{|c|c|}
\hline & not feeling listened to. \\
\hline Illustration & $\begin{array}{l}\text { "My son had been seeing a counsellor and she was so concerned that she phoned the CMHT and she } \\
\text { actually took him there. They phoned me up to say he needed to be admitted and I was so angry because } \\
\text { I had been trying for three years and no-one had taken the blind bit of notice of me." (Maxine) (p.77) }\end{array}$ \\
\hline Finding11 & $\begin{array}{l}\text { Leading up to admission the child/partner's behaviour and symptoms significantly deteriorated. Most } \\
\text { relatives got to a point beyond which they were no longer prepared or felt safe to go. }\end{array}$ \\
\hline Illustration & $\begin{array}{l}\text { "She was putting a front on and we clearly knew what was happening. It was trying to make the doctors } \\
\text { see what was going on but she still wasn't offered treatment. As the eating got worse and worse I had to } \\
\text { get the GP out to see her and only then was she sectioned and taken into hospital. I felt really low myself". } \\
\text { (Christine) (p.77) }\end{array}$ \\
\hline Finding12 & Service users were often admitted after a range of traumatic incidents had occurred. \\
\hline Illustration & $\begin{array}{l}\text { "I was at work and I got a phone call and thought "oh God something is not right". He was saying all these } \\
\text { bizarre things and I knew I had to go home and he was just climbing the walls. I phoned the GP and } \\
\text { eventually after a lot of angriness I took him down there and he sent him straight up to the assessment } \\
\text { clinic". (Sue) (p.78) } \\
\text { "He eventually (the patient) said that if this woman came round he would kill her. I felt awful. We were } \\
\text { crying and breaking down, I have been in some nasty situations in my life but this was the worst...this was } \\
\text { the last straw. I then thought, even with my own inner desires to protect your children, you can't have this } \\
\text { woman and the neighbours at risk. I then phoned the police and said you have to come and they did". (Jo } \\
\text { \&amp; Sid) (p.78) }\end{array}$ \\
\hline Finding13 & $\begin{array}{l}\text { All relatives expressed a sense of relief that admission to hospital had finally been achieved and a } \\
\text { diagnosis (of some sort) made so their relative could commence treatment. }\end{array}$ \\
\hline Illustration & $\begin{array}{l}\text { "I found it re-assuring when he finally received a diagnosis, you know what you are dealing with (this } \\
\text { mother had suspected for some time because of a family history that her son may be suffering with } \\
\text { schizophrenia). It makes it easier because you can read about it and learn how to deal with and handle } \\
\text { them." (Sue) (p.78) }\end{array}$ \\
\hline Finding14 & $\begin{array}{l}\text { Relatives wrestled with feelings of shame, stigma and guilt whilst trying to get help for their partner or } \\
\text { relative. }\end{array}$ \\
\hline Illustration & $\begin{array}{l}\text { "My husband left because they ended up punching each other. He can't understand that his son wasn't } \\
\qquad \text { well". (Maxine) (p.80) } \\
\text { "My ex-husbands sister has schizophrenia but the family said that she was just spoilt, they didn't really } \\
\text { understand the illness. Whether he felt guilty at the fact that his son has schizophrenia is from his side of } \\
\text { the family I don't know. He will still say today although he doesn't actually talk to Barry or his brother that } \\
\text { there is nothing wrong with our son". (Sue) (p.80) }\end{array}$ \\
\hline Finding15 & $\begin{array}{l}\text { Relatives appeared to feel guilt and shame that they could think their child could be suffering from a } \\
\qquad \text { mental illness. }\end{array}$ \\
\hline
\end{tabular}




\begin{tabular}{|c|c|}
\hline Illustration & $\begin{array}{l}\text { "And then you start thinking I'm not sure if Sarah is mentally ill or not. And then you think aren't I awful, } \\
\qquad \text { what an awful person I am even thinking about my own child". (Helen) (p.80) } \\
\text { "I was overwhelmed with anxiety and guilt that you hear about it (mental illness) and never expect it in your } \\
\text { own children". (jean) (p.80) }\end{array}$ \\
\hline Finding16 & A relative reported guilt about the difficulty they had in recognising mental illness. \\
\hline Illustration & $\begin{array}{l}\text { "It's hard, it's really hard when you don't know and think- and your brain is buzzing because you're thinking } \\
\text { this is just teenage experimentation that's maybe gone a bit wrong. If you have never had any experience } \\
\text { of it and because I wasn't 100\% sure I was thinking am I just being an awful mother". (Helen)(p.81) }\end{array}$ \\
\hline
\end{tabular}

\begin{tabular}{|c|c|c|c|}
\hline $\begin{array}{l}\text { Compton et } \\
\text { al. }\end{array}$ & 2004 & $\begin{array}{l}\text { Observations on parent/family factors that may influence the duration of untreated } \\
\text { psychosis among African American first-episode schizophrenia-spectrum patients }\end{array}$ & USA \\
\hline Finding1 & \multicolumn{3}{|c|}{$\begin{array}{l}\text { Family members' levels of knowledge about schizophrenia may not necessarily have a major impact upon } \\
\text { the length of treatment delays. }\end{array}$} \\
\hline Illustration & \multicolumn{3}{|c|}{$\begin{array}{l}\text { Among the parents, Mr. B had worked previously as a social worker, during which time he had clients with } \\
\text { schizophrenia; Mrs. C was a registered nurse; Mrs. F was a nurse's assistant and had previously worked } \\
\text { in a psychiatric hospital; and Ms. H herself had schizophrenia. (p.380) }\end{array}$} \\
\hline Finding2 & \multicolumn{3}{|c|}{$\begin{array}{l}\text { Parents' decisions to seek help often hinged upon a behaviour that became unbearable or that created a } \\
\text { social disturbance. }\end{array}$} \\
\hline Illustration & \multicolumn{3}{|c|}{$\begin{array}{l}\text { This is exemplified by the descriptions provided by Mr. B (his daughter was pulled over by police due to } \\
\text { dangerous driving), Mrs. C and Mr. D (their son had abandoned his car and was found in someone else's } \\
\text { car), and Ms. E (she called for emergency assistance when her son was agitated and pacing in the street). } \\
\text { (p.381) }\end{array}$} \\
\hline Finding3 & \multicolumn{3}{|c|}{$\begin{array}{l}\text { Some family members reported initiating psychiatric evaluation when the patients' delusions began to } \\
\qquad \text { incorporate the family members themselves. }\end{array}$} \\
\hline Illustration & \multicolumn{3}{|c|}{$\begin{array}{l}\text { Almost } 4 \text { months prior to his daughter's admission, Mr. B first noticed that something was wrong. He } \\
\text { described that she became "obsessed" with death, worrying that she and other family members were } \\
\qquad \text { dead. (p.378) } \\
\text { Mrs. F reported that she had noticed him staying to himself and occasionally sitting in the dark? He was } \\
\text { diagnosed with depression? His social withdrawal and paranoid thoughts gradually increased until the time } \\
\text { of admission, when he was even becoming paranoid of his mother. (p.379) }\end{array}$} \\
\hline Finding4 & \multicolumn{3}{|c|}{$\begin{array}{l}\text { Unrelated events led to initial psychiatric contact for one parent. The main factors leading to the delay } \\
\text { appeared to be lack of insurance and lack of knowledge about available resources. }\end{array}$} \\
\hline Illustration & \multicolumn{3}{|c|}{$\begin{array}{l}\text { Ms. A stated that she had wanted to [seek help] from the beginning of his paranoia, but that they had no } \\
\text { insurance, and she thought that they needed insurance to obtain evaluation. Additionally, they had moved }\end{array}$} \\
\hline
\end{tabular}




\begin{tabular}{|c|c|}
\hline & $\begin{array}{l}\text { around the time of the patient's first signs of paranoia and she did not know about the available facilities in } \\
\text { the new city. Due to her loss of employment and lack of income, Ms. A reports that her electricity was } \\
\text { about to be turned off. When she called the electric company to discuss this, they mentioned that she } \\
\text { could get a 30- day extension if someone in the home has a disability. Ms. A states that this was a "selfish } \\
\text { reason" to seek evaluation, but that she was worried about her son and herself if the electricity was turned } \\
\text { off. (p.376) }\end{array}$ \\
\hline Finding5 & $\begin{array}{l}\text { Concern about effect of medications and racial discrimination was reported by one parent [as impacting } \\
\qquad \text { upon their decision to seek help]. }\end{array}$ \\
\hline Illustration & $\begin{array}{l}\text { The clinicians wanted to admit him for further evaluation, but his mother did not want him to be given drugs } \\
\text { that would "just cover up the problem" and "make him a zombie". He was discharged with a prescription, } \\
\text { which was not filled. "To be honest, when I called I prayed for Black officers, because I knew that they } \\
\text { would be more understanding and caring". The first officer to arrive was Caucasian, and he was, in fact, } \\
\text { perceived as quite uncaring (the police officer didn't want to take the patient to the hospital). Soon } \\
\text { thereafter, additional officers arrived and the patient was taken to the hospital by one of the African } \\
\text { American police officers. (p.378-379) }\end{array}$ \\
\hline Finding6 & $\begin{array}{l}\text { Issues related to insurance coverage and the health care system emerged [as impacting upon family } \\
\qquad \text { members' decision to seek help]. }\end{array}$ \\
\hline Illustration & $\begin{array}{l}\text { Ms. A stated that she had wanted to do so from the beginning of his paranoia, but that they had no } \\
\text { insurance, and she thought that they needed insurance to obtain evaluation. Additionally, they had moved } \\
\text { around the time of the patient's first signs of paranoia and she did not know about the available facilities in } \\
\text { the new city. (p.376) }\end{array}$ \\
\hline Finding 7 & $\begin{array}{l}\text { Several parents attributed developing psychotic symptoms to depression, lack of motivation or stress } \\
\text { related to interpersonal relationships that could account for delays in help-seeking. }\end{array}$ \\
\hline Illustration & $\begin{array}{l}\text { Ms. A viewed her son's evolving negative symptoms as depression, and Mrs. F's son was diagnosed with } \\
\text { depression when she initially took him to see a primary care physician. Mrs. F and Mr. G attributed their } \\
\text { son's problems to difficulty getting over a failed relationship, and Ms. H attributed her son's problems to } \\
\text { not grieving after a friend's death. (p.380) }\end{array}$ \\
\hline
\end{tabular}

\begin{tabular}{|l|l|l|l|}
\hline Corcoran et al. & 2007 & Trajectory to a first episode of psychosis: a qualitative research study with families & USA \\
\hline
\end{tabular}

\begin{tabular}{|l|r|}
\hline Finding1 & $\begin{array}{r}\text { Family members attributed behavioural changes to a number of causes, including the onset of } \\
\text { adolescence, stress or drugs. }\end{array}$ \\
\hline Illustration & $\begin{array}{r}\text { "A 16-year-old who is grumpy and doesn't want to talk to his mother", seemed to one mother like typical } \\
\text { teen behaviour. Another parent suspected it was "probably a change of age, from a little boy to a } \\
\text { teenager". Another relative recalled, "I didn't know whether it was her age. I mean, she was rebellious and } \\
\text { she didn't like school as much". (p.312) }\end{array}$ \\
\hline
\end{tabular}




\begin{tabular}{|c|c|}
\hline & $\begin{array}{l}\text { Many relatives cited the stress of school and its many transitions. A few parents suspected drugs or } \\
\text { alcohol: "In the club maybe, maybe she drink something", "[He] got involved with different people ... not } \\
\text { healthy people ... late parties, they talk a lot of funny things, some into drugs", "I thought he was on } \\
\text { drugs". (p.312) }\end{array}$ \\
\hline Finding2 & $\begin{array}{l}\text { Family members described a slow change in behaviour and mood in patients as they entered the teen } \\
\text { years, including social withdrawal, decline in function, and developing symptoms of depression and } \\
\text { irritability. }\end{array}$ \\
\hline Illustration & $\begin{array}{l}\text { One mother described her daughter as less talkative than previously: "she really wasn't going out } \\
\text { anymore", which contributed to a new "inability to keep a friendship". (p.311) } \\
\text { One student slept all day, and refused to go to work or class. Another became "very slow" at school and } \\
\text { his grades dropped. A family described forcing their son to leave their house and go to school: he had } \\
\text { become depressed and had lost interest in most activities, including playing sports. (p.311) } \\
\text { "There was obviously something not right with him. When he came home he ate like a barbarian and it } \\
\text { was almost like he was protecting his food ... he was fighting with his friends and everything, he would } \\
\text { call up on the phone and there would be hour-long harangues about what bad parents we were and what } \\
\text { a horrible family we had". (p.311) }\end{array}$ \\
\hline Finding3 & $\begin{array}{l}\text { Attributing behavioural changes to the onset of adolescence, stress or drugs influenced families' strategies } \\
\text { for coping. This included prayer and religion, and the use of reasoning and persuasion with the young } \\
\text { individual. }\end{array}$ \\
\hline Illustration & $\begin{array}{l}\text { One woman prayed to understand why her son had become like a stranger, and to gain understanding as } \\
\text { to how she could help him. Another mother sent her daughter to a church retreat, and tried to push her to } \\
\text { find a job. The elder brother of one patient remembers, "I told him to go get a job and don't sleep too much } \\
\text {.. He was just taking his sweet time finding a job and I remember screaming at him sometimes". (p.312) } \\
\text { An African-American woman tried to reason with her daughter who had begun to hear voices: "The } \\
\text { windows are closed. How are you going to hear somebody talking about you outside?" She sought help } \\
\text { from a priest for blessings and holy water, and tried saying prayers to "see if we could help her ourselves". } \\
\text { The priest urged her to seek psychiatric care for her daughter. (p.312) } \\
\text { One girl started to believe that people were talking about her on the train and in her neighbourhood, and } \\
\text { her mother advised her to simply ignore them. (p.312) }\end{array}$ \\
\hline Finding4 & $\begin{array}{l}\text { Family members consistently reported that after consulting with a network of relatives, friends and } \\
\text { religious leaders, they sought psychiatric help only as a last resort or at the insistence or recommendation } \\
\text { of others in their social network. }\end{array}$ \\
\hline Illustration & $\begin{array}{l}\text { "My friend tells me my son is very upset. I brought him to the hospital". "I go to my friend who told me, } \\
\text { 'take her to the clinic". "The priest said we should take her to see a psychiatrist". (p.312) }\end{array}$ \\
\hline Finding5 & $\begin{array}{l}\text { Family members reported seeking help from mental health professionals when behaviours became more } \\
\qquad \text { alarming, frequently in the context of overt psychotic symptoms. }\end{array}$ \\
\hline Illustration & $\begin{array}{l}\text { For six patients, either yelling at family members or reports of hearing voices were what prompted family } \\
\qquad \text { members to seek help. (p.312) }\end{array}$ \\
\hline
\end{tabular}




\begin{tabular}{|c|c|}
\hline Finding6 & $\begin{array}{l}\text { Families focused on the many problems and frustrations they encountered in seeking help for their family } \\
\text { members in crisis. [These included difficulties getting their relative to seek help as well as difficulties } \\
\text { encountered with services.] }\end{array}$ \\
\hline Illustration & $\begin{array}{l}\text { Three describe protracted efforts to schedule appointments with mental health professionals. (p.312) } \\
\text { Four could not persuade their symptomatic children to attend appointments, as they were ambivalent or } \\
\text { hostile to their efforts to seek help. Consequently, treatment often began with emergency services and } \\
\text { inpatient hospitalization, which four family members described explicitly as "traumatic". (p.312) } \\
\text { Three family members described inpatient psychiatrists as insensitive or unavailable, providing little } \\
\text { information. (p.312) }\end{array}$ \\
\hline Finding7 & Some families interviewed endorsed greatly diminished expectations for the future. \\
\hline Illustration & $\begin{array}{l}\text { One family member felt "it is all over". One parent wondered if her son could ever get married and have } \\
\text { children, and another mother worried what would happen to her child when she eventually died. (p.312- } \\
313 \text { ) }\end{array}$ \\
\hline Finding8 & Stigma was a major concern. \\
\hline Illustration & $\begin{array}{l}\text { One parent worried her other children would be teased now because of their brother, and would eventually } \\
\text { be afraid to have children. Another mother thought her mentally ill son would be treated like a rapist. Yet, } \\
\text { another mother said: "The S word- schizophrenia. I'm going to deal with it for the rest of my life". (p.313) }\end{array}$ \\
\hline Finding9 & Some families had guarded hope. \\
\hline Illustration & $\begin{array}{l}\text { One [parent] hoped her child could be like others, talk to people, and go out with friends. Another parent } \\
\text { hoped her son could go to work and have a girlfriend. One mother still believed her son would get married } \\
\text { and have children. One father said "I just hope he can have a normal life". (p.313) }\end{array}$ \\
\hline
\end{tabular}

\begin{tabular}{|c|c|c|c|}
\hline $\begin{array}{c}\text { Czuchta et } \\
\text { al. }\end{array}$ & 2001 & Help-seeking for parents of individuals experiencing a first episode of & Canada \\
schizophrenia
\end{tabular}

\begin{tabular}{|c|c|}
\hline Finding1 & $\begin{array}{r}\text { Participants identified noticeable change(s) in their children, which intensified over time, and engaged in a } \\
\text { constant search for understanding the changes that were occurring. }\end{array}$ \\
\hline Illustration & $\begin{array}{c}\text { "He wasn't talking to the family, ahm, he was.. was more or less withdrawn. . he would not respond unless } \\
\text { he would ask the question. And, ah, on the street he wouldn't say 'hi' to his sisters, his sisters said hi to } \\
\text { him he would just stare. . he wouldn't say hello when he came home and would just sort of glare. I wasn't } \\
\text { sure if he was angry or just tired from work. I didn't I couldn't understand or read his gestures". (p.166) }\end{array}$ \\
\hline Finding2 & $\begin{array}{c}\text { Continuous help-seeking was described by all participants which at times involved persuading both their } \\
\text { children and convincing health care professionals that their child was in need of help. }\end{array}$ \\
\hline Illustration & $\begin{array}{c}\text { One parent described trying to convince health care professionals for over } 1 \text { year that her son needed help } \\
\text { for his psychiatric illness. After a number of attempts to get help, she recalled an incident where her son }\end{array}$ \\
\hline
\end{tabular}




\begin{tabular}{|c|c|}
\hline & $\begin{array}{l}\text { was found by a girl along the side of a road after being missing in the woods for } 11 \text { days. The police } \\
\text { brought her son to the emergency department so that he could be physically stabilized. After he was } \\
\text { physically stable the staff were about to discharge him, which greatly concerned his parents. (p.167) }\end{array}$ \\
\hline Finding3 & $\begin{array}{l}\text { Continuous help-seeking is characterized by the following subthemes: (1) identifying the need to seek } \\
\text { help, (2) persuading their children to seek help, (3) seeking help from community supports, (4) seeking } \\
\text { help from health care professionals, (5) urgency to seek help marked by a critical incident/worsening of } \\
\text { symptoms leading to hospitalization. }\end{array}$ \\
\hline Illustration & No data to support several of the subthemes. \\
\hline Finding4 & The help-seeking experience had a definite impact on all of the parents. \\
\hline Illustration & $\begin{array}{l}\text { "I think I broke down and cried, but I tried to keep the tears in because they all wanted to know, so what } \\
\text { happened? My daughter and [my husband were] home; and I find I just couldn't talk. I said, 'They kept him } \\
\text { in'. I felt. . I wanted to get help from him-for him, have. . . him kept there at the same time I wanted them to } \\
\text { say, 'you're okay, go home', you know, 'you're just depressed.' So when the reality hit that hey, he's really. } \\
\text {. sick, he needs to stay here, it really. . . it bothered me. It really bothered me. And it got worse when I } \\
\text { found out he was psychotic. The doctors were saying he was hearing voices and getting messages from } \\
\text { the TV and the radio. I thought, no!" (p.167) }\end{array}$ \\
\hline Finding5 & $\begin{array}{l}\text { The effect of the impact of help-seeking on parents is characterized by the following subthemes: (1) } \\
\text { disruption in the family, (2) illness recognition: need for understanding and support, (3) parental beliefs } \\
\text { associated with the illness, and (4) range of emotional responses to the help-seeking experience. }\end{array}$ \\
\hline Illustration & No data to support the first 3 subthemes. The fourth subtheme was supported by the illustration in Finding \\
\hline
\end{tabular}

\section{\begin{tabular}{|l|l|l|l|}
\hline Dodge & 2011 & Caregiving and Schizophrenia: The Well Siblings' Perspective & Canada \\
\hline
\end{tabular}}

\begin{tabular}{|c|c|}
\hline Finding1 & $\begin{array}{l}\text { From the prodromal phase until the time of their sibling's diagnosis of schizophrenia, most well siblings } \\
\text { were embracing their independence and were immersed in other things, such as schooling and work, as } \\
\text { the majority were in adolescence and early adulthood. }\end{array}$ \\
\hline Illustration & $\begin{array}{l}\text { "To be honest I was totally focused on my own life and didn't even have much of a relationship with Isaac } \\
\text { at that time (when the illness was emerging)". Similarly, when Chloe began to experience difficulties in her } \\
\text { work, Ethan recalled "I probably just didn't pay that much attention." In Sienna's case, she stated: "At that } \\
\text { age, I just sort of distanced myself from him, I didn't know how to take it. So I lived my life apart from him } \\
\text { and I really didn't want to have him a part of my life and I wasn't involved in his life at all". (p.59-60) }\end{array}$ \\
\hline Finding2 & Some [seven] well siblings reported incidents of violence involving their sibling. \\
\hline Illustration & $\begin{array}{l}\text { Carter, Sienna's ill brother, has had a couple of episodes of violence involving their father who he would } \\
\text { physically hit. Sienna explained: 'I'm his sister, so sisters' and brothers' fight, right? But when it comes to }\end{array}$ \\
\hline
\end{tabular}




\begin{tabular}{|c|c|}
\hline & $\begin{array}{l}\text { my dad, I can't see it. If I'm around it I get so angry I would blow up at him and then he (Carter) gets angry } \\
\qquad \text { at me". (p.65) }\end{array}$ \\
\hline Finding3 & $\begin{array}{l}\text { Violent episodes were traumatic for the well siblings and they had difficulty forgetting this dark period of } \\
\text { their relationship with the ill sibling. It also impacted upon the relationship between the well sibling and } \\
\text { parent. }\end{array}$ \\
\hline Illustration & $\begin{array}{l}\text { "I have talked to my parents about it and about the physical abuse stuff and my mom has distanced it quite } \\
\text { a bit on 'oh Joe was just sick.' She kind of has acknowledged it more that it was wrong now but he can be } \\
\text { sick and not be physically abusive. I think there's a difference. He was really angry and had probably really } \\
\text { felt a loss of control from feeling whatever he was due to the schizophrenia but there are different ways to } \\
\text { display anger and I think there's a reason why he hit me instead of, say, my brother or my sister or my } \\
\text { mom". (p.66) } \\
\text { A father stated: "I think she actually blames her mother and me to a greater extent for not offering better } \\
\text { protection against Joe (unwell sibling). There's a sort of feeling that it's really more our fault than it is } \\
\text { actually Joe's fault". (p.66) }\end{array}$ \\
\hline Finding4 & $\begin{array}{l}\text { Psychotic symptoms were the most distressing indicators for well siblings that their brother's or sister's } \\
\text { condition was worsening. }\end{array}$ \\
\hline Illustration & $\begin{array}{l}\text { Amy recalled how her brother Joe felt that a "Vietnamese gang [or ninjas] were going to come and kill him" } \\
\text { (Jen). Joe panicked and reacted by "stuffing pillows up the fireplace and locking all the doors and nailing } \\
\text { stuff like clothes [to the wall] to prevent them from coming in." Troy added: "he lodged the vacuum up in } \\
\text { the chimney and he was like literally that scared that he put a mattress against the window or whatever, } \\
\text { literally that scared that he felt like he had to do stuff like that." Tyler recounted a time when Isaac believed } \\
\text { that "people [were] coming into his room at night and taking spinal fluid from his back and tapping him." } \\
\text { Audrey confided that she thought there were "Nazi concentration camp trains and that people were being } \\
\text { put into them by her father and Central Intelligence Agency (CIA) paraphernalia installed in the family car } \\
\text { and the house was bugged and that her dad sexually abused and molested her". (p.68-69) }\end{array}$ \\
\hline Finding5 & $\begin{array}{l}\text { The period preceding the diagnosis was like a guessing game. Family members knew something was "off" } \\
\text { but first rationalized the disturbing behaviours. }\end{array}$ \\
\hline Illustration & $\begin{array}{l}\text { Corry and his family felt that Mike was battling depression. Amy speculated that Joe had "gotten into } \\
\text { drugs" Because he was around the age of } 18 \text { or } 19 \text { when teenagers usually experiment with these types of } \\
\text { things: "who knows like maybe he's having a bad acid trip... [He] could have partied too much. [We] had to } \\
\text { get him into rehab is what I thought". Troy also thought Joe was experimenting with mind-altering } \\
\text { substances, specifically alcohol. (p.70) }\end{array}$ \\
\hline Finding6 & $\begin{array}{l}\text { Problematic behaviours identified by well siblings included unusual sleeping habits and routines that } \\
\qquad \text { isolated them from the rest of the family. }\end{array}$ \\
\hline Illustration & $\begin{array}{l}\text { Many ill siblings withdrew socially to their bedrooms and would "stay up later" Even at "all hours of the } \\
\text { night" (Holden), while others were "really high" And "sleep all the time... [and] all day and watch TV all } \\
\text { night"(Sienna).(p.64) }\end{array}$ \\
\hline
\end{tabular}




\begin{tabular}{|c|c|}
\hline Finding7 & Families were often a part of the delusional system. \\
\hline Illustration & $\begin{array}{l}\text { One time Mike insisted that Corry not use the phones in their house because their "lives were in danger } \\
\text { and that they'll [the government] know and they'll find out and get them". (Corry) (p.69) } \\
\text { "When I look back on it, some of it was delusional but there was always such a grain of truth of what my } \\
\text { parents were like and what growing up in our house was like. So it didn't quite occur to me maybe that he } \\
\qquad \text { was having even more delusional thoughts than that". (p.70) }\end{array}$ \\
\hline Finding8 & $\begin{array}{l}\text { Siblings tried to conceal their brother or sisters abnormal behaviour from others, often employing } \\
\text { techniques of information control. }\end{array}$ \\
\hline Illustration & $\begin{array}{l}\text { They lied to others and try to hide the fact that their brother's or sister's mental health was progressively } \\
\text { deteriorating. They only shared this sensitive information with close friends and relatives. (p.64) }\end{array}$ \\
\hline Finding9 & $\begin{array}{l}\text { In the early stages siblings' Lacked an understanding of what was actually occurring though suspected } \\
\text { that something was "off', "wrong" or "just not right". }\end{array}$ \\
\hline Illustration & $\begin{array}{l}\text { Jen said she had an inkling Joe was "going a bit crazy but did not know it was schizophrenia at the time". } \\
\qquad \text { (p.62) }\end{array}$ \\
\hline Finding10 & Well siblings spoke of how their sibling began to act in unsettling ways and to behave abnormally. \\
\hline Illustration & $\begin{array}{l}\text { "I was kind of scared of her a little bit. She was always aggressive. I really didn't like the fighting. I'm more } \\
\text { of a subdued, calm person so I didn't like to have conflict and when she always did get angry, she always } \\
\text { had to have some kind of issue going on. When that happened, I always wanted to get away from that kind } \\
\text { of environment. I think that speaks to our relationship too". (p.62) }\end{array}$ \\
\hline Finding11 & $\begin{array}{l}\text { Most well siblings reported receiving phone calls on a regular basis from parents in a panic and clueless } \\
\qquad \text { as to what was happening to their child. }\end{array}$ \\
\hline Illustration & $\begin{array}{l}\text { Troy received numerous phone calls from his mother regarding Joe's early psychotic behaviours, such as } \\
\text { lodging a vacuum cleaner up the chimney and putting mattresses up against the windows. (p.61) }\end{array}$ \\
\hline Finding12 & $\begin{array}{l}\text { Parents were the ones who primarily noticed the initial changes to their child. They became concerned and } \\
\text { apprehensive for their child's well-being, relaying this news to their other well children. In a few cases, } \\
\text { close friends of the family became concerned. }\end{array}$ \\
\hline Illustration & $\begin{array}{l}\text { "Either your brother is really trying to freak me out or there's something wrong with him and he has some } \\
\text { kind of mental illness or something[s] happening". (as stated by a friend) (p.61) }\end{array}$ \\
\hline Finding13 & $\begin{array}{l}\text { Most of the well siblings were seldom around their brother or sister. As a result, they did not encounter } \\
\text { first-hand the early indicators of the illness. }\end{array}$ \\
\hline Illustration & $\begin{array}{l}\text { "I think from what I heard (from my parents)...cause I wasn't around I was at university from } 18 \text { and that's } \\
\text { kind of really (when it) started and Joe was around } 14 \text { and that was when it got progressively worse. The } \\
\text { whole time things were really bad at home, I wasn't here to experience it at all". }\end{array}$ \\
\hline
\end{tabular}




\begin{tabular}{|c|c|}
\hline & $\begin{array}{l}\text { Others expressed similar remarks. When Holden came home from university to visit during holidays, his } \\
\text { parents cautioned him that "Audrey is being very temperamental".(p.60) }\end{array}$ \\
\hline Finding14 & $\begin{array}{l}\text { If well siblings were less involved than their parents, they were still integral to the process of seeking } \\
\text { professional help. }\end{array}$ \\
\hline Illustration & $\begin{array}{l}\text { "Worried", Amy asked her mother if she should fly home but her mother said "they had everything pretty } \\
\text { much under control". (p.75) }\end{array}$ \\
\hline Finding15 & Parents, especially mothers, were generally more active in the hospitalization of their loved one. \\
\hline Illustration & $\begin{array}{l}\text { "I felt my parents were the ones that needed to deal with it, not me, and that I could talk to them and say } \\
\text { 'you can't just ignore this.' So I felt that at least there was something to deal with that they could then } \\
\text { pursue and they did... My participation was more involved with crisis and what to do with Isaac. I } \\
\text { remember having a couple of family meetings where we were trying to figure out whether he should live at } \\
\text { home and whether he should move out or what should happen cause there was still, I guess, a concern } \\
\text { that we were maybe overreacting, and that there really wasn't a big problem". (p.75) }\end{array}$ \\
\hline Finding16 & $\begin{array}{l}\text { A few well siblings normalized their sibling's personality and behavioural changes and reasoned these } \\
\text { changes might be typical of individuals at the stage of the life course. }\end{array}$ \\
\hline Illustration & $\begin{array}{l}\text { Holden reasoned that Audrey's outbursts were typical for a female teenager to "act up" And have "temper } \\
\text { tantrums." "Well, then I talked to him and I was thinking, well, it's cause he always had these weird ideas } \\
\text { about the world and was asking all these questions about the universe and I was thinking this is maybe } \\
\text { normal". (p.71) }\end{array}$ \\
\hline Finding17 & $\begin{array}{l}\text { In two cases, there were family histories of mental illness and the well siblings' Fathers were aware of the } \\
\text { symptoms of schizophrenia because of their medical profession as doctors. However, they were still } \\
\text { reluctant to admit there was a problem and postponed dealing with it. }\end{array}$ \\
\hline Illustration & $\begin{array}{l}\text { "Well my mom was trying to convince my dad that something needed to be done because I think my dad } \\
\text { was in denial about it for quite a while. But I remember my mom just kind of being really frantic about } \\
\text { wanting him to get help and that, because my dad's a doctor, he has kind of the resources. [He] knows } \\
\text { obviously what he can do about it. So I remember it being a struggle for my mom to get my dad to admit } \\
\text { that there was something wrong with Joe". (Jen) (p.72) } \\
\text { "The schizophrenia option was on the table for a couple of years, and it was not concluded upon for quite } \\
\text { a long time, and my mom blames my dad a lot for that because he held back some pretty important } \\
\text { information about his family. Like his mom, of course, we all know is psychotic, but his grandfather was in } \\
\text { an institution his whole life with schizophrenia. So he didn't disclose this information initially, which } \\
\text { probably would have been helpful. So my mom was a little upset when the final diagnosis was concluded. } \\
\text { You know like 'hello' you could have told us this a couple years ago". (Amy) (p.72) }\end{array}$ \\
\hline Finding18 & $\begin{array}{l}\text { The most turbulent and emotionally disruptive time for the well siblings was when families sought } \\
\qquad \text { professional help. }\end{array}$ \\
\hline Illustration & Corry gave an insightful description of his thoughts and emotions when he saw Mike in "full-fledged \\
\hline
\end{tabular}




\begin{tabular}{|c|c|}
\hline & $\begin{array}{l}\text { psychosis": "I think I was probably paralyzed between complete fear, adrenaline rush to solve problems, } \\
\text { total sadness like imagine that your mom died or something like that just all these things". Corry compared } \\
\text { his extent of sadness when Mike was acutely ill to the mourning process of a death in the family. (p.74) }\end{array}$ \\
\hline Finding19 & $\begin{array}{l}\text { The ill sibling began to regress in social skills. This type of behaviour was embarrassing, confusing, and } \\
\text { intensely stressful for well siblings. }\end{array}$ \\
\hline Illustration & $\begin{array}{l}\text { Holden described how they had to "walk on eggshells" around Audrey to make sure she did not "snap "or } \\
\text { "just randomly yell at someone or freak out if they touched her or even gazed at her in passing." (p.63) }\end{array}$ \\
\hline Finding20 & $\begin{array}{l}\text { Abnormal behaviour (on the part of the unwell sibling) made it difficult for well siblings to maintain a } \\
\text { positive and affectionate relationship with their brother or sister. }\end{array}$ \\
\hline Illustration & $\begin{array}{l}\text { Well siblings reported being treated harshly, rejected, and put down, even threatened, by their ill sibling. } \\
\text { They were "fed up" and tired of the treatment their loved one put them and their parents through. (p.62) }\end{array}$ \\
\hline Finding21 & $\begin{array}{l}\text { Some siblings were more involved in having their brother or sister admitted to the hospital. This } \\
\text { involvement consisted mostly of being part of some type of deception to bring the ill relative to the hospital. }\end{array}$ \\
\hline Illustration & $\begin{array}{l}\text { Holden recalled when his family decided to hospitalize Audrey: "eventually one day my mom said we have } \\
\text { to do this. So, we kind of lied to her and said we were going to a doctor and all got in the car with her and } \\
\text { my cousin was there as well to help restrain her if need be and we grabbed her and involuntarily } \\
\text { committed her". (p.76) }\end{array}$ \\
\hline Finding22 & $\begin{array}{l}\text { When the family was unable to manage the situation themselves. Police and paramedics were contacted } \\
\text { to facilitate the process (of getting help). }\end{array}$ \\
\hline Illustration & $\begin{array}{l}\text { "My mom started talking to North Shore Mental Health describing what was going on and they were } \\
\text { planning on having a meeting with Mike and they wanted Mike to see doctors to get [him] committed and I } \\
\text { remember because he wouldn't admit that he was sick. We were trying to get him to see the first doctor } \\
\text { and told Mike 'you don't look healthy, you're getting really thin, [and] you are losing weight.' Something to } \\
\text { get him in to get it started so that was starting to happen... I was like 'shit' and I didn't know what } \\
\text { schizophrenia was but the word popped into my mind. I went downstairs and told my mom and I'm like } \\
\text { 'mom Mike's got schizophrenia.' She was calm actually she was like 'ok'. She left the house I think to } \\
\text { scream and went down the street, or something like that and then what happened...then I was at UBC } \\
\text { doing some course- an education course- and I had my phone with me because we were trying to get him } \\
\text { to the doctor. We were worried about him running away. This all happened in the same week... I got this } \\
\text { call at UBC that the police had come and I was like 'oh shit' So I ran home and I didn't have a car then. I } \\
\text { grabbed a cab and was just like 'go as fast as you can, this is an emergency.' I remember coming down in } \\
\text { the cab to this cul-de-sac where there was two police cars and an ambulance parked in front of my house. } \\
\text { Stopped and the cab driver said like 'oh my god what's going on?' I just gave him forty bucks or something } \\
\text { like that and got out of the car and he turned around and Mike was just coming up the driveway with the, I } \\
\text { guess, RCMP or whatever, and then he got into the ambulance and then I actually cried from the other } \\
\text { side of the police car where he couldn't see me. I was so devastated at seeing this happening and so that } \\
\text { was Mike getting schizophrenia". (p.76) }\end{array}$ \\
\hline
\end{tabular}




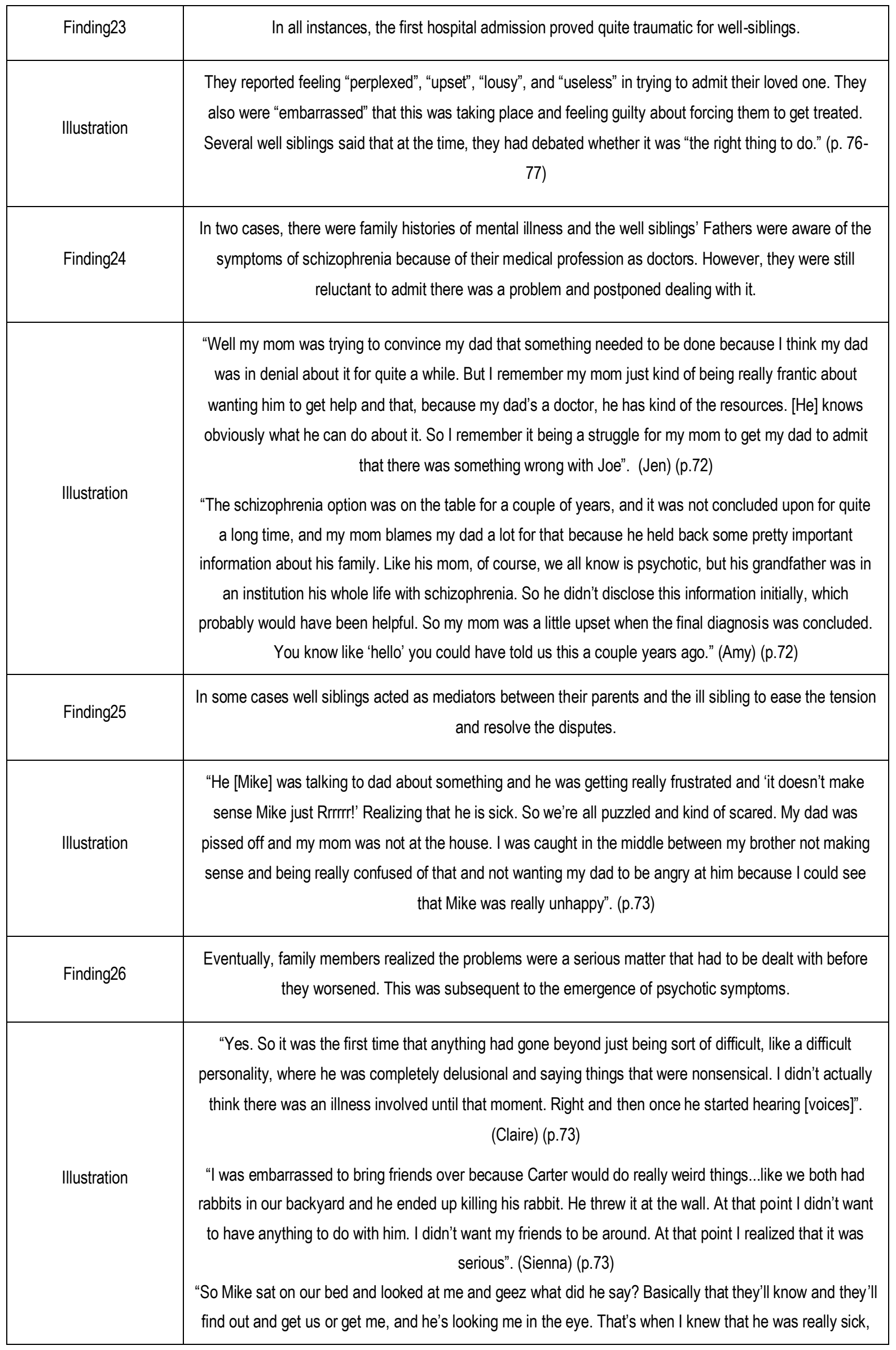




\begin{tabular}{|l|c|}
\hline Finding27 & \multicolumn{1}{c|}{ like seriously sick". (Corry) (p.73) } \\
\hline Illustration & $\begin{array}{r}\text { Some parents were in denial and refused to believe that their child was sick, justifying it as normal teenage } \\
\text { behaviour. Siblings tried to influence their parents' Recognition of the severity of the problem. }\end{array}$ \\
\hline $\begin{array}{c}\text { "Now, my parents were obviously not quite eager to embrace this idea but, given my own family history, } \\
\text { they knew that they [had] some experience with mental illness. My dad is a doctor, for one thing, and so } \\
\text { he is a scientifically orientated guy and his own mother was very seriously ill. He had his own breakdown. } \\
\text { It wasn't as if there was no experience. There was some denial but then we did convince them that it was } \\
\text { nottle deeper, you'd realize there were these things going on that he was really troubled by". (Tyler) (p. 71- } \\
72)\end{array}$ \\
\hline
\end{tabular}

\begin{tabular}{|l|l|l|l|l|}
\hline Donnelly & 2005 & $\begin{array}{l}\text { Mental health beliefs and help seeking behaviors of Korean American parents of adult } \\
\text { USA }\end{array}$ \\
\hline
\end{tabular} children with schizophrenia

\begin{tabular}{|c|c|}
\hline Finding1 & $\begin{array}{l}\text { Each parent had sought treatment through folk methods such as the Chinese Dispensary for tonic } \\
\text { medicine to energize, an acupuncturist to balance Chi (Qi) energy (cosmic life force), and KA ministers to } \\
\text { get rid of the Devil through prayer. }\end{array}$ \\
\hline Illustration & $\begin{array}{l}\text { Sheryl: "I searched for a healer and a place to treat my daughter. I took Sandra to the Church to pray for } \\
\text { cure diligently. Eventually, Sandra packed her stuff and went to live in that church. I let her do that in } \\
\text { desperation. But it didn't work". (p.27) } \\
\text { Carol: "When my son said 'I am not his mother' I thought that Satan entered his body and was speaking to } \\
\text { me instead of him. That is why he was disturbed and being shaken". (p.27) } \\
\text { Tricia: "The same devil who tortured my husband was torturing my son again. I took him to the minister to } \\
\text { chase away the Devil, but nothing helped him". (p.27) } \\
\text { Jincy: "He looked weak and had no energy. I took him to an acupuncturist to balance his Chi and to the } \\
\text { Catholic Church to pray, but nothing worked". (p.28) }\end{array}$ \\
\hline Finding2 & $\begin{array}{l}\text { When traditional healing methods didn't stabilize their children's psychotic behaviours, the participants in } \\
\text { the study were faced with a crisis. At this turning point, the parents began to realize the seriousness of } \\
\text { their children's illness. They recognized the need to expand their help seeking. }\end{array}$ \\
\hline Illustration & $\begin{array}{l}\text { Nancy: "The minister came to my house to pray for her and I prayed for two years. She also received } \\
\text { acupuncture combined with tonic medication. But her symptom didn't improve at all. After I found a knife } \\
\text { under her bed to kill herself I contacted the AMHC for a help through the Korean Newspaper".(p.28) }\end{array}$ \\
\hline Finding3 & Guilt, shame, and the need for secrecy shadowed the participants. \\
\hline Illustration & $\begin{array}{l}\text { Sheryl: "We preferred to live away from the Korean community to avoid the felt stigma". (p.29) } \\
\text { Tricia: "Phil's mental disorder may affect my younger son's marriage negatively". (p.30) }\end{array}$ \\
\hline
\end{tabular}




\begin{tabular}{|c|c|}
\hline Findong4 & \multicolumn{1}{|c|}{ Participants believed themselves culpable for their children's schizophrenia. } \\
\hline Illustration & $\begin{array}{c}\text { They assumed poor parenting and strong demands regarding study habits as causes of the illness. Some } \\
\text { parents questioned what they had done wrong to have a child with schizophrenia. Since a genetic basis of } \\
\text { schizophrenia implied an ancestral connection, the parents either blamed themselves or acts of Satan. } \\
\text { p.29 }\end{array}$ \\
$\begin{array}{c}\text { Evelyn: "I was ashamed, my son is not capable to assume any responsibilities and function in this society. } \\
\text { Our family line could not be continued because of his illness. God punished us leaving my ancestors. We } \\
\text { should have never left homeland". P.30 }\end{array}$ \\
\end{tabular}

\section{\begin{tabular}{|l|l|l|l|l|}
\hline Franz et al. & 2010 & Stigma and treatment delay in first-episode psychosis: A grounded theory study & USA \\
\hline
\end{tabular}}

\begin{tabular}{|c|c|}
\hline Finding1 & $\begin{array}{l}\text { Participants' perceptions of society's reaction to the behaviour of their increasingly ill family member were } \\
\qquad \text { noted to be extremely negative. }\end{array}$ \\
\hline Illustration & $\begin{array}{l}\text { "Oooh they don't look at 'em good. They think they're a joke. l've seen people laugh at folks and, ya know, } \\
\text { make comments and stuff, but society does not have a clue or understand what's going on". (p.4) } \\
\text { "They make a joke of them and laugh at them. They don't give them treatment, they just want to stand } \\
\text { there and laugh at them if they do something funny". (p.4) }\end{array}$ \\
\hline Finding2 & $\begin{array}{l}\text { The behaviour of the individual, even before a diagnosis was given, was sufficient to initiate the labelling } \\
\text { process, and link the individual to undesirable societal stereotypes. }\end{array}$ \\
\hline Illustration & $\begin{array}{l}\text { "You know, laypeople, if they think someone has a mental illness they're gonna just label them as crazy". } \\
\qquad(\text { p.4) }\end{array}$ \\
\hline Finding3 & $\begin{array}{l}\text { Participants perceived that the initiation of treatment appeared to be a path by which society would label } \\
\qquad \text { an individual. }\end{array}$ \\
\hline Illustration & $\begin{array}{l}\text { "I think when people have a diagnosis of schizophrenia or whatever, they automatically think, 'He's just } \\
\text { gonna do something outrageous'". (p.5) }\end{array}$ \\
\hline Finding4 & $\begin{array}{l}\text { Family members perceived that society reacts to an individual with a mental illness by displaying a distinct } \\
\text { preference for social distance. }\end{array}$ \\
\hline Illustration & $\begin{array}{l}\text { "They look at them in a different way, ya know. They see something wrong with them. They look at them } \\
\text { strange. They don't seem like they want to be around them". (p.5) }\end{array}$ \\
\hline Finding5 & $\begin{array}{l}\text { Family members highlighted the fact that their own perspectives differed vastly from those held by society, } \\
\text { possibly due to their proximity, both physically and emotionally, to the individual with the emerging illness. }\end{array}$ \\
\hline Illustration & $\begin{array}{l}\text { "Unless they've dealt with it personally, they think that the person is just crazy and needs to get some help, } \\
\text { or they think, 'Don't fool with them because they are crazy.' They don't treat them nice, or they don't, ya } \\
\text { know, they're not as nice to them as family members who understand what they're going through. I didn't }\end{array}$ \\
\hline
\end{tabular}




\begin{tabular}{|c|c|}
\hline & like it because that's my brother, ya know; don't treat him like that". (p.5) \\
\hline Finding6 & $\begin{array}{l}\text { Family members' responses to the behaviour of their loved ones experiencing early psychosis was in } \\
\text { general, not as negative as society's reactions as perceived by participants. }\end{array}$ \\
\hline Illustration & $\begin{array}{l}\text { "I feel sorry for them, um, you can't really go into their mind and see what happened. All of a sudden it just } \\
\text { happens. It could have happened to me - normal, and then the next day I just lose my mind". (p.5) } \\
\text { "I just can only imagine, ya know, being in that situation. I was telling my mom the other day, 'You don't } \\
\text { know unless you're walking in that person's shoes"'. (p.5) }\end{array}$ \\
\hline Finding7 & Some families' beliefs about mental illnesses was that of empathy and compassion. \\
\hline Illustration & $\begin{array}{l}\text { "I feel compassion for 'em; I really do. And I do believe there are issues in their mind. They are big, they } \\
\text { are issues, they are issues for them. Ya know, to them it is real, and I don't think any less of them. And } \\
\text { your heart kinda goes out to them. You just want them to not feel the way they feel." (p.5) }\end{array}$ \\
\hline Finding8 & $\begin{array}{l}\text { Some families had the perception that some behaviours demonstrated by the individual were under his or } \\
\qquad \text { her control. A sense of blame was elicited. }\end{array}$ \\
\hline Illustration & $\begin{array}{l}\text { "I was seeing it as being lazy. I would say, 'You don't want to do anything. You started school and then } \\
\text { you stopped going, and you had a job.' And I was thinking it was just him being lazy and not wanting to do } \\
\text { anything". (p.5) }\end{array}$ \\
\hline Finding9 & $\begin{array}{l}\text { Some families had the perception that some behaviours demonstrated by the individual were under his or } \\
\qquad \text { her control. A sense of blame was elicited. }\end{array}$ \\
\hline Illustration & $\begin{array}{l}\text { "I was seeing it as being lazy. I would say, 'You don't want to do anything. You started school and then } \\
\text { you stopped going, and you had a job'. And I was thinking it was just him being lazy and not wanting to do } \\
\text { anything". (p.5) }\end{array}$ \\
\hline Finding10 & Some participants felt that their loved ones carried no responsibility for their condition. \\
\hline Illustration & $\begin{array}{l}\text { "It's not their fault. It's just something that, I guess, they go through or, like they say, it's through genetics, } \\
\text { or maybe just something that's happened throughout their lives to where they just break down". (p.5) }\end{array}$ \\
\hline Finding11 & $\begin{array}{l}\text { Participants' refrained from labelling their relatives as having a mental illness, and acknowledged that a } \\
\text { formal diagnosis would result in an official label, associated with negative stereotypes. }\end{array}$ \\
\hline Illustration & $\begin{array}{l}\text { "I guess they think they're different, but they're not. They're people too. They just got some kind of dis - } \\
\qquad \text { um, no not disease - but some kind of problem". (p.6) } \\
\text { "I didn't want him to think that, ya know, we were trying to tell him that he was crazy or something like } \\
\text { that, but just that he needed to talk to someone who could probably explain to him better than I could what } \\
\text { he was experiencing".(p.6) }\end{array}$ \\
\hline Finding12 & $\begin{array}{l}\text { Participants were aware of the seemingly permanent nature of the stigma associated with the official label } \\
\text { of a mental illness. }\end{array}$ \\
\hline
\end{tabular}




\begin{tabular}{|c|c|}
\hline Illustration & $\begin{array}{l}\text { "Stigma to me is something big as far as like it is just embedded in you. You know, it's engraved with } \\
\text { something permanent almost. It just traumatizes you". (p.6) }\end{array}$ \\
\hline Finding13 & $\begin{array}{l}\text { Participants felt a distinct sense of discomfort acknowledging that their relatives suffered from a mental } \\
\text { illness, and were more at ease attributing their behaviours to external factors. }\end{array}$ \\
\hline Illustration & $\begin{array}{l}\text { "All I could think of was that it was due to the head injury because he had said to me a couple of months } \\
\text { before that, 'Mom l'm going crazy in this house.' I'm not satisfied with the diagnosis that he got, um, } \\
\text { psychosis schizophrenia. I don't think that's the problem that he has. Um, I think it's more of, ya know, } \\
\text { head injury, and I don't think schizophrenia comes from a head injury". (p.6) }\end{array}$ \\
\hline Finding14 & $\begin{array}{l}\text { In order to protect their loved one from harm, participants reported that they would warn those who came } \\
\text { into contact with the individual that he or she could behave in bizarre ways, thereby mitigating the impact } \\
\text { of the patient's behaviour. }\end{array}$ \\
\hline Illustration & $\begin{array}{l}\text { "I didn't mind that they knew because by him just walking off and talking to people they might, ya know, } \\
\text { hurt him if they don't know how he is. I would rather them be aware because he might say something and, } \\
\text { ya know, some people can jump off the handle, thinking it's intentional". (p.6) }\end{array}$ \\
\hline Finding15 & $\begin{array}{l}\text { Family members reported that secrecy would protect them and their loved ones from the negative } \\
\qquad \text { reactions of others. }\end{array}$ \\
\hline Illustration & $\begin{array}{l}\text { "You really don't want anyone to know because no one wants to be looked at in a different way, as } \\
\text { abnormal. You know, something's wrong with that person. Sometimes it's just overwhelming, dealing with } \\
\text { them differently". (p.6) }\end{array}$ \\
\hline Finding16 & Denial was adopted as a means of coping. \\
\hline Illustration & $\begin{array}{l}\text { "There was nothing I could really do to try to make him come together, so I kinda ignored it completely. I } \\
\text { just forgot about it". (p.6) }\end{array}$ \\
\hline Finding17 & $\begin{array}{l}\text { Participants described a high threshold [for the initiation of treatment], for example, their family members } \\
\text { were only brought into care following confrontation with the police for violent or suicidal behaviour. }\end{array}$ \\
\hline Illustration & $\begin{array}{l}\text { "I knew she had to hit rock bottom to open up her eyes to some changes that needed to be made. I felt like } \\
\text { something was gonna give. I think it just takes something very negative to open up your eyes". (p.7) } \\
\text { "I didn't pay attention, you know, I said, 'Well, maybe he'll be alright.' But he wasn't. When the accident } \\
\text { happened - ya know, what happened with his little brother and stuff - he was acting up, talking crazy in the } \\
\text { parking lot, saying, 'Mom, I'm not gonna let nobody hurt you.' He was thinking his brother was trying to } \\
\text { hurt me, but his brother wasn't. He was choking his brother like this and he was so heavy, ya know. I tried } \\
\text { to get him off of him. It was just awful". (p.7) }\end{array}$ \\
\hline Finding18 & $\begin{array}{l}\text { Once the patient demonstrated violent or suicidal behaviour, the coping mechanisms of the family seemed } \\
\text { to be overwhelmed, and treatment was initiated. }\end{array}$ \\
\hline Illustration & "I hate to say it, but that's the only thing that helped him - when he came up with that gun". (p.7) \\
\hline
\end{tabular}




\section{\begin{tabular}{|l|l|l|l} 
Gerson et al. & 2009 & Families' experience with seeking treatment for recent-onset psychosis & USA \\
\hline
\end{tabular}}

\begin{tabular}{|c|c|}
\hline Finding1 & $\begin{array}{l}\text { Although families recognized the importance of protecting the privacy and autonomy of their ill family } \\
\text { member, they nonetheless expressed frustration with feeling kept in the dark. }\end{array}$ \\
\hline Illustration & $\begin{array}{l}\text { As one mother said, "There's the issue of patient confidentiality, which is so important, but then there's the } \\
\text { issue of the parents out there, who have no clue as to what is happening with their child. You could be } \\
\text { walking around with a time bomb. ... I recognize the need from a therapy standpoint for there to be } \\
\text { exclusive keeping of confidentiality. On the other hand, is there not a way for families to be brought in } \\
\text { sooner?" (p.814) }\end{array}$ \\
\hline Finding2 & $\begin{array}{l}\text { For most patients the diagnosis of a psychotic disorder was made in the context of involuntary } \\
\text { hospitalization and was described by most as traumatic yet necessary. }\end{array}$ \\
\hline Illustration & $\begin{array}{l}\text { One mother reported: "I will not forget when the door shut and we had to leave him in the psychiatric ward. } \\
\text { It was a horrible feeling ... I was completely in shock ... . my older son immediately said, 'Oh, I should } \\
\text { have been a better brother."' (p.813) One teenage African-American girl locked herself in the bathroom, } \\
\text { threatening to hurt herself if anyone came in. Her family called } 911 \text {, and as her family described, "You } \\
\text { know it looked like } 100 \text { police was here. ... They had like a SWAT thing or whatever. They had all these } \\
\text { trucks and everything outside ... everybody was screaming and everything . . I I thought they might shoot } \\
\text { or something like that. Her sister was saying, 'Don't hurt my sister.' .... they broke the door down ... they } \\
\text { handcuffed her ... and she was [cry-ing], 'Why are you doing this to me?"' (p.813-814) }\end{array}$ \\
\hline Finding3 & Families grappled with the stigma of psychotic illness. \\
\hline Illustration & $\begin{array}{l}\text { As one mother said, "People tend to stigmatize people who are mentally ill ... I'm kind of ashamed, really, } \\
\text { to tell somebody". (p.814) }\end{array}$ \\
\hline Finding4 & $\begin{array}{l}\text { Families reported difficulty in finding outpatient doctors and struggles with third-party payers regarding } \\
\qquad \text { coverage. }\end{array}$ \\
\hline Illustration & $\begin{array}{l}\text { One mother explained, "The doctor that was supposed to take care of him, [the one] that they got, she } \\
\text { bailed out. She said she would treat him . . . and then she decided he was too sick. She does not want to } \\
\text { take care of him. So then I couldn't get anyone who takes his insurance". (p.814) } \\
\qquad \text { "I was told I had no more coverage". (p.814) } \\
\text { "It was clear that if I just went by my health insurance, it was going to be my son going to see someone for } \\
15 \text { minutes twice a month. And in that } 15 \text { minutes time she was supposed to be able to figure out how he } \\
\text { was doing". (p.814) }\end{array}$ \\
\hline Finding5 & Many families still held out hope. \\
\hline Illustration & $\begin{array}{l}\text { One family member said, "I want any parent who has to hear for the first time that their beloved son or } \\
\text { daughter is developing this illness ... [to know,] yes, they can become well". (p.814) }\end{array}$ \\
\hline
\end{tabular}




\begin{tabular}{|c|c|c|c|}
\hline Jung & 2000 & Lives of two Korean mothers of children with schizophrenia: An interpretive & Korea \\
approach
\end{tabular}

\begin{tabular}{|c|c|}
\hline Finding1 & Neither mother recognised her child's illness until obvious symptoms appeared. \\
\hline Illustration & $\begin{array}{l}\text { Before the mothers achieved some perspective on the illness, they perceived the child as a "confused } \\
\qquad \text { spirit" Or "lost soul". (p. 88) }\end{array}$ \\
\hline Finding2 & $\begin{array}{l}\text { These mothers related the concept of illness to the concept of punishment; for them to admit that their } \\
\text { child was suffering from a mental illness, because of the inherent implication, was not likely. }\end{array}$ \\
\hline Illustration & $\begin{array}{l}\text { After the mothers acquired a better perspective on the illness they termed it "gradual illness", "scary } \\
\text { illness", and "incurable illness". (p.88) } \\
\text { In terms of attitude, they saw it as a "dirty illness", a "shameful illness", and an illness "causing pain to all } \\
\text { the family members". (p.88) }\end{array}$ \\
\hline Finding3 & $\begin{array}{l}\text { The guilt arising from their ignorance of the illness, inability to detect the illness earlier, overprotection or } \\
\text { poor supervision made them feel like sinners. They blamed themselves for their children's illness. }\end{array}$ \\
\hline Illustration & $\begin{array}{c}\text { Inaja's mother said, "I am no different to a criminal. Having a handicapped child is more sinful than killing a } \\
\text { person". }\end{array}$ \\
\hline
\end{tabular}

\begin{tabular}{|c|c|c|c|}
\hline Jungbauer & 2002 & $\begin{array}{c}\text { Living with a schizophrenic patient: A comparative study of burden as it affects } \\
\text { parents and spouses. }\end{array}$ & Germany \\
\hline
\end{tabular}

\begin{tabular}{|c|c|}
\hline Finding1 & $\begin{array}{c}\text { [Accessing psychiatric services] can become extremely difficult for relatives, as medical treatment cannot } \\
\text { commence if the affected person refuses to recognise his or her illness and if there is no evidence of the } \\
\text { patient endangering either himself or herself or a third person. }\end{array}$ \\
\hline Illustration & $\begin{array}{c}\text { "It wasn't easy for me to watch all this and to get no help. Every doctor we went for then said: 'Well, is he } \\
\text { injuring himself? Is he threatening you?' and when I said, 'Well, not threatening in that sense, he hasn't } \\
\text { shot us yet but it is already quite critical!' 'Well, we can't do anything then. When there is no acute danger, } \\
\text { he has to deal with it himself.' Yes, it was always about to what extent he's threatening someone or to } \\
\text { what extent he's endangering someone. If that had been the case, we would have admitted him to } \\
\text { hospital. We just couldn't get anywhere". (Interview 029 mother of a schizophrenic patient; 130/144) } \\
\text { (p.113) }\end{array}$ \\
\hline Finding2 & $\begin{array}{c}\text { Caregivers initially do not see the psychotic experiences and behaviour as symptoms of a mental illness, } \\
\text { and alternative possible explanations are drawn. }\end{array}$ \\
\hline Illustration & $\begin{array}{l}\text { "At the beginning, we were, as anyone would be, completely lost, because it could've been anything. At } \\
\text { first, we didn't think of it as an illness. At the beginning, we thought she had gotten involved with a sect } \\
\text { because she was talking such nonsense. And this was because, she said, other people had bewitched her } \\
\text { in some ways. And so we thought: 'It can only be a sect.' At first, we didn't think of it as an illness." }\end{array}$ \\
\hline
\end{tabular}




\begin{tabular}{|c|c|}
\hline & (Interview 006/mother of a schizophrenic patient; $5 / 12)(p .113$ ) \\
\hline Finding3 & $\begin{array}{l}\text { First contact with psychiatric facilities can become an additional burden compounded by anxiety and fears } \\
\text { of being stigmatized. }\end{array}$ \\
\hline Illustration & $\begin{array}{l}\text { "When you come into contact with something like that for the first time, you just think what others think too: } \\
\text { 'A nut-house' And 'he's thick,' And everything you've seen in scary Edgar-Wallace-movies comes to mind, } \\
\text { and what the people say about them. And then you read it in a book. 'Oh Christ! A schizophrenic!' And } \\
\text { then you see strait jackets or whatever in your head, some obscure cellars which look like a hospital on } \\
\text { the outside, and then you really get scared." (Interview } 167 / \text { wife of a schizophrenic patient; } \\
507 / 515)(\text { p.114) }\end{array}$ \\
\hline
\end{tabular}

\begin{tabular}{|c|c|c|c|}
\hline $\begin{array}{l}\text { McCann et } \\
\text { al. }\end{array}$ & 2011 & $\begin{array}{l}\text { First-time primary caregivers' experience accessing first-episode psychosis } \\
\text { services }\end{array}$ & Australia \\
\hline Finding1 & \multicolumn{3}{|c|}{$\begin{array}{l}\text { Several carers had positive experiences with GPs who were engaged with the young person, were } \\
\text { resourceful and prompt in referring to FEP services and provided ongoing support and encouragement to } \\
\text { carers. }\end{array}$} \\
\hline Illustration & \multicolumn{3}{|c|}{$\begin{array}{l}\text { "Our GP has been fantastic. His relationship is such that ... (carer's son) actually went to him when he } \\
\text { was first ill. So that's a huge bonus I think, and he referred ... (carer's son) to our local hospital and he } \\
\text { rang them and organised for them to accept ... (carer's son) as a way of referring him on to Orygen ..., } \\
\text { because he knew that he needed that. My GP's gives ongoing support; I suppose by him just encouraging } \\
\text { us to keep going, because he tells us, 'you are a good mum"'. (Interviewee 5) }\end{array}$} \\
\hline Finding2 & \multicolumn{3}{|c|}{$\begin{array}{l}\text { Other carers felt GPs were unresourceful when they sought assistance about their son or daughter's } \\
\text { condition, and concerning access to FEP services. }\end{array}$} \\
\hline Illustration & \multicolumn{3}{|c|}{$\begin{array}{l}\text { "Our GP done nothing; takes your blood tests (sic) every 3-month. We try to talk to him (about our son), } \\
\text { but he always just says he's not sure.... . He always said to ... (our son) that 'you should have a walk } \\
\text { every day have a run', but ... (our son) is withdrawn. He just agrees and leaves the room. He (the GP) } \\
\text { should be more understanding, more compassionate, and try to work out with the family". (Interviewee 12) }\end{array}$} \\
\hline Finding3 & \multicolumn{3}{|c|}{$\begin{array}{l}\text { One structural barrier carers experience is that, due to limited government funding, there are insufficient } \\
\text { mental health services specializing in FEP or meeting the specific needs of young people (aged 15-24 } \\
\text { years). }\end{array}$} \\
\hline Illustration & \multicolumn{3}{|c|}{$\begin{array}{l}\text { "The resourcing; the crisis stuff. It seems like there needs to be more services out there for young people } \\
\text { because there not kids and they don't fit into the adult mental health system". (Interviewee 8) }\end{array}$} \\
\hline Finding4 & \multicolumn{3}{|c|}{$\begin{array}{l}\text { One procedural service barrier is that young people need to be convincingly unwell when they present to } \\
\qquad \text { clinicians; otherwise, they may be denied access to a service. }\end{array}$} \\
\hline Illustration & \multicolumn{3}{|c|}{ "Usually people have to get really sick ... and, you know, some sort of crisis happens, (then) it's a } \\
\hline
\end{tabular}




\begin{tabular}{|c|c|}
\hline & case of intervention. ... It was always too late and a lot of damage (is) already done". (Interviewee 14) \\
\hline Finding5 & $\begin{array}{l}\text { Carers experience two carer-focussed barriers relating to limitations in their knowledge of services, and } \\
\qquad \text { unfamiliarity about how to negotiate access to services. }\end{array}$ \\
\hline Illustration & $\begin{array}{l}\text { "I was 'door-knocking' Around Footscray (suburb)... . It took me long time to find help as he didn't fit into } \\
\text { any categories (for access to a specific service)... . I went to } 4 \text { or } 5 \text { of them (services). One of them said } \\
\text { to, 'ring this number (Orygen)'.... Then he was put in to hospital for a month. Once you found the help, it } \\
\text { works well, but it took me years just to get someone to listen". (Interviewee 12) }\end{array}$ \\
\hline Finding6 & $\begin{array}{l}\text { Communication problems and misunderstandings may be experienced by carers from culturally and } \\
\text { linguistically diverse backgrounds (CALD), when accessing services. }\end{array}$ \\
\hline Illustration & $\begin{array}{l}\text { "Language is one of the main barriers, and the other is maybe about social. ... and, yes, culture, different } \\
\text { culture". (Interviewee 2) }\end{array}$ \\
\hline Finding7 & Being assertive and knowing how to "play the system" enhance the possibility of gaining access. \\
\hline Illustration & $\begin{array}{l}\text { "It's been a bit of an education ... accessing ... but also I got good at 'playing the system'. I've heard } \\
\text { many families say that, 'playing the system'. It's been very frustrating along the way but you get quite good } \\
\text { at pushing for your family member to get what they need". (Interviewee } 8 \text { ) }\end{array}$ \\
\hline
\end{tabular}

\section{\begin{tabular}{|l|l|l|l|}
\hline McKenzie & 2006 & Service users and carers' experiences of a psychosis service & UK \\
\hline
\end{tabular}}

\begin{tabular}{|c|c|}
\hline Finding1 & A number of carer respondents noted that they did not receive help when they sought it. \\
\hline Illustration & "I called the GP out and they said they thought he was on drugs and just a bad teenager". (p.637) \\
\hline Finding2 & $\begin{array}{c}\text { Explanations for difficulties in accessing services included GP's reluctance to refer for psychotic diagnosis, } \\
\text { no mental health assessment available due to staff shortage and poor communication between hospital } \\
\text { and surgery. }\end{array}$ \\
\hline Illustration & $\begin{array}{l}\text { "GP stated son needed expert mental health assessment. I was told none available for at least } 3 \text { months } \\
\qquad \text { due to shortage of staff". (p.637) } \\
\text { "GP provided antidepressants but no-one from mental health was able to provide any help. When I phoned } \\
\text { they asked if he was suicidal and because he wasn't [at that time] they had no-one to see him, short } \\
\text { staffed". (p.638) }\end{array}$ \\
\hline Finding3 & Stigma was reported as a reason for delaying seeking help. \\
\hline Illustration & $\begin{array}{l}\text { One service user noted that they had not requested help earlier for ... "fear of being locked away and } \\
\text { being branded mad . . . stigma". }\end{array}$ \\
\hline Finding4 & $\begin{array}{l}\text { There seems to be some difficulty with regard to the person with psychotic symptoms admitting to having } \\
\text { problems and asking for help before being able to receive it. }\end{array}$ \\
\hline
\end{tabular}




\begin{tabular}{|c|c|}
\hline Illustration & $\begin{array}{l}\text { One carer respondent recalls: "We had approached our GP but he was unable to help until our son } \\
\text { admitted he had a problem and was willing to ask for help". (p.637-638) }\end{array}$ \\
\hline Finding5 & $\begin{array}{l}\text { Several statements made by respondents ...suggests that early intervention with people with psychotic } \\
\text { symptoms is crucial to providing an effective treatment approach. }\end{array}$ \\
\hline Illustration & $\begin{array}{l}\text { 'I just felt he could have been in ... if he had been seen at the beginning instead of waiting until he was } \\
\text { absolutely ... in a collapsed state saying he wanted to commit suicide ... could have been prevented.' } \\
\qquad \text { p.639 } \\
\text { '. . . early intervention is paramount we think ... to minimize damage .... p.639 }\end{array}$ \\
\hline
\end{tabular}

\begin{tabular}{|c|c|c|c|}
\hline $\begin{array}{c}\text { Mizuno et } \\
\text { al. }\end{array}$ & 2011 & $\begin{array}{c}\text { Subjective experiences of husbands of spouses with schizophrenia: an analysis of the } \\
\text { husbands' descriptions of their experiences. }\end{array}$ & Japan \\
\hline
\end{tabular}

\begin{tabular}{|c|c|}
\hline Finding1 & Some husbands were unclear when the illness started. \\
\hline Illustration & $\begin{array}{l}\text { "It is not clear when my wife's illness started"; "I was completely unaware of her change"; and "I could see } \\
\text { her odd behavior, but I took it simply as menopausal symptoms, not illness". (p.369) } \\
\text { One husband explained: "She was emotionally unstable, suddenly rushing out of the house and saying } \\
\text { that people were out to get her. But I didn't do anything because I thought she was just in a bad mood or } \\
\text { kidding. After a month I finally began to suspect that something was wrong with her and took her to a } \\
\text { psychiatrist". (p.369) }\end{array}$ \\
\hline Finding2 & $\begin{array}{l}\text { When [the husbands] became aware of their wives' abnormal behaviour, they took action for involuntary } \\
\text { hospitalization, getting help from the police and relatives. }\end{array}$ \\
\hline Illustration & $\begin{array}{l}\text { "As she was speaking delusively and violently and making troubling phone calls, I suggested to her to see } \\
\text { a doctor. But she refused, saying, 'Nothing is wrong with me. I won't go to the hospital'. So, two relatives } \\
\text { and I took her to the hospital. After hospitalization, she calmed down and was discharged a month later". } \\
\text { (p.369) }\end{array}$ \\
\hline Finding3 & Some children noted the changes in their mothers. \\
\hline Illustration & $\begin{array}{l}\text { "I work during the day and didn't realize what was going on. One day, when I came home, the older child } \\
\text { said to me, 'Mom is talking strange'. Then, I took her to see a doctor. At that time, her face was so flat that } \\
\text { even I could see this was not normal. I learned the name of the illness, schizophrenia, from her doctor } \\
\text { quite recently (30 years after the onset)". (p.369) }\end{array}$ \\
\hline
\end{tabular}

\begin{tabular}{|l|l|l|l|}
\hline Monteiro et al. & 2006 & Patients' relatives delayed help seeking after a first psychotic episode & Brazil \\
\hline
\end{tabular}

\begin{tabular}{|l|r|}
\hline Finding1 & $\begin{array}{r}\text { Relatives held prejudiced and derogatory stereotyped misconceptions about mental illness before } \\
\text { treatment. This meant that when they first perceived behavioural changes in the patient, they did not see it } \\
\text { as an illness as their relative was not seen as crazy. }\end{array}$ \\
\hline
\end{tabular}




\begin{tabular}{|c|c|}
\hline Illustration & $\begin{array}{l}\text { Some relatives used the terms 'loucos' (crazy) and 'malucos' (lunatics) to refer to individuals with mental } \\
\text { disorders: "For me, lunatics tear up money, throw rocks at people [...] Curse at people, you know, for me } \\
\text { that was crazy. You know, I didn't have this business of a head problem, you know, get upset by } \\
\text { something, say things that don't, I had no idea what that was". (p.107) }\end{array}$ \\
\hline Finding2 & $\begin{array}{l}\text { Relatives tried to understand and fit the patient's problem into a category of known ideas. The main } \\
\qquad \text { explanation was to deny its importance. }\end{array}$ \\
\hline Illustration & "It's nothing". (p.107) \\
\hline Finding3 & $\begin{array}{l}\text { Initially people tried to understand their relatives' problem as a passing stress; a crisis characteristic of the } \\
\qquad \text { age or the heightening of some personality traits, an eccentricity. }\end{array}$ \\
\hline Illustration & No data to support this. \\
\hline Finding4 & Some relatives thought the first behavioural changes and psychotic symptoms were a result of drug use. \\
\hline Illustration & $\begin{array}{l}\text { "The first thing that came into my head is that he was using drugs, because a behavior like that, he talked } \\
\text { to himself in the bathroom, cursed the neighbours from the bathroom". (p.107) }\end{array}$ \\
\hline Finding5 & $\begin{array}{l}\text { One of the ways of understanding psychotic symptoms is to consider the patient as possessed by a } \\
\text { spiritual entity, most frequently the devil. }\end{array}$ \\
\hline Illustration & $\begin{array}{l}\text { "I thought, it must be somebody who died and I don't know, invaded his body, his soul, beats me? That's } \\
\text { what I thought, that somebody had died like that, because there was no way he could have invented so } \\
\text { many things, talking so much about things that had never happened in his life". (p.107) }\end{array}$ \\
\hline Finding6 & $\begin{array}{l}\text { Some relatives explained what happened through the idea of "cursed". The evil a person is carrying now is } \\
\text { a consequence of the mistakes of his ancestors, a kind of spiritual inheritance. }\end{array}$ \\
\hline Illustration & $\begin{array}{l}\text { "That's the way it is, suddenly someone in my family, from my ancestors who were involved in something, } \\
\text { black magic or something, that goes on from generation to generation. So for three or four generations } \\
\text { nothing happens, but suddenly in the fifth generation something can happen, [...] First the people from the } \\
\text { church said that this came from my mother's womb, and could have been anyone, even more so the last } \\
\text { daughter, so it came out in her. So it's like that, if some family goes into something wrong, or black magic, } \\
\text { it may not come out in that generation, but in future generations; someone can, I don't know, get sick or } \\
\text { have an attack and die".(p.108) }\end{array}$ \\
\hline Finding7 & $\begin{array}{l}\text { The illness is understood as an imbalance manifested at different levels: body, soul and spirit. As a result, } \\
\text { seeking out religious help in most cases does not exclude medical treatment. }\end{array}$ \\
\hline Illustration & $\begin{array}{l}\text { In two cases relatives saw the patient's problem as exclusively spiritual and concerned themselves solely } \\
\qquad \text { with the spiritual question for a period of one to three years. (p.108) }\end{array}$ \\
\hline Finding8 & $\begin{array}{l}\text { The search for psychiatric treatment was often delayed because relatives were afraid of psychiatric } \\
\text { services. }\end{array}$ \\
\hline
\end{tabular}




\begin{tabular}{|c|c|}
\hline Illustration & $\begin{array}{l}\text { "My neighbors [...] said: 'Carlos isn't right in his head and if you put him in a hospital, he's going to end up } \\
\text { out there among the lunatics, they'll give him shock, I don't know what will happen, they'll dope him, tie } \\
\qquad \text { him up in a straightjacket'. So I got scared, I mean really scared". (p.108) } \\
\text { "Once on television I saw it, they went to some insane asylum or other, but it was on television, they were } \\
\text { all put together there, all kind of imbalanced, dazed, walking around and all the family rejects put together } \\
\text { in there, you know. So I said my son isn't going to end up in a place like that, no way". (p.108) }\end{array}$ \\
\hline Finding9 & $\begin{array}{l}\text { Some of the relatives looked for treatment earlier but did not follow recommendations due to structural } \\
\text { questions of mental health care services (there were difficulties to get initial care, consultations were brief } \\
\text { and there were considerable delays in scheduling return visits) and due to difficulties in the doctor-patient } \\
\text { relationship. }\end{array}$ \\
\hline Illustration & $\begin{array}{l}\text { "So time passed, so the health system wasn't working out, it wasn't working. The doctor looked at me like } \\
\text { this, handed me the medications and said to come back in three months. You know it just wasn't right". } \\
\text { (p.108) }\end{array}$ \\
\hline
\end{tabular}

\begin{tabular}{|c|c|c|c|}
\hline Pearse & 1998 & $\begin{array}{c}\text { A qualitative study exploring relatives' experience of seeking help for a person during the } \\
\text { early stages of schizophrenia }\end{array}$ & UK \\
\hline
\end{tabular}

\begin{tabular}{|c|c|}
\hline Finding1 & $\begin{array}{l}\text { If the person was active and willing to seek help this put the least strain on the relationship between the } \\
\text { person and relative. However it did not necessarily lead to any help from health care professionals. }\end{array}$ \\
\hline Illustration & $\begin{array}{l}\text { "He kept going back to the doctor and trying to explain how he felt. And the doctor kept saying 'Oh, no } \\
\text { you're just depressed you'll get over it'. [name] came back and said 'Mum I just can't get through to him' } \\
\text { (p.39) }\end{array}$ \\
\hline Finding2 & $\begin{array}{l}\text { It was found that some of the males had sought help for themselves from their GP but the family had been } \\
\text { unaware of this. }\end{array}$ \\
\hline Illustration & $\begin{array}{l}\text { "I didn't know at the time, that [name] had already been to a doctor in that preceding six months. We didn't } \\
\text { know this until after the episode when we were searching his bedroom thinking that perhaps he was taking } \\
\text { drugs. We came across a prescription drug...... a form of tranquilliser. So obviously [name] knew early on } \\
\text { that he needed some help". (p.41) }\end{array}$ \\
\hline Finding3 & $\begin{array}{l}\text { The [male] group reported more dissatisfaction in their interactions with their GP and less faith in their } \\
\qquad \text { GP's ability to understand the person's difficulties. }\end{array}$ \\
\hline Illustration & $\begin{array}{l}\text { "The doctor came. Well, he was a useless bugger. And he said 'Oh, well he's a little bit depressed'. I } \\
\text { mean, I'm his mother but I knew he was more than depressed He said 'Do you want to go to hospital?' and } \\
\text { [name] said 'No' so the doctor said 'Oh, well he'll be all right'. (p.40) }\end{array}$ \\
\hline Finding4 & $\begin{array}{l}\text { In many cases the first contacts with psychiatric services were often unsatisfactory for the family. Often } \\
\text { families would have to be very insistent and persistent to get the care they thought was appropriate. }\end{array}$ \\
\hline
\end{tabular}




\begin{tabular}{|c|c|}
\hline Illustration & $\begin{array}{l}\text { "Anyway, I'm afraid I just sat down. They didn't want to take him in and I said 'I'm not going home with him' } \\
\text { and they had to get him a bed, I just sat down". (p.37) }\end{array}$ \\
\hline Finding5 & $\begin{array}{l}\text { When the person denied their symptoms and/or refused help, this was the most pressurising situation for } \\
\text { relatives. This also interfaced with professionals being unable or unwilling to see the person without their } \\
\text { consent. }\end{array}$ \\
\hline Illustration & $\begin{array}{l}\text { "At first she was saying that there was nothing wrong with her 'I'm all right, there's nothing wrong'. But we } \\
\text { could see that there was something wrong and she wasn't admitting it. She was defeating it all the time } \\
\text { and it was getting worse and worse and worse". (p.40) }\end{array}$ \\
\hline Finding6 & For some [a crisis] was the only way that they could get anyone to listen to them or access help. \\
\hline Illustration & $\begin{array}{l}\text { "We only got help because she rang the police to say I was holding her hostage...I'd spoken to the GP so } \\
\text { many times and he said 'We can't do anything until there is a crisis'. Well, I suppose that was the crisis } \\
\text { that had to happen". (p.38) }\end{array}$ \\
\hline Finding7 & $\begin{array}{l}\text { When the crisis involved a suicide attempt this did not necessarily result in prompting any further help, } \\
\qquad \text { other than the initial emergency help. }\end{array}$ \\
\hline Illustration & $\begin{array}{l}\text { "He just came home to live with my parents.... We knew he was unhappy but we felt he must take } \\
\text { responsibility for it....We never thought of it in terms of madness....My mother just tried to deal with things } \\
\text { at home". (p.38) }\end{array}$ \\
\hline Finding8 & One major influence on the help seeking process was a 'crisis'. \\
\hline Illustration & $\begin{array}{l}\text { "That day I went off to work and during the day [name] threw herself out of her bedroom window. My } \\
\text { husband was home..... She'd jumped through the glass. He saw her lying all crumpled on the ground. The } \\
\qquad \text { ambulance came and took her to hospital". (p.38) } \\
\text { "She was attacking and kicking out She was kicking and biting my husband I said 'Right, we'll get her } \\
\text { down to our doctor' which we did". (p.38) }\end{array}$ \\
\hline Finding9 & $\begin{array}{l}\text { Sometimes pressure from outside the nuclear family was needed for the family to take the first step to } \\
\qquad \text { contact health care professionals. }\end{array}$ \\
\hline Illustration & $\begin{array}{l}\text { "Well, she was just acting so weird. One day [name] rang up her nephew and asked him to get her some } \\
\text { sanitary towels. Her aunt, my sister, went round to see her and saw that the house was in a filthy state. } \\
\text { [Name] was in the nude and her daughter was all dirty..... She [sister] rang me in a horrified state". (p.38) }\end{array}$ \\
\hline Finding10 & $\begin{array}{l}\text { If the decision to seek help was not made by the person then, in the main, the decision maker and the help } \\
\qquad \text { seeker were most often the mother of the person. }\end{array}$ \\
\hline Illustration & $\begin{array}{l}\text { "My husband and I, my mum, my brother- the four of us knew that something wasn't right. I being her } \\
\text { mum, I had to make the decision. My husband you can understand, he's always been very good but he's } \\
\text { still the step-father. So really it was my decision to take it further to get her to the doctor".(p.35) }\end{array}$ \\
\hline
\end{tabular}




\begin{tabular}{|c|c|}
\hline Finding11 & $\begin{array}{l}\text { A lot of families had to struggle with the tension between: a) trying to protect, and act in the best interests } \\
\qquad \text { of, a vulnerable person and; b) being over-intrusive in a person's life. }\end{array}$ \\
\hline Illustration & $\begin{array}{l}\text { "I was afraid to go to people I didn't really want to be a busy-body. I felt afraid of what he'd [the person] feel } \\
\text { about me going". (p.35) }\end{array}$ \\
\hline Finding12 & $\begin{array}{l}\text { The nature of [the illness] seemed to have an impact on how much responsibility and action the family } \\
\text { should take in regard to the person, particularly when the person was secretive, paranoid or withdrawn. } \\
\text { This became more complicated if the person was over } 18 \text { and unwilling to seek help. }\end{array}$ \\
\hline Illustration & $\begin{array}{l}\text { "We had two doctors here hut he flatly refused to see them, and as he flatly refused to go down to the } \\
\text { surgery, we were told there was nothing we could do. So we were batting our heads against a brick wall". } \\
\text { (p.35) }\end{array}$ \\
\hline Finding13 & $\begin{array}{l}\text { Most participants strongly expressed an intuitive feeling that the person was 'not themselves' or 'not quite } \\
\text { right.' }\end{array}$ \\
\hline Illustration & "You know something's wrong. I mean you just know, don't you, that there's something not right". (p.36) \\
\hline Finding14 & $\begin{array}{l}\text { Most people did not discuss their concerns about their relative with anyone outside of the immediate } \\
\text { family, especially in the early stages. This seems to be related to loyalty and respect for the person's } \\
\text { privacy. }\end{array}$ \\
\hline Illustration & $\begin{array}{l}\text { "I didn't tell the family anything about it. If anyone at all has a problem I keep it to myself and don't discuss } \\
\qquad \text { it". (p.34) } \\
\text { "We didn't talk to anybody outside of the family. I talked it over with my husband, obviously, about the } \\
\text { strange things that were happening with her. I also talked with my son. And my sister and her husband". } \\
\text { (p.34) }\end{array}$ \\
\hline Finding15 & $\begin{array}{l}\text { In many cases people felt that although family were supportive they were left to cope on their own by } \\
\text { friends leading to a sense of isolation. }\end{array}$ \\
\hline Illustration & $\begin{array}{l}\text { "We just felt totally isolated. It wasn't just a case of our daughter losing all her friends, my husband and I } \\
\text { have one set of friends, nobody else. I've got just a mum and a brother. They've been very good". (p.33) }\end{array}$ \\
\hline Finding16 & $\begin{array}{l}\text { The whole experience of the help seeking process was marked by very strong negative emotions for the } \\
\text { participants. }\end{array}$ \\
\hline Illustration & $\begin{array}{l}\text { "There were times that I nearly cracked up and walked out altogether, washed my hands of it. A couple of } \\
\qquad \text { times". (p.29) } \\
\text { "You're desperate. You're desperate because you don't know what's going on. We were totally confused". } \\
\text { (p.29) }\end{array}$ \\
\hline Finding17 & $\begin{array}{l}\text { A main difficulty people found with primary care staff (i. e. GP) was that they were often left to cope alone } \\
\qquad \text { with acute psychiatric difficulties. }\end{array}$ \\
\hline
\end{tabular}




\begin{tabular}{|c|c|}
\hline Illustration & $\begin{array}{l}\text { "By about five o'clock in the morning he was at the point of collapse- He was pleading with me to take him } \\
\text { to hospital or get him a doctor .... So my husband phoned the GP. He said 'Oh, this doesn't justify a call } \\
\text { out. Bring him to me at 9am in the morning'. So we were left with him in this state". (p.29) }\end{array}$ \\
\hline Finding18 & $\begin{array}{l}\text { Where people did have experience within their families of either mental disorder or learning disability it did } \\
\text { not seem helpful in the help seeking process. However, it was helpful in others ways such as making it } \\
\text { easier to process the experience. }\end{array}$ \\
\hline Illustration & $\begin{array}{l}\text { "I've also got a brother with Down's syndrome ... I helped to bring him up really. I think that has helped me } \\
\text { a lot to cope with [son]. I was used to dealing with stigma from the age of } 12 \ldots . . \text { The sooner you can come } \\
\text { to terms with things then the easier it is to get on with it". (p.31) }\end{array}$ \\
\hline Finding19 & $\begin{array}{l}\text { For a proportion of participants, especially in the early stages, schizophrenia was viewed as frightening } \\
\text { and a 'hopeless' condition. }\end{array}$ \\
\hline Illustration & "I know this sounds stupid but I thought schizophrenia was a bit like a murderer or a bank robber". (p.31) \\
\hline Finding20 & For some participants views about mental disorder did influence whether they sought help or not. \\
\hline Illustration & $\begin{array}{l}\text { "Our negative fearful views on mental illness delayed, for many months, our seeking help (e-g. media } \\
\qquad \text { images of 'loony bins)".(p.32) }\end{array}$ \\
\hline Finding21 & $\begin{array}{l}\text { People often had no idea of what they were dealing with or the best way to manage the situation which } \\
\text { seemed to account for much of the confusion and isolation felt. }\end{array}$ \\
\hline Illustration & $\begin{array}{l}\text { "If you know someone is going to die you can cope, but with mental illness you don't know what you're } \\
\text { dealing with". (p.32) }\end{array}$ \\
\hline Finding22 & $\begin{array}{l}\text { The level of support and understanding received from other people particularly family and friends, } \\
\qquad \text { impacted on whether the family felt isolated. }\end{array}$ \\
\hline Illustration & $\begin{array}{l}\text { "I had plenty of help. That's when you find out who your true friends were. I had quite a few stand by me } \\
\text { and help me out". (p.32) } \\
\text { "My sister was a great help. She gave me lots of help". (p.32) }\end{array}$ \\
\hline Finding23 & $\begin{array}{l}\text { When events or behaviours are still 'explainable' (e. g. teenage behaviour, stress) the drive to seek help is } \\
\text { not very strong. }\end{array}$ \\
\hline Illustration & $\begin{array}{l}\text { "And he'd say things as if he was talking to himself. I just thought he was talking to himself. I mean, I go } \\
\text { round the house talking to myself". (p.36) }\end{array}$ \\
\hline Finding24 & $\begin{array}{l}\text { When behaviours start to cross over and become 'unexplainable' (e. g. wild mood swings, very suspicious) } \\
\text { then people are more likely to start to look for help. }\end{array}$ \\
\hline Illustration & $\begin{array}{l}\text { "She became very, very religious. That was the first pointer. She could actually quote the bible to you. I } \\
\text { knew by then, especially when this religion thing caught hold, that just wasn't right, it was awful. It really }\end{array}$ \\
\hline
\end{tabular}




\begin{tabular}{|c|c|}
\hline & $\begin{array}{l}\text { got a bit weird". (p.36) } \\
\text { "We went shopping and we were standing in the aisle and all of a sudden he'd say 'Bloody hell!' and l'd } \\
\text { say 'What? What's the matter?' And he'd look at the group of people as if somebody walked in that he'd } \\
\text { seen and I was trying to look to see if I could distinguish anybody that's walking down towards us. He'd } \\
\text { frighten me as if somebody was following us". (p.36) }\end{array}$ \\
\hline Finding25 & $\begin{array}{l}\text { Initial contacts seemed quite informal where concerns were 'checked out' and tended to involve people } \\
\text { who were not mental health professionals (i. e. extended family, teachers, vicars, help-lines, Accident and } \\
\text { Emergency staff). }\end{array}$ \\
\hline Illustration & $\begin{array}{l}\text { "I was just worried because she was just not herself. I rang someone I think it was Saneline. They were } \\
\qquad \text { absolutely hopeless". (p.37) } \\
\text { "We even ended up going to the local vicar because things weren't right". (p.37) }\end{array}$ \\
\hline Finding26 & If the family goes on to seek more help, then the GP is usually the next contact [after informal contacts]. \\
\hline Illustration & $\begin{array}{l}\text { "I was quite worried so I made an appointment for her to go down and see the doctor that evening. I } \\
\text { thought she was depressed". (p.37) }\end{array}$ \\
\hline Finding27 & $\begin{array}{l}\text { In most cases the GP did not to refer onto further mental health professionals (e. g. psychiatrist, } \\
\qquad \text { psychologist) straight away. }\end{array}$ \\
\hline Illustration & $\begin{array}{l}\text { "So I went in to the GP and asked him his opinion. He just said 'It's OK I've given him some melleril. Come } \\
\text { back in } 4 \text { days"'. (p.37) }\end{array}$ \\
\hline Finding28 & $\begin{array}{l}\text { Continuing contact with the GP seemed to be important. A good relationship with the GP made it easier for } \\
\text { relatives to get the help they needed. }\end{array}$ \\
\hline Illustration & $\begin{array}{l}\text { "They had to get another doctor from the surgery and because I used to work there I knew all of them. He } \\
\text { was quite understanding because, he knew me ...... He didn't muck about then, he knew that if I was there } \\
\text { and I was saying these things then it must he what was going on". (p.37) }\end{array}$ \\
\hline Finding29 & $\begin{array}{l}\text { In many cases the first contacts with psychiatric services were often unsatisfactory for the family. Often } \\
\text { families would have to be very insistent and persistent to get the care they thought was appropriate. }\end{array}$ \\
\hline Illustration & $\begin{array}{l}\text { "Anyway, I'm afraid I just sat down. They didn't want to take him in and I said 'I'm not going home with him' } \\
\text { and they had to get him a bed, I just sat down". (p.37) }\end{array}$ \\
\hline
\end{tabular}

\begin{tabular}{|l|l|l|l|}
\hline Redko & 2003 & Religious construction of a first episode of psychosis in urban Brazil & Brazil \\
\hline
\end{tabular}

\begin{tabular}{|c|l|}
\hline Finding1 & $\begin{array}{r}\text { Some families felt overwhelmed with the diversity of religious resources being offered to them, which was } \\
\text { then experienced more as an "added burden" to the problem. }\end{array}$ \\
\hline Illustration & Even before the family had the chance to consider existing sources of religious help, believers often would \\
\hline
\end{tabular}




\begin{tabular}{|c|c|}
\hline & $\begin{array}{l}\text { come to visit. Neighbours, friends, and the extended family would come to suggest names of spiritual } \\
\text { healers, or they attracted the family to their church or spiritual center. This phenomenon intensified during } \\
\text { the first weeks of the psychotic crisis, although I observed it happening over the whole course of the study. } \\
\text { (p.513-514) }\end{array}$ \\
\hline Finding2 & $\begin{array}{l}\text { Most families strongly believed that religious resources were essential to complement the treatment } \\
\text { provided by psychiatric care. }\end{array}$ \\
\hline Illustration & $\begin{array}{l}\text { "There is the spiritual part and the material part. The spiritual part belongs to the church while the material } \\
\text { part belongs to the medical specialities". [Leonardo's mother](p.515) } \\
\text { "There is a part that was done by physicians; there is another part that was done by God plus the power of } \\
\text { prayers and [spiritual] healing". [Sarah's mother](p.515) }\end{array}$ \\
\hline Finding3 & $\begin{array}{l}\text { Families often resorted to religion because it yields causal explanations for the problem. Several psychotic } \\
\text { symptoms are easily confused with signs of spiritual possession, some other kind of spiritual disturbance } \\
\text { or the consequence of some kind of malice, "black magic". }\end{array}$ \\
\hline Illustration & $\begin{array}{l}\text { This can be exemplified by the case of a youth that will be called José. His mother was convinced that } \\
\text { José's problem had a supernatural causation: some "evil spirit" was disturbing her son, or that he was the } \\
\text { prey of some black magic perpetrated by her ex-lover. This belief motivated José's mother to force her son } \\
\text { to be exorcised in a Pentecostal church.(p.515) }\end{array}$ \\
\hline Finding4 & $\begin{array}{l}\text { Families claimed a kind of "added efficacy": the more religious places to which one goes the more God's } \\
\qquad \text { power one attains to solve the problem. }\end{array}$ \\
\hline Illustration & $\begin{array}{l}\text { "I took my son to the Church of Grace because the God who is in my church is inside all the others. I have } \\
\text { faith that God operated in his life, and that God helped in his treatment, and still is helping. We did prayers. } \\
\text { In several churches we prayed for him. When the person has a problem we do collective praying for } 6 \\
\text { days, } 7 \text { days always at the same time, to talk with God about it. Thanks God, God has been operating". } \\
\text { [Mateus' mother](p.514) } \\
\text { "It was God [who healed my daughter]. In part it was the physicians' help, but in another part it was God } \\
\text { through prayers and searching for [God].We did two collective fasting and prayers. I would search for } \\
\text { people in churches, and when they got acquainted with her they would always pray and fast for her. I took } \\
\text { her to four churches... Trombetas, Assembly of God, Celestial Arc, and God is Love ... they are all } \\
\text { good, all of them have the correct doctrine to be followed. Just like in the words of ... the more prayers, } \\
\text { more power, like they say. If I go into somebody's church then to somebody else's church, then the church } \\
\text { sisters will help more, they are going to see her situation, and mine, that I am fighting with her, they will } \\
\text { pray more for her and look more for [God], consequently God will liberate her [spiritually] even faster, } \\
\text { that's why I did it". [Sarah's mother](p.514) }\end{array}$ \\
\hline
\end{tabular}

\section{\begin{tabular}{|l|l|l|l|l}
\hline Tanskanen & 2011 & Service user and carer experiences of seeking help for a first episode of psychosis: a UK & UK
\end{tabular} qualitative study}




\begin{tabular}{|c|c|}
\hline Illustration & $\begin{array}{l}\text { "Well I'm just beginning to understand all the aspects of the illness because I don't think I did know } \\
\text { enough. And obviously I understand that all his aggression is caused by his paranoia and insecurity so } \\
\text { me, err, being such a horrible mother and trying to kick him out of the house and make him, push him to } \\
\text { make him go to work or go to school or whatever, did not have positive impact on Tom's recovery. And the } \\
\text { reason was because I was stupid, I didn't have, I was ignorant about this illness and I didn't understand } \\
\text { that illness..." (Carer; mother, 55, White Other)(Additional File 1,1.2) }\end{array}$ \\
\hline Finding2 & $\begin{array}{l}\text { Carers noticed uncharacteristic and bizarre behaviours which alerted them to consider taking action, } \\
\text { although a majority reported that help seeking was not initiated until a crisis point was reached. }\end{array}$ \\
\hline Illustration & $\begin{array}{l}\text { "[...] My house was full of relatives so I wasn't completely focused on her but I was noticing she was } \\
\text { behaving oddly, she was kind of disengaged. She was saying odd things, she was talking inappropriately } \\
\text { to the children, like 'Don't listen to your mummy' or 'Don't do this' totally odd and not Mary at all [...] She } \\
\text { was just completely spaced out. I took her to the doctor right that minute, early evening, because it was a } \\
\text { build up over that week, over a couple of days, but it was very quick. She did go into it very quickly". } \\
\text { (Carer; mother, 58, White Irish)(p.5) } \\
\text { "It took me quite a long time to understand that there was a mental issue there but it wasn't until she } \\
\text { started to become very ill. She actually had a crisis". (Carer; mother-in-law, 68, White British)(Additional } \\
\text { File 2, 2.3) }\end{array}$ \\
\hline Finding3 & $\begin{array}{l}\text { Carers reported attributing symptoms to alternative explanations e.g. rebellious teenage behaviour, illicit } \\
\text { drug use, stress, physical, neurological and other psychological problems. }\end{array}$ \\
\hline Illustration & $\begin{array}{l}\text { "If I talked to people they would say 'he sounds like a normal teenager to me'. You do sort of wonder, } \\
\text { because the other two had not been like this at all, you wonder whether if this is what they mean by } \\
\text { "stroppy obnoxious teenagers" and so you put it down to that". (Carer; mother, 49, White British)(p.4) }\end{array}$ \\
\hline Finding4 & $\begin{array}{l}\text { Carers described thinking symptoms were transient and would resolve without the need for further } \\
\text { intervention. This seemed to be linked to longer DUP and attribution of symptoms to other causes. }\end{array}$ \\
\hline Illustration & $\begin{array}{l}\text { "I was stuck up and I was thinking like I can handle it, I can push him straight because if I like stop } \\
\text { providing for him he will find some common sense, like find himself a job or perhaps if he works hard } \\
\text { physically for one year or two, he will be able to go back to school, get some common sense". (Carer; } \\
\qquad \text { mother, } 55 \text {, White Other)(Additional File } 1,1.5)\end{array}$ \\
\hline Finding5 & $\begin{array}{l}\text { Uncharacteristic and bizarre behaviours alerted carers to consider taking action, though the majority }(n=5) \\
\text { reported that help seeking was initiated only when a crisis point was reached. }\end{array}$ \\
\hline Illustration & $\begin{array}{l}\text { "It took me quite a long time to understand that there was a mental issue there but it wasn't until she } \\
\text { started to become very ill. She actually had a crisis". (Carer; mother-in-law, 68, White British)(Additional } \\
\text { File } 2,2.3)\end{array}$ \\
\hline Finding6 & $\begin{array}{l}\text { All the carers described having tried to convince their family member to seek help but often faced denial, } \\
\text { anger and stigma-related worries that consequently delayed appropriate help-seeking. }\end{array}$ \\
\hline Illustration & "I don't think he wanted any help. He wasn't really acknowledging that he had a mental illness. [...] when \\
\hline
\end{tabular}




\begin{tabular}{|c|c|}
\hline & you tried to talk to him he became very defensive". (Carer; mother, 59, White British)(p.5) \\
\hline Finding7 & $\begin{array}{l}\text { Carers were concerned about the potential social and psychological consequences of their family } \\
\text { members entering the mental health system. }\end{array}$ \\
\hline Illustration & $\begin{array}{l}\text { "I didn't want my daughter associated with other psychiatric patients. I didn't want her to think what she } \\
\text { had was psychiatric". (Carer; mother, 58, White Other)(Additional File 3, 3.2) } \\
\text { "They [relatives] were all saying the same thing, he needed to go to services, but underlying that there } \\
\text { were issues that should he really go to services because they are just going to pump him up with drugs, } \\
\text { give him an injection and section [compulsorily detain] him off and we'd never see the John that we know } \\
\text { and love again. So that was a huge concern for everybody including myself'. (Carer, mother, 51, Black } \\
\text { Caribbean)(p.5) }\end{array}$ \\
\hline Finding8 & $\begin{array}{l}\text { Carers reported having insufficient knowledge about mental health services and feeling uncertain where to } \\
\text { seek help. }\end{array}$ \\
\hline Illustration & $\begin{array}{l}\text { "I have a feeling I did try. I mean I spoke to friends about it. I didn't even think to go to a psychiatrist; I } \\
\text { wouldn't even have known where to go. I mean I didn't know this place [CIEIS] here existed. Had I known } \\
\text { about it and had they had a helpline or something, I might have done that and I think that would be very, } \\
\text { very good if they had a helpline for confused and worried parents or parents-in-law or friends". (Carer; } \\
\text { mother-in-law, } 68, \text { White British) (Additional File 3, 3.4) }\end{array}$ \\
\hline Finding9 & $\begin{array}{l}\text { The vagueness of symptoms added to (carers') feelings of confusion and made it harder to determine the } \\
\text { type of help needed. }\end{array}$ \\
\hline Illustration & $\begin{array}{l}\text { "I suppose not knowing what to do is always one of the hardest things. Because even taking them to the } \\
\text { doctor is a very vague thing. There is nothing you can put your finger on and say. [...] Because it's such a } \\
\text { vague thing it's hard to know where to go and who to talk to". (Carer; mother, 49, White British)(p.6) }\end{array}$ \\
\hline Finding10 & $\begin{array}{l}\text { One third of carers described unhelpful responses from those on their social network which had delayed or } \\
\qquad \text { discouraged contact with mental health services. }\end{array}$ \\
\hline Illustration & $\begin{array}{l}\text { "My mother would often get very irritated and say 'what do you want us to do - put her in a mental } \\
\text { asylum?' like that was the most horrible thing one could say. [...] My father used to say 'oh let her go out } \\
\text { into the world, she'll soon be put in her place or something..." (Carer; sister, 33, White British)(p.6) }\end{array}$ \\
\hline Finding11 & Contact with occupational, educational or religious community groups did not facilitate help seeking. \\
\hline Illustration & $\begin{array}{l}\text { In three cases, schools and occupational health had noticed deterioration in functioning but this had not } \\
\text { led to a referral to mental health services. In four cases the community organizations had not instigated } \\
\qquad \text { help-seeking or raised any concerns. (pp.6-7) }\end{array}$ \\
\hline Finding12 & $\begin{array}{l}\text { Carers whose family members were in contact with church youth groups perceived their support to have } \\
\text { been valuable, even though they had not advocated help-seeking. }\end{array}$ \\
\hline Illustration & "Their [church] response was they were praying for him and encouraged him to come. Just spoke to him. \\
\hline
\end{tabular}




\begin{tabular}{|c|c|}
\hline & $\begin{array}{l}\text { There is a youth group within the church and I think really that was his saving grace, that gave him insight. } \\
\text { Because when he got sectioned [compulsorily detained] after that he continued to go to the church and } \\
\text { today he is a strong man of the Lord. So I really do believe that that has pulled him through". (Carer; } \\
\text { mother, 51, Black Caribbean). (p.7) }\end{array}$ \\
\hline Finding13 & $\begin{array}{l}\text { Carers reported receiving what they viewed as uninformed or insensitive responses from health and } \\
\qquad \text { educational professionals. }\end{array}$ \\
\hline Illustration & $\begin{array}{l}\text { "So I brought him along to our local GP and told her what I felt was really wrong with him and she kind of } \\
\text { dismissed it and said 'no, I think he just needs to sleep, he needs some sleeping tablets and he needs to } \\
\text { sleep'. [...] She [GP] said 'No, no give him these tablets and he'll be fine'. And his situation got worse". } \\
\qquad \text { (Carer; mother, 51, Black Caribbean)(p.7) } \\
\text { "He had a week or two off, I went in and saw the staff [sixth form college], I went in with him and said that } \\
\text { he was having difficulties. They didn't take it on board". (Carer; mother, 60, White British)(p.7) } \\
\text { "He was using very abusive words towards me which broke my heart. On one occasion we had } \\
\text { disagreement and he pushed me on the floor. That was the kind of point that I decided well I cannot } \\
\text { accept this kind of behaviour anymore and I called the police. When the police came they said is there } \\
\text { something strange going with his behaviour and before anything else I would like him to be consulted by a } \\
\text { psychiatrist, which he was. The psychiatrist said there was nothing really wrong with him apart from his } \\
\text { drug abuse". (Carer; mother, 55, White Other)(Additional file 5,5.3) }\end{array}$ \\
\hline Finding14 & $\begin{array}{l}\text { Carers reported further delays in detection of psychosis subsequent to family members not disclosing } \\
\text { positive symptoms to family or health care professionals. }\end{array}$ \\
\hline Illustration & $\begin{array}{l}\text { "When we got there [GP surgery] he started making out as though he had gone for a medical problem and } \\
\text { that he had a lump somewhere. No, and even now he's not acknowledged that he's hearing any voices. } \\
\text { He never admits to it". (Carer; mother, } 59 \text {, White British)(Additional file } 5,5.4 \text { ) }\end{array}$ \\
\hline Finding15 & $\begin{array}{l}\text { Delays [in recognising users' problems as signs of psychosis] were attributed to the vagueness of early } \\
\text { symptoms and to the lack of awareness of psychosis at individual and community levels. }\end{array}$ \\
\hline Illustration & $\begin{array}{l}\text { "[l] didn't have a clue. There is no history of anything like that in my family so we had no experience of it } \\
\text { whatsoever. No, I didn't know what it was and I was really frightened". (Carer; mother, 58, White } \\
\text { Other)(p.4) }\end{array}$ \\
\hline
\end{tabular}

\begin{tabular}{|c|c|c|c|}
\hline Wong & 2007 & $\begin{array}{c}\text { Crucial individuals in the help-seeking pathway of Chinese caregivers of relatives with } \\
\text { early psychosis in Hong Kong }\end{array}$ & $\begin{array}{c}\text { Hong } \\
\text { Kong }\end{array}$ \\
\hline
\end{tabular}

\begin{tabular}{|l|r|}
\hline Finding1 & $\begin{array}{r}\text { Most of the initiators who first noticed the problems of the ill relatives were informal network members, } \\
\text { including family members and friends. }\end{array}$ \\
\hline Illustration & $\begin{array}{r}\text { "I knew something was wrong with my son. I did not know what to do, and so I asked my sister-in-law } \\
\text { about it. She thought that my son might have a mental illness". (p.130) }\end{array}$ \\
\hline
\end{tabular}




\begin{tabular}{|c|c|}
\hline Finding2 & Parents approached others in their informal network for help. \\
\hline Illustration & $\begin{array}{l}\text { "He is my flesh and blood. It is my duty to take good care of him. Regardless of the amount of money, } \\
\text { time, and energy I need to spend on helping him, I must do it. Nothing is more important than this". (p.130) }\end{array}$ \\
\hline Finding3 & $\begin{array}{l}\text { The most critical people in the informal networks who linked the ill relatives to psychiatric services were } \\
\text { family members, relatives, and friends. }\end{array}$ \\
\hline Illustration & $\begin{array}{l}\text { "I found my good friend and told her my daughter's problem. She said she might have some mental } \\
\text { problems. She asked me to find the social worker. I trusted her very much; my friend and I always met } \\
\text { together". (p.131) }\end{array}$ \\
\hline Finding4 & $\begin{array}{l}\text { The confirmation process [regarding the illness] would not be possible without the correct perception of } \\
\text { mental illness held by the informal network members. }\end{array}$ \\
\hline Illustration & $\begin{array}{l}\text { "I observed that there was something wrong with my son. I immediately recalled the TV advertisement on } \\
\text { early psychosis, and the telephone number mentioned on the advertisement. So I rang them the next day, } \\
\text { and my son was seen by the team within two weeks". (p.131) }\end{array}$ \\
\hline Finding5 & A quarter of the helpers perceived the symptoms as related to [issues other than mental illness]. \\
\hline Illustration & $\begin{array}{l}\text { [These included]: "youth- and school-related problems," "emotional problems," "interpersonal difficulties," } \\
\text { and "issues related to traditional Chinese health beliefs such as yin-yang imbalance". (p.131) }\end{array}$ \\
\hline Finding6 & $\begin{array}{l}\text { Social workers were the most critical people in the formal network of the help-seeking pathway of the } \\
\text { caregivers. }\end{array}$ \\
\hline Illustration & $\begin{array}{l}\text { "He [the social worker] acted as the bridge between my daughter and the school. Also, he helped me } \\
\text { understand my daughter's condition". (p.131) }\end{array}$ \\
\hline Finding7 & $\begin{array}{l}\text { III relatives were viewed as a deterrent in the help-seeking pathway. Family caregivers complained they } \\
\text { could not persuade their ill relative to seek help [before reaching crisis point]. }\end{array}$ \\
\hline Illustration & $\begin{array}{l}\text { "My daughter refused to see the doctor in spite of our efforts to arrange a consultation for her. She was } \\
\text { angry with us, and we did not know what to do. After a long time, her condition worsened, and we had to } \\
\text { take her to the emergency unit". (p.132) }\end{array}$ \\
\hline
\end{tabular}

